UNIVERSIDADE DE SÃO PAULO

ESCOLA DE ENGENHARIA DE SÃO CARLOS

\title{
AVALIAÇÃO DE TÉCNICA DE MELHORIA DE SOLOS COLAPSÍVEIS POR MEIO DE COLUNAS DE SOLO LATERÍTICO COMPACTADO
}

Milena Cardoso de Freitas 

Milena Cardoso de Freitas

\title{
AVALIAÇÃO DE TÉCNICA DE MELHORIA DE SOLOS COLAPSÍVEIS POR MEIO DE COLUNAS DE SOLO LATERÍTICO COMPACTADO
}

\author{
Milena Cardoso de Freitas
}

Dissertação apresentada à Escola de Engenharia de São Carlos, da Universidade de São Paulo, como requisito para a obtenção do Título de Mestre em Geotecnia.

Área de Concentração: Geotecnia

Orientador: Prof ${ }^{\mathrm{a}}$. Dr $^{\mathrm{a}}$. Cristina de Hollanda Cavalcanti Tsuha

Versão corrigida

Original se encontra disponível na Unidade que aloja o Programa

SÃO CARLOS

2016 
AUTORIZO A REPRODUCÃ̃O TOTAL OU PARCIAL RESTE TRABALHO, POR QUALQUER MEIO CONVENCIONAL OU ELETRONICO, PARA FINS DE ESTUDO E PESQUISA, DESDE QUE CITADA A FONTE.

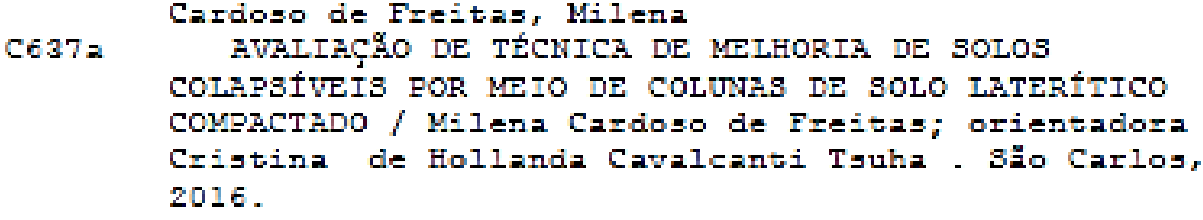




\section{FOLHA DE JULGAMENTO}

Candidata: Engenheira MILENA CARDODO DE FREITAS.

Título da dissertaçāo: "Avaliação de técnica de melhoria de solos colapsiveis por meio de colunas de solo laterífico compactado".

Data da defesa: 06/07/2016

\section{Comissāo Julgadora:}

Profa. Dra ${ }^{a}$. Cristina de Hollanda Cavalcanti Tsuha (Orientadora) (Escola de Engenharia de São Carlos/EESC)

Prof. Dr. Glauco Tulio Pessa Fabbri

(Escola de Engenharia de São Carlos/EESC)

Prof. Dr. Paulo José Rocha de Albuquerque

(Universidade Estadual de Campinas/UNICAMP)

\section{Resultado:}

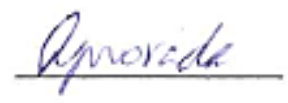

Apwovade

$\triangle P N O V \triangle D O$

Coordenador do Programa de Pós-Graduação em Geotecnia:

Prof. Dr. Edmundo Rogério Esquivel

Presidente da Comissāo de Pós-Graduaçāo:

Prof. Associado Luis Fernando Costa Alberto 

Dedicatória

À minha família pelo apoio constante e ao Gabriel pela paciência e pelo companheirismo. 



\section{AGRADECIMENTOS}

Por traz de uma conquista individual existe sempre uma grande equipe. Gostaria de agradecer individualmente cada um que contribuiu para que tudo acontecesse.

Inicialmente, quero agradecer à Deus pela saúde e proteção de todos os dias.

À Professora Cristina pela orientação, amizade e pelo apoio durante a realização da pesquisa.

Ao Professor Orencio pelo coorientação, pela atenção, incentivo e prontidão para sempre me ajudar.

À CAPES pela concessão da bolsa de estudo.

À Rochedo Fundações, principalmente ao Nestor, pelo apoio e pela execução das colunas de solo compactado em campo.

Ao Professor Paulo Albuquerque e à UNICAMP pelo empréstimo da placa utilizada nos ensaios de prova de carga.

Aos técnicos do laboratório do Departamento de Geotecnia da EESC/USP e principalmente ao Oscar que me ajudou nos ensaios realizados neste trabalho.

Aos técnicos do laboratório de Geossintéticos do Departamento de Geotecnia da EESC/USP Thiago e Clever que me ajudaram na execução dos ensaios em escala reduzida.

À todos os meus amigos que me ajudaram nas leituras das provas de cargas, Nene, Ayla, Denis, Paula e principalmente ao João e à Thaise pelo suporte dado nos ensaios realizados.

Aos meus primos Danilo e Mateus, que vieram à São Carlos me ajudar nas provas de carga e na montagem e desmontagem de alguns ensaios.

Aos funcionários do Departamento de Geotectnia Maristela, Neiva, Álvaro e Herivelto pela amizade e por estarem sempre dispostos a nos ajudar.

À todos os professores do departamento de Geotecnia pelos ensinamentos adquiridos na minha formação geotécnica.

À todos os colegas do Departamento de Geotecnia, principalmente à Paula, Ayla, Fernanda, Nene, João e Thaise pela amizade durante o mestrado.

Aos meus pais e à minha irmã pelo apoio, motivação e por estarem sempre ao meu lado.

Ao Gabriel, pelo amor, carinho e companheirismo de sempre. 



\section{RESUMO}

FREITAS, M. C. Avaliação de técnica de melhoria de solos colapsíveis por meio de colunas de solo laterítico compactado. 2016. 200 f. Dissertação (Mestrado) - Escola de Engenharia de São Carlos, Universidade de São Paulo, São Carlos, 2016.

A fundação direta é limitada em solos colapsíveis pois o efeito do colapso é mais acentuado nas camadas superficiais do terreno. Diante deste cenário, nesta pesquisa foi avaliada uma nova técnica de reforço de solo com a finalidade de viabilizar o uso de fundações diretas para controlar e reduzir o recalque das fundações devido ao colapso. A técnica proposta consiste na execução de colunas de solo laterítico compactado, inseridas na camada colapsível. O processo de compactação das colunas provoca a densificação do solo ao seu entorno, e consequentemente reduz a compressibilidade da massa de solo reforçado. Neste trabalho também foi verificado se a compactação radial do solo em torno da coluna estava relacionada com a geometria do pilão utilizado. Para compreender estes efeitos, foram realizados ensaios em laboratório, em escala reduzida, para avaliar qualitativamente duas geometrias de pilões diferentes, uma cônica e outra cilíndrica (tradicionalmente utilizada na engenharia de fundações). Como resultado desta análise, concluiu-se que a geometria cônica apresentou uma maior compactação lateral do solo no entorno da coluna, comparando-se com a geometria cilíndrica. Para analisar a eficiência do método de reforço proposto, foram executadas e ensaiadas colunas em escala real no solo colapsível do Campo Experimental de Fundações da Escola de Engenharia de São Carlos da Universidade de São Paulo. Para esta análise, foram realizadas provas de carga em placa em solo com e sem reforço. Os ensaios foram realizados com e sem a inundação do terreno para se verificar o efeito da inundação no comportamento do solo reforçado. Desta forma, foi possível avaliar o ganho de capacidade de carga e a redução dos recalques devido à execução dos elementos de reforço ensaiados. Por meio dos resultados obtidos nas provas de carga em placa constatou-se a eficiência do método na redução do recalque e no aumento da capacidade de carga. Comparando-se as curvas dos ensaios de placa com e sem reforço, observou-se um aumento da capacidade de carga de quatro vezes em consequência da instalação do reforço.

Palavras chave: Fundações, solos colapsíveis, solo laterítico, melhoria de solos, colunas de compactação 

ABSTRACT

FREITAS, M. C. Evaluation of compacted lateritic columns as a soil improvement technique for collapsible soils. 2016. 200 f. Dissertação (Mestrado) - Escola de Engenharia de São Carlos, Universidade de São Paulo, São Carlos, 2016.

The use of shallow foundation is limited on collapsible soils due to the collapse effect pronounced in superficial layers. Considering this scenario, this research presents a new soil reinforcement technique in order to reduce the settlement of foundations due to the collapse. The proposed technique involves the execution of compacted lateritic soil columns inserted into the collapsible soil. The compaction of these columns causes the densification of the surrounding soil and consequently reduces compressibility of the reinforced soil mass. In this work, it was also evaluated the effect of the hummer geometry on the radial compaction of the soil around the column. For this evaluation, laboratory tests were conducted using two different geometries of hammer, one conical and other cylindrical (traditionally used in foundation engineering). The results showed that the conical geometry provided greater lateral compaction of the soil around the column compared to the cylindrical geometry. The efficacy of the compacted lateritic soil columns was evaluated by the results of plate load tests performed on the collapsible soil of the Experimental Field of the University of São Paulo in São Carlos city. The tests were carried out on a plate installed in the ground with and without reinforcement. The gain on bearing capacity and settlement reductions due to the reinforcement were verified by using these tests results. The tests were performed in natural and in flooded condition to verify the efficiency of the soil reinforcement in the flooding situation. Based on the results of the plate load tests, it was verified the efficacy of the method to reduce the effect of collapse. The load-displacement curves of the load tests showed that the solution evaluated provided an increase of $400 \%$ on the ultimate capacity of the plate installed on the collapsible soil tested in this investigation.

Keywords: Foundations, collapsible soils, lateritic soils, soil improvement, compacted columns. 



\section{LISTA DE FIGURAS}

FIGURA 2.1 - OCORRÊNCIA DE SOLOS LATERÍTICOS NO BRASIL ...........................................29

FIGURA 2.2 - GRÁFICO DA CLASSIFICAÇÃO MCT FONTE - NOGAMI E VILLIBOR (1981) ............ 31

2.3 - ASCENSÃO DA ÁGUA NO TUBO CAPILAR: (A) FORMAÇÃO DO MENISCO, (B) ASCENSÃO, (C) PRESSÃO NA ÁGUA APÓS EQUILÍBRIO

FiguRA 2.4 - TENSÃO CAPILAR EM ÁGUA ADSORVIDA E COESÃO APARENTE FonTE - PINTO

(2006) 34

FIGURA 2.5 - ILUSTRAÇÃO DA ZONA SATURADA E NÃO SATURADO COM RELAÇÃO À POSIÇÃO DO NÍVEL D'ÁGUA

FiguRA 2.6 - ESQUEMA ILUSTRATIVO DA DEFINIÇÃO DE SUCÇÃO (COMUMENTE UA = PATM) ... 35

FigURA 2.7 - CURVA DE RETENÇÃO DA ÁGUA FonTE - FREDLUND E XING (1994) ..................... 37

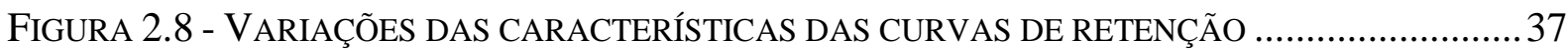

FIGURA 2.9 - ENVOLTÓRIO DE RUPTURA TRIDIMENSIONAL PARA SOLOS NÃO SATURADOS ..........39

FIGURA 2.10 - LINHAS DA ENVOLTÓRIA DE RUPTURA NO PLANO T VERSUS ( $\sigma$ - UA) FONTE -

FREDLUND E RAHARDJO (1993)

FIGURA 2.11 - VARIAÇÃO DA COESÃO COM A SUCÇÃO MATRICIAL DO SOLO FONTE - MACHADO (1998)

FIGURA 2.12 - AVARIAS DAS EDIFICAÇÕES DEVIDO AO EFEITO DO COLAPSO FONTE - RODRIGUES

FigURA 2.13 - RELAÇÃO ENTRE $P_{D}$ CAMPO E $P_{D}$ MÁX PARA SOLOS DE DIFERENTES REGIÕES DO BRASIL

FIGURA 2.14 -A) ENSAIO DE ADENSAMENTO COM INUNDAÇÃO POR ESTÁGIOS DE

CARREGAMENTO; B) ENSAIO DE ADENSAMENTO DUPLO (VILAR ET AL., 1981)

FIGURA 2.15 - RESULTADOS DA VARIAÇÃO DO POTENCIAL DE COLAPSO COM RELAÇÃO À TENSÃO DE INUNDAÇÃO LÍQUIDA.

FIGURA 2.16 - LIMITAÇÕES NA INTERPRETAÇÃO DOS ENSAIOS DE PLACA DEVIDO À DIFERENÇA DE ESCALA DOS BULBOS DE TENSÃO.

FIGURA 2.17- CURVA TÍPICA DA OCORRÊNCIA DO COLAPSO DO SOLO EM PROVAS DE CARGA COM INUNDAÇÃO REALIZADA DURANTE O ENSAIO FONTE - CINTRA (1995)

FigURA 2.18- A) COLAPSO SOB A CARGA DE TRABALHO, B) COLAPSO SOB UMA CARGA SUPERIOR À DE INUNDAÇÃO

FIGURA 2. 19 - PROVA DE CARGA EM SOLO COLAPSÍVEL PREVIAMENTE INUNDADO.....................50

FIGURA 2.20- CURVAS TENSÃO X RECALQUE TÍPICAS FONTE - TERZAGHI (1943) ........................51

FIGURA 2.21 - CURVA TENSÃO X RECALQUE DOS ENSAIOS DE PROVA DE CARGA FONTE - COSTA (1999)

FIGURA 2.22 - TENSÃO DE RUPTURA EM FUNÇÃO DA SUCÇÃO MATRICIAL ...............................53

FIGURA 2.23 - FAMÍLIA DE CURVAS CARGA X RECALQUE EM FUNÇÃO DA SUCÇÃO MATRICIAL DO SOLO.

FIGURA 2.24 - VARIAÇÃO DA SUCÇÃO MATRICIAL E PRECIPITAÇÃO MÉDIA DIÁRIA FONTE -

MORAES (2005)

FIGURA 2.25- VARIAÇÃO DE $\mathrm{N}_{\text {SPT }}$ COM O TEOR DE UMIDADE FONTE - REGINATTO (1971) .........55

FIGURA 2.26 - TÉCNICA DE MELHORAMENTO IDEAL DE ACORDO COM A GRANULOMETRIA DO SOLO FONTE - MITCHELL (1968) 
FIGURA 2.27 - ESQUEMA DE ESTABILIZAÇÃO TÉRMICA COMO TRATAMENTO DE SOLO COLAPSÍVEL FONTE - ADAPTADO DE LITVINOV (1960)

FIGURA 2.28 - CURVA DE COMPACTAÇÃO DESTACANDO A DENSIDADE SECA MÁXIMA E O TEOR DE UMIDADE ÓTIMO.

FIGURA 2.29 - TEORIA DE HOGENTOGLER (1937) PARA EXPLICAR A FORMA DA CURVA DE COMPACTAÇÃO

FIGURA 2.30 - TEORIA DE LAMBE (1958) QUE EXPLICA A FORMA DA CURVA DE COMPACTAÇÃO

FiguRA 2.31 - CURVAS DE PROCTOR DE SOLOS DIFERENTES, COMPACTADOS COM A MESMA ENERGIA

FIGURA 2.32 - MiCROESTRUTURA DE UM SOLO LATERÍTICO COLETADO A 1 METRO DE PROFUNDIDADE: A) AUMENTO DE 1000 VEZES EVIDENCIANDO A MACROCOPOROSIDADE ENTE OS AGREGADOS; B) AUMENTO DE 10000 VEZES EVIDENCIANDO OS MICROPOROS NO INTERIOR DO AGREGADO

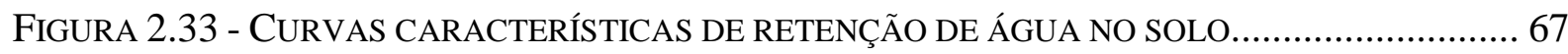

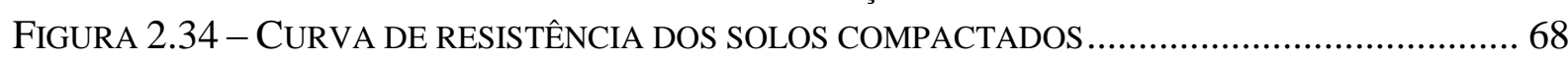

FIGURA 2.35- INTERVALO COM TAMANHO DE PARTÍCULAS ADEQUADO PARA DENSIFICAÇÃO POR

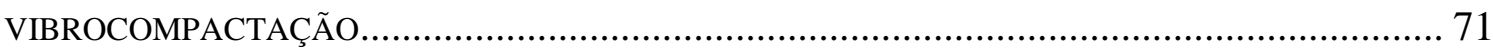

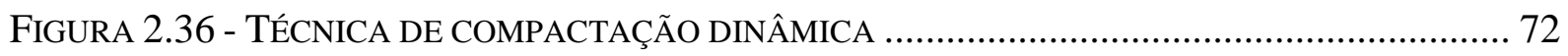

FIGURA 2.37 - ESQUEMA DE EXECUÇÃO DAS COLUNAS DE DESLOCAMENTO............................ 73

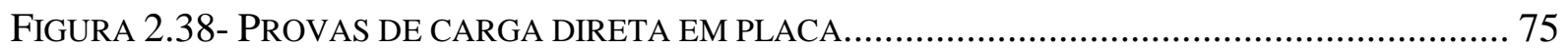

FIGURA 2.39- USO DE SAPATAS EM SOLO COLAPSÍVEL COMPACTADO ......................................... 76

FIGURA 2.40 - FATOR DE INFLUÊNCIA NA DEFORMAÇÃO VERTICAL ......................................... 77

FIGURA 2.41 - COMPARAÇÃO ENTRE O POTENCIAL DE COLAPSO DO SOLO COMPACTADO E NA SUA CONDIÇÃO NATURAL A UMA PROFUNDIDADE DE 1,5 A 1,8 METROS ................................... 78

FIGURA 2.42 - TÉCNICA DE EXECUÇÃO POR MEIO DE VIBRO-SUBSTITUIÇÃO ............................... 79

FIGURA 2.43 - TÉCNICA DE EXECUÇÃO POR MEIO DE VIBRO-DESLOCAMENTO........................... 80

FIGURA 2.44 - REFORÇO DE SOLO COM COLUNAS ENCAPSULADAS .......................................... 81

FIGURA 2.45 - CURVA CARGA X RECALQUE DAS COLUNAS GRANULARES ENCAPSULADAS COM

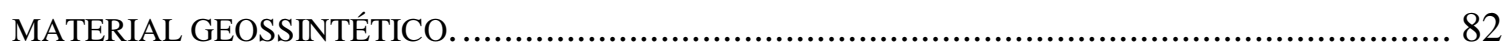

FIGURA 2.46 - DETALHE DA FERRAMENTA UTILIZADA PARA CORTE E MISTURA DO SOLO.......... 83

FIGURA 2.47 - EXECUÇÃO DAS COLUNAS DE JET GROUTING ................................................... 85

FIGURA 2.48- SISTEMAS TRADICIONAIS DE JET GROUTING - MONOFLUIDO, BIFLUIDO E TRIFLUIDO

FIGURA 2.49 - INFLUÊNCIA RADIAL DO EFEITO DA COMPACTAÇÃO....................................... 87

FIGURA 2.50- FORMAS DE AVALIAR UM SOLO REFORÇADO COM COLUNAS UTILIZANDO O ENSAIO DE PROVA DE CARGA EM PLACA. A) ENSAIO EM UM GRUPO DE COLUNA, B) ENSAIO NO SOLO ENTRE COLUNAS, C) ENSAIO NO ELEMENTO DE REFORÇO ….............................................. 87

FIGURA 2.51 - ENSAIO DE CONE EM SOLO NATURAL ............................................................ 88

FIGURA 2.52 - ENSAIO DE CONE EM SOLO COM COLUNAS ESPAÇADAS DE 90 CM ...................... 89

FIGURA 2.53 - FATOR DE INFLUÊNCIA NA DEFORMAÇÃO VERTICAL......................................... 91

FIGURA 2.54 - CURVA TÍPICA DO ENSAIO TRIAXIAL E DEFINIÇÃO DOS MÓDULOS...................... 94

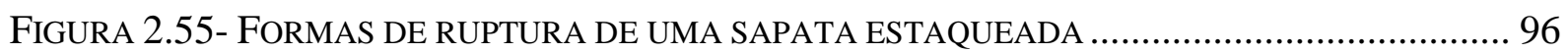

FIGURA 2.56- ÁBACO PARA ESTIMATIVA DO MÓDULO DE ELASTICIDADE EQUIVALENTE 
FIGURA 2.57- ÁBACO PARA ESTIMATIVA DO MÓDULO DE ELASTICIDADE EQUIVALENTE ECOLUNA $=500 \mathrm{MPA}$

FIGURA 2.58 - ÁBACO PARA O PROJETO DE MALHA DE COLUNAS DE AREIA E BRITA 101

FIGURA 2.59 - A) ENSAIO DE PROVA DE CARGA NO SOLO B) ENSAIO DE PROVA DE CARGA NO CONJUNTO COLUNA SOLO

FigURA 2.60 - GRÁFICO DE RIGIDEZ: A) APENAS DO SOLO E B) SOLO COM COLUNAS DE SOLO E BRITA

FIGURA 2.61- GRÁFICO DE RIGIDEZ DA COLUNA: A) PARA NÍVEL DE CARREGAMENTO SUPERIOR A $160 \mathrm{KN}$ E B) PARA NÍVEL DE CARREGAMENTO SUPERIOR A $160 \mathrm{KN}$.

FIGURA 2.62 - DISTRIBUIÇÃO DO CARREGAMENTO NO CONTATO SAPATA SOLO REFORÇADO.. 104 FigURA 2.63 - DiSTRIBUIÇÃO DA CARGA NO ENSAIO DE PLACA PARA AS ESTACAS DE ARGAMASSA

FIGURA 2.64 - DiSTRIBUIÇÃO DA CARGA NO ENSAIO DE PLACA PARA AS ESTACAS DE SOLO E BRITA

FIGURA 2.65 - CONCEITO DE CÉLULA UNITÁRIA E PADRÕES DE MALHA

FIGURA 2.66- REPRESENTAÇÃO DA ÁREA DA COLUNA E DA CÉLULA UNITÁRIA .......................... 108

FIGURA 2.67 - DIFERENTES CENÁRIOS DE CARREGAMENTO DAS COLUNAS DE BRITA ...............110

FIGURA 2.68- RUPTURA POR AFUNDAMENTO DE UMA COLUNA ISOLADA ................................. 110

FIGURA 2.69 - ANÁLISE DO COMPORTAMENTO DE GRUPO DE COLUNAS GRANULARES .............112

FIGURA 2.70 - ABERTURA DO FUSTE DA ESTACA APILOADA COM O AUXÍLIO DO PILÃO .............113

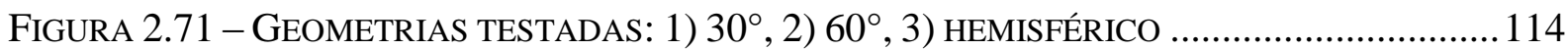

FiguRA 3.1 - RESULTADOS DOS ENSAIOS PENETROMÉTRICOS DE SPT E CPTU REALIZADOS NO

CAMPO EXPERIMENTAL DE FUNDAÇÕES DA CIDADE DE SÃO CARLOS

FIGURA 3.2 - CURVA DE RETENÇÃO DE ÁGUA NO SOLO PARA A PROFUNDIDADE DE 2,0 M-

CAMPO EXPERIMENTAL DE FUNDAÇÕES

FIGURA 3.3 - LOCAÇÃO DAS PROVAS DE CARGA EM PLACA REALIZADAS NO CAMPO EXPERIMENTAL DE FUNDAÇÕES DA EESC/ USP

FIGURA 3.4 - CURVAS TENSÃO X RECALQUE OBTIDAS NOS ENSAIOS: (A) ENSAIO SML, (B) ENSAIO QML, (C) ENSAIO MML INUNDADOS

FIGURA 3.5 - CURVAS TENSÃO X RECALQUE OBTIDAS NOS ENSAIOS: (A) ENSAIO SML, (B) ENSAIO QML, (C) ENSAIO MML COM SUCÇÃO

FIGURA 4.1 - AMOSTRA DEFORMADA RETIRADAS DO CAMPO EXPERIMENTAL DE FUNDAÇÕES COM TRADO TIPO CAVADEIRA

FiguRA 4.2 - A) SOQUETE UTILIZADO PARA COMPACTAÇÃO DAS CAMADAS; B) DELIMITAÇÃO DAS CAMADAS

FIGURA 4.3 - GEOMETRIAS DOS PILÕES: TIPO A (CÔNICA) E TIPO B (CILÍNDRICA) 126

FigURA 4.4 - PRENSA DO LABORATÓRIO DE GEOSSINTÉTICOS DA EESC/USP UTILIZADA NOS ENSAIOS

FIGURA 4.5 - DISPOSIÇÃO DOS ENSAIOS (DOIS ENSAIOS EM CADA CAIXA) 127

FIGURA 4.6 - FOTO DA ESCAVAÇÃO DA CAIXA 4: COLUNA EXECUTADA COM PILÃO TIPO B ..... 128

FIGURA 4.7 - EQUIPAMENTO UTILIZADO NA EXECUÇÃO DAS COLUNAS .................................. 129

FIGURA 4.8 - PREENCHIMENTO DA COLUNA DURANTE A EXECUÇÃO …................................... 130

FIGURA 4.9 - RELAÇÃO DAS TRÊS COLUNAS EXECUTADAS EM CAMPO ...................................131 
FIGURA 4.10 - RELAÇÃO DOS ENSAIOS DE PROVA DE CARGA EM PLACA NO TERRENO COM E SEM REFORÇO

FIGURA 4.11 RELAÇÃO ENTRE O EFEITO DO REFORÇO DE SOLO E A PLACA UTILIZADA NO ENSAIO DE PROVA DE CARGA 134

FIGURA 4.12 - ESQUEMATIZAÇÃO DO ENSAIO NAS COLUNAS. 134

FIGURA 4.13 - INUNDAÇÃO DO SOLO DE APOIO DA PLACA PARA A PROVA DE CARGA INUNDADA

FIGURA 4.14 - PLACA UTILIZADA NOS ENSAIOS DE PROVA DE CARGA.

FIGURA 4.15 - MACACO HIDRÁULICO E BOMBA UTILIZADOS NOS ENSAIOS...

NOS ENSAIOS FOI UTILIZADA UMA CÉLULA DE CARGA COM CAPACIDADE DE 100 TF. ESTA CÉLULA FOI ACOPLADA A UM PAINEL DE LEITURA DIGITAL, DA MARCA ALFA, PARA A LEITURA E CONTROLE DA APLICAÇÃO DE CARGA. A CÉLULA UTILIZADA HAVIA SIDO CALIBRADA E AFERIDA EM LABORATÓRIO ANTES DA REALIZAÇÃO DOS ENSAIOS (FIGURA 4.16).

FIGURA 4.17 - TORRE DE TRANSFERÊNCIA DE CARGA UTILIZADA NOS ENSAIOS 138

FIGURA 4.18 - INSTALAÇÃO DOS EXTENSÔMETROS MECÂNICOS PARA MEDIR O DESLOCAMENTO VERTICAL DA PLACA NAS PROVAS DE CARGA .

FIGURA 4.19 - VIGAS DE REFERÊNCIA UTILIZADAS NOS ENSAIOS........................................... 139

FIGURA 4.20- ESQUEMA DAS PROVAS DE CARGA REALIZADAS ............................................... 140

FIGURA 4.21 - INSTALAÇÃO DO TENSIÔMETRO NO INTERIOR DA CAVA ................................... 141

FIGURA 4.22 - ESQUEMATIZAÇÃO DA SIMPLIFICAÇÃO PARA O MÓDULO DE DEFORMABILIDADE EQUIVALENTE

FIGURA 4.23- ILUSTRAÇÃO DA DISPOSIÇÃO DAS AMOSTRAS INDEFORMADAS RETIRADAS NO ENTORNO DAS COLUNAS.

FIGURA 5.1 - CURVA DE GRANULOMETRIA ABNT NBR 6502/95 ....................................... 145

FIGURA 5.2 - RESULTADO DA CURVA DE COMPACTAÇÃO NA ENERGIA PROCTOR NORMAL .... 146

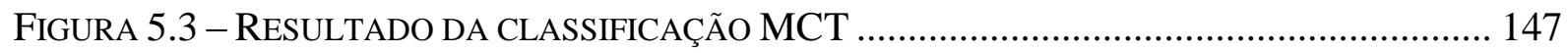

FIGURA 5.4 - COMPARAÇÃO DA GEOMETRIA FINAL DOS TRÊS TIPOS DE COLUNA ESTUDADOS (E-

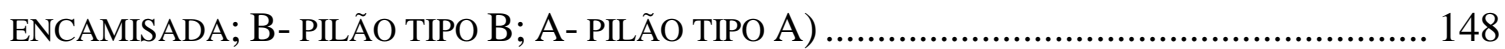

FIGURA 5.5 - CAIXA 3: COMPARAÇÃO ENTRE COLUNAS EXECUTADAS COM PILÃO TIPO A E PILÃO

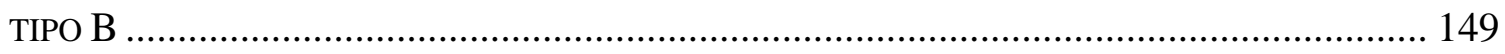

FIGURA 5.6 - CAIXA 4: COMPARAÇÃO DAS COLUNAS EXECUTADAS COM PILÃO TIPO A E PILÃO TIPO B

FIGURA 5.7 - CAIXA 5: COMPARAÇÃO DAS COLUNAS EXECUTADAS COM PILÃO TIPO B COM E SEM ENCAMISAMENTO.....

FIGURA 5.8- CAIXA 6: COMPARAÇÃO DAS COLUNAS EXECUTADAS COM PILÃO TIPO A E COM PILÃO TIPO B

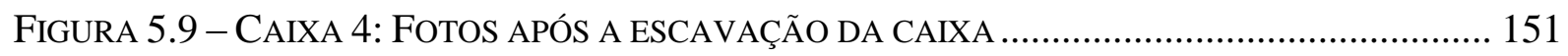

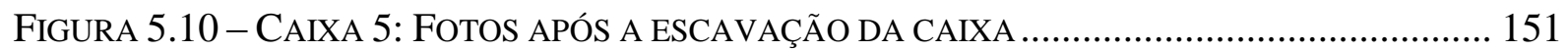

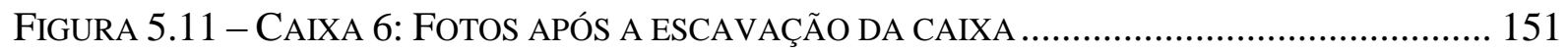

FIGURA 5.12 - POSIÇÃO DOS ANÉIS RETIRADO NO ENTORNO DA COLUNA DE SOLO COMPACTADO 1

FIGURA 5.13 - POSIÇÃO DOS ANÉIS RETIRADO NO ENTORNO DA COLUNA DE SOLO COMPACTADO 2. 
FIGURA 5.14 - POSIÇÃO DOS ANÉIS RETIRADOS NO ENTORNO DA COLUNA DE SOLO E BRITA ... 154 FIGURA 5.15 - RESULTADOS DA VARIAÇÃO DO ÍNDICE DE VAZIOS NO ENTORNO DAS TRÊS

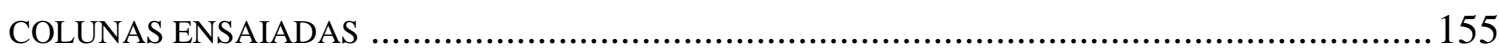

FIGURA 5.16 - RESULTADOS DA VARIAÇÃO DA MASSA ESPECÍFICA APARENTE SECA NO ENTORNO

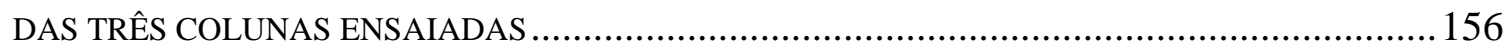

FIGURA 5.17 - CURVA TENSÃO X RECALQUE PARA A COLUNA DE SOLO COMPACTADO NA

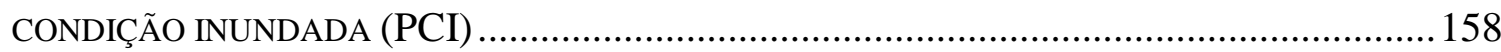

FIGURA 5.18 - EXTRAPOLAÇÃO DA CURVA TENSÃO X RECALQUE PARA A COLUNA DE SOLO COMPACTADO INUNDADA (PCI) PELO MÉTODO PROPOSTO .............................................. 158

FiguRA 5.19 - CURVA TENSÃO X RECALQUE PARA A COLUNA DE SOLO COMPACTADO COM SUCÇÃO DE 13 KPA (PCN).

FIGURA 5.20 - CURVA TENSÃO X RECALQUE PARA A COLUNA DE SOLO E BRITA NA CONDIÇÃO INUNDADA (PSB) 160

FIGURA 5.21 - CURVA TENSÃO X RECALQUE O PARA O SOLO COM SUCÇÃO DE 6 KPA E PARA A CONDIÇÃO INUNDADA NA TENSÃO ADMISSÍVEL DE $50 \mathrm{KPA}$

FIGURA 5.22 - COMPARAÇÃO DAS CURVAS CARGA X RECALQUE OBTIDAS PARA O TERRENO REFORÇADO COM COLUNAS

FIGURA 5.23 - CURVAS CARGA X RECALQUE PARA PLACAS INUNDADAS OBTIDAS POR COSTA (1999) À PROFUNDIDADE DE $1,50 \mathrm{M}$

FIGURA 5.24 - COMPARAÇÃO DAS CURVAS TENSÃO X RECALQUE PARA O SOLO REFORÇADO E SEM REFORÇO

FIGURA 5.25 - CURVAS TENSÃO X RECALQUE PARA ENSAIOS DE PLACA NO SOLO COM REFORÇO E SEM REFORÇO NA CONDIÇÃO DE UMIDADE NATURAL DO TERRENO (COM SUCÇÃO). 165

FIGURA 5.26 - RESULTADOS DA VARIAÇÃO DO MÓDULO DE DEFORMABILIDADE DO SOLO, COM E SEM REFORÇO, COM O AUMENTO DA TENSÃO APLICADA.

FIGURA 5.27 - CURVAS TENSÃO X RIGIDEZ PARA OS ESTÁGIOS DE CARREGAMENTO DOS ENSAIOS DE PROVA DE CARGA SOBRE PLACA REALIZADOS 



\section{LISTA DE TABELA}

TABELA 2.1 - CRITÉRIOS DE IDENTIFICAÇÃO DE SOLO COLAPSÍVEL ...........................................42

TABELA 2.2 - ClASSIFICAÇÃO DA COLAPSIBILIDADE EM OBRAS DE ENGENHARIA A PARTIR DE RESULTADO DE ENSAIOS EDOMÉTRICOS

TABELA 2.3 - RESULTADOS DOS ENSAIOS DE PROVA DE CARGA EM PLACA .............................. 48

TABELA 2.4 - COMPARAÇÃO ENTRE OS RECALQUES PREVISTOS E MEDIDOS PARA OS VÁRIOS TIPOS DE TRATAMENTOS

TABELA 2.5- FAIXAS DOS DIÂMETROS DAS COLUNAS QUE PODEM SER OBTIDOS COM OS DIFERENTES SISTEMAS DE EXECUÇÃO

TABELA 3.1 - RESULTADOS OBTIDOS AO LONGO DO PERFIL DE COLETA DE BLOCOS INDEFORMADOS (MACHADO, 1998)

TABELA 3.2 - RESULTADOS DOS ENSAIOS DE CARACTERIZAÇÃO E COMPACTAÇÃO ..................117

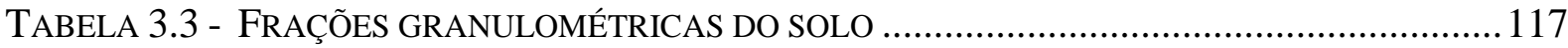

TABELA 3.4 - RELAÇÃO DOS ENSAIOS DE PROVA DE CARGA REALIZADOS ............................... 120

TABELA 4.1 - TEORES DE UMIDADE DO SOLO AO LONGO DA PROFUNDIDADE DURANTE A

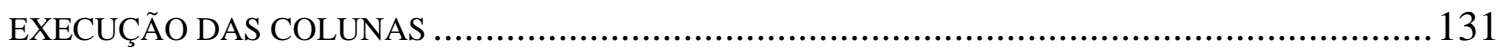

TABELA 5.1 - RESULTADOS DE MASSA ESPECÍFICA DOS SÓLIDOS E LIMITES DE CONSISTÊNCIA DO SOLO.

TABELA 5.2 - MASSA ESPECÍFICA DO SOLO DO CAMPO EXPERIMENTAL DE FUNDAÇÕES À

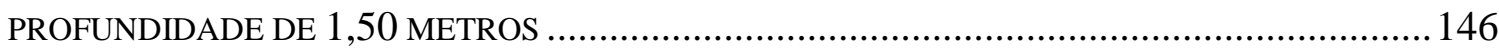

TABELA 5.3 - VALORES MÉDIOS DOS RESULTADOS ENCONTRADOS ..................................... 148

TABELA 5.4 - RESULTADOS DA VARIAÇÃO DO ÍNDICE DE VAZIOS NO ENTORNO DA COLUNA DE SOLO COMPACTADA 1

TABELA 5.5 - RESULTADOS DA VARIAÇÃO DO ÍNDICE DE VAZIOS NO ENTORNO DA COLUNA DE SOLO COMPACTADA 2

TABELA 5.6 - RESULTADOS DA VARIAÇÃO DO ÍNDICE DE VAZIOS NO ENTORNO DA COLUNA DE SOLO E BRITA.

TABELA 5.7 - VARIAÇÃO DO TEOR DE UMIDADE NO ENTORNO DA COLUNA ANTES E APÓS O ENSAIO DE PROVA DE CARGA

TABELA 5.8 - MÓDULO DE DEFORMABILIDADE PARA OS VALORES DE TENSÕES ADMISSÍVEIS . 167

TABELA 5.9 - APLICAÇÃO DA RETROANÁLISE PELO MÉTODO DE SCHMERTMANN (1978) PARA

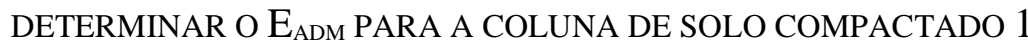

TABELA 5.10 - APLICAÇÃO DA RETROANÁLISE PELO MÉTODO DE SCHMERTMANN (1978) PARA

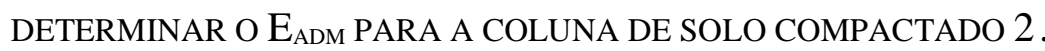

TABELA 5.11 - APLICAÇÃO DA RETROANÁLISE PELO MÉTODO DE SCHMERTMANN (1978) PARA DETERMINAR O E

TABELA 5.12 - APLICAÇÃO DA RETROANÁliSE PELO MÉTODO DE SCHMERTMANN (1978) PARA DETERMINAR O E $E_{A D M}$ PARA O SOLO SEM REFORÇO.

TABELA 5.13 - MódULO DE DEFORMABILIDADE ELÁSTICO (E $\left.\mathrm{E}_{\mathrm{EL}}\right)$ E PARA AS COLUNAS ENSAIADAS

TABELA 5.14 - APLICAÇÃO DA RETROANÁLISE PELO MÉTODO DE SCHMERTMANN (1978) PARA DETERMINAR O E EL DA COLUNA DE SOLO COMPACTADO 1 
TABELA 5.15 - APLICAÇÃo DA RETROANÁLISE PELO MÉTODO DE SCHMERTMANN (1978) PARA

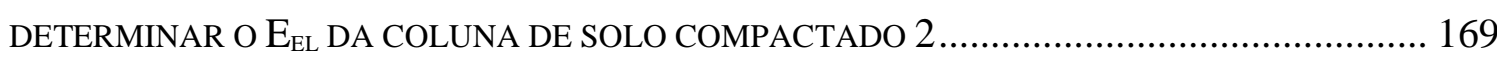

TABELA 5.16 - APLICAÇÃO DA RETROANÁLISE PELO MÉTODO DE SCHMERTMANN (1978) PARA

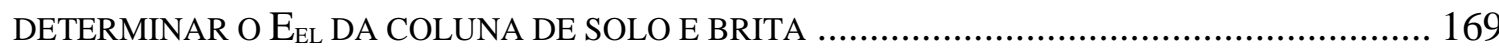

TABELA 5.17 - TENSÃO ADMISSÍVEL E TENSÃO DE RUPTURA ENCONTRADAS NOS ENSAIOS DE

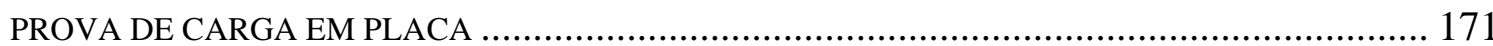




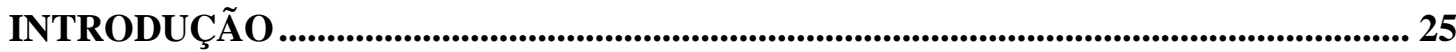

1.1

OBJETIVOS

ORGANIZAÇÃO DO TRABALHO.

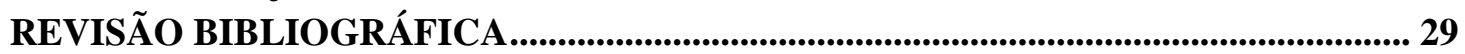

Capilaridade e adsorção.

Sucção

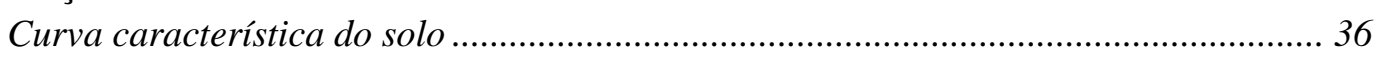

Resistência ao cisalhamento dos solos não saturados...

Critérios para identificar um solo colapsivel.

Ensaios para analisar o efeito do colapso .................................................................. 44

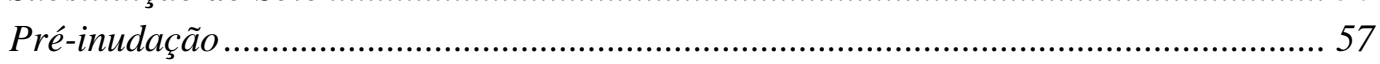

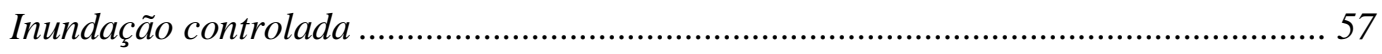

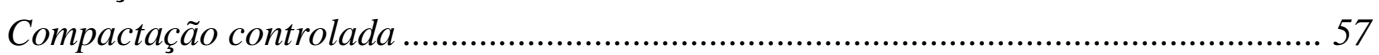

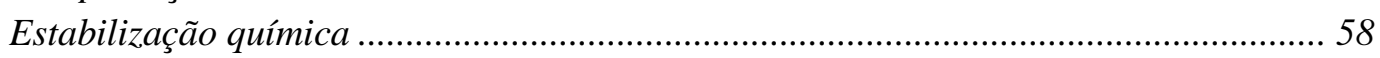

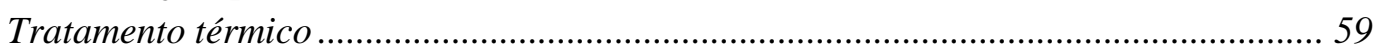

Avaliação dos métodos de reforço e tratamento do solo.................................................. 60

COMPACTAÇÃO DOS SOLOS ..................................................................661

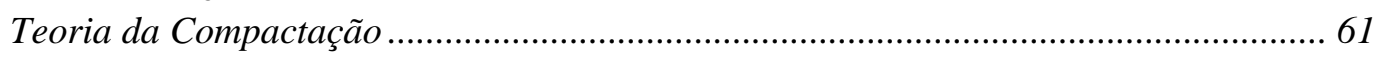

Interferência da compactação no comportamento e resistência dos solos ...................... 67

Métodos de compactação do solo em campo ................................................................. 69

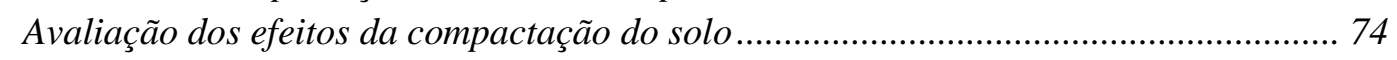

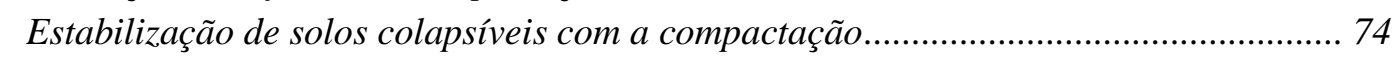

TRATAMENTO DE SOLO COM COLUNAS ........................................................78

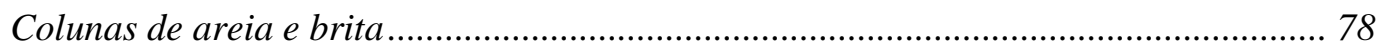

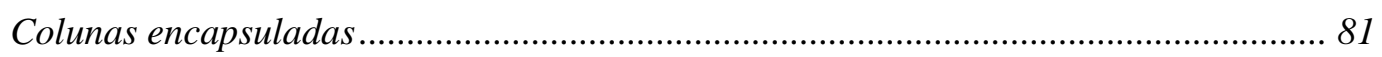

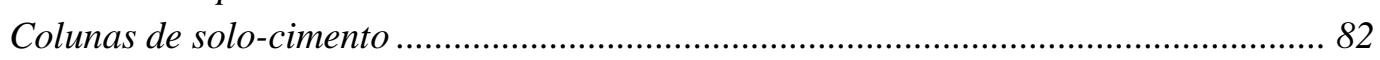

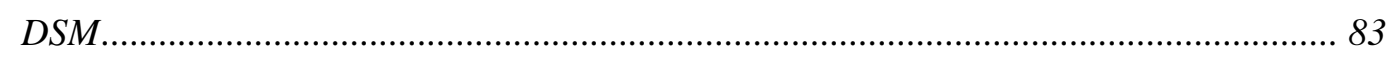

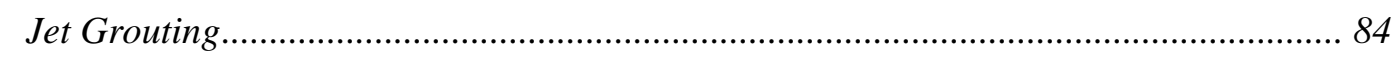

AVALIAÇÃO DO SOLO REFORÇADO COM COLUNAS......................................86

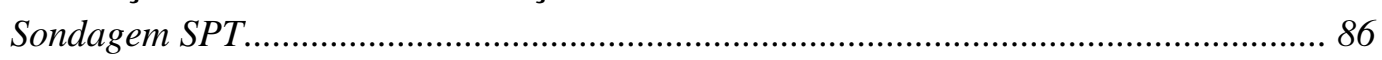

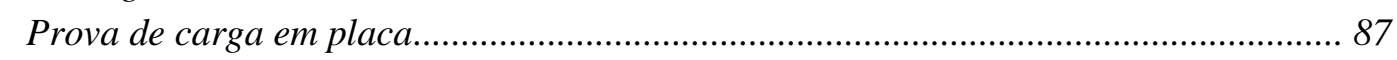

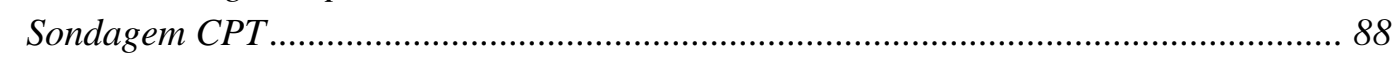

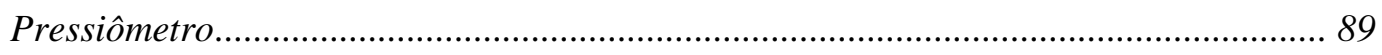

Ensaios em laboratório com amostras indeformadas ..................................................... 89

Módulo de deformabilidade a partir de ensaios de campo e laboratório .......................... 89

2.8 SAPATAS APOIADAS EM SOLO REFORÇADO COM COLUNAS ........................94

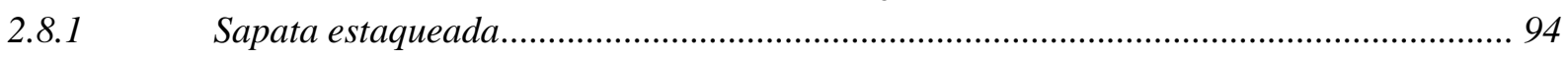

2.8.2 Módulo de Elasticidade equivalente para o solo reforçado............................................ 98 
2.8.3 Análise da rigidez e da transferência de carga do solo reforçado............................... 101

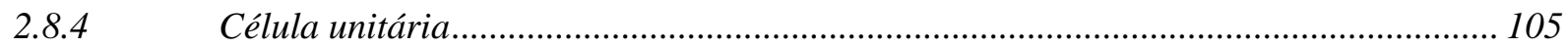

2.8.5 Capacidade de carga do solo reforçado com colunas................................................... 109

2.9 ESTACAS APILOADAS ........................................................................................ 112

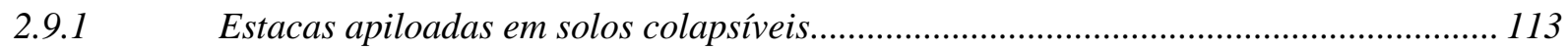

2.10 INFLUÊNCIA DA GEOMETRIA DO PILÃO NA EXECUÇÃO DAS COLUNAS . 114

3 CARACTERÍSTICAS DO SOLO ESTUDADO …......................................................... 115

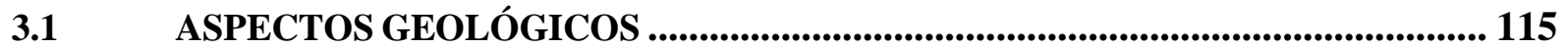

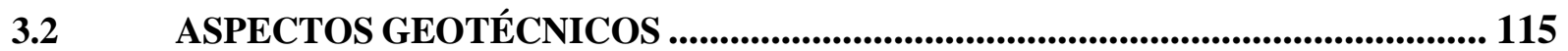

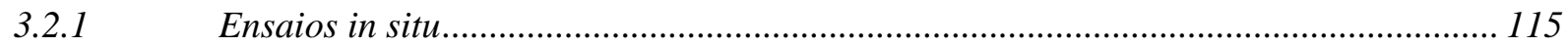

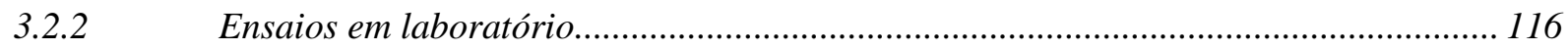

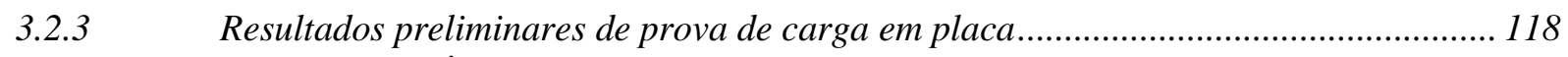

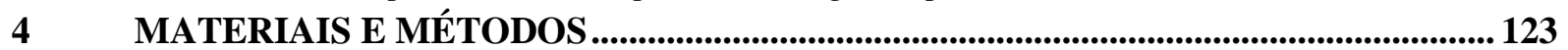

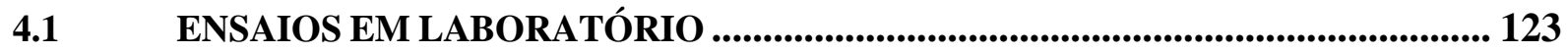

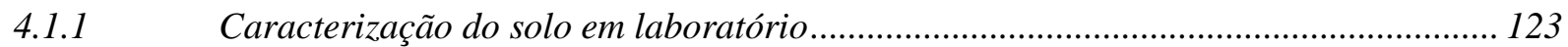

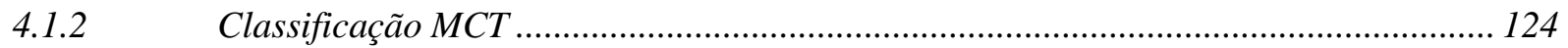

4.1.3 Execução de colunas de solo compactado em escala reduzida ....................................... 124

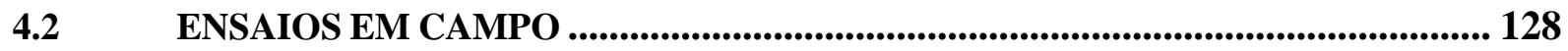

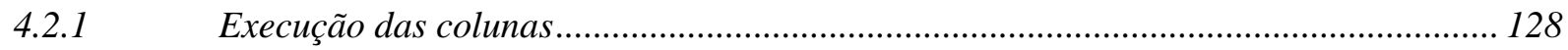

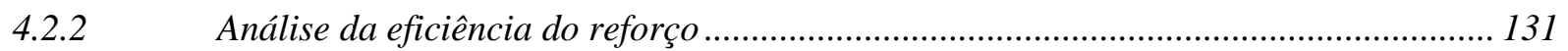

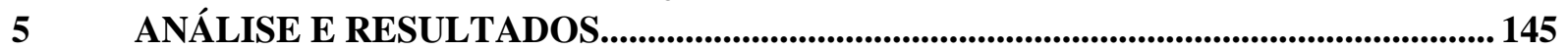

5.1 ANÁLISE E RESULTADOS DOS ENSAIOS EM LABORATÓRIO ......................... 145

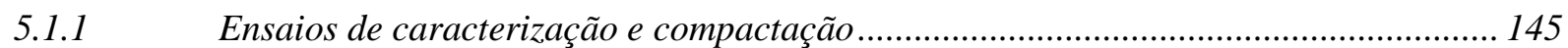

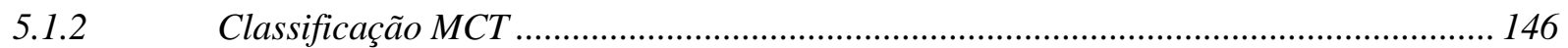

5.1.3 Execução das colunas de solo compactado em escala reduzida .................................... 147

5.2 ANÁLISE E RESULTADOS DOS ENSAIOS EM CAMPO ....................................... 152

5.2.1 Variação do índice de vazios no entorno das colunas.................................................... 152

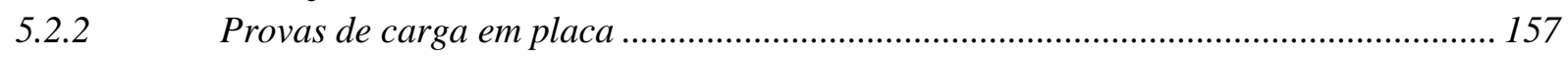

5.2.3 Análise da deformabilidade do solo reforçado............................................................... 165

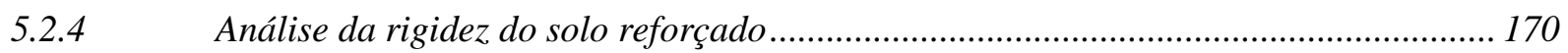

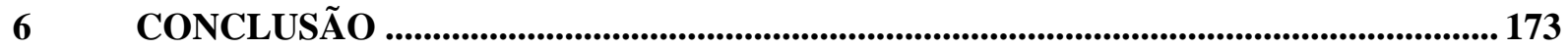

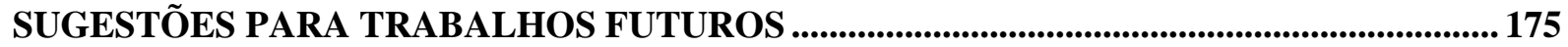

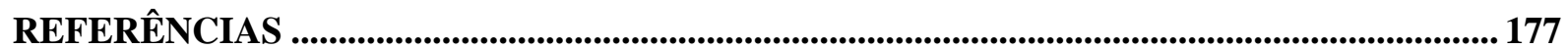

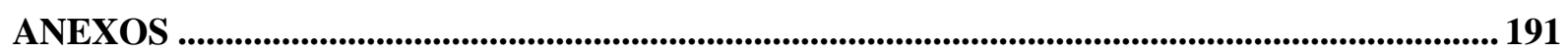

ANEXO A - LOCAÇÃO DOS FUROS DE SONDAGEM E DOS ENSAIOS DE PROVA DE

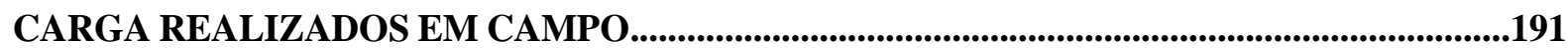

ANEXO B - RESULTADOS DOS ENSAIOS DE PROVA DE CARGA REALIZADOS .......... 191

ANEXO C - RESULTADOS DOS ENSAIOS DE PROVA DE CARGA COSTA (1999) ............ 197

ANEXO D - CURVA DE CALIBRAÇÃO DA CÉLULA DE CARGA...................................... 201 


\section{INTRODUÇÃ̃O}

No Brasil, a predominância do clima tropical e subtropical resulta em alterações pedogênicas que favorecem o desenvolvimento de solos porosos e potencialmente colapsíveis. O colapso é um comportamento problemático pois, quando há a infiltração da água em quantidade suficiente, o solo submetido a um determinado nível de tensão sofre uma brusca redução de volume. As edificações apoiadas nessas camadas estão sujeitas às variações do comportamento do solo, o que pode levar ao aparecimento de trincas e fissuras acentuadas, de modo a comprometer o estado limite de serviço da obra.

O solo colapsível apresenta uma estrutura instável que é mantida pelas elevadas pressões de sucção e/ou cimentação. Como o efeito do colapso é mais acentuado nas camadas superficiais, a norma brasileira ABNT NBR 6122/2010 limita a execução de fundações diretas nestes solos. A falta de soluções econômicas e de fácil execução para reduzir os recalques por colapso das fundações resulta na execução de fundações profundas, o que encarece as obras.

Para reduzir os efeitos nocivos do recalque de fundações diretas por colapso, deve-se adotar alguma medida de reforço ou melhoria do solo. Al Rawas (2000), realizou ensaios com os principais métodos de estabilização existentes para os solos colapsíveis e concluiu que a compactação dinâmica foi um dos métodos mais eficazes para reduzir o recalque dos solos por colapso. Além disso, alguns autores como Vargas (1951), Aflitos et al. (1990), Souza (1993) e Cintra e Aoki (2009), analisaram o efeito da compactação do solo na redução dos recalques por colapso e comprovaram a eficiência da técnica. No entanto, no caso de fundação direta de grande dimensão, a camada de solo compactado deverá ser demasiadamente espessa para ser eficiente, o que pode deixar esta solução inviável.

Deste modo, com base nos resultados positivos do efeito da compactação na redução do colapso encontrados na literatura, foi proposto e avaliado nesta pesquisa um novo método de melhoria e reforço do solo, por meio de colunas de solo laterítico compactado. Neste caso, ao invés de se compactar uma camada espessa de solo, seria executado um grupo de colunas compactas sob a área a ser carregada pela fundação direta.

A técnica proposta concilia baixo custo e facilidade de execução e tem como objetivo viabilizar a implantação de fundações diretas apoiadas nos terrenos reforçados. Com base nos resultados preliminares encontrados nesta pesquisa, pretende-se proporcionar um avanço no dimensionamento de fundações em solos não saturados e colapsíveis. 


\subsection{OBJETIVOS}

O objetivo principal deste trabalho foi avaliar experimentalmente uma técnica de melhoria e reforço de solo colapsível por meio de colunas de solo laterítico compactado, proposta para possibilitar o uso de fundações diretas assentes em solos colapsíveis, típicos da região estudada.

Esta solução de reforço foi executada in situ pela primeira vez para esta pesquisa. Portanto, também foi objeto deste trabalho o desenvolvimento de um procedimento executivo para a realização das colunas de solo laterítico compactado.

Como objetivo secundário deste trabalho, foi analisado o efeito na compactação de duas geometrias diferentes de pilões para a execução das colunas. Para isto, foram feitos ensaios em laboratório, em escala reduzida, devido à dificuldade de visualizar e mensurar esses efeitos em campo. O primeiro pilão utilizado (tipo A) possui ponta com geometria cônica e o segundo pilão (tipo B), apresenta as mesmas dimensões que o pilão A, no entanto a sua ponta é cilíndrica. Em campo, o pilão adotado para a abertura e compactação do material de preenchimento da coluna possui geometria cilíndrica (pilão de estaca Strauss).

Na literatura, poucos estudos são encontrados a respeito da influência da geometria da ponta do pilão nos efeitos de compactação das colunas. Consequentemente, este fato motivou esta análise. O objetivo foi avaliar, de forma qualitativa, a similaridade das características das colunas executadas com os diferentes tipos de pilão e a influência radial do efeito de compactação por meio de fotografias das colunas.

\subsection{ORGANIZAÇÃO DO TRABALHO}

No Capítulo 2 deste trabalho apresenta-se uma revisão bibliográfica dos seguintes temas: solos lateríticos, solos não saturado do solo, comportamento colapsível e problemas de fundações diretas assentes neste tipo de solo. Além disso, a revisão bibliográfica apresenta alguns métodos de melhoria e reforço de solos existentes e destaca aqueles utilizados para reforço de solos colapsíveis e sua eficácia. Esta revisão também aborda as diferentes maneiras de considerar a transferência de carga de uma sapata apoiada em solos reforçados com colunas.

No Capítulo 3, são descritas as características do solo estudado como: aspectos geológicos, geotécnicos, resultados de ensaios em laboratório, ensaios de campo e de provas de carga em placa. 
No Capítulo 4 são apresentados os materiais e métodos adotados neste trabalho: em laboratório e em campo. Neste capítulo são detalhados os procedimentos dos ensaios e as considerações e interpretações dos resultados dos ensaios de campo.

No Capítulo 5 são expostos os resultados obtidos nos ensaios e neste mesmo capítulo é feita a análise do desempenho do reforço analisado.

O Capítulo 6 apresenta as conclusões provenientes dos ensaios realizados nesta pesquisa. 


\section{REVISÃO BIBLIOGRÁFICA}

\subsection{SOLOS LATERÍTICOS}

De acordo com Nogami e Villibor (1995) os solos lateríticos são solos típicos das regiões de clima tropical e subtropical provenientes do intenso intemperismo físico e químico das rochas devido às variações climáticas. No Brasil, país de clima predominantemente tropical, os solos lateríticos cobrem aproximadamente 70\% do seu território, como mostra a Figura 2.1, sendo a sua extensão geográfica o principal motivo da importância do estudo deste solo.

A estrutura do perfil de intemperismo, segundo Mello (1972) e Vargas (1977), pode ser dividida em três horizontes principais: laterítico, saprolítico e os blocos de rocha alterada. A camada de solo laterítico, podendo ser de origem residual ou transportada, é formada por um solo que perdeu a estrutura da rocha mãe, tornando-se relativamente homogêneo, podendo atingir mais de dez metros de profundidade. O saprolítico, localizado na camada subjacente, mantém as características da rocha que lhe deu origem e pode atingir dezenas de metros. Os blocos de rocha alterada correspondem ao horizonte em que a ação do intemperismo progrediu ao longo das fraturas ou zonas de menor resistência da rocha (MASSAD, 2005).

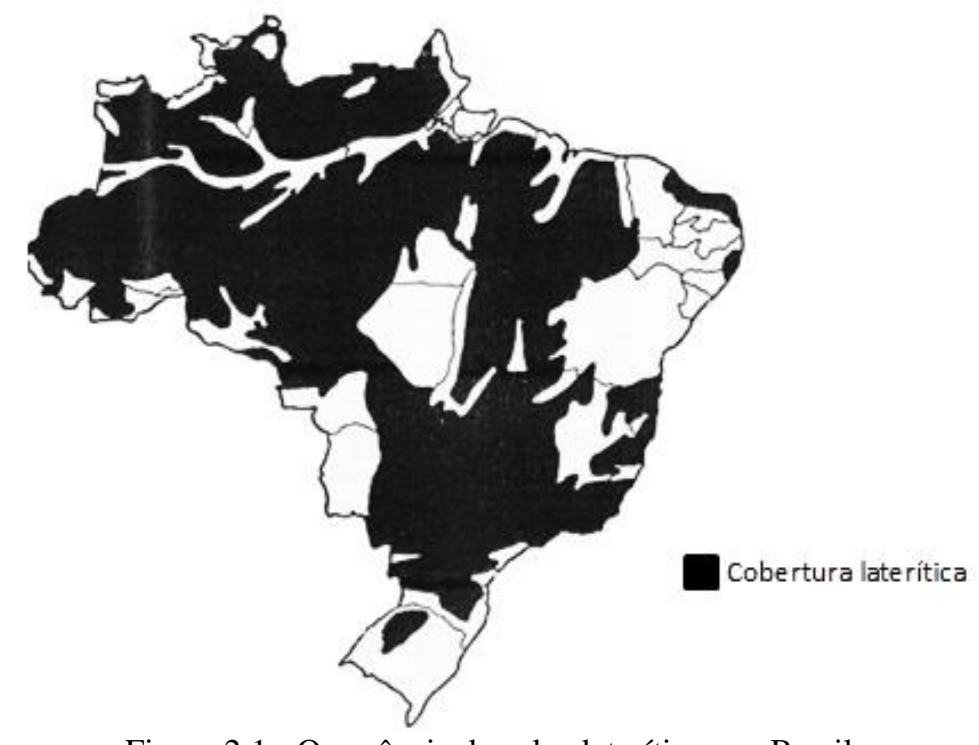

Figura 2.1 - Ocorrência de solos lateríticos no Brasil Fonte - Melfi (1994)

De acordo com Nogami e Vilibor (1995) a granulometria dos solos lateríticos varia entre limites muito amplos: desde areias com poucos finos argilosos até argilas, podendo conter uma porcentagem de silte que varia de 0 a mais de $50 \%$, sem imprimir características siltosas. 
Estes solos possuem algumas peculiaridades que os diferem dos solos de clima temperado (BENATTI et al., 2011). De acordo com Melfi (1994), um dos fatores fundamentais ao processo de intemperismo é a evolução da matéria orgânica, que em climas temperados ocorre de forma lenta resultando na formação de compostos orgânicos. Porém, em climas tropicais, devido às altas temperaturas e a umidade, a degradação da matéria orgânica acontece de forma rápida dando origem a água e ao gás carbônico $\left(\mathrm{CO}_{2}\right)$.

A presença do $\mathrm{CO}_{2}$ resulta em soluções ácidas $(\mathrm{pH} \cong 5,5-6)$ em regiões de clima tropical. Consequentemente, para estas condições de $\mathrm{pH}$, o alumínio e o ferro são praticamente insolúveis e se acumulam na forma de óxidos e hidróxidos, enquanto que os elementos alcalinos e alcalinos terrosos são lixiviados, assim como a sílica. Porém, a sílica é mobilizada com menor velocidade que os alcalinos o que faz com que haja a possibilidade de recombinação da sílica com o alumínio, formando os argilominerais do grupo caulinita (MELFI, 1994).

Os óxidos e hidróxidos de ferro e de alumínio conferem ao solo laterítico a cor avermelhada e a cimentação entre os grãos que, juntamente com a sucção, garantem uma rigidez e resistência que podem ser facilmente destruídas (FOOKES, 1997).

A estrutura das argilas lateríticas caracteriza-se, tanto em escala microscópica como em escala macroscópica, pela coalescência de seus grãos, com aspecto parecido a uma esponja, fazendo com que as suas propriedades dependam da sua conservação ou destruição (NOGAMI e VILLIBOR, 1995). De acordo com os autores, as propriedades índices tradicionais como granulometria e Limites de Atterberg variam em função desta estrutura do solo tornando-as inadequadas para identificar o comportamento mecânico deste solo.

Neste contexto, diante das limitações de utilização dos procedimentos tradicionais de caracterização e classificação, como a AASHO/HRB e a SUCS, que foram desenvolvidas em regiões não tropicais, surgiu a necessidade de criar um método de previsão do comportamento do solo que fosse adequado às peculiaridades do solo brasileiro.

Nogami e Villibor (1981) propuseram o método MCT (Miniatura Compactada Tropical) que envolve critérios de classificação mais apropriados para solos tropicais baseados no comportamento mecânico e hidráulico do solo. Neste método, por meio de ensaios de compactação com energia crescente e ensaios de perda de massa por imersão, foi possível separar o solo em duas classes principais: os solos com comportamento laterítico (classe L) e os solos com comportamento não lateríticos (classe N), como ilustra a Figura 2.2.

Para identificar o caráter laterítico do solo também podem ser realizados outros ensaios como microscopia eletrônica de varredura (MEV), difração de raio-x (DRX) e o ensaio de 
adsorção de azul de metileno pelo método da mancha que possibilitam identificar os argilominerais presentes na fração fina do solo. Porém, estes métodos não são encontrados com facilidade nos laboratórios geotécnicos.

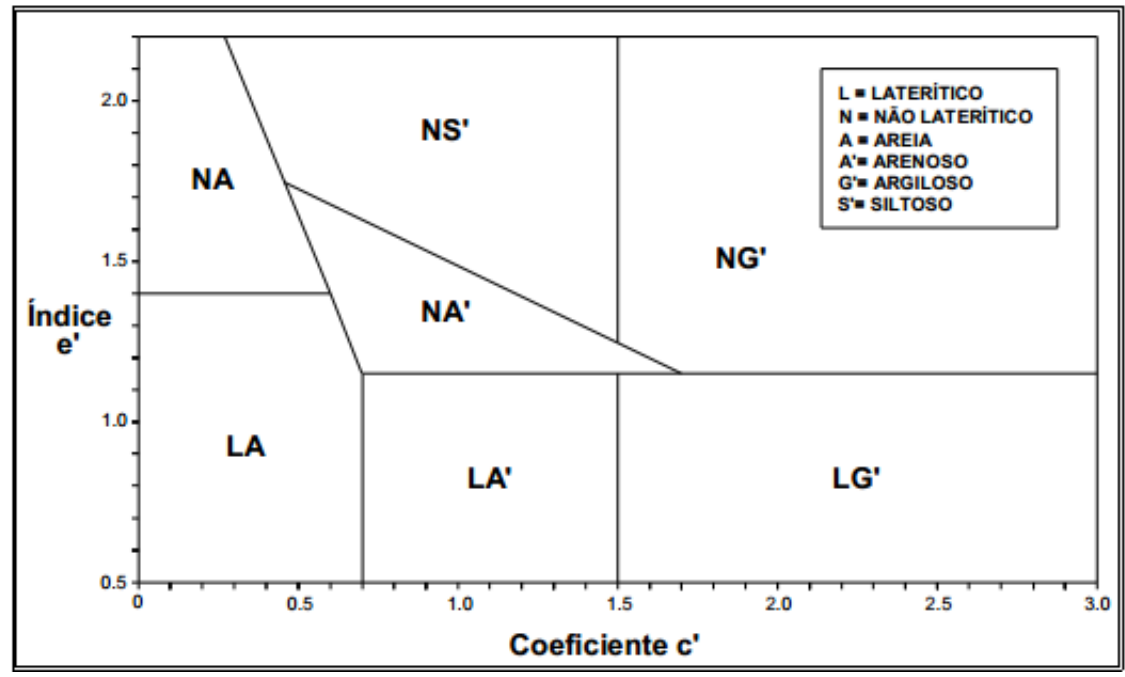

Figura 2.2 - Gráfico da classificação MCT

Fonte - Nogami e Villibor (1981)

De acordo com Décourt (2002) as argilas lateríticas apresentam rigidez muito acima das argilas não lateríticas, mesmo se ambas apresentarem o mesmo índice de resistência à penetração nos ensaios de SPT (Standard Penetration Test). Segundo o autor, todos os métodos de estimativa da capacidade de carga de uma fundação subestimam o real valor da resistência das fundações implantadas em solos lateríticos.

Os solos lateríticos se encontram na natureza na forma não saturada, apresentando elevado índice de vazios, o que resulta em seu baixo peso específico e baixa capacidade de suporte (PINTO, 2006). Porém, quando compactados, sua capacidade de suporte é elevada sendo, por isso, muito utilizado na pavimentação (NOGAMI e VILLIBOR, 1995).

Dias (2007) analisou o comportamento mecânico dos solos lateríticos e não lateríticos por meio de ensaios triaxiais convencionais. O autor constatou que os solos lateríticos apresentam maior resistência e menor deformabilidade na ruptura do que os solos não lateríticos. Além disso, segundo o mesmo autor, o solo laterítico apresenta menor umidade ótima e maior massa específica seca quando compactado comparado ao solo não laterítico.

\subsection{CARACTERÍSTICAS DO SOLO NÃO SATURADO}


Os solos que se encontram acima do lençol freático apresentam um comportamento característico que não é possível de ser explicado pela mecânica dos solos tradicional. Estes solos são geralmente não saturados e estão submetidos à uma pressão neutra negativa, conhecida como sucção (FREDLUND e RAHARDJO, 1993).

Os solos lateríticos, devido à alternância de estações chuvosas e estações secas típicas de clima tropical, sofrem a lixiviação dos finos do horizonte superficial criando uma estrutura muito porosa e permeável, resultando em nível freático profundo com espessas camadas de solo não saturado (LOBO et al., 1997).

As variações climáticas que causam a evaporação, a infiltração, e a transpiração dos vegetais influenciam o conteúdo de água e consequentemente a sucção presente nos solos não saturados. Como resultado, as propriedades hidráulicas, a resistência ao cisalhamento, e o volume do solo mudam em resposta à essas variações (ALI e RAHARDJO, 2009).

Segundo Rodrigues (2007), os solos não saturados são considerados como materiais multifásicos que apresentam três fases principais: a fase sólida, constituída pelos minerais, a fase líquida, formada por água e ar dissolvido, e a fase gasosa, composta pela mistura de ar seco e vapor d'água.

O conhecimento da estrutura dos solos não saturados é de extrema importância para o entendimento das respostas mecânicas do solo quando solicitado, e na previsão, mesmo que de maneira qualitativa, do seu comportamento. Para isto, é necessário compreender fenômenos como a capilaridade, adsorção e sucção matricial do solo.

\subsubsection{Capilaridade e adsorção}

De acordo com Pinto (2006), os vazios no solo são tão pequenos que podem ser associados à tubos capilares interconectados. Quando o solo seco é colocado em contato com a água, esta tende a ser "sugada" para o interior do solo devido ao efeito da capilaridade.

O fenômeno da capilaridade nos vazios do solo pode ser representado por um tubo capilar imerso em água livre. Uma das características da água é que ela apresenta comportamento diferenciado na superfície em contato com o ar e na sua massa, onde as moléculas estão envoltas por água (PINTO, 2006).

No interior deste tubo haverá a ascensão da água até uma certa altura, devido ao equilibrio das pressões do ar $\left(\mathrm{u}_{\mathrm{a}}\right)$ e da água $\left(\mathrm{u}_{\mathrm{w}}\right)$, gerando como resultante a tensão superficial formada na interface entre os dois elementos (Figura 2.3). 


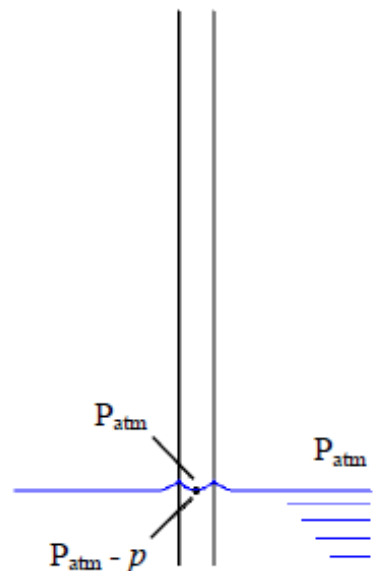

(a)

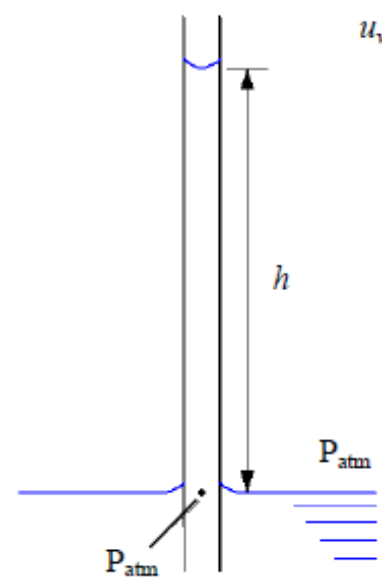

(b)

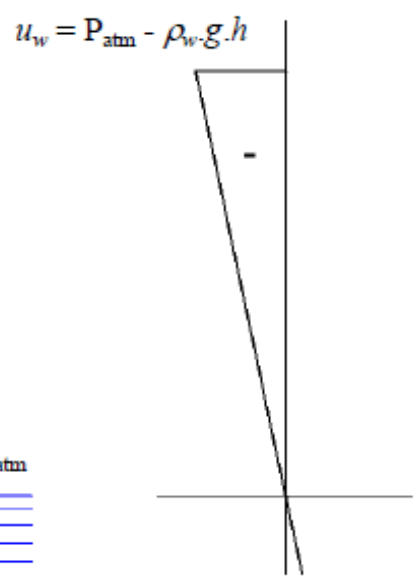

(c)

Figura 2.3 - Ascensão da água no tubo capilar: (a) formação do menisco, (b) ascensão, (c) pressão na água após equilíbrio

Fonte - Georgetti (2010)

A altura de ascenção capilar pode ser caculada pela seguinte equação, assumindo que a curvatura do menisco seja esférica:

$$
h=\frac{2 \cdot T_{s}}{\rho_{w} \cdot g \cdot r} \cdot \cos \alpha
$$

Nesta equação $h$ corresponde à altura de ascenção capilar, $T_{s}$ é a tensão superficial, $\alpha$ é o ângulo de contato entre o sólido e o líquido, $\rho_{w}$ a massa específica da água, $g$ a aceleração da gravidade e $r$ o raio do tubo capilar. Pela equação é possível notar que a altura de ascenção capilar é inversamente proporcional ao raio do tubo, consequentemente, para os solos, quanto maior for o poro menor será a altura atingida pela água.

A água que não se comunica com o lençol freático, pode ser encontrada na forma adsorvida nos contatos entre os grãos, formando meniscos capilares. Quando existe um menisco capilar, a água se encontra em uma pressão abaixo da pressão atmosférica. Como resultado da tensão superficial (T) gerada pelo contato ar- água no interior do solo, surge uma força $(\mathrm{P})$ de aproximação entre as partículas, como ilustra a Figura 2.4, fazendo com que haja o aumento de tensão efetiva (PINTO, 2006). A este incremento de tensão da-se o nome de "sucção". 


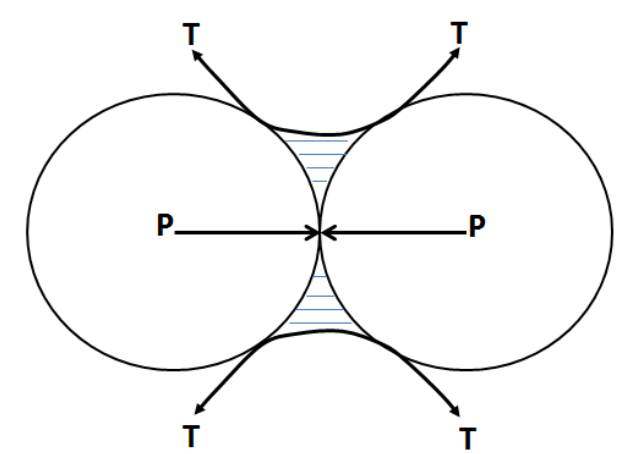

Figura 2.4 - Tensão capilar em água adsorvida e coesão aparente Fonte - Pinto (2006)

A Figura 2.5 apresenta o perfil de um terreno dividido em duas zonas distindas com relação à posição do nível d'água onde é possível observar a combinação dos efeitos da capilaridade e adsoção.

A zona abaixo do lençol está saturada e a pressão neutra é positiva, aumentando com a profundidade. A zona acima do lençol é não saturada e pode ser dividida em duas regiões principais. A primeira corresponde a mais próxima do nível d'água, onde os vazios do solo estão todos preenchidos com água devido ao efeito da capilaridade. Nesta região, denominada de franja capilar, o solo se encontra saturado por capilaridade e a pressão neutra é negativa. Acima deste trecho algumas particulas de solo estão envolvidas por água na forma adsorvida e a pressão neutra nesta região também é negativa, diminuindo com a redução do teor umidade do solo.

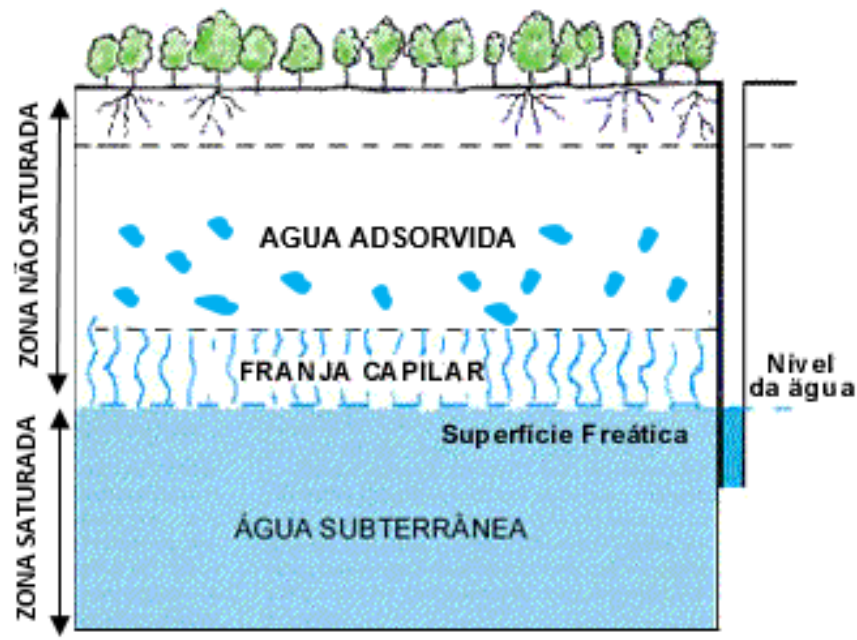

Figura 2.5 - Ilustração da zona saturada e não saturado com relação à posição do nível d'água Fonte - Gontijo (2015) 


\subsubsection{Sucção}

Segundo Richards (1928), a existência da sucção em solos não saturados é decorrente dos efeitos combinados de capilaridade (predominante em solos arenosos), de adsorção (predominate em solos argilosos), e de osmose (devido a presença de íons dissolvidos na água). A sucção total é a soma das parcelas da sucção matricial e osmótica, sendo que, a sucção matricial é resultado da soma de duas componetes, a capilaridade e a sucção devido às forças de adsorção. Quanto à sucção osmótica, esta é dependente do efeito de osmose, associado à composição da água.

Fredlund e Rahardjo (1993) relatam que a maioria dos problemas de engenharia envolvendo solos não saturados estão relacionados a mudanças ambientais, o que afeta principalmente a componente de sucção matricial do solo, tornando as variações da sucção osmótica menos significativas. Deste modo, para grande parte dos problemas geotécnicos envolvendo solos não saturados, uma variação da sucção total será equivalente a uma variação da sucção matricial (GEORGETTI, 2010).

Aitchison (1965) define sucção total do solo $(\Psi)$ como a pressão manométrica negativa, em relação à pressão externa de gás sobre a água do solo, que deve ser aplicada a um reservatório de água pura, à mesma cota e temperatura, de modo que seja mantido o equilíbrio, através de uma membrana semipermeável (que permite fluxo de água e não permite fluxo de solutos), entre a água do reservatório e a água do solo, Figura 2.6.

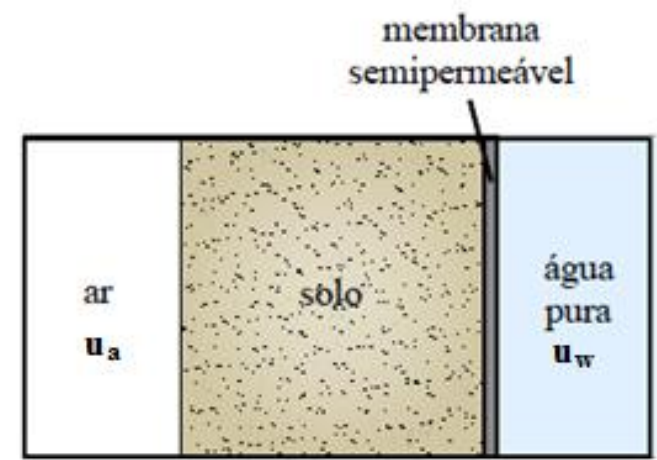

Figura 2.6 - Esquema ilustrativo da definição de sucção $($ Comumente ua = patm)

Na região não saturada, de acordo com Gerscovichi (2013), a sucção está diretamente relacionada ao volume de água presente nos vazios, que pode ser representado e quantificado em termos de grau de saturação $(\mathrm{S})$, teor de umidade gravimétrico $(\omega)$ ou teor de umidade volumétrico $(\theta)$, que é o parâmetro mais adotado na prática. A relação entre a umidade 
volumétrica e a sucção do solo $(\theta x \psi)$ é denominada de curva característica do solo ou curva de retenção de água no solo.

\subsubsection{Curva característica do solo}

A determinação da curva de retenção pode ser feita seguindo duas trajetórias típicas, a de umedecimento e a de secagem das amostras de solo. No umedecimento, ocorre o descréscimo dos potenciais matricias devido ao aumento da umidade do solo. Já na secagem, a amostra é inicialmente saturada e submetida a potenciais matriciais crescentes em consequência da redução da umidade do solo.

Comparando as curvas obtidas por ambos os procedimentos para o mesmo solo, observa-se a presença da histerese, ou seja, os pares ordenados obtidos na trajetória de secagem do solo não são os mesmos daqueles obtidos na trajetória de umedecimento, como ilustra a Figura 2.7. Nota-se que a curva de secagem apresenta umidades mais elevadas do que a curva de umedecimento para os mesmos valores de sucção.

Hillel (1971) atribui diferentes causas ao fenômeno da histerese, dentre elas, a não uniformidade geométrica dos poros, ao aprisionamento de ar nos vazios do solo, a alteração na sua estrutura devido à expansão e contração, o efeito do ângulo de molhamento durante os processos de drenagem e umedecimento do solo.

Um exemplo da curva de retenção de água no solo está ilustrado na Figura 2.7 e os parâmetros indicados nesta curva são: $\theta_{\mathrm{s}}$ - teor de umidade volumétrica de saturação para a trajetória de secagem, $\theta_{\mathrm{r}}$ - teor de umidade volumétrica residual, $\theta_{\mathrm{s}}$ ' - o teor de umidade volumétrica de saturação para a trajetória de umedecimento, $\Psi_{\mathrm{b}}$ - pressão de entrada de ar, que corresponde a sucção na qual o ar começa a penetrar os maiores poros do solo.

As características da curva de retenção como posição e inclinação podem variar de acordo com a granulometria, mineralogia, estrutura e histórico de tensões do solo. Fredlund e Xing (1994) observaram que quanto maior a plasticidade do solo, maiores serão os valores da umidade de saturação e da pressão de entrada de ar, Figura 2.8. 


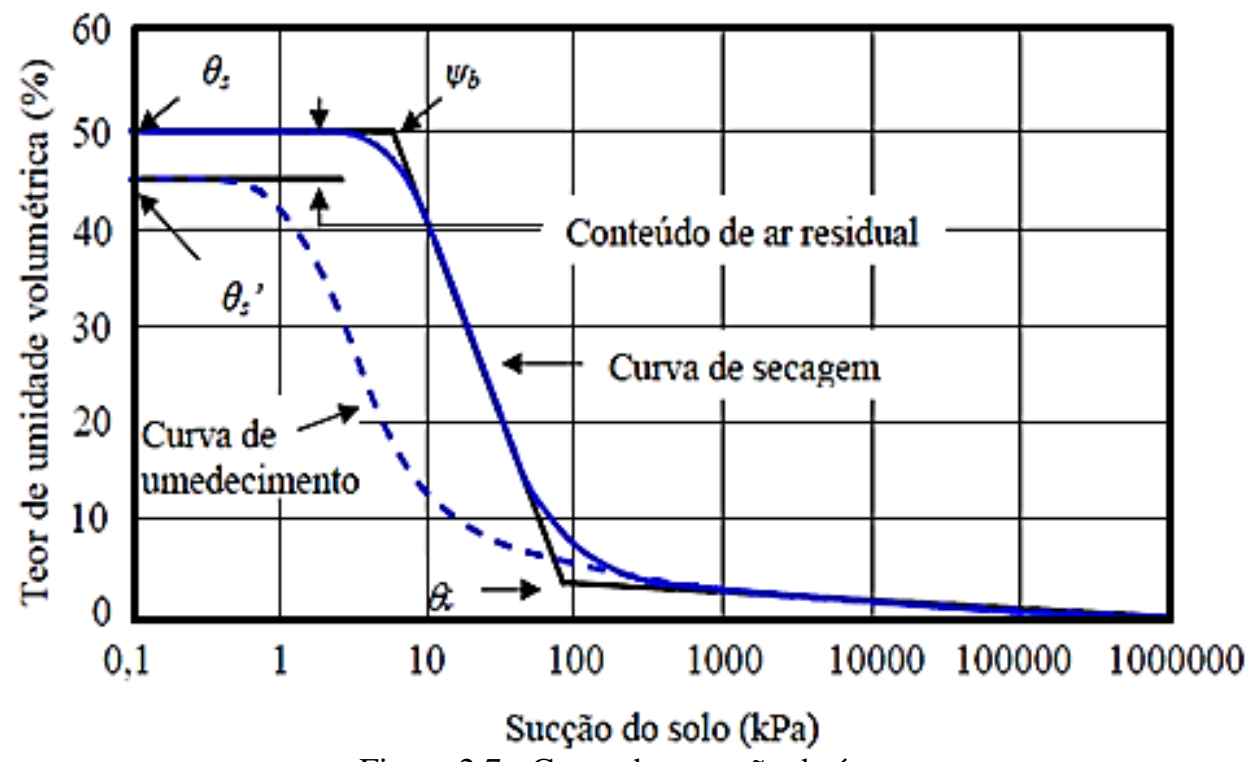

Figura 2.7 - Curva de retenção da água

Fonte - Fredlund e Xing (1994)

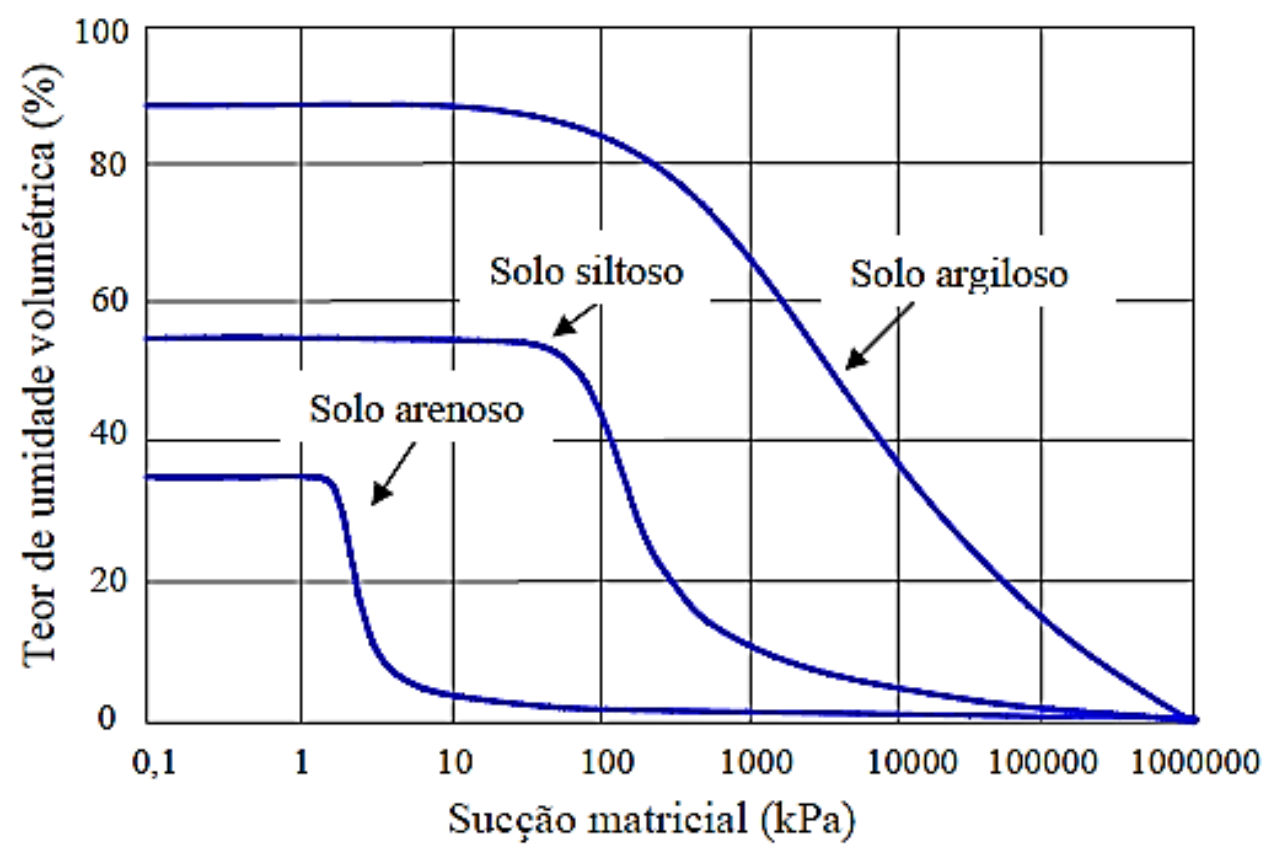

Figura 2.8 - Variações das características das curvas de retenção

Fonte - Fredlund e Xing (1994)

A curva de retenção pode ser obtida por diversas formas, existindo vários ensaios de campo e de laboratório para determinar a sucção. Apresenta-se, de maneira sucinta, os principais equipamentos para a medida de sucção:

- Psicrômetro: utilizado para determinar a sucção total e osmótica. Este instrumento mede a umidade relativa do ar em equilíbrio com a interface solo-água nos vazios do 
solo. Este método é recomendado para medidas de altos valores de sucção permitindo medir sucções de 100 a 8000 kPa (MENEGOTTO, 2004).

- Papel Filtro: utilizado para determinar a sucção total e matricial do solo. Baseia-se no equilíbrio entre os potenciais do solo e do papel filtro. Para medir a sucção matricial do solo, o papel filtro é colocado em contato com a amostra de solo, já para medir a sucção total, não coloca-se os corpos em contato para que não haja a transferência de solutos. Em seguida, determina-se a umidade de equilíbrio do papel filtro com o solo e por meio da curva de calibração do papel é possível determinar indiretamente o valor da sucção.

- Tensiômetro: nesta técnica a medida da sucção é obtida de forma direta em campo. O tensiômetro é um aparelho tubular, cheio de água, dotado de um medidor de pressão e de uma pedra porosa com alta resistência de entrada de ar na sua extremidade inferior. Esta pedra porosa deve ser completamente saturada antes da instalação do equipamento em campo. Quando é atingido o equilíbrio entre o solo e o sistema de medida, a água no interior do tubo apresenta a mesma pressão negativa da água nos vazios do solo. Essa pressão negativa corresponde à sucção matricial do solo. Os valores de sucção medidos pelo equipamento são limitados a aproximadamente $80 \mathrm{kPa}$ devido ao efeito da cavitação.

\subsubsection{Resistência ao cisalhamento dos solos não saturados}

Para compreender o fenômeno da sucção em solos não saturados é necessário que seja feita uma revisão do conceito de tensão efetiva, que apresenta uma certa complexidade, pois os poros são preenchidos por ar e água, atuando duas pressões diferentes, o que impossibilita a aplicação da equação de Terzaghi. Fredlund et al. (1978) apresentaram uma metodologia interessante para determinar a influência das pressões da água e do ar na resistência dos solos não saturados por meio da equação (2.1).

$$
\tau=c^{\prime}+\left(\sigma-u_{a}\right) \cdot \tan \Phi^{\prime}+\left(u_{a}-u_{w}\right) \cdot \tan \Phi^{\prime b}
$$

Em que c'é a coesão efetiva do solo no seu estado saturado, $\left(\sigma-\mathrm{u}_{\mathrm{a}}\right)$ é a tensão normal líquida, sendo $\mathrm{u}_{\mathrm{a}}$ a pressão no ar e $\mathrm{u}_{\mathrm{w}}$ na pressão na água existente nos poros, $\phi$ ' o ângulo de atrito interno, $\phi^{\mathrm{b}}$ o ângulo indicativo da taxa de aumento da resistência ao cisalhamento relacionada à sucção matricial do solo. 
A representação tridimensional da equação proposta por Fredlund et al. (1978) está ilustrada na Figura 2.9, sendo que nos eixos do plano horizontal estão as variáveis de estado de tensão e na ordenada está a tensão cisalhante. Dessa forma, a resistência do solo não saturado é composta por três fatores principais: coesão efetiva, tensão normal líquida $\left(\sigma-\mathrm{u}_{\mathrm{a}}\right)$ e pela sucção matricial $\left(\mathrm{u}_{\mathrm{a}}-\mathrm{u}_{\mathrm{w}}\right)$. Esta expressão é conveniente quando a pressão no ar é nula, ou seja, quando os canalículos de ar estão em contato com o meio ambiente, sendo a pressão igual à pressão atmosférica.

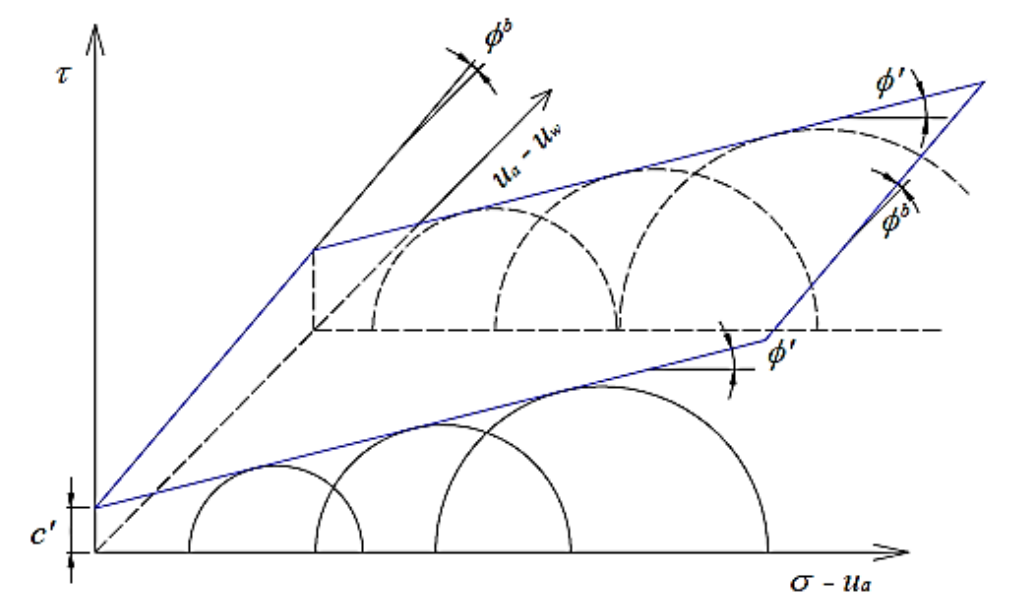

Figura 2.9 - Envoltório de ruptura tridimensional para solos não saturados Fonte - Fredlund et al. (1978)

Ho e Fredlund (1982) sugeriram que a parcela da resistência ao cisalhamento devido a sucção matricial fosse considerada como contribuinte para o aumento da coesão do solo, ilustrada na Figura 2.10. A proposta de Fredlund et al.(1978) considera que o ângulo de atrito do solo não se altera com a sucção e que a influência mensurável da sucção na resistência se traduz pelo ângulo $\phi^{\mathrm{b}}$.

$$
c=c^{\prime}+\left(u_{a}-u_{w}\right) \cdot \tan \Phi^{b}
$$




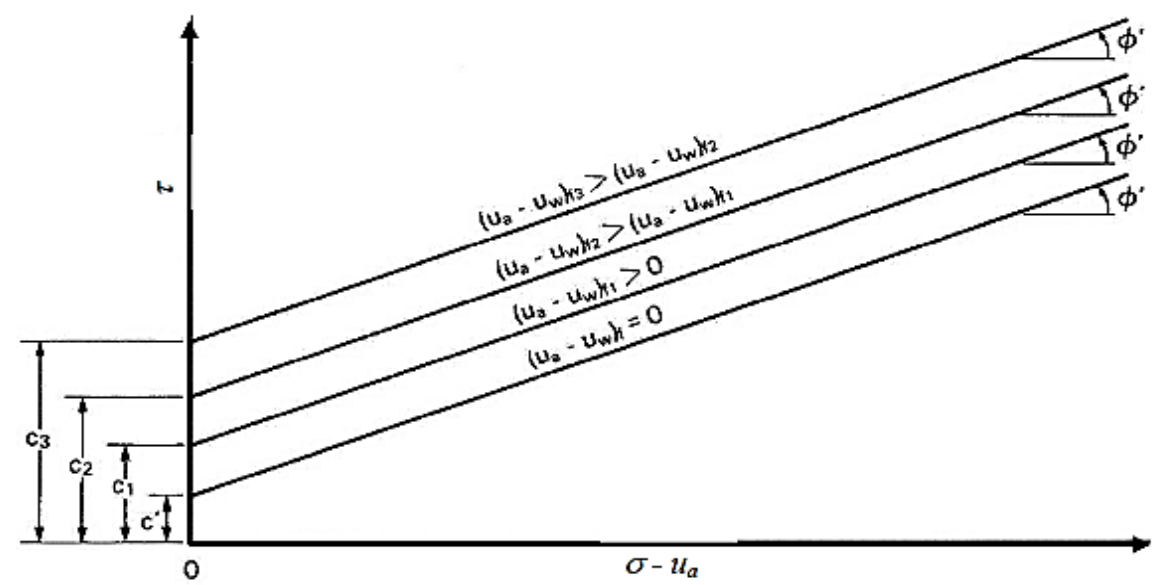

Figura 2.10 - Linhas da envoltória de ruptura no plano $\tau$ versus ( $\sigma$ - ua)

Fonte - Fredlund e Rahardjo (1993)

Machado (1998) avaliou a variação da coesão do solo com relação à sucção matricial por meio de ensaios triaxiais com sucção controlada em amostras indeformadas retiradas do Campo Experimental de Fundações da cidade de São Carlos. Confirmando o efeito da proposta de Ho e Fredlund (1982). Os resultados obtidos indicam que quanto maior a sucção matricial do solo, maior é a sua coesão como ilustrado na Figura 2.11. Quanto ao ângulo de atrito, o autor considerou que seu valor não varia com a sucção matrial do solo.

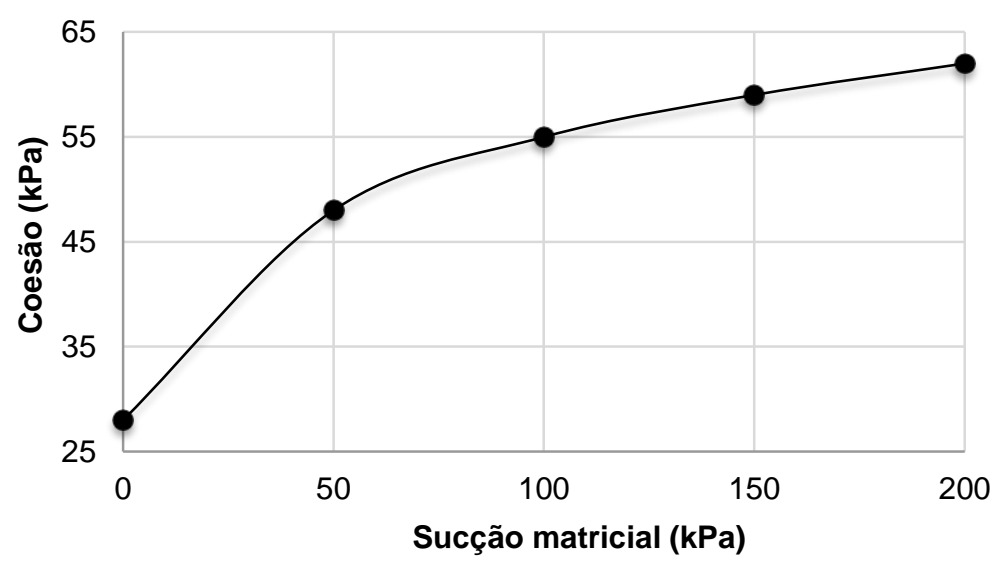

Figura 2.11 - Variação da coesão com a sucção matricial do solo Fonte - Machado (1998)

À este acréscimo de resistência, considerando o incremento de coesão devido à sucção, dá-se o nome de "coesão aparente" do solo. O termo "aparente" é dado pois este acréscimo de resistência não se mantém quando o solo é saturado. A "coesão aparente" é frequentemente referida às areias, devido a facilidade de infiltração e evaporação da água. Entretanto, o efeito 
do acréscimo de coesão é mais significativo nas argilas em virtude das dimensões reduzidas dos vazios, podendo atingir valores elevados de sucção (PINTO, 2006).

A água em contato com solos não saturados pode agir de duas maneiras: eliminando as forças capilares que proporcionam resistência adicional temporária ao solo, devido ao incremento de tensão efetiva, ou reduzindo a cimentação existente entre os grãos (VILAR, 1979). Se as tensões capilares forem destruídas, em função da saturação parcial ou total do solo, a resistência diminui tornando o solo mais susceptível à ocorrência do colapso estrutural (SOUZA, 1993).

\subsection{SOLOS COLAPSÍVEIS}

As regiões de clima tropical apresentam condições favoráveis ao desenvolvimento de solos potencialmente colapsíveis, seja pela lixiviação dos finos dos horizontes superficiais nas regiões onde há a alteração de estações secas e de precipitações intensas, seja pela deficiência de umidade dos solos que se desenvolve em regiões áridas e semiáridas (VILAR et al., 1981).

Cintra e Aoki (2009) definiram colapso como um fenômeno que ocorre em certos solos porosos não saturados ao serem inundados, sob carga constante. A inundação é responsável por anular a sucção matricial existente nos vazios do solo, reduzindo a sua resistência ao cisalhamento, levando a grandes variações de volume, conhecidas como recalque por colapso.

Como consequência, os recalques podem causar danos de pequena magnitude, como trincas e rachaduras nas paredes das edificações, ou podem causar danos de maiores proporções, como a ruína parcial ou total da edificação, como ilustra a Figura 2.12. No trabalho de Lobo et al. (1997) é possível encontrar um estudo do efeito do colapso em obras de diferentes cidades.

A magnitude do colapso apresentado pelo solo depende de alguns fatores como umidade inicial, histórico de tensões, espessura da camada de solo envolvida, variação de umidade do solo (devido a infiltração ou elevação do lençol freático) e da sobrecarga imposta (MACHADO, 1998).

Para Gonçalves (2006), o fenômeno do colapso não deve ser confundido com o adensamento, pois são completamente distintos. No adensamento ocorre a expulsão da água dos vazios do solo enquanto que no colapso ocorre a expulsão de ar. Outra diferença é que a variação de volume no colapso ocorre em curto espaço de tempo, enquanto que no adensamento a variação de volume ocorre lentamente. 


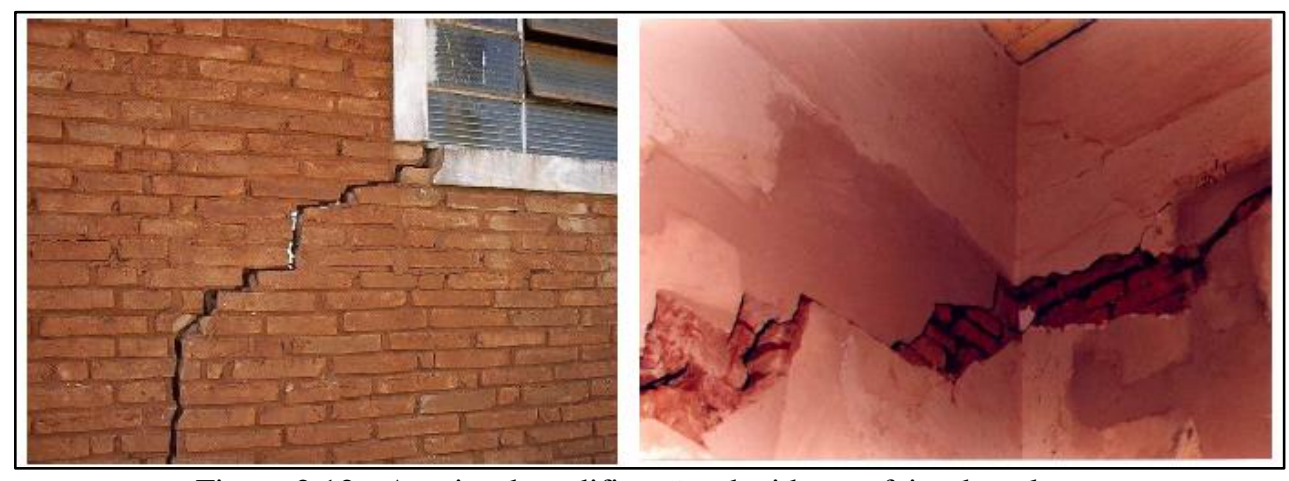

Figura 2.12 - Avarias das edificações devido ao efeito do colapso

Fonte - Rodrigues (2013)

\subsubsection{Critérios para identificar um solo colapsível}

Os critérios existentes para identificação do comportamento colapsível dos solos são baseados nos seus limites de consitência e em ensaios edométricos com inundação do corpo de prova. Alguns critérios estão apresentados na Tabela 2.1.

Segundo Ali (2015) a densidade seca e a plasticidade dos solos colapsíveis são ambas baixas e os seus valores de limite de liquidez, índice de plasticidade e teor de umidade são geralmente inferiores à $45 \%, 25 \%$ e $10 \%$ respectivamente.

Tabela 2.1 - Critérios de Identificação de solo colapsível

\begin{tabular}{|c|c|c|}
\hline Referência & Expressão & Observações \\
\hline Denisov (1951) & $k=\frac{e_{1}}{e_{0}}$ & $\begin{array}{l}0,5<\mathrm{k}<0,75 \\
\text { Solo colapsível }\end{array}$ \\
\hline Priklonkij (1952) & $k=\frac{w_{1}-w_{0}}{I P}$ & $\begin{array}{l}\mathrm{k}<0 \\
\text { Solo colapsível }\end{array}$ \\
\hline Feda (1966) & $K I=\frac{w_{0} / S_{r o}-w_{p}}{I P}$ & $\begin{array}{c}\text { Válida para solos com } \\
\text { Sro }<60 \% . k<0,85 \\
\text { Solo colapsível }\end{array}$ \\
\hline $\begin{array}{c}\text { Priklonskij (1952) citado por } \\
\text { Feda (1966) }\end{array}$ & $k=\frac{w_{1}-w_{0}}{w_{1}-w_{p}}$ & $\begin{array}{ll}\text { - } & \mathrm{k}<0 \text {, altamente colapsível } \\
\text { - } & \mathrm{k}<0,5 \text {, colapsível } \\
\text { - } & \mathrm{k}>1,0 \text {, expansivo }\end{array}$ \\
\hline Gibbs \& Bara (1967) & $k=\frac{w_{s}}{w_{1}}$ & $\begin{array}{l}\mathrm{k}>1 \\
\text { Solo colapsível }\end{array}$ \\
\hline Kassif e Henkin (1967) & $k=\gamma_{d} \cdot w$ & $\begin{array}{c}\mathrm{k}<15 \\
\text { Solo colapsível }\end{array}$ \\
\hline
\end{tabular}




\begin{tabular}{|c|c|c|}
\hline \multirow{6}{*}{ Jennings e Knight (1975) } & \multirow{2}{*}{ Cascalho fino } & $\mathrm{S}_{\mathrm{r}}<6 \%$ colapsível \\
\hline & & $\mathrm{S}_{r}>10 \%$ não colapsível \\
\hline & \multirow{2}{*}{ Areia fina } & $\mathrm{S}_{\mathrm{r}}<50 \%$ colapsível \\
\hline & & $\mathrm{S}_{\mathrm{r}}>60 \%$ não colapsível \\
\hline & \multirow{2}{*}{ Silte argiloso } & Sr $<90 \%$ colapsível \\
\hline & & Sr > 95\% não colapsível \\
\hline \multirow{2}{*}{$\begin{array}{l}\text { Código de obras da URSS } \\
\text { (1977) citado por Resnik } \\
\text { (1989) }\end{array}$} & $C I=\frac{e_{o}-e_{1}}{1+e_{0}}$ & \multirow{2}{*}{$\begin{array}{ll} & \text { Ocorre colapso para: } \\
\text { - } & 1 \% \leq \mathrm{wp} \leq 10 \%, \mathrm{Cl}<0,1 \\
\text { - } & 10 \% \leq \mathrm{wp} \leq 14 \%, \mathrm{Cl}<0,17 \\
\text { - } & 14 \% \leq \mathrm{wp} \leq 22 \%, \mathrm{Cl}<0,24\end{array}$} \\
\hline & $S_{r}<80 \%$ & \\
\hline \multicolumn{3}{|c|}{ 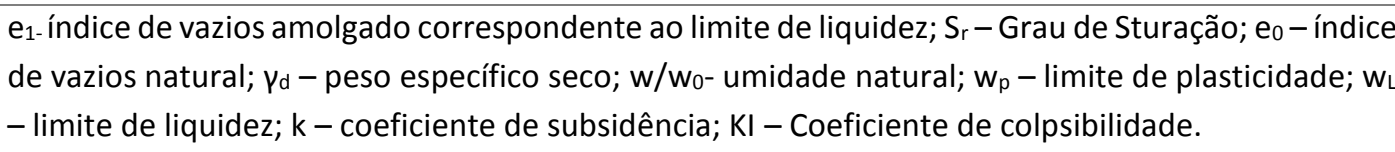 } \\
\hline
\end{tabular}

Fonte - Vilar et al. (2015)

Vilar et al. (2007) propuseram um outro método de identificação de solos colapsíveis baseado na relação entre a massa específica seca de campo $\left(\rho_{d \text { campo }}\right)$ e a massa específica seca máxima fornecida no ensaio de compactação Proctor Normal ( $\rho_{d}$ máx). Tem-se assim a medida do Grau de Compactação denominado de "natural” do solo analisado, equação (2.4).

$$
G C_{N}=\frac{\rho_{d \text { campo }}}{\rho_{d \text { máx }}} \cdot 100(\%)
$$

Esta proposta resgata a proposição de Mello (1972) que considera como "solos potencialmente colapsíveis" aqueles que apresentam valores de grau de compactação natural inferiores a $80 \%$. Os autores analisaram esta relação para solos de diferentes regiões do Brasil e concluíram, que os solos com $\mathrm{GC}_{\mathrm{N}}$ inferior a $90 \%$ apresentam comportamento colapsível, como ilustra a Figura 2.13, atualizando a antiga proposta de Mello (1972).

Os autores observaram que a manifestação do colapso dos solos potencialmente colapsíveis dependerá do teor de umidade inicial do solo e da sobrecarga aplicada no terreno antes da inundação. Neste trabalho também foi feita a verificação do desvio de umidade do solo natural com relação à umidade ótima do ensaio de Proctor Normal. Os autores concluíram que quanto maior for o desvio de umidade, maior será a possibilidade de um comportamento colapsível. 


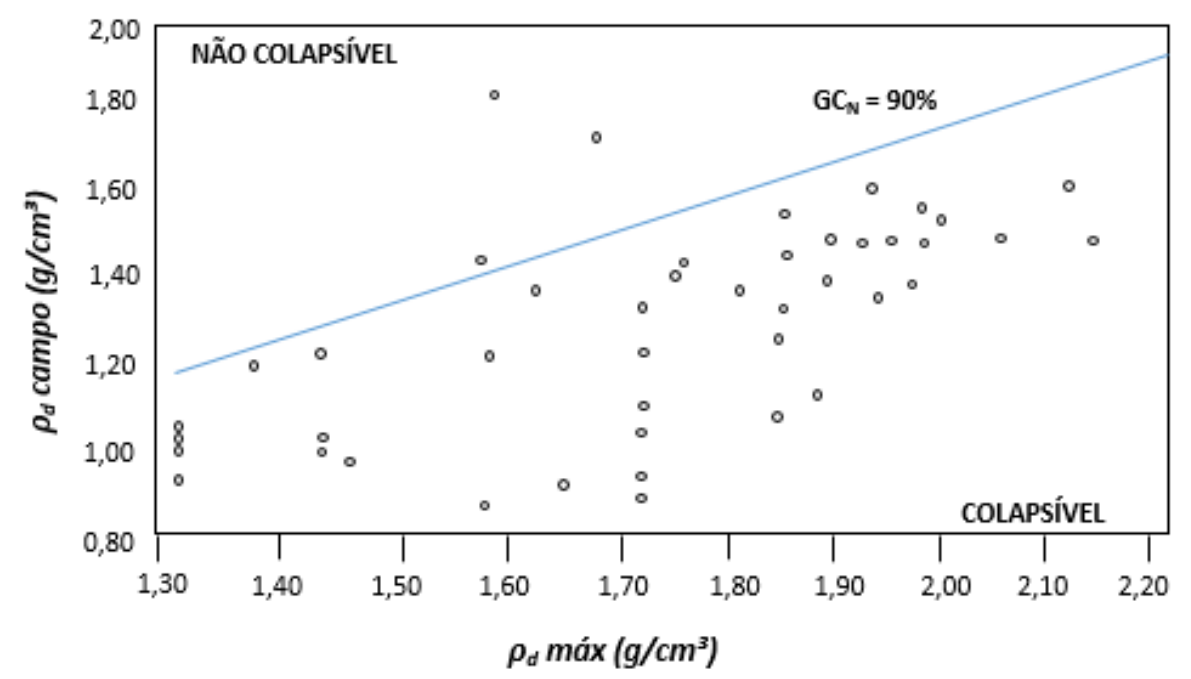

Figura 2.13 - Relação entre $\rho_{d \text { campo }}$ e $\rho_{d \text { máx }}$ para solos de diferentes regiões do Brasil Fonte -Vilar e Rodrigues (2008)

Vargas (1973) também desenvolveu um critério para analisar a colapsíbilidade dos solos. O critério se baseia no efeito do colapso dos solos por meio de ensaio edométrico com amostra inicialmente seca. Durante o ensaio, foi adicionado água após um certo estágio de pressão para provocar a saturação do solo e consequentemente apresentar uma compressão volumétrica acentuada e uma variação correspondente do índice de vazios, denominada $\Delta_{\mathrm{ec}}$ (ORTIGÃO, 1993).

A deformação volumétrica correspondente à variação dos índices de vazios $\left(\Delta_{\varepsilon c}\right)$ é obtida pela equação: $\Delta_{\varepsilon c}=\Delta_{\mathrm{ec}}\left(1+\mathrm{e}_{0}\right)$, onde $\mathrm{e}_{0}$ é o índice de vazios inicial da amostra seca. Segundo Vargas (1973), o solo é considerado colapsível se $\Delta_{\varepsilon \mathrm{c}}>2 \%$.

Segundo Vilar et al. (1981), pode-se dizer que não existe um critério absolutamente confiável para a identificação de solos colapsíveis pois em alguns lugares a definição deste comportamento do solo é imediata. Porém, há situações em que o seu reconhecimento não é tão simples. Desta forma, os métodos de identificação não substituem estudos mais avançados mas servem para simplificar e otimizar as etapas preliminares de investigação.

\subsubsection{Ensaios para analisar o efeito do colapso}

\subsubsection{Ensaio edométrico duplo}

Jennings e Knight (1957) propuseram o ensaio edométrico duplo para avaliar o recalque por colapso, se tornando um marco nos estudos de colapsibilidade dos solos. Neste ensaio são conduzidos dois ensaios de adensamento: o primeiro com o teor de umidade natural 
do solo e o outro com a amostra inundada. Considerando-se que não devem ocorrer variações volumétricas devido à variação de umidade, sob condições de equilíbrio com o peso do solo sobrejacente no campo, os autores sugerem sobrepor as curvas de compressão dos dois testes para determinar os recalques devido a inundação, Figura 2.14.
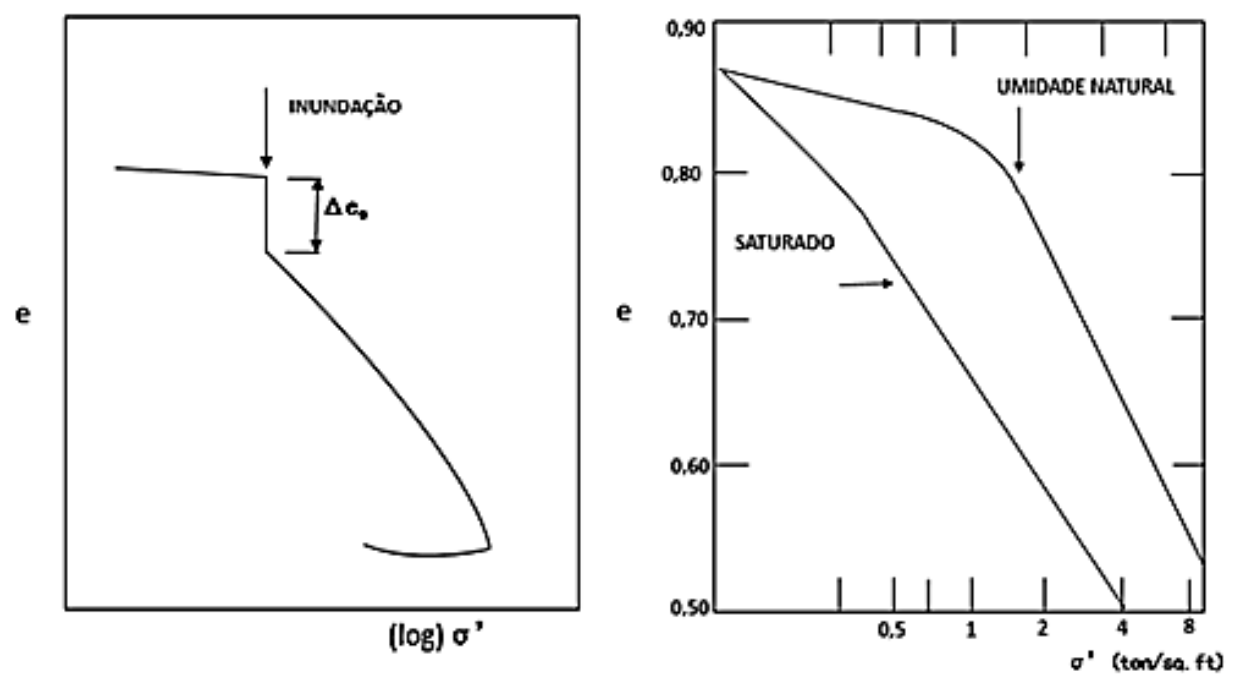

Figura 2.14 -a) Ensaio de adensamento com inundação por estágios de carregamento; b) Ensaio de adensamento duplo (VILAR et al., 1981)

Jennings e Knight (1975) definiram o potencial de colapso (PC) do solo baseado na variação do índice de vazios $\left(\Delta_{\mathrm{e}}\right)$ do ensaio edométrico com inundação da amostra a uma tensão de $200 \mathrm{kPa}$, em que e é o índice de vazios inicial da amostra.

$$
P C=\frac{\Delta_{e}}{1+e_{0}} \cdot 100(\%)
$$

Vargas (1977) faz uma adaptação na mesma equação substituindo o índice de vazios inicial da amostras $\left(\mathrm{e}_{0}\right)$ pelo índice de vazios no início da inundação $\left(\mathrm{e}_{1}\right)$ e altera o nome potencial de colapso para "coeficiente de colapso estrutural". Neste critério, para que o solo seja considerado como colapsível, é necessário que o potencial de colapso seja no mínimo igual a $2 \%$.

Com base nos valores de potencial de colapso (PC), Jennings \& Knight (1975) classificam o solo quanto a gravidade dos problemas de colapso nas edificações e Lutenegger e Saber (1988) indicam o grau de severidade do colapso apresentados na Tabela 2.2. 
Tabela 2.2 - Classificação da colapsibilidade em obras de engenharia a partir de resultado de ensaios edométricos

\begin{tabular}{|c|c|c|c|}
\hline \multicolumn{2}{|c|}{$\begin{array}{c}\text { Jennings \& Knight (1975) para tensão de inundação } \\
\text { de } 200 \mathrm{kPa}\end{array}$} & \multicolumn{2}{|c|}{$\begin{array}{c}\text { Lutenegger \& Saber (1988) para tensão de } \\
\text { inundação de } 300 \mathrm{kPa}\end{array}$} \\
\hline$P C(\%)$ & Gravidade dos Problemas & $P C(\%)$ & Grau de Severidade do Colapso \\
\hline 0 a 1 & Sem problemas & 2 & Leve \\
\hline 1 a 5 & Problema moderado & 6 & Moderado \\
\hline 5 a 10 & Problemático & 10 & Alto \\
\hline 10 a 20 & Problema grave & & \\
\hline$>20$ & Problema muito grave & & \\
\hline
\end{tabular}

Para Aitchison (1973), os recalques decorrentes do colapso determinados pelos ensaios edométricos com inundação podem não ser confiáveis, pois a magnitude do colapso depende do estado inicial de umidade do solo. O autor acrescenta que o mecanismo do colapso depende da trajetória de tensões do solo e de outros mecanismos deflagradores do processo de colapso além da água.

\subsubsection{Ensaio edométrico com sucção controlada}

Rodrigues (2007) analisou, por meio de ensaios edométricos com sucção controlada, a variação do potencial de colapso do solo com relação à tensão de inundação aplicada na amostra. As tensões verticais líquidas para umedecimento adotadas foram 50, 100, 200 e 400 $\mathrm{kPa}$ e os ensaios foram realizados para sucções iniciais de $60 \mathrm{kPa}$ e $200 \mathrm{kPa}$. O autor observou que as amostras ensaiadas apresentaram potenciais de colapso crescentes até um determinado valor de tensão de inundação, e em seguida os resultados passaram a ser decrescentes. Para o solo analisado, a tensão vertical em que o solo apresentou o maior potencial de colapso foi de $100 \mathrm{kPa}$. O autor também notou que as deformações das amostras foram maiores para os ensaios realizados com sucção inicial de $200 \mathrm{kPa}$, ou seja, para solos mais secos. Os resultados obtidos nos ensaios estão apresentados na Figura 2.15. 


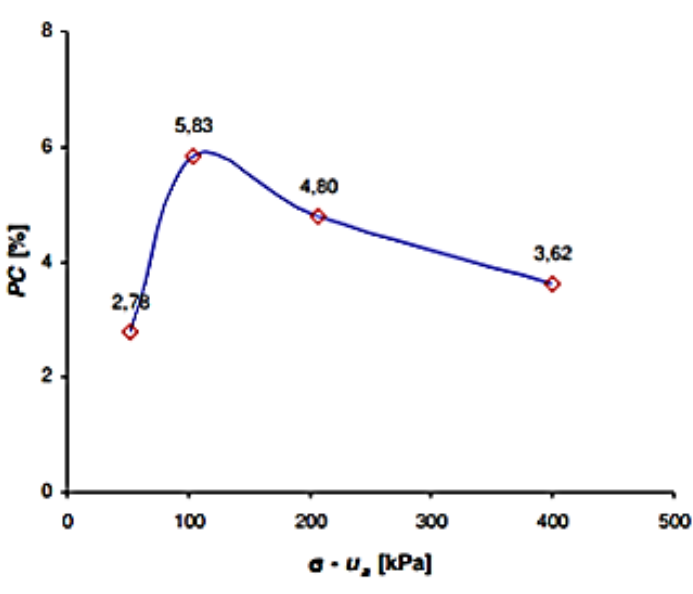

a) Amostras com sucção inicial de $60 \mathrm{kPa}$

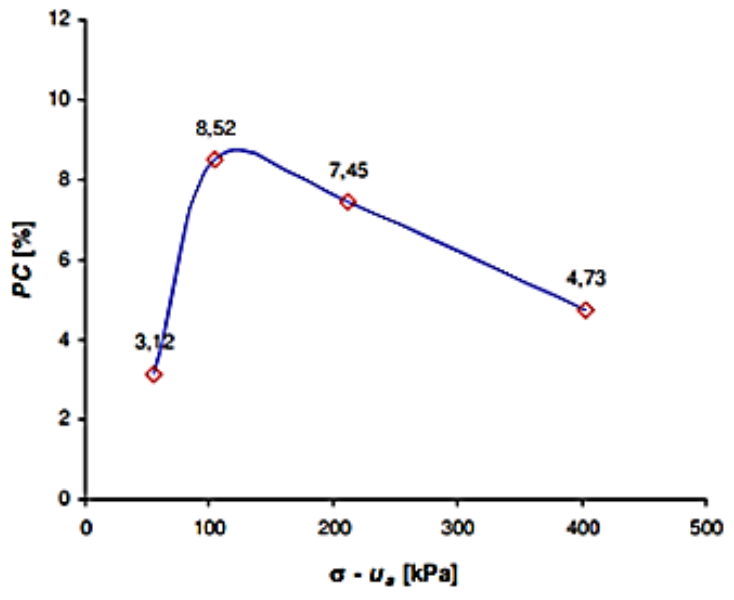

b) Amostras com sucção inicial de $200 \mathrm{kPa}$

Figura 2.15 - Resultados da variação do potencial de colapso com relação à tensão de inundação líquida Fonte - Rodrigues (2007)

\subsubsection{Prova de carga em placa}

O ensaio de campo normalmente utilizado para verificar o efeito colapsível dos depósitos de solo é a prova de carga em placa, cuja execução é normatizada pela ABNT NBR 6489/1984. As vantagens do ensaio de campo incluem a minimização das perturbações das amostras, possibilidade de ensaiar grandes volumes e reais condições de tensão e de umidade do solo (HOUSTON et al., 2001).

A desvantagem do ensaio de prova de carga sobre placa está relacionada ao efeito escala, como ilustra a Figura 2.16. Se houver estratificação do terreno ensaiado, os resultados obtidos não serão representativos da realidade uma vez que o bulbo de tensões da placa não atinge camadas do solo que serão solicitadas pelo bulbo de tensões da fundação a ser executada no local.

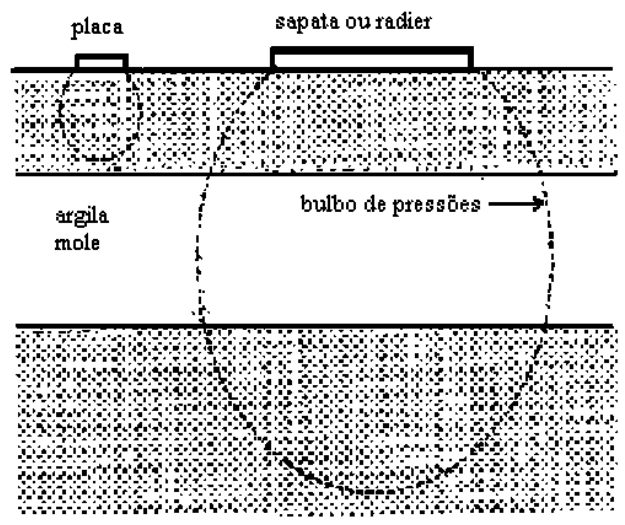

Figura 2.16 - Limitações na interpretação dos ensaios de placa devido à diferença de escala dos bulbos de tensão Fonte - Velloso e Lopes (1996) 
Alguns autores como Ferreira et al. (1990), Carvalho e Souza (1990), Agnelli (1992), Conciani (1997), Costa (1999), realizaram ensaios de prova de carga em placa para avaliar o comportamento colapsível dos solos.

Ferreira et al. (1990) analisou o colapso em três profundidades diferentes do terreno por meio de provas de carga em placa utilizando uma placa rígida, circular, com diâmetro de $80 \mathrm{~cm}$. Para cada profundidade, foram realizadas duas provas de carga sendo a primeira com o terreno na umidade natural, e a segunda com o terreno inundado. A Tabela 2.3 apresenta os resultados encontrados pelos autores nas provas de carga inundadas para as três profundidades ensaiadas bem como o teor de umidade do solo antes de iniciar a inundação do terreno.

De acordo com os autores, o maior colapso ocorreu à profundidade de $2 \mathrm{~m}$, pois à esta profundidade o solo estava com o menor teor de umidade em comparação com as demais profundidades ensaiadas.

\begin{tabular}{|cccc|}
\multicolumn{4}{c}{ Tabela 2.3 - Resultados dos ensaios de prova de carga em placa } \\
\hline Prof. $(\mathbf{m})$ & Tensão de inundação $\mathbf{( k P a )}$ & Colapso $(\mathbf{m m})$ & Teor de umidade (\%) \\
\hline 1 & 60 & 36,6 & 7,8 \\
2 & 100 & 71,1 & 6,9 \\
4 & 125 & 22,9 & 9,5 \\
\hline
\end{tabular}

Fonte - Ferreira et al. (1990)

Para que ocorra o colapso do solo é necessário aumentar o seu teor de umidade até um determinado valor "crítico". Mesmo que não seja atingida a sua saturação, os solos colapsíveis, quando submetidos a um determinado nível de tensões, sofrem uma redução brusca do seu volume.

Nos ensaios de prova de carga em placa, para que se possa analisar o comportamento típico do colapso, é necessário que haja a inundação do solo. Cintra (1995) apresenta dois métodos de inundação diferentes durante o ensaio e as curvas tensão $x$ recalque típicas obtidas em cada um deles.

O primeiro método, muito utilizado no Brasil para analisar o colapso, consiste em inundar o solo durante o ensaio de prova de carga, quando se atinge o estágio referente à tensão admissível estimada ou qualquer outro nível de tensão. A curva característica destes ensaios apresenta uma descontinuidade, com aumento abrupto do recalque, devido ao colapso. A Figura 2.17 ilustra um exemplo destas curvas. 


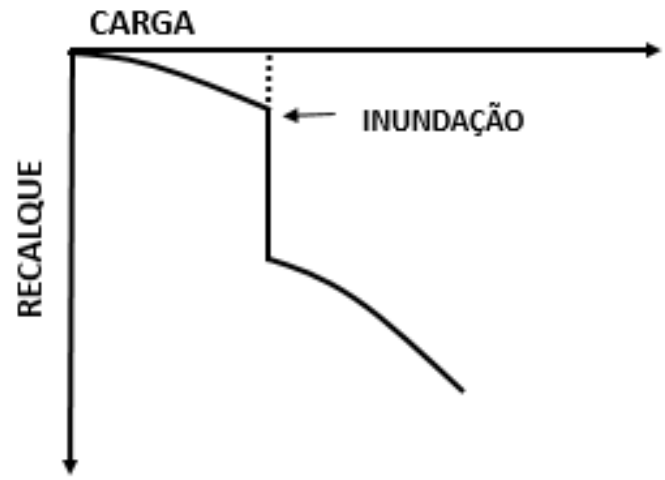

Figura 2.17- Curva típica da ocorrência do colapso do solo em provas de carga com inundação realizada durante o ensaio

Fonte - Cintra (1995)

Em alguns casos, considerando este primeiro método de ensaio, a tensão admissível $\left(\mathrm{Q}_{\mathrm{a}}\right)$ prevista é inferior à tensão crítica para a ocorrência do colapso. Nestes casos, após a inundação o solo tem um comportamento semelhante ao solo natural e sofre uma mudança de comportamento ao atingir a carga de colapso $\left(\mathrm{Q}_{\mathrm{c}}\right)$, Figura 2.18.
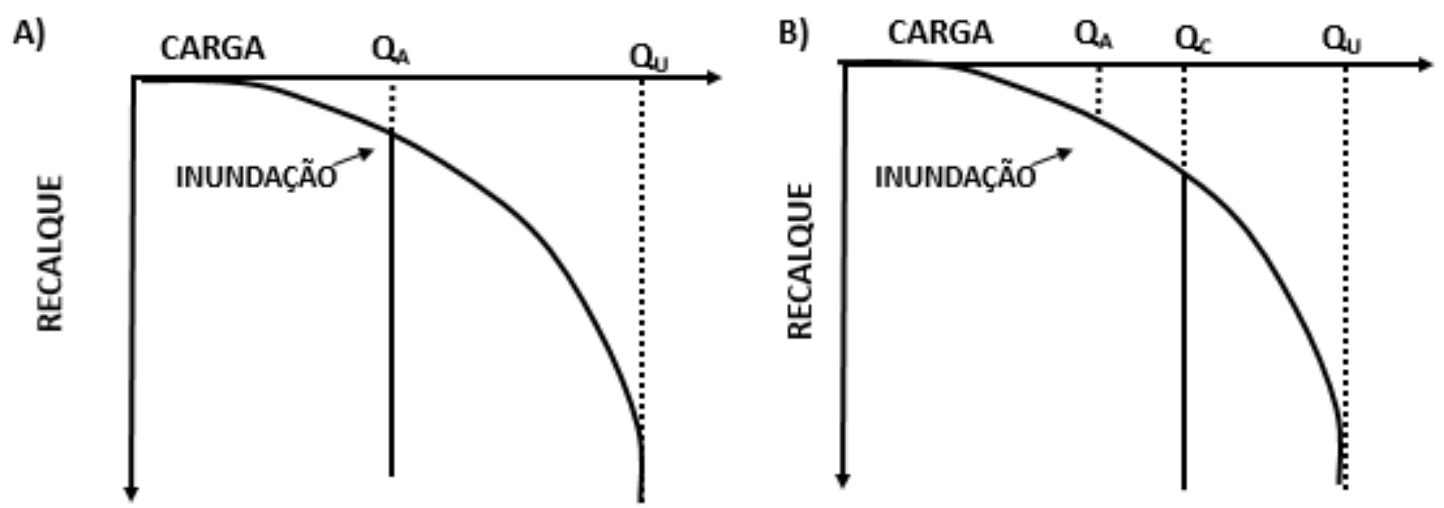

Figura 2.18- a) Colapso sob a carga de trabalho, b) Colapso sob uma carga superior à de inundação Fonte - Cintra et al. (1997)

O segundo método de ensaio consiste em realizar a inundação antes do início prova de carga. Neste caso, a colapsibilidade do solo se manifesta não por um recalque abrupto na carga de colapso, mas pela redução da capacidade de carga do solo, como ilustra a Figura 2.19. 


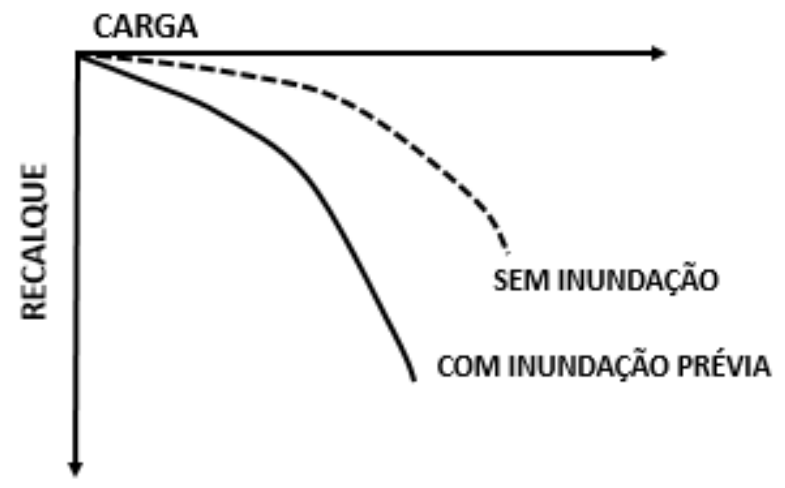

Figura 2. 19 - Prova de carga em solo colapsível previamente inundado Fonte - Cintra et al. (1997)

\section{a) Interpretação dos resultados}

Por meio das curvas tensão x recalque obtidas nos ensaios de prova de carga, é possível determinar tensão de ruptura do solo de fundação. A ruptura da fundação superficial acontece quando a resistência ao cisalhamento do solo sob a fundação é atingida (COSTA, 1999). Terzaghi (1943), define dois mecanismos de ruptura do solo: a generalizada e a localizada, ilustrados na Figura 2.20. A curva $\mathrm{C}_{1}$ representa o comportamento tensão x recalque dos solos compactos ou rijos e a curva $\mathrm{C}_{2}$ representa o comportamento dos solos fofos ou moles.

Para os solos compactos ou rijos, curva $\mathrm{C}_{1}$, a ruptura é caracterizada pelo prolongamento de uma reta vertical tangente à curva, até interceptar a abscissa no ponto denominado de $\sigma_{r}$. Para solos fofos ou moles, curva $\mathrm{C}_{2}$, a ruptura corresponde ao ponto em que a curva tensão $x$ recalque começa a obter comportamento linear $\tau_{r}$ ' (VELLOSO e LOPES, 2002).

Normalmente, nos resultados de prova de carga, a ruptura nítida nem sempre é alcançada. Para situações intermediárias como ruptura localizada, por puncionamento ou quando o ensaio é finalizado prematuramente, faz-se necessário utilizar critérios para determinar a tensão de ruptura do solo. 


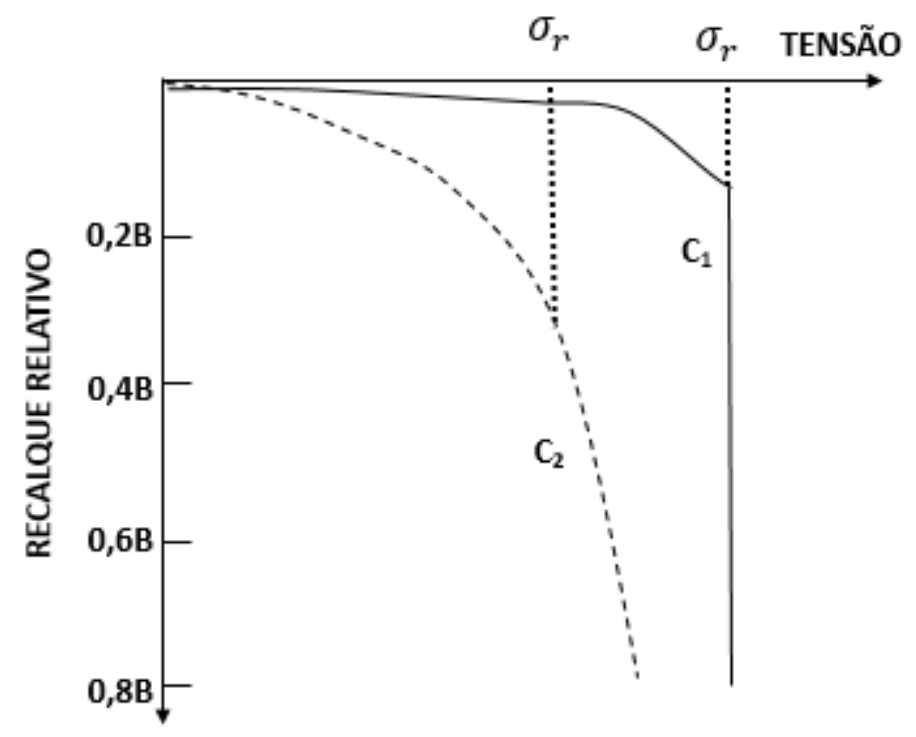

Figura 2.20- Curvas tensão $x$ recalque típicas Fonte - Terzaghi (1943)

Alguns critérios, como o da norma brasileira ABNT NBR 6122/2010 e o código de obras da cidade de Boston, nos EUA, fixam um deslocamento limite para terminar a tensão de ruptura do sistema. Para este último critério, desenvolvido para uma placa quadrada de $0,30 \mathrm{x}$ 0,30 m, são estipulados limites de recalque de $10 \mathrm{~mm}$ para a tensão admissível e de $25 \mathrm{~mm}$ para a tensão de ruptura. No critério de Boston, será considerada como tensão admissível, o menor entre os dois seguintes valores:

- Critério de recalque: $\sigma_{a} \leq \sigma_{10}$, sendo $\sigma_{10}$ a tensão admissível para o recalque de $10 \mathrm{~mm}$.

- Critério de ruptura: $\sigma_{a} \leq \sigma_{25} / 2$, sendo $\sigma_{25}$ a tensão de ruptura para o recalque de $25 \mathrm{~mm}$, adotando-se o fator de segurança igual a 2 .

Segundo Teixeira e Godoy (1996), o valor de $1 \frac{1}{2} \sigma_{25}$ é sempre mais rigoroso do que $\sigma_{10}$. O critério de Boston foi importado e padronizado pela norma brasileira ABNT NBR 6122/2010 sem que fosse feita nenhuma adaptação para a placa circular com diâmetro de 0,80 m. A norma brasileira, para adimensionalizar o valor do recalque, e para poder aplicar o critério em casos com sapatas maiores do que a placa da norma, considerou o recalque limite de ruptura como D/30, sendo D o diâmetro da placa.

Além destes critérios, também existe o de B/10 e o de Leonards (1962), sendo B o diâmetro da placa utilizada no ensaio. O critério de B/10 ou $10 \%$ de $\mathrm{B}$, limita a tensão de ruptura 
a um recalque correspondente a 10 \% do diâmetro da placa. Já no critério de Leonards (1962), a capacidade de carga corresponde à intersecção de duas tangentes, a primeira traçada sobre a parte inicial da curva tensão $x$ recalque e a outra traçada na parte descendente da curva.

\section{b) Influência da sucção nos resultados}

A sucção do solo está diretamente relacionada ao seu teor de umidade e, consequentemente, ao efeito do colapso do solo. Costa (1999) avaliou o colapso do solo para diferentes níveis de sucção utilizando provas de carga em placa. O objetivo principal do estudo foi analisar a influência da sucção na resistência do solo por meio das curvas carga x recalque obtidas nos ensaios. Os resultados de Costa (1999) estão ilustrados na Figura 2.21.

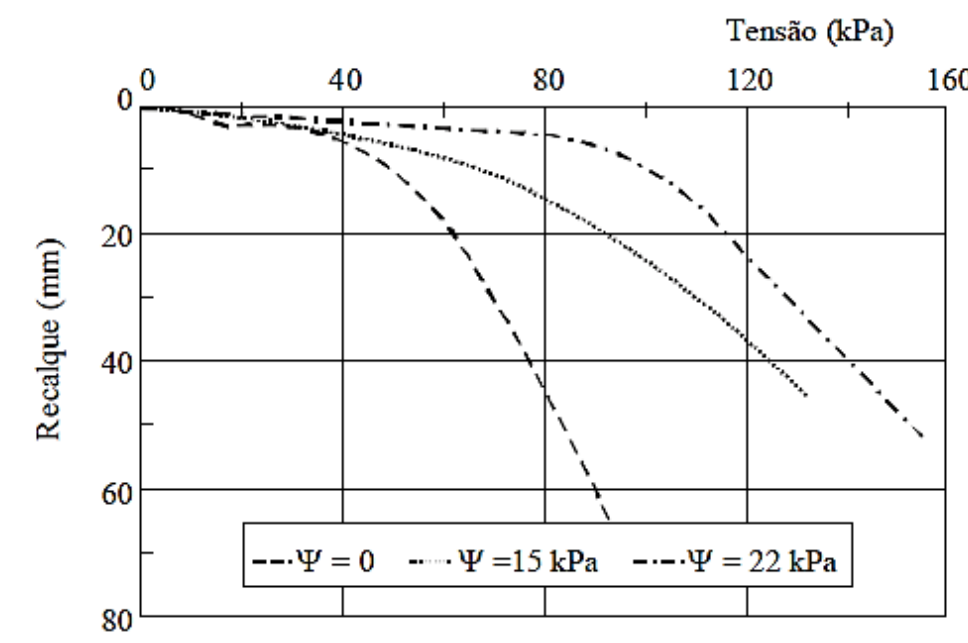

Figura 2.21 - Curva tensão x recalque dos ensaios de prova de carga Fonte - Costa (1999)

\subsubsection{Fundações em solos colapsíveis}

As fundações implantadas em solos colapsíveis podem apresentar um comportamento satistatório por um tempo e bruscamente sofrer recalques consideráveis devido ao aparecimento de uma fonte de água que inunda o solo, por infiltração de águas das chuvas, fissuras em reservatórios enterrados, ascenção do lençol freático, ou até mesmo devido às rupturas de tubulações (Cintra et al., 2009).

A norma brasileira ABNT NBR 6122/2010 faz a seguinte recomendação no caso de solos não saturados: "Para fundações apoiadas em solos de elevada porosidade, não saturados, deve ser analisada a possibilidade de colapso por encharcamento, pois estes solos são 
potencialmente colapsíveis. Em princípio devem ser evitadas fundações superficiais apoiadas neste tipo de solo, a não ser que sejam feitos estudos considerando as tensões a serem aplicadas pelas fundações e a possibilidade de encharcamento do solo".

Nos projetos de fundações em solos colapsíveis, normalmente opta-se por um tipo de fundação que atinja profundidades maiores, de modo a diminuir o efeito da colapsibilidade do solo. Portanto, as fundações diretas são mais limitadas nestes locais, pois os efeitos do colapso são mais acentuados nas camadas superficiais.

A importância do papel da sucção para o aumento da capacidade de carga das fundações foi demonstado por Fredlund e Rahardjo (1993). Os autores utilizaram a equação de Terzaghi para correlacionar os valores de sucção com os valores de capacidade de carga. Para este estudo, foram empregadas sapatas corrida de $0,50 \mathrm{~m}$ e de $1,0 \mathrm{~m}$ de largura, assente a 0,5 $\mathrm{m}$ de profundidade. A Figura 2.22 ilustra a influência da sucção matricial nos valores da capacidade de carga da sapata. Neste ábaco, c'é a coesão efetiva do solo, $\Phi$ ' o ângulo de atrito interno efetivo, $\Phi$ o ângulo indicativo da taxa de aumento da resistência ao cisalhamento relacionada à sucção matricial do solo.

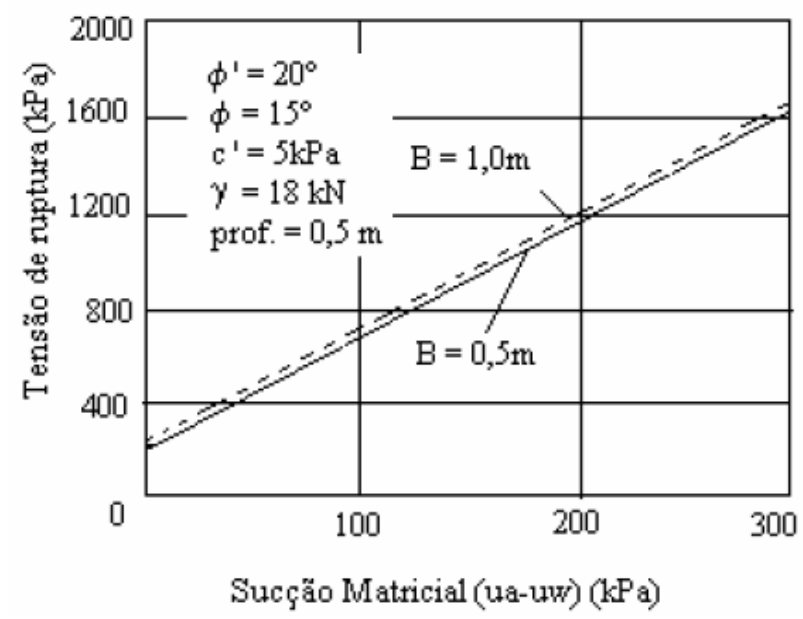

Figura 2.22 - Tensão de ruptura em função da sucção matricial Fonte - Fredlund e Rahardjo (1993)

A sucção matricial do solo sofre variações naturais no decorrer do tempo devido às condições climáticas e metereológicas que modificam seu teor de umidade. Consequentemente, o aumento do teor de umidade leva à redução da sucção matricial, provocando a diminuição da capacidade de carga e o aumento dos recalques. Para ilustrar essas condições, Cintra et al. (2009) apresentaram a existência de uma família de curvas carga versus recalque, obtidas por 
meio de provas de cargas, que variam em função da sucção matricial do solo início do ensaio, Figura 2.23.

Conhecendo este comportamento variável do solo com relação à sucção matricial, Cintra e Aoki (2009) recomendam que seja adotado algum procedimento para avaliar a sucção matricial na data de realização da prova de carga no solo.

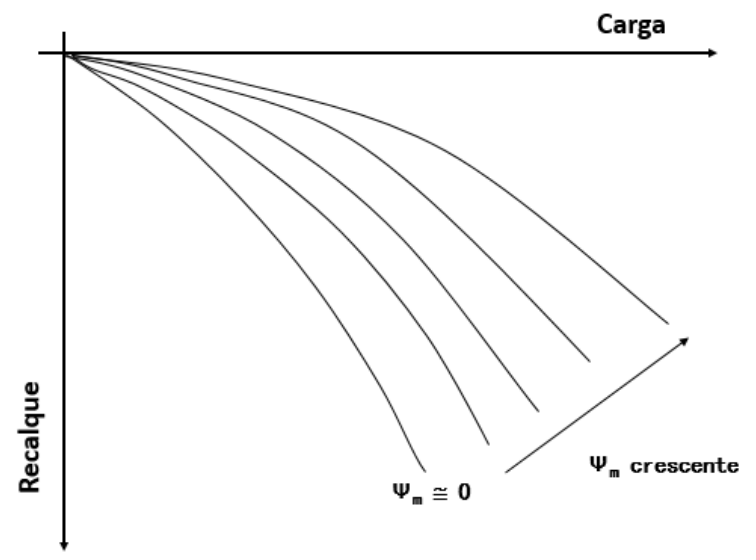

Figura 2.23 - Família de curvas carga x recalque em função da sucção matricial do solo Fonte - Cintra (2005)

Moraes (2005) apresenta em seu trabalho a variação da sucção com o decorrer do tempo e das condições climáticas. Para isso, o autor monitorou diariamente a sucção matricial por meio de tensiômetros instalados a 1,5 m de profundidade na cidade de São Carlos, por um período de 110 dias. A Figura 2.24 ilustra as curvas que relacionam os valores da sucção matricial com os valores da precipitação média diária nos mesmos períodos.

As variações naturais da sucção matricial do solo também refletem nos resultados obtidos pelos ensaios de penetração estáticos e dinâmicos. Ensaios como SPT (Standard Penetration Test) e CPT (Cone Penetration Test) realizados em diferentes épocas apresentarão alterações nos valores de $\mathrm{N}_{\mathrm{SPT}}$ e $\mathrm{q}_{\mathrm{c}}$. Reginatto (1971) considera que o uso dos valores obtidos na sondagem SPT são muito limitados para determinar o valor da capacidade de carga de solos colapsíveis, pois na maioria dos casos pode resultar em valores muito maiores do que os valores reais nas condições inundadas, trazendo riscos aos projetos de fundações apoiadas nestes solos, Figura 2.25.

De acordo com Cintra e Aoki (2009), a sucção matricial nula corresponde a uma espécie de condição crítica da curva carga x recalque na qual é possível obter o valor da deformação máxima e da capacidade de carga mínima para a fundação. Os autores recomendam que os ensaios de prova de carga e as sondagens SPT também sejam executados na condição inundada para determinar a capacidade de carga mínima, ou seja, a carga de colapso. 
A variação da sucção matricial, segundo Gusmão Filho (1994), pode ocorrer sem que haja a mudança de umidade do solo. $\mathrm{O}$ carregamento devido à fundação faz com que o volume do solo poroso diminua, reduzindo os vazios e aumentando o grau de saturação do solo. O autor acrescenta que para pequenos recalques, como no início do carregamento, a sucção permanece praticamente constante. Porém, conforme as deformações volumétricas aumentam, devido ao crescimento dos recalques ou colapso, a sucção diminui fazendo com que o solo se torne saturado.

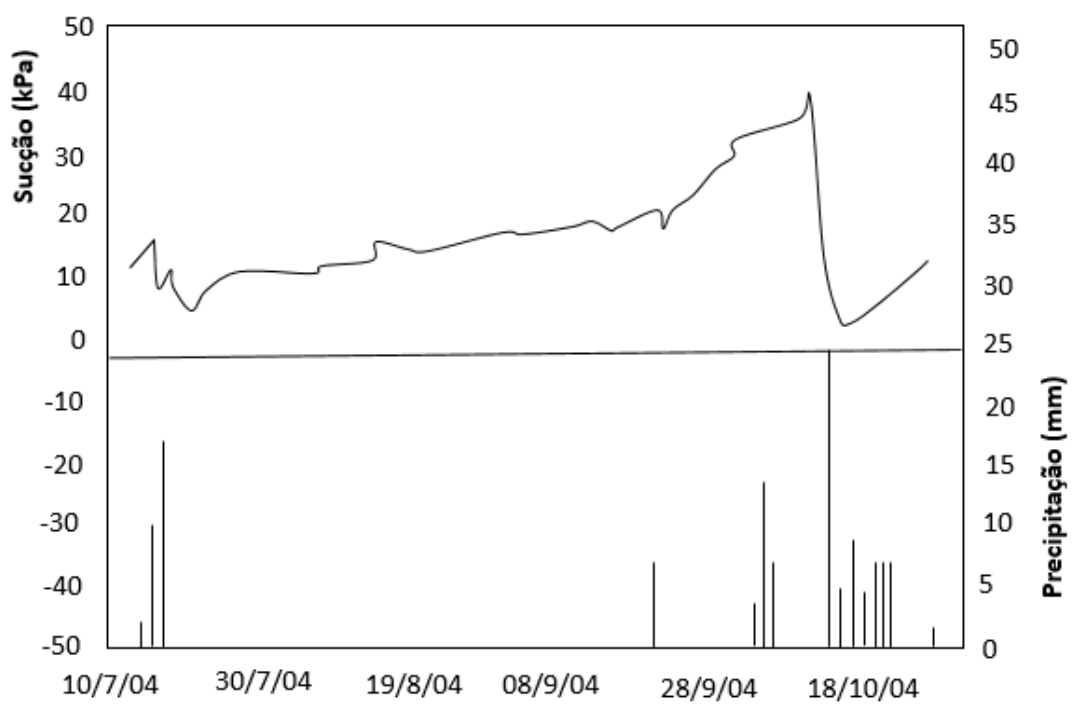

Figura 2.24 - Variação da sucção matricial e precipitação média diária Fonte - Moraes (2005)

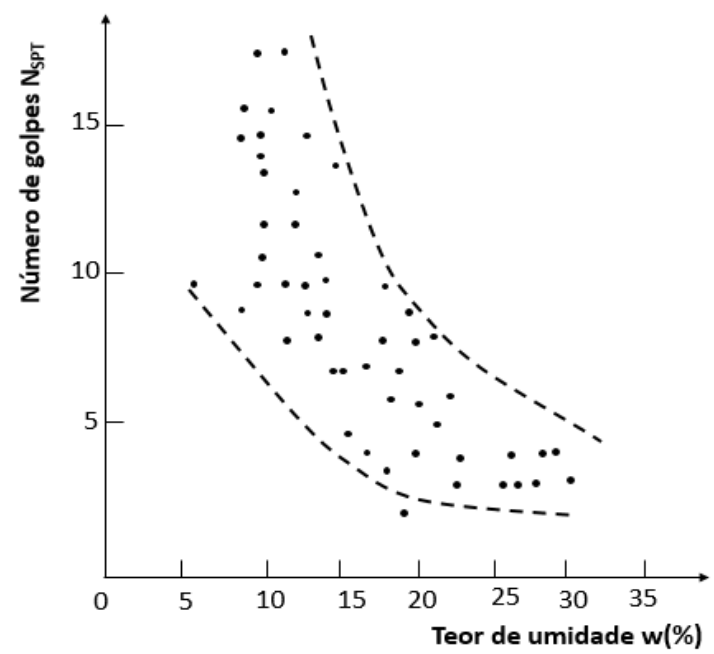

Figura 2.25- Variação de $\mathrm{N}_{\mathrm{spt}}$ com o teor de umidade Fonte - Reginatto (1971) 


\subsection{TÉCNICAS DE TRATAMENTO E MELHORIA DE SOLOS COLAPSÍVEIS}

Para reduzir os efeitos nocivos do recalque de fundações diretas por colapso, deve-se adotar alguma medida de reforço ou melhoria do solo. Segundo Souza (1993), as bibliografias sobre solos colapsíveis apresentam, na sua maioria, casos históricos de ocorrência do colapso e descrevem o comportamento estrutural destes solos. Porém, são poucas que relatam casos de soluções adotadas para utilizá-lo como solo de fundação.

A solução ou estabilização dos solos colapsíveis através de técnicas de reforço e tratamento é de grande importância, principalmente aquelas que conciliem baixo custo com facilidade e rapidez na execução. Existem alguns métodos que podem ser utilizados para minimizar ou eliminar o efeito do colapso do solo e a escolha do método apropriado depende das características do solo colapsível, da estrutura a ser construída, além do custo e praticidade do método.

Mitchell (1968) apresenta um resumo da aplicabilidade de diversas técnicas de melhoramento de solos em função da granulometria do terreno, Figura 2.26.

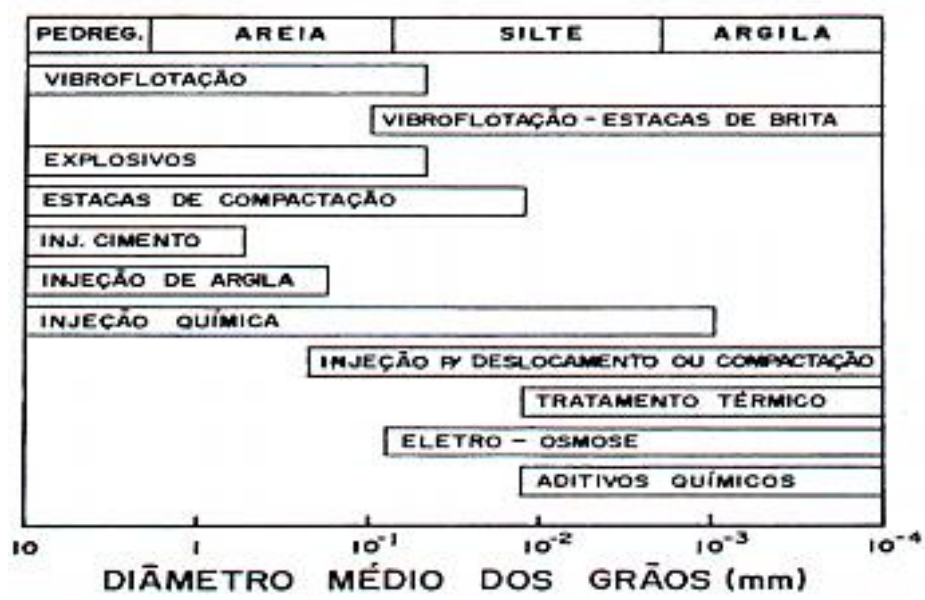

Figura 2.26 - Técnica de melhoramento ideal de acordo com a granulometria do solo Fonte - Mitchell (1968)

Os principais métodos de estabilização dos solos colapsíveis encontrados são:

\subsubsection{Substituição do Solo}

Uma simples solução para estabilização do solo é escavá-lo até a profundidade requerida e remover a camada de solo colapsível. O solo removido pode ser reutilizado, de forma compactada, como solo de fundação. Esta técnica é geralmente aplicada quando a camada de solo colapsível envolvida ocorre em pequenas profundidades (AL RAWAS, 2000). 
A compactação do solo substituído deve atingir um grau de compactação entre 95 e 100\% (Especificação americana AASHTO) e segundo Jennings e Knight (1975), deve sempre ser compactado com umidade $2 \%$ inferior à sua umidade ótima.

\subsubsection{Pré-inudação}

A técnica de pré-inundação consiste em umedecer o solo, que apresenta comportamento colapsível quando saturado, antes que este seja solicitado devido à construção de uma edificação (AL RAWAS, 2000). A finalidade deste método é minimizar o colapso do solo quando solicitado. Porém, a técnica pode não ser suficiente para prevenir futuros recalques da fundação, uma vez que o colapso pode ter sido causado por uma pressão inferior à sobrecarga que será inserida. Desta forma, a carga adicional imposta pela fundação não é compensada e pode resultar em recalques adicionais após a construção da obra (ROLLINS e ROGERS, 1994).

\subsubsection{Inundação controlada}

A técnica de inundação controlada é similar à técnica de pré-inundação, porém, neste caso, a inundação é realizada após a construção da edificação. As quantidades de água devem ser controladas e adicionadas em incrementos iguais. Este método também é utilizado quando a estrutura exibe dano ou inclinação devido aos recalques diferenciais (AL RAWAS, 2000).

\subsubsection{Compactação controlada}

Um dos métodos mais práticos e eficientes de minimizar o colapso do solo é por meio da compactação. Esta técnica é utilizada tanto para camadas profundas de solo colapsível quanto para as camadas mais rasas. A compactação pode ser alcançada com o uso de rolos compactadores, colunas de deslocamento, compactação dinâmica e vibrocompactação. No sul da Califórnia (USA), geralmente utiliza-se como técnica de melhoria de solos colapsíveis o método de substituição do solo em que o solo é removido e recompactado. Porém, este processo de compactação é eficiente somente nos primeiros 5 metros de profundidade, com maior melhoria nos primeiros 3 metros (ROLLINS e ROGERS, 1994).

Segundo Ferreira (2010), quando a compactação do solo é feita na umidade ótima, atingindo a massa específica aparente seca máxima, o solo apresenta uma estrutura estável em presença de água para diferentes níveis de tensão. 


\subsubsection{Colunas de deslocamento}

Poucos trabalhos são encontrados na literatura que envolvem a inclusão de colunas de deslocamento em solos colapsíveis, para reduzir os efeitos do colapso. O princípio desta técnica baseia-se na transferência do carregamento aplicado no solo colapsível às camadas com maior resistência. As colunas de deslocamento mais comuns na literatura são constituídas de brita, areia, solo cimento, podendo ser encamisadas ou não com materiais geossintéticos (AYADAT e HANNA, 2005; SOARES, 2002; MORETTI, 2012; CONCIANI, 2006; BARLACU ET AL., 2013 e ARAÚJO, 2009). As colunas compactadas com material granular podem servir como drenos, acelerando o adensamento dos solos argilosos, além de compactar o solo circundante, reduzindo o índice de vazios do solo no entorno das colunas.

Araújo (2009) avaliou a utilização de colunas granulares de areia, brita e solo-cimento instrumentadas em solo colapsível. Para isto, foram executadas colunas em campo com e sem encamisamento com material geotêxtil e os resultados foram obtidos por meio de provas de carga sobre placa. O autor observou o ganho de capacidade de carga devido a utilização do encamisamento com geossintético para colunas de areia e brita. Porém, para as colunas de solocimento, não houve tanta diferença na resistência do solo reforçado devido à utilização do encamisamento.

Com o auxílio de extensômetros, o autor concluiu que as colunas encamisadas transferiram mais carga para a ponta do que as colunas tradicionais. Com base na análise realizada o autor também observou o potencial uso de colunas granulares encamisadas com geossintéticos para estabilização de solos colapsíveis.

Ayadat et al. (2005) estudaram a técnica de reforço de solos colapsíveis com colunas de brita encamisadas. Os autores concluíram que as colunas de brita construídas com a mesma profundidade das camadas colapsíveis apresentaram recalques equivalentes a 1/3 do recalque do solo sem reforço, viabilizando a utilização destas colunas como reforço de solo para reduzir o efeito do colapso.

\subsubsection{Estabilização química}

A estabilização química do solo colapsível, por meio de aditivos como silicato de sódio (utilizado em cimentos) e óxido de cálcio, vem sendo estudada há alguns anos e, segundo Mitchell (1981), a estabilização com cálcio e o cimento são eficazes em vários tipos de solo. O 
método envolve o efeito da cimentação no interior da estrutura do solo e a sua resistência ao colapso quando inundado.

Quando o solo é misturado com a cal ativa $(\mathrm{CaO})$ o aditivo se dissolve na água intersticial do solo, hidratando-se, reduzindo o teor de umidade do solo e liberando íons de cálcio e hidroxilas. O tratamento é feito por meio da troca de íons entre o aditivo e o solo cujo produto final da reação é a aglutinação das partículas de solo e, consequentemente, o ganho de resistência (MORETTI, 2012). A penetração da solução química até a profundidade desejada é essencial para o sucesso da operação. A vantagem do método é que ele pode ser aplicado quando a edificação já foi construída (AL RAWAS, 2000).

$\mathrm{Na}$ Bulgária, utiliza-se a estabilização química com cimento para o tratamento do loess colapsível. A mistura é feita com aproximadamente $5 \%$ de cimento e solo e em seguida é compactada em camadas formando espécies de mantas com consideráveis espessuras (MITCHELL, 1981).

\subsubsection{Tratamento térmico}

O método consiste na queima de combustíveis em furos vedados realizados no terreno, sob temperatura controlada, forçando a saída do ar aquecido sob pressão pelos vazios do solo (TSCHEBOTARIOFF, 1978). Os furos são estreitamente espaçados e as temperaturas podem alcançar até $1000^{\circ} \mathrm{C}$, produzindo uma coluna de solo estabilizado com diâmetro variando com os espaçamentos adotados entre os furos, geralmente de 1,5 a 2,0 metros. Litvinov (1960) desenvolveu um método de aquecimento e tratamento do terreno cujo esquema está apresentado na Figura 2.27.

O tratamento térmico provoca um significativo e permanente ganho de resistência, incluindo a redução da sensibilidade do solo ao colapso provocado pela água. Para a execução desta técnica, é necessário que no projeto sejam conhecidos parâmetros como estrutura, condutividade térmica e teor de umidade do solo para a estimativa de propriedades finais obtidas com o tratamento, assim como, as zonas de influência alcançadas pelo efeito da temperatura e o tempo necessário para o tratamento (MITCHELL, 1981).

Os solos colapsíveis do leste europeu foram satisfatoriamente estabilizados com a técnica do tratamento térmico em camadas abaixo de edificações já construídas (BELES e STÂNCULESCU, 1958; KURNAKOV, 1972). 


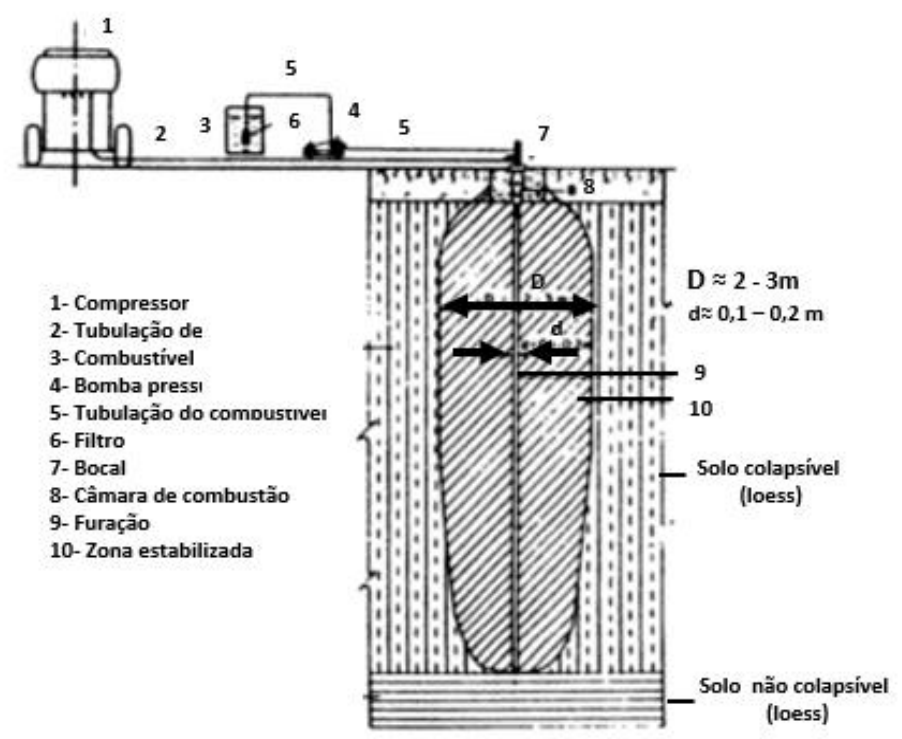

Figura 2.27 - Esquema de estabilização térmica como tratamento de solo colapsível Fonte - Adaptado de Litvinov (1960)

\subsubsection{Avaliação dos métodos de reforço e tratamento do solo}

Rollins e Rogers (1994) realizaram um estudo em Néfi (EUA) para avaliar o custo e a eficácia de alguns métodos de tratamento de solos colpsíveis executados em campo. Foram feitos seis testes, em escala real, com sapatas quadradas de 1,5 m de largura. Os métodos de reforço executado foram: 1) pré-umedecimento com água; 2) pré-umedecimento com solução de silicato de sódio com concentração igual a 2\%;3) escavação parcial do solo e substituição com material granular compactado; 4) compactação dinâmica em solo seco; 5) compactação dinâmica em solo pré-umedecido e 6) solo sem tratamento. A avaliação da melhoria de solo foi feita por meio de testes edométricos duplos, com amostras indeformadas, juntamente com testes de penetração de cone (CPT) e testes pressiométricos.

O perfil do solo envolvido no estudo era composto por areia argilosa (CL-ML), com teor de umidade natural entre $7 \%$ e $10 \%$, limite de liquidez de $22 \%$ e índice de plasticidade de $5 \%$. A distribuição granulométrica dos grãos consistiu tipicamente de $30 \%$ areia, $60 \%$ de silte e 10\% de argila. A Tabela 2.4 apresenta os valores dos recalques previstos por testes edométricos e os recalques medidos em campo. Verificou-se que o pré-umedecimento com silicato de sódio e a compactação dinâmica foram os métodos mais eficazes para reduzir o recalque dos solos colapsíveis.

Os recalques passaram de $250 \mathrm{~mm}$ para menos de $25 \mathrm{~mm}$, utilizando-se a técnica de pré-umedecimento do solo com silicato de sódio e quando empregada a técnica de tratamento 
com compactação do solo na sua umidade natural, o recalque foi reduzido de mais de $390 \mathrm{~mm}$ para $10 \mathrm{~mm}$, como apresentado na Tabela 2.4 .

Tabela 2.4 - Comparação entre os recalques previstos e medidos para os vários tipos de tratamentos

\begin{tabular}{|c|c|c|c|c|c|}
\hline \multirow[b]{2}{*}{ Teste } & \multirow[b]{2}{*}{ Método de Tratamento } & \multicolumn{2}{|c|}{ Recalque por colapso previsto } & \multicolumn{2}{|c|}{ Recalque medido } \\
\hline & & $\begin{array}{c}\text { Sem Tratamento } \\
(\mathrm{mm})\end{array}$ & $\begin{array}{c}\text { Com tratamento } \\
(\mathrm{mm})\end{array}$ & $\begin{array}{c}\text { Colapso } \\
(\mathrm{mm})\end{array}$ & $\begin{array}{l}\text { Deformação } \\
(\mathrm{mm})\end{array}$ \\
\hline 1 & Sem Tratamento & 267 & N/A & 282 & 12 \\
\hline 2 & Pré umedecido com água & 270 & 300 & 243 & 12 \\
\hline 3 & Pré umedecido com silicato de sódio & 270 & 32 & 27 & 9 \\
\hline 4 & Escavação e reposição & 267 & 183 & 114 & 9 \\
\hline 5 & $\begin{array}{l}\text { Compactação dinâmica w(\%) natural } \\
\text { Compactação dinâmica pré }\end{array}$ & 254 & 31 & 3 & 14 \\
\hline 6 & umedecimento & 396 & 15 & 11 & 18 \\
\hline
\end{tabular}

Fonte - Rollins e Rogers (1994)

\subsection{COMPACTAÇÃO DOS SOLOS}

\subsubsection{Teoria da Compactação}

Fernandes (1994) define a compactação dos solos como o processo pelo qual uma massa constituída por sólidos, água e ar tem o seu índice de vazios reduzido devido à diminuição do volume da fase gasosa do material em consequência da aplicação de uma carga. Como resultado da compactação, deseja-se obter um material com comportamento mais adequado para a aplicação ao qual se destina.

No artigo publicado por Proctor (1933), o autor divulgou, pela primeira vez, um dos mais importantes princípios dos solos compactados: a variação da sua densidade com o teor de umidade, sob uma determinada energia de compactação. Neste artigo, Proctor (1933) desenvolveu um ensaio dinâmico para a determinação da curva de compactação que relaciona o peso específico aparente seco $\left(\gamma_{\mathrm{d}}\right)$ com o teor de umidade gravimétrico do solo $(w)$. A Figura 2.28, que ilustra os resultados obtidos neste ensaio, mostra que o peso específico aparente seco pode aumentar ou diminuir com a variação do teor de umidade do solo, fixada uma determinada energia de compactação.

Segundo Proctor (1933), no ramo ascendente da curva, também conhecido como ramo seco, à medida que aumenta-se o teor de umidade, a água provoca a lubrificação das partículas do solo, reduzindo o atrito entre os grãos, aumentando-se o peso específico seco do solo. A partir de um determinado valor de umidade, a água impede a expulsão do ar dos vazios durante a compactação, ou seja, com o aumento do teor de umidade para além deste valor, o ar presente 
no solo não estaria mais conectado com o ar nos outros vazios. Nesta condição o ar se encontra ocluso e como consequência deste efeito as cargas de compactação aplicadas no solo não conseguem provocar um novo rearranjo das partículas, causando um decréscimo no peso específico seco do solo.

O ponto de inflexão apresentado na curva da Figura 2.28 é denominado umidade ótima $\left(w_{o t}\right)$ e o peso específico seco correspondente à essa umidade é o máximo encontrado no ensaio $\left(\gamma_{\mathrm{d} \text { máx }}\right)$. Este resultado indica a relação ideal entre as quantidades de partículas de solo, ar e água para obter o melhor resultado para uma determinada energia de compactação aplicada no solo.

A curva mais à direita apresentada no gráfico da Figura 2.28 representa a relação entre a massa específica seca e o teor de umidade para o solo saturado $\left(S_{\mathrm{r}}=100 \%\right)$, neste caso não existe mais ar presente nos vazios pois estão todos preenchidos com água. Esta condição não poderá ser alcançada pela compactação. $\mathrm{Na}$ apresentação dos resultados do ensaio de compactação é comum traçar as linhas correspondentes aos variados graus de saturação do solo, como pode ser observado na Figura 2.28. De acordo com Massad (2006), o lugar geométrico da linha dos pontos ótimos situa-se entre as linhas hiperbólicas com grau de saturação entre 80 e 90\%. Em geral, quanto maior a energia de compactação utilizada em um mesmo tipo de solo, maior será seu peso específico seco máximo e menor será a sua umidade ótima (Villar et al., 2015).

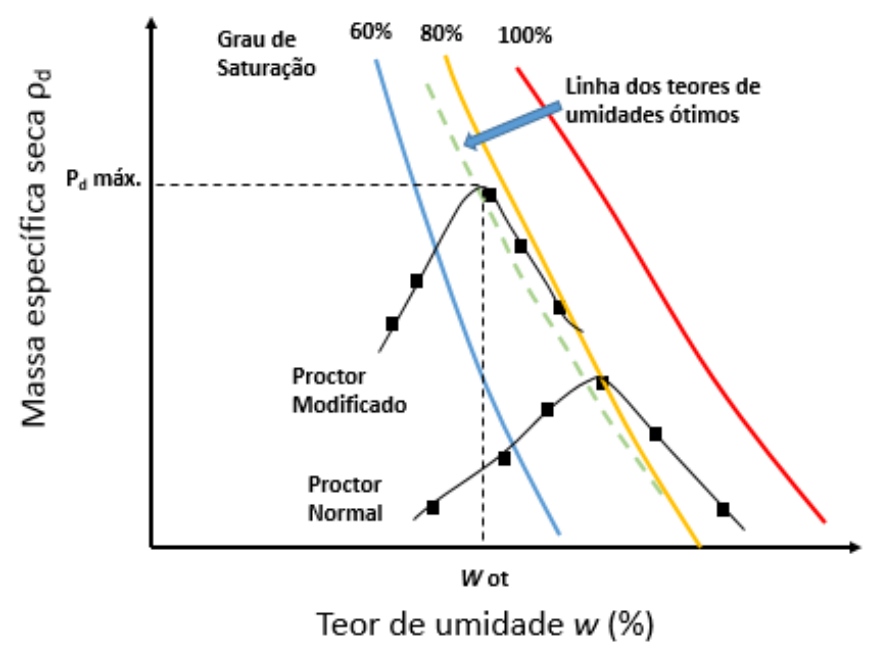

Figura 2.28 - Curva de Compactação destacando a densidade seca máxima e o teor de umidade ótimo. Fonte - Adaptado Villar et al. (2015)

Além de Proctor (1933), outros autores também estudaram a interação entre as partículas de solo no processo de compactação como: Hogentogler (1937); Hilf (1956); Lambe 
(1958); Olson (1963); Barden e Sides (1973). Estes autores procuraram justificar o formato da curva obtida no ensaio de compactação, apresentada na Figura 2.28, em função de variáveis como capilaridade, permeabilidade, viscosidade da água e tensões efetivas.

Segundo Hogentogler (1937), a forma da curva de compactação indica quatros estágios de umidade lineares relacionados à viscosidade da água. O primeiro estágio é a hidratação, o segundo é a lubrificação, o terceiro o inchamento e o quarto estágio corresponde à saturação do solo (Figura 2.29).

$\mathrm{Na}$ fase de hidratação, com o aumento de umidade do solo, a água é adsorvida pelas partículas envolvendo-as com uma fina camada. Como consequência deste efeito ocorre a redução do atrito entre os grãos permitindo que as partículas se rearranjem mais facilmente, aumentando o peso específico do solo. A partir de certa umidade, além de formar uma camada superficial de água, que reduz o atrito entre os grãos, a água começa a atuar como um lubrificante, facilitando ainda mais a ocorrência de novos arranjos entre as partículas durante a compactação, tornando o solo ainda mais denso.

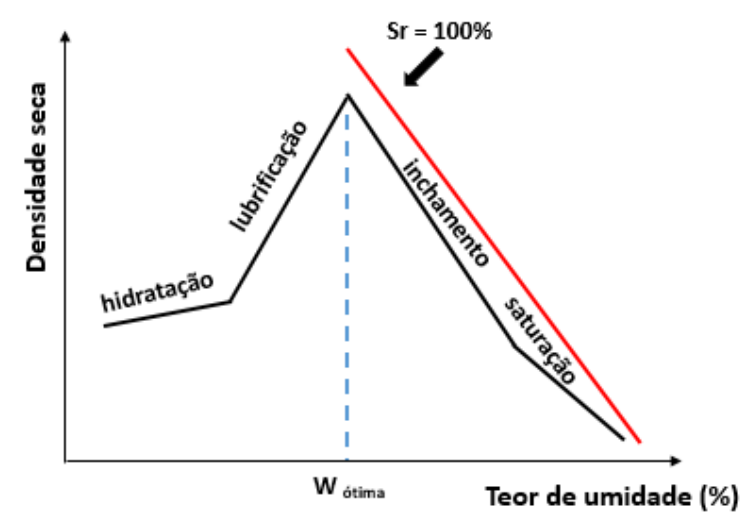

Figura 2.29 - Teoria de Hogentogler (1937) para explicar a forma da curva de compactação Fonte - Adaptado de Hogentogler (1937)

Já na fase de inchamento, a umidade do solo ultrapassa o valor da umidade ótima, levando a um aumento do volume do solo sem que ocorra a redução do volume de ar, o que justifica a redução do peso específico seco neste trecho. No último estágio, correspondente à fase de saturação, a curva de compactação se aproxima à linha correspondente ao grau de saturação de $100 \%$ (Figura 2.29). Neste estágio todo o ar é expelido do solo, e a presença de água nos seus vazios não permite que os grãos consigam obter novos arranjos (HOGENTOGLER, 1937).

Estudos realizados por Lambe (1958), baseados em exames microóticos do arranjo dos grãos de argila compactada, o levaram a propor uma nova hipótese da estrutura dos solos 
compactados, que é cada vez mais aceita. Nesta hipótese, a explicação para a forma da curva de compactação para solos argilosos tem como base a teoria da química coloidal. A proposição de Lambe (1958) se fundamenta no fato de que as partículas de solos argilosos, sob um determinado estado de tensões, necessitam de uma quantidade de água para desenvolver a camada dupla. Segundo Lambe (1958), geralmente para os solos argilosos compactados, o valor do teor de umidade é positivo, ou seja, há uma deficiência de água no solo para a formação da dupla camada. A Figura 2.30 apresenta duas curvas de um mesmo solo compactados com energias diferentes.

No ponto A, situado sobre a curva inferior, a pequena quantidade de água no solo não permite o desenvolvimento pleno da camada dupla, porém há uma concentração eletrolítica que provoca a redução das forças de repulsão entre as partículas, fazendo com que haja uma tendência à formação de flóculos, resultando em solo com arranjo estrutural aleatório, com baixo valor de massa específica (NOGUEIRA, 1971).

Isso ocorre, pois nessa condição há forças atrativas entre as partículas que as ligam, formando flocos que são indestrutíveis pelas forças comumente utilizadas na compactação. Porém, o aumento do teor de umidade desfaz essas forças atrativas e os grãos começam a atuar como partículas dispersa em água, carregadas negativamente, tendendo a se dispersarem. Essa tendência será tanto mais pronunciada quanto maior for o teor de umidade do solo (VARGAS, 1977).

No ponto B, situado na mesma curva, a quantidade de água no solo permite que haja uma expansão da camada dupla com uma redução da concentração eletrolítica, reduzindo desta forma a floculação e permitindo um arranjo estrutural mais ordenado, resultando em um solo com massa específica maior. No ponto C, indicado na Figura 2.30, uma maior quantidade de água permite uma expansão continuada da camada dupla e uma redução das forças de atração entre as partículas, diminuindo a floculação e induzindo a formação de um arranjo mais ordenado que $\mathrm{B}$, com partículas tendendo a ficar paralelas entre si. Mesmo com esse novo arranjo, a massa específica em C é menor que em B. (NOGUEIRA, 1971).

No ramo úmido, onde a umidade está acima da umidade ótima, o aumento da energia de compactação provocará o alinhamento das partículas sem diminuir as distâncias entre elas, ponto indicado pela letra D na Figura 2.30.

A quantidade de água é um parâmetro decisivo para a compactação, ao lado da energia de compactação e do tipo de solo (MASSAD, 2010). Ao tentar compactar um solo, o esforço 
de compactação pode ser mais ou menos efetivo de acordo com a granulometria e a plasticidade do solo (VARGAS, 1977).

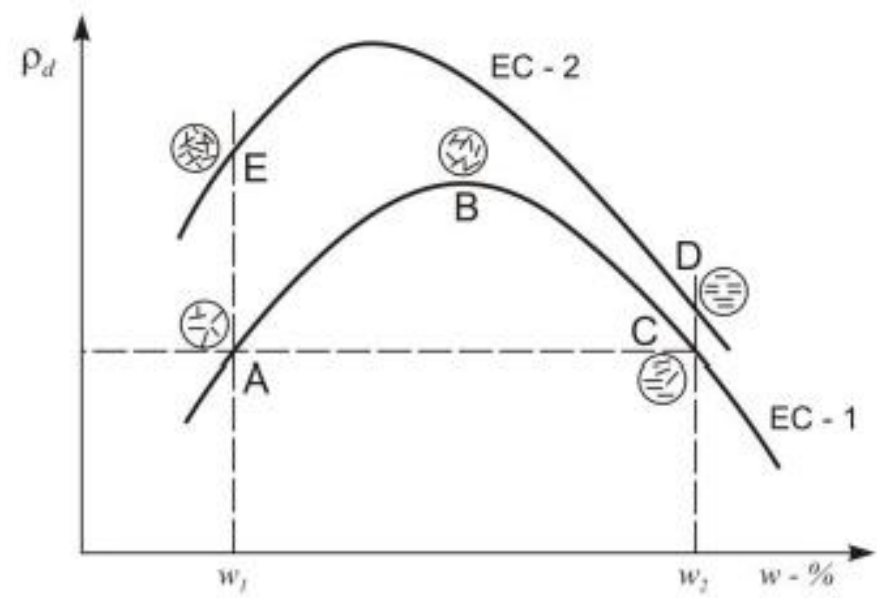

Figura 2.30 - Teoria de Lambe (1958) que explica a forma da curva de compactação Fonte - Lambe (1958)

A Figura 2.31 ilustra alguns valores típicos de peso específico seco máximo e umidade ótima de diferentes solos, para a energia padrão do ensaio de Proctor. As diferenças entre as curvas são significativas podendo-se utilizar estes parâmetros para identificar o tipo de solo.

Nas teorias de compactação apresentadas nota-se que a relação entre o solo e a água está associada à natureza químico-mineralógica das partículas individualizadas de solo e ambas as teorias auxiliam na compreensão dos mecanismos que levam à densificação dos solos argilosos. Porém, em perfis de intemperismo de regiões de clima tropical não é possível considerar as partículas de solo de forma individualizada. Os grãos de argila nos solos lateríticos geralmente compõem os agregados e não têm a liberdade necessária para se orientarem devido ao processo de compactação e hidratação (VILLAR et al., 2015).

Os solos tropicais são constituídos de agregados que possuem macroporosidade e microporos em seu interior, como ilustra a Figura 2.32. O comportamento deste solo é comandado pela macroporosidade, formada entre os agregados, e pela água que ocupa os macroporos (VILLAR et al., 2015).

Durante o processo de compactação ocorre o fechamento dos macros e mesoporos formados entre os agregados. Os efeitos da capilaridade e sucção interferem na compactação na faixa de umidade compreendida entre a entrada de ar nos microporos e o término da entrada de ar nos macroporos, indicadas na Figura 2.33. O aumento do teor de umidade do solo provoca a redução da resistência interna à energia externa de compactação até que a umidade ótima seja atingida, umidade na qual ocorre a oclusão da fase de ar (FARIAS et al., 2011). 
Para solos arenosos, devido à baixa atividade superficial dos grãos de quartzo, a interação entre as fases ar, água e mineral é de natureza física, ou seja, está relacionada com o fenômeno da capilaridade. Considerando que o solo se encontra no ponto A da curva de compactação proposta por Lambe (Figura 2.30) ocorre a maior capilaridade e o menor efeito de lubrificação entre os grãos, para uma dada energia de compactação. Com o aumento do teor de umidade, a capilaridade vai diminuindo (Figura 2.33) e aumenta-se o efeito lubrificante entre os grãos, reduzindo desta forma a resistência do solo à energia externa de compactação, fazendo com que o peso específico seco do solo aumente, até atingir o ponto B (VILLAR et al., 2015).

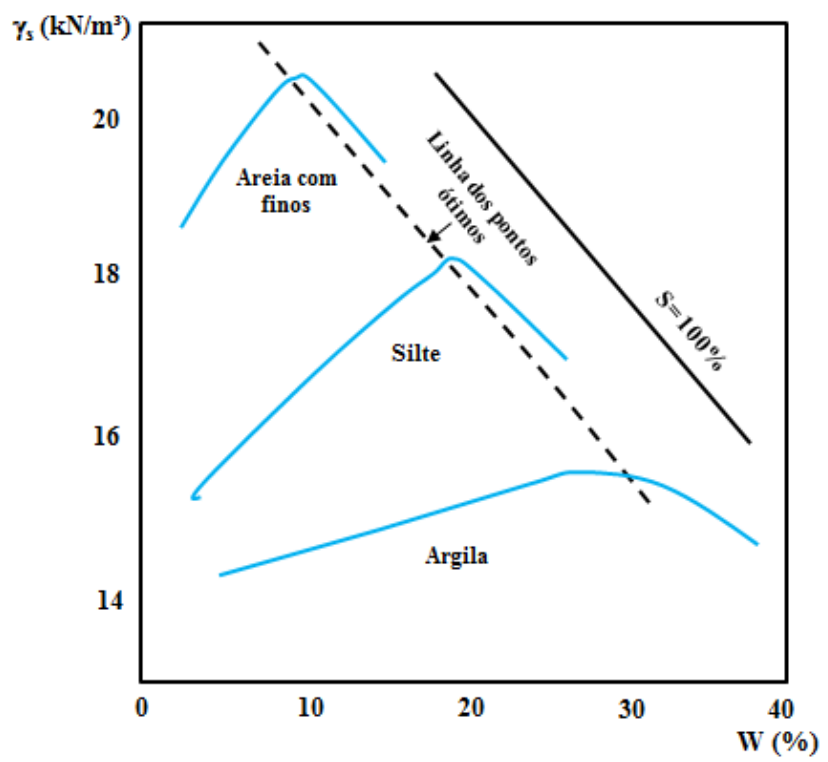

Figura 2.31 - Curvas de Proctor de solos diferentes, compactados com a mesma energia Fonte - Massad (2010)

A partir do ponto $\mathrm{B}$, a fase de ar torna-se descontínua, reduzindo a permeabilidade do solo arenoso, fazendo com que a aplicação da energia de compactação gere o acréscimo de pressão neutra resultando na redução da energia efetiva de compactação. Com o aumento da umidade, reduz a compressibilidade do material, o que justifica o decréscimo da massa específica seca no trecho BC da curva, Figura 2.30 (VILLAR et al., 2015). 


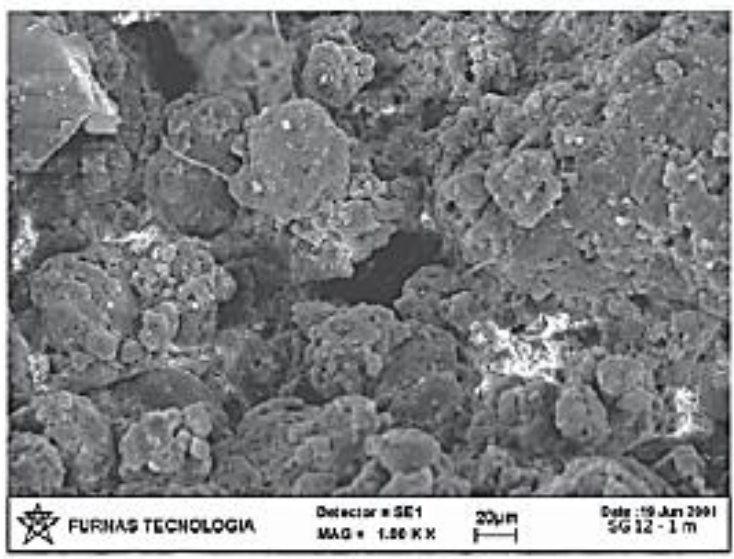

(a)

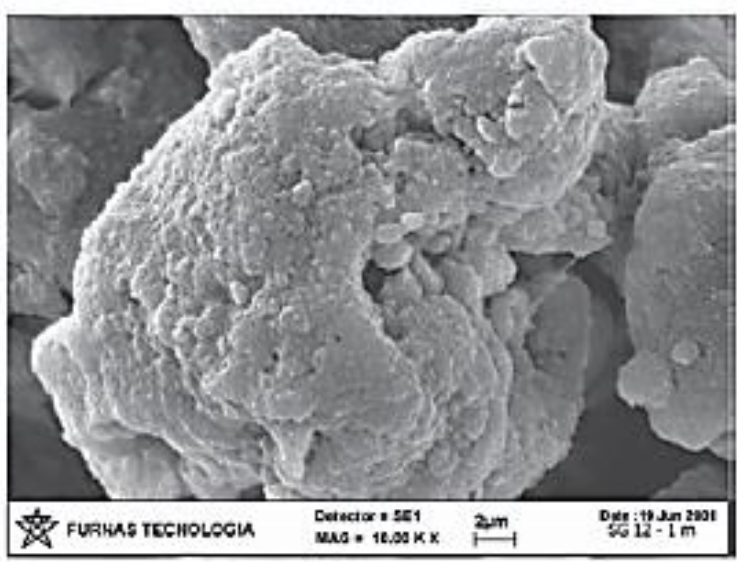

(b)

Figura 2.32 - Microestrutura de um solo laterítico coletado a 1 metro de profundidade: a) aumento de 1000 vezes evidenciando a macrocoporosidade ente os agregados; b) aumento de 10000 vezes evidenciando os microporos no interior do agregado Fonte - Villar et al. (2015)

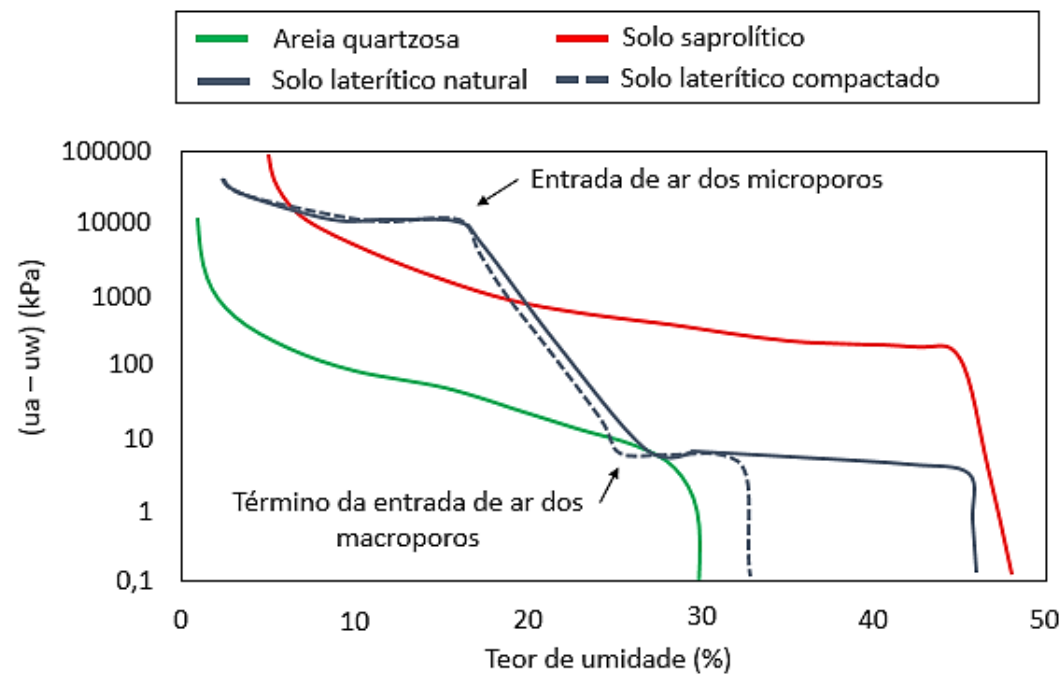

Figura 2.33 - Curvas características de retenção de água no solo

Fonte - Villar et al. (2015)

\subsubsection{Interferência da compactação no comportamento e resistência dos solos}

A resistência dos solos compactados pode ser estimada por vários ensaios como, por exemplo, o de compressão simples. De acordo com Vargas (1977), os resultados dos ensaios mostram que qualquer índice de resistência de um solo (resistência à compressão, resistência à penetração de agulha de Proctor, resistência à penetração do cone) decresce com o aumento da umidade, Figura 2.34. Colocando em correspondência essa curva com a de Proctor, verifica-se que a umidade ótima não corresponde ao máximo da curva de resistência do solo.

A umidade ótima, na realidade, é a condição mais estável do solo em que há a menor perda de resistência, ou seja, a menor variação do seu valor com o aumento da umidade em 
diferentes épocas do ano (VARGAS, 1977). Portanto, um solo compactado na umidade ótima não é o que apresenta maior resistência, mas sim aquele cuja resistência final é estável e independente das variações climáticas.

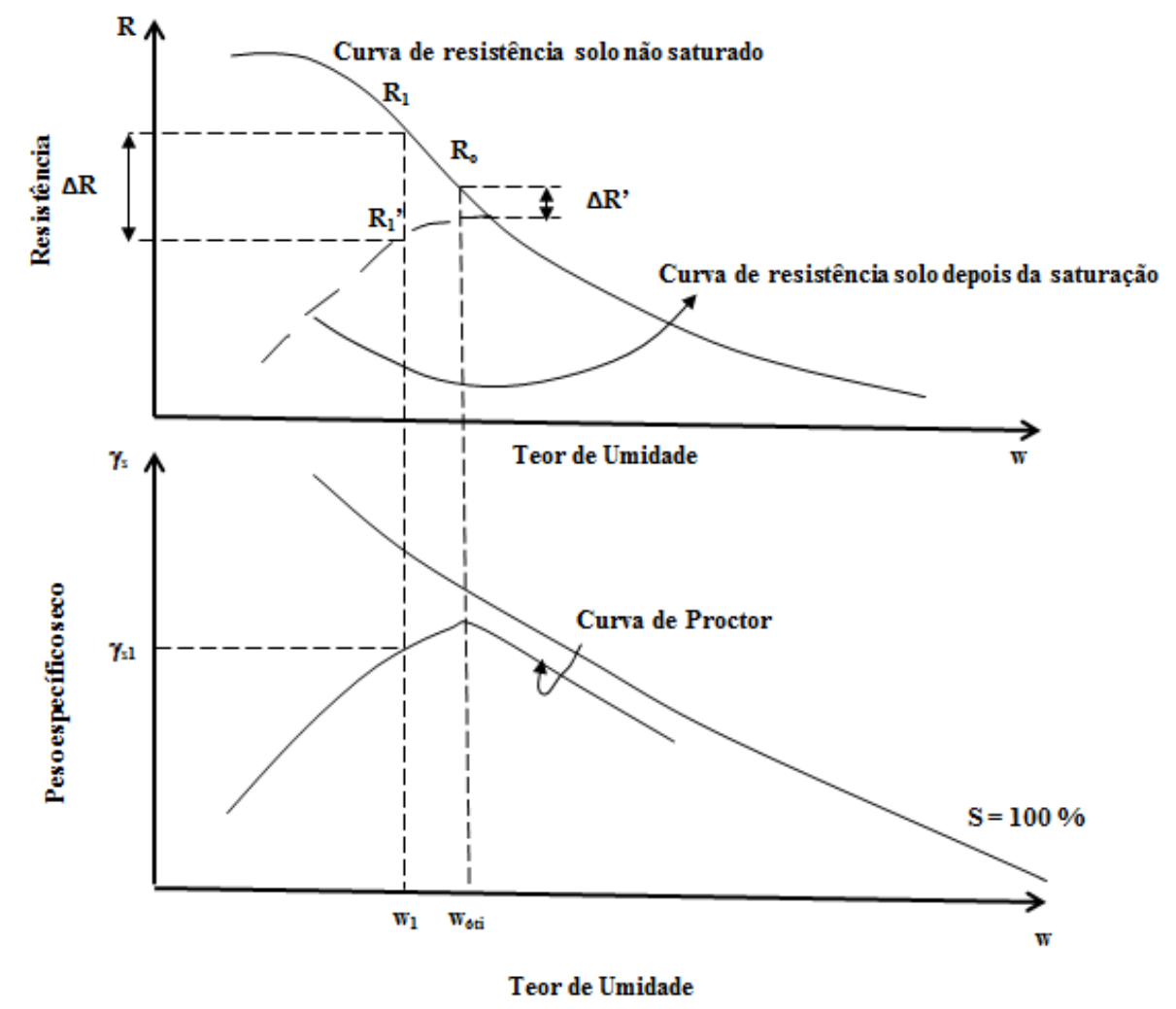

Figura 2.34 - Curva de resistência dos solos compactados Fonte - Vargas (1977)

Alguns autores como Vilar e Gaioto (1994) avaliaram o comportamento colapsível de solos lateríticos compactados e observaram a influência da umidade de compactação e dos valores de sobrecarga aplicada nas deformações encontradas. Para a verificação do comportamento do solo compactado ao colapso, os autores recorreram aos ensaios edométricos onde as amostras foram inundadas após o equilíbrio das deformações sob uma carga de interesse.

Os autores variaram parâmetros como umidade de compactação e densidade na moldagem das amostras, além de variar também os valores das sobrecargas aplicadas durante a inundação. Os resultados encontrados revelaram que, para qualquer valor de massa específica seca, as deformações foram crescentes com as sobrecargas, para amostras ensaiadas no ramo seco. Mesmo o solo compactado com a máxima densidade encontrada no ensaio de Proctor Normal apresentou deformações significativas para altos valores de sobrecarga. Para umidades 
de compactação elevadas, 3\% acima da ótima, as deformações por colapso foram insignificantes, mesmo para amostras compactadas com massa específica seca baixa. Os solos compactados na umidade ótima encontrada no ensaio Proctor Normal apresentaram deformações crescente até atingir um determinado valor da sobrecarga e com o aumento do carregamento os recalques foram diminuindo até se tornarem praticamente nulos.

\subsubsection{Métodos de compactação do solo em campo}

Existem vários métodos utilizados para a compactação dos solos em campo e os resultados fornecidos por cada processo depende de fatores como a natureza do solo, energia, método de compactação adotado e teor de umidade do solo (HOLTZ et al., 1981).

Para que ocorra a densificação do solo por meio da compactação, é necessário que a energia externa aplicada seja maior do que a energia resistente do solo proveniente dos efeitos combinados de capilaridade e sucção. A energia externa pode ser oriunda de ações dinâmicas, estáticas, semiestáticas ou vibratórias (VILLAR et al., 2015).

\subsubsection{Compactação Estática e Semiestática}

A compactação semiestática baseia-se na aplicação de uma pressão uniformemente distribuída no solo. Em campo esta compactação pode ser alcançada com uso de rolos compactadores, com ou sem o controle de umidade. Neste método o solo é removido até a profundidade que se deseja melhorar e em seguida é compactado em camadas (AL RAWAS, 2010). A aplicação mais rotineira deste tipo de compactação é na engenharia de transportes, durante a execução de pavimentos e revestimentos asfálticos.

Existem diversos tipos de rolos compactadores como os lisos, pé de carneiro, grelha e pneumáticos. O primeiro tipo, os lisos, recobrem $100 \%$ da largura do rolo, com uma pressão que pode atingir $280 \mathrm{kPa}$, podendo ser utilizados em qualquer tipo de solo. Geralmente, o solo é compactado em camadas com aproximadamente $15 \mathrm{~cm}$ de espessura. Os rolos pneumáticos recobrem $80 \%$ da sua largura, podendo atingir uma pressão de $700 \mathrm{kPa}$. São usados tanto para solos granulares como para solos coesivos, compactados em camadas de $40 \mathrm{~cm}$ de altura (HOLTZ; KOVACS, 1981).

Já os rolos tipo pé de carneiro recobrem de 8 a 12\% da largura do rolo e exercendo uma pressão no solo que pode variar de 1400 a $7000 \mathrm{kPa}$. As camadas são geralmente compactadas com altura de $15 \mathrm{~cm}$ (HOLTZ; KOVACS, 1981). Apesar de serem indicados para 
compactação de solos coesivos, podem ser utilizados em outros tipos de solo quando se deseja atingir a compactação de camadas mais profundas (VILLAR et al., 2015).

O rolo de tela é frequentemente utilizado quando o material a ser compactado possui dimensões maiores do que as dimensões admitidas. A medida que o rolo é passado no solo, os grãos são vibrados e quebrados em diferentes tamanhos, atingindo-se desta forma a granulometria de projeto desejada (VILLAR et al., 2015). Este rolo cobre aproximadamente $50 \%$ da largura do rolo e a pressão aplicada varia de 1440 à 6200 kPa (HOLTZ; KOVACS, 1981).

\subsubsection{Compactação por vibração}

A compactação dos solos também pode ser alcançada com a vibração das partículas, sendo mais eficiente para solos granulares devido à baixa atividade de superfície dos grãos (VILLAR et al., 2015). A vibrocompactação, também conhecida como vibroflotação, envolve a densificação de camadas de solos granulares espessas, utilizando-se um vibrador que atinge altas profundidades (vibroflotador) variando de 3 a $15 \mathrm{~m}$.

A sonda de vibração, geralmente acoplada e suspendida por uma lança de um guindaste, é inserida no solo e levada até alcançar a profundidade que se deseja realizar o tratamento do solo. A injeção de ar ou de água podem ser utilizadas para facilitar a penetração da sonda. O método de compactação por meio da vibração combina tanto a vibração vertical, durante a inserção da sonda vibrante, como a vibração horizontal das partículas (MITCHELL, 1981).

Em grandes áreas, a vibrocompactação é executada em grelha podendo ser distribuída de forma retangular ou triangular, comumente com espaçamentos variando de 1,0 a 3,0 m do centro da inserção da sonda. A escolha do espaçamento adequado depende do tipo de solo, do tipo de sonda de compactação adotada, da energia de vibração aplicada e do nível de melhoramento do solo requerido no projeto (MITCHELL, 1981).

A viabilidade de aplicação deste método de compactação está diretamente relacionada com a granulometria do solo. O método é mais indicado para materiais não coesivos, com menos de $20 \%$ de cascalho e menos de $18 \%$ de argila e silte. Solos com mais de $18 \%$ de finos têm a densificação prejudicada quando utilizada a vibrocompactação (MITCHELL, 1981). Segundo Craig (2007) os solos finos, siltes e argilas, amortecem os efeitos de vibração fazendo com que haja a redução do raio de influência dos efeitos da compactação. 
O intervalo de granulometria dos solos adequado para o tratamento com esta técnica está apresentado na Figura 2.35.

O uso de vibração em solos profundamente intemperizados, como os lateríticos e saprolítico, constituídos por aglomerados de partículas, pode resultar na quebra dos agregados, provocando o aumento do peso específico aparente seco que traz a falsa impressão de que o comportamento do solo foi melhorado (VILLAR et al., 2015).

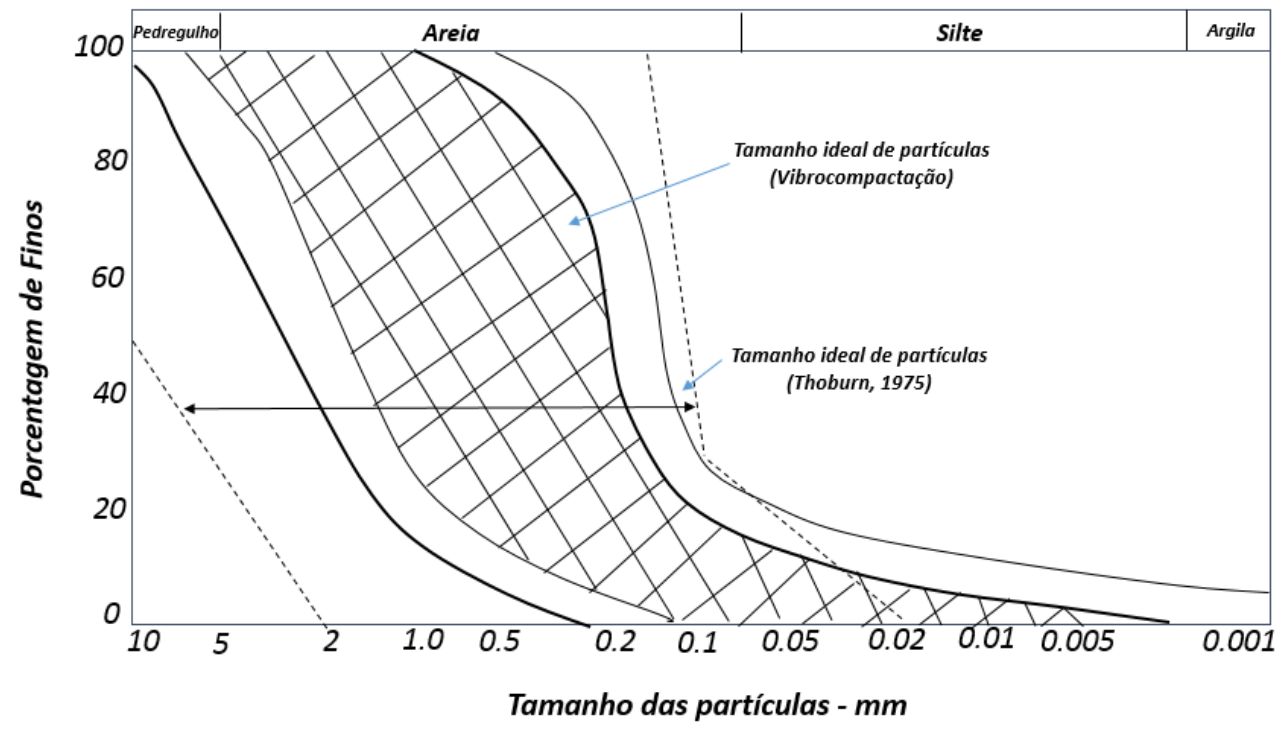

Figura 2.35- Intervalo com tamanho de partículas adequado para densificação por vibrocompactação Fonte - adaptado Mitchell (1981)

\subsubsection{Compactação Dinâmica}

A compactação dinâmica dos solos é executada em campo por meio da aplicação de golpes repetitivos distribuídos homogeneamente em uma malha, de forma que a energia aplicada por um peso na superfície seja transmitida a alguns metros de profundidade. $O$ peso, ou soquete, é acoplado por meio de cabos de aço à um guindaste ou equipamento de elevação e a compactação é realizada pela queda livre deste peso de uma determinada altura (RESENDE, 2012). Este método de compactação é utilizado para reduzir os recalques de fundações, subsidência sísmica, potencial de liquefação e recalques por colapso dos solos (GUNARATNE, 2006). A resistência do solo aumenta e a sua deformabilidade e compressibilidade são reduzidas devido à densificação do solo. A superfície do solo sofre um recalque imediato devido ao rearranjo das partículas, e a sua magnitude varia entre 5 e $10 \%$ da altura da camada (SCHAEFER et al., 1997). 
A eficiência da compactação dinâmica é maior em solos granulares e permeáveis. Solos coesivos tendem a absorver a energia aplicada, assim como na vibrocompactação, o que limita a eficácia do método. A profundidade do lençol freático também pode limitar a aplicação desta técnica de compactação. Segundo Gunaratne (2006), o nível do lençol freático deve estar a pelo menos $6 \mathrm{~m}$ de profundidade da superfície a ser tratada para que a compactação seja efetiva.

O fator determinante para escolher o tipo de solo a ser melhorado com a técnica da compactação dinâmica é a habilidade que o solo tem para dissipar a poro pressão. Durante a compactação, se houver água presente nos vazios do solo, ocorrerá o aumento da pressão neutra durante a compactação e consequentemente a redução da sua resistência (SCHAEFER et al., 1997).

A profundidade de influência dos efeitos da compactação dinâmica está diretamente relacionada com a energia adotada que depende do peso e da altura de queda do bloco. $\mathrm{O}$ alcance dos efeitos de compactação pode ser calculado pelo produto da raiz quadrada da energia adotada com o fator empírico $n$, que varia de 0,3 a 0,6 . Geralmente adota-se para $n$ o valor médio de 0,5 (SCHAEFER et al., 1997). De acordo com Gunaratne (2006), a altura de queda do bloco varia de 15 a 40 m e sua massa varia de 10 a 30 ton. Um esquema da técnica de compactação dinâmica esta apresentado na Figura 2.36.

Mitchell (1981) recomenda por segurança que a compactação dinâmica do solo seja estendida lateralmente à área de reforço requerida para o apoio da fundação a uma distância igual a espessura da camada a ser reforçada.

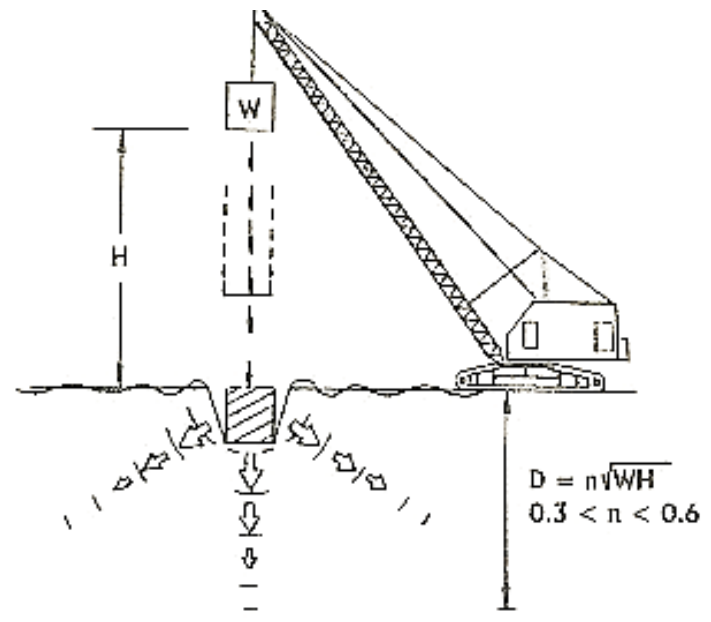

Figura 2.36 - Técnica de compactação dinâmica Fonte - Lukas (1995) 
Segundo Rollings et al. (1994), a compactação dinâmica foi utilizada para densificar solos colapsíveis por meio da queda livre de grandes pesos, com aproximadamente 30 toneladas, liberados de alturas consideráveis, mais de 40 metros, da superfície do solo.

\subsubsection{Colunas de deslocamento}

As colunas de deslocamento são colunas verticais inseridas no solo, cuja finalidade é a densificação do solo no entorno da coluna, devido ao seu deslocamento para as laterais. Os principais materiais utilizados como preenchimento das colunas, relatados na literatura, são: brita, areia, e solo-cimento, podendo estes materiais estarem misturados e encamisados com geossintético. O material inserido no solo em forma de coluna pode ser compactado tanto pela compactação dinâmica, por impactos, como pela vibrocompactação, sendo esta última a técnica mais utilizada (GUNARATNE, 2006).

Segundo Mitchell (1981), as colunas de areia compactadas por métodos vibratórios são executadas pela introdução de uma sonda vibrante no solo que penetra por meio de vibração e, dependendo do caso, pode ser necessário utilizar jatos de água para facilitar a instalação da sonda no solo. Nas colunas de areia, são emitidos esforços de vibração que densificam o solo no seu entorno, formando uma espécie de coluna de solos mais resistente. Para as colunas de brita, o material é inserido no solo e efeitos de vibração são emitidos para a compactação do material lançado no interior da coluna, como ilustra a Figura 2.37.

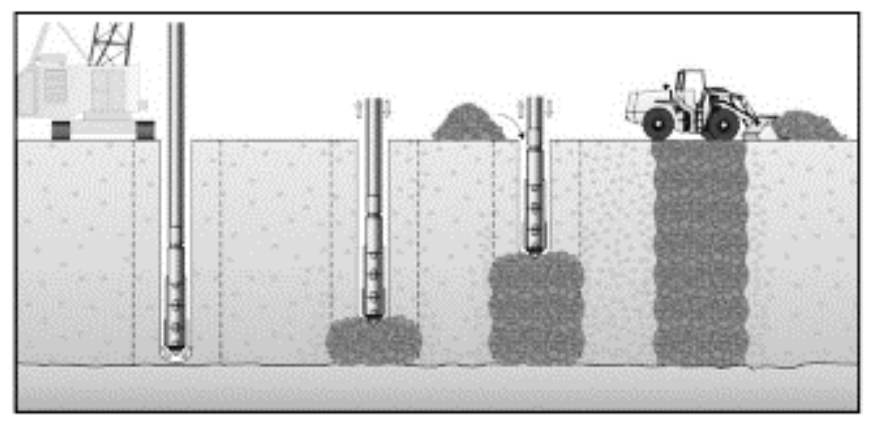

Figura 2.37 - Esquema de execução das colunas de deslocamento Fonte - Gunaratne (2006)

Como efeito da compactação pela execução de colunas de deslocamento tem-se o aumento da capacidade de carga do solo, a redução dos recalques de fundações, melhoramento da estabilidade de taludes, redução da subsidência sísmica, redução do potencial de liquefação e dos efeitos do colapso do solo (GUNARATNE, 2006). 
De acordo com Ablev (1975), este método de compactação foi bastante empregado como reforço de camadas de solo tipo loess com mais de $6 \mathrm{~m}$ de profundidade. Em 1948, segundo o mesmo autor, na URSS, mais de 45 milhões de $\mathrm{m}^{3}$ de solo colapsível foram compactados com colunas de deslocamento.

\subsubsection{Avaliação dos efeitos da compactação do solo}

O controle da compactação em campo deve ser feito com o objetivo de verificar se as propriedades de engenharia previstas no projeto foram realmente obtidas. A avaliação do efeito da compactação no solo geralmente é realizada por meio de ensaios in situ, sendo a prova de carga em placa, e os ensaios de penetração como o CPT e o SPT os mais utilizados para avaliar o desempenho dos métodos de compactação e o ganho de resistência. O CPT apresenta algumas vantagens pois a resistência à penetração do solo é medida de forma contínua ao longo da profundidade da camada de solo.

Segundo Mitchell (1981), para a compactação com colunas de deslocamento, compactação dinâmica e vibrocompactação, os ensaios de penetração devem ser executados em pontos intermediários aos pontos compactados. Desta forma, a estimativa do reforço obtido pela compactação é mais conservadora.

Os efeitos da compactação dinâmica, assim como as outras técnicas de compactação, dependem do tempo transcorrido após o tratamento do material em decorrência da dissipação da poropressão gerada na compactação, devendo esperar um certo tempo para a realização dos ensaios (RESENDE, 2012).

Os resultados obtidos nos ensaios de penetração de solos granulares compactados são, na maioria dos casos, convertidos em valores de densidade relativa antes e após a compactação, por meio de correlações existentes, de modo a avaliar o efeito resultante do melhoramento do solo (MITCHELL, 1981).

\subsubsection{Estabilização de solos colapsíveis com a compactação}

No Brasil, o método de tratamento mais usual corresponde à compactação do solo. Os primeiros relatos do emprego desta técnica, para reduzir a compressibilidade dos solos porosos, foram propostos por Vargas (1951). Na década de 50, o autor utilizou o método para viabilizar a execução de fundações diretas com a finalidade de apoiar o reservatório da Consolação, localizado na cidade de São Paulo e com capacidade de cerca de $50000 \mathrm{~m}^{3}$ de água. 
$\mathrm{Na}$ época da construção do reservatório foi realizado o devido controle tecnológico das camadas compactadas onde foi executada uma prova de carga sobre placa para avaliar o ganho de capacidade de suporte devido ao efeito da compactação (RIBEIRO JUNIOR; FUTAI, 2010). Durante o ensaio realizado por Vargas (1951) não foi medido o valor da sucção do solo, pois na época pouco se conhecia sobre a interferência da sucção no comportamento colapsível dos solos porosos.

Os resultados obtidos na prova de carga em placa estão apresentados na Figura 2.38. Segundo Vargas (1951), a tensão de ruptura $\left(\sigma_{\text {rup }}\right)$ do terreno natural era inicialmente de 160 $\mathrm{kPa}$, aumentando para $550 \mathrm{kPa}$ após a compactação do solo, como pode ser visto na Figura 2.38 .

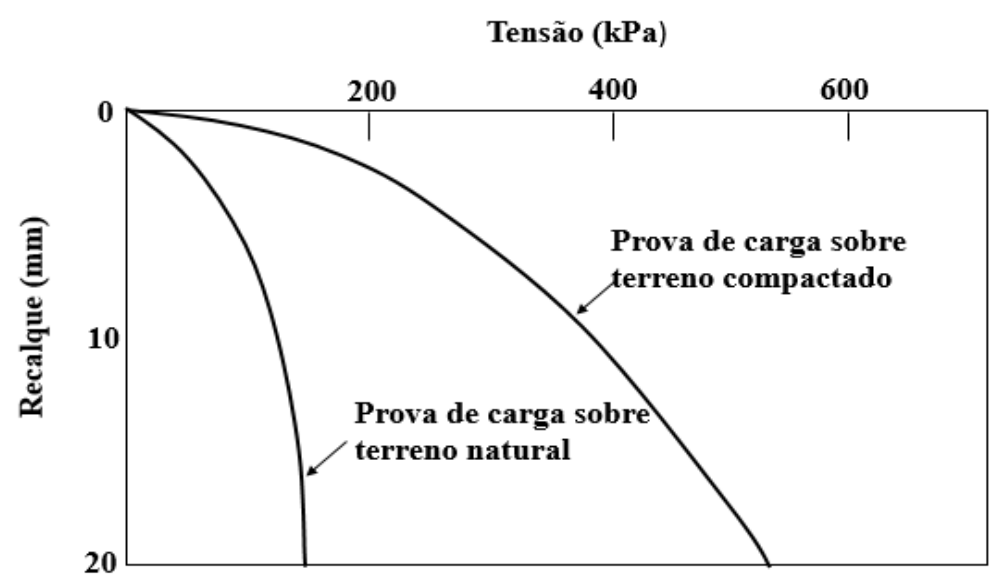

Figura 2.38- Provas de carga direta em placa Fonte - Vargas (1951)

Ribeiro Junior e Futai (2010) realizaram ensaios de compressão odométrica com sucção controlada, curvas de retenção e microscopia eletrônica em amostras de solo natural e compactada com a finalidade de explicar o tratamento e verificar a estabilidade do solo tratado. Os autores observaram durante os ensaios que, o solo compactado é menos dependente do efeito da sucção e constataram que não ocorreu o efeito do colapso nas amostras compactadas.

Souto Silveira e Silveira (1963) também estudaram a técnica de recompactação do solo solto em cava na cidade de São Carlos (SP). Os autores utilizaram como método de avaliação a prova de carga sobre placa e obtiveram como resultado de seus experimentos um aumento da capacidade de carga, após a compactação, de 200\%. Devido aos bons resultados alcançados, este método de melhoria do solo foi adotado na construção de Edifícios no Campus da USP de São Carlos (SP) que até hoje não apresentaram fissuras e recalques relevantes. 
Outro trabalho que também relata o aumento da resistência do solo com a compactação é o de Aflitos et al. (1990) que utiliza ensaios edométricos e provas de carga sobre placa como método de avaliação do reforço. O trabalho foi realizado no município de Bom Jesus, na Bahia, onde verificou-se que a camada colapsível do solo possuía espessura de aproximadamente $4 \mathrm{~m}$ e que, quando compactada nas condições de umidade ótima do Proctor Normal, apresentava coeficiente de permeabilidade muito baixo, sendo considerada praticamente impermeável. Além disso, outro resultado obtido com a compactação do solo foi o potencial de colapso nulo da camada compactada.

Souza (1993) realizou uma pesquisa buscando estudar com exatidão os recalques "in situ" de fundações rasas apoiadas em solos naturais e compactados, no município de Ilha Solteira (SP). Para isto, foram executadas quatro provas de carga diretas a $0,70 \mathrm{~m}$ de profundidade sendo a primeira prova de carga em cava seca, a segunda em cava inundada, a terceira em cava seca com 0,60 m de solo subjacente compactado e a quarta prova de carga em cava inundada com $0,60 \mathrm{~m}$ de solo subjacente compactado. $\mathrm{O}$ autor apresenta em seus resultados a redução da capacidade de carga em torno de $40 \%$ devido ao efeito da inundação do solo. Além disso, para a cava compactada inundada, o autor verificou o acréscimo de $110 \%$ na carga admissível, comparado a cava sem camada compactada, e redução do recalque por colapso em mais de 70\%, demonstrando que o processo de compactação do solo subjacente é eficiente.

Cintra et al. (2003) apresentam uma solução para viabilizar o emprego de fundações por sapatas assentes em solos não saturados com comportamento colapsível. A solução consiste em remover a camada de apoio de cada sapata com espessura correspondente à largura da sapata, e sua reposição em subcamadas compactadas, como ilustra a Figura 2.39.

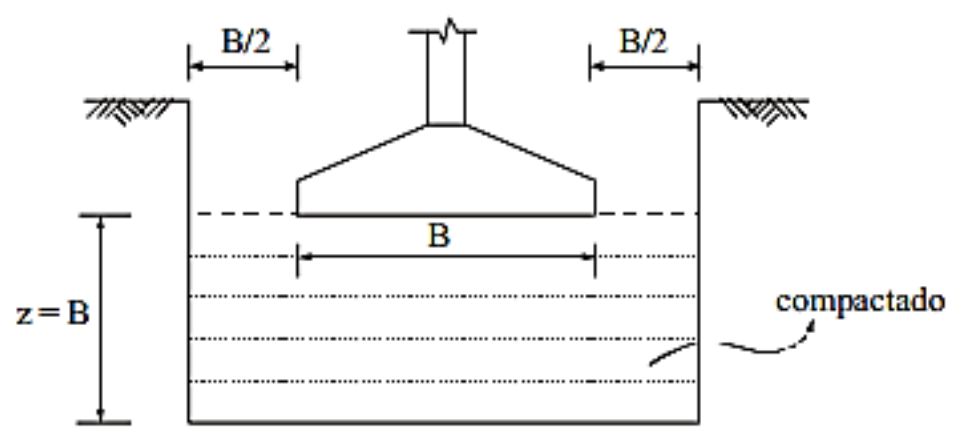

Figura 2.39- Uso de sapatas em solo colapsível compactado Fonte - Cintra et al. (2003)

Os autores justificam a compactação do solo até metade do bulbo de tensões, pois além da questão econômica, na profundidade igual a B (largura da sapata) a parcela de tensão 76 
propagada equivale a somente $25 \%$ da tensão aplicada por uma sapata quadrada segundo a propagação 2:1. Esta solução não elimina completamente o efeito do colapso, mas reduz os recalques a valores aceitáveis. Entretanto, esta solução não é aplicada nos casos de sapatas com grandes dimensões, pois economicamente e tecnicamente pode se tornar inviável remover uma camada de solo muito espessa para recompacta-lo.

Outra explicação para a profundidade de compactação adotada na solução proposta por Cintra et al. (2003) pode ser dada pelo ábaco de Schmertmann (1970). Por meio deste ábaco é possível determinar o fator de influência (Iz) para estimar as deformações verticais no centro de sapatas rígidas apoiadas em solos arenosos. Segundo o ábaco proposto, as maiores deformações do solo acontecem a uma profundidade igual à metade da largura da sapata (B), Figura 2.40.

Souza Neto (2004) também comprovou em laboratório a eficiência da compactação para a redução dos recalques por colapso. Para isto, realizou ensaios edométrico com amostras compactadas inundadas e com amostras com umidade natural. $\mathrm{O}$ objetivo principal destes ensaios foi analisar o efeito da compactação na redução dos recalques por colapso, pela simulação de uma situação real de uma obra em que se tenha adotado a técnica de remoção e compactação do solo (Figura 2.41).

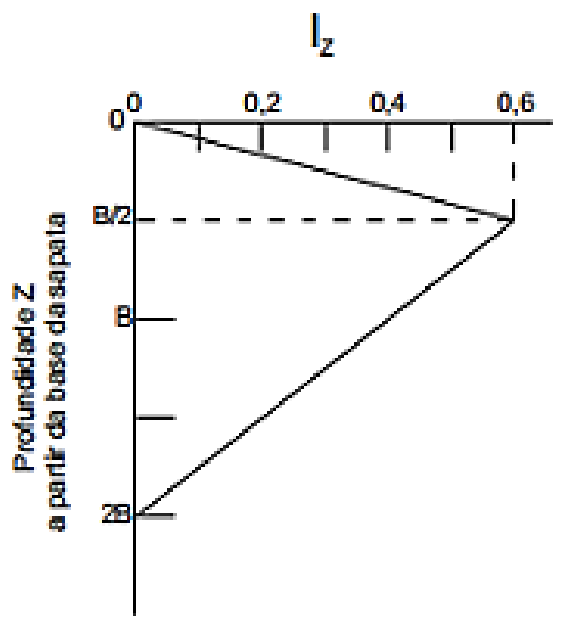

Figura 2.40 - Fator de Influência na deformação vertical Fonte - Adaptado de Schmertmann (1970) 


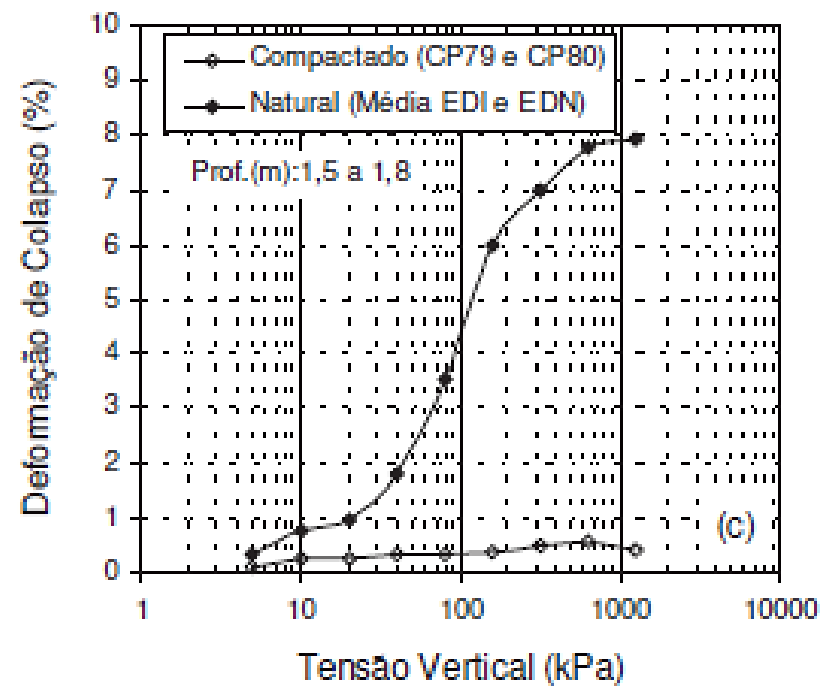

Figura 2.41 - Comparação entre o potencial de colapso do solo compactado e na sua condição natural a uma profundidade de 1,5 a 1,8 metros

Fonte - Neto (2004)

\subsection{TRATAMENTO DE SOLO COM COLUNAS}

A técnica de reforço com colunas de compactação tem sido amplamente utilizada com a finalidade de melhorar as propriedades geotécnicas e reduzir a compressibilidade de solos com baixa resistência. A execução da técnica constitui na introdução de material compactado com grandes energias por esforços dinâmicos, pela vibração ou por grandes pressões. O processo executivo das colunas garante o deslocamento físico das partículas, provocando a redução do índice de vazios do solo e aumentando sua resistência. Existem diversos métodos de reforço com de colunas de compactação e a sua escolha depende de fatores como o tipo de solo do local a ser reforçado, profundidade da camada, tipo e utilização da estrutura projetada e altura do nível d’água.

\subsubsection{Colunas de areia e brita}

O princípio fundamental do reforço com colunas granulares é o deslocamento do solo natural provocado pela introdução de volumes de materiais granulares compactados, geralmente em forma de cilindros, com a finalidade de reduzir recalques e aumentar a capacidade de carga do maciço tratado (PASSOS, 2005). Em cidades como João Pessoa, Natal e Aracajú, $90 \%$ das obras de fundações têm sido projetadas em sapatas com melhoramento prévio do solo de apoio, utilizando-se estacas de areia e brita, ou somente de areia vibrocompactada (GUSMÃO FILHO, 1998). 
Existem duas técnicas de execução das colunas de compactação: a vibro-substituição e o vibro-deslocamento. Na vibro-substituição, inicialmente são executados furos cilíndricos no interior do maciço por meio de uma sonda denominada "torpedo". Nesta técnica empregase água ou ar como fluído de desagregação do solo, espargido pela extremidade da agulha. O material granular é lançado dentro do furo e vibrado dando origem a uma coluna com maior resistência que o solo natural, Figura 2.42.

A reação do solo durante o processo de compactação depende do tipo de solo e da energia empregada, existindo diferença entre a compactação de solos coesivos e não coesivos. Em solos coesivos, a presença dos finos dificulta a transmissão dos efeitos da vibração ao solo, que são absorvidos em um raio relativamente pequeno a partir do ponto de aplicação da compactação. Para estes casos, o aumento da resistência dos solos contendo finos é alcançado através do uso de materiais de preenchimento com maior granulometria, pois as colunas funcionam como drenos, acelerando o adensamento destes solos (SOARES, 2002).
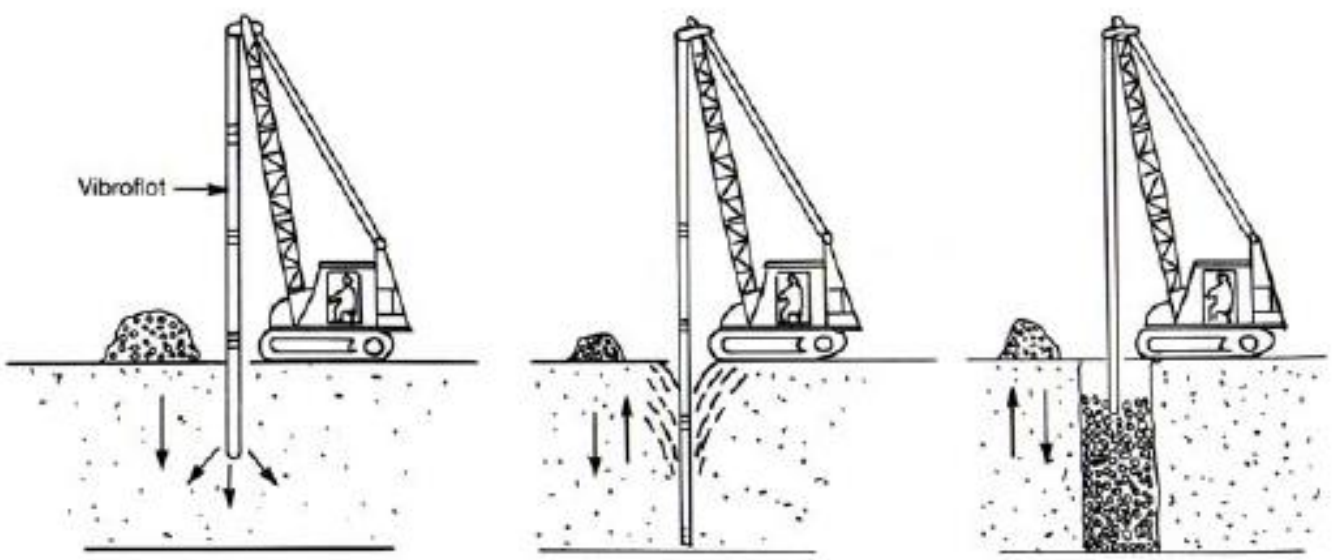

Figura 2.42 - Técnica de execução por meio de vibro-substituição Fonte - Soares (2002)

A técnica de vibro-deslocamento, como relatado por Soares (2002), pode ser executada com torre do tipo Franki, cravando-se inicialmente um tubo de revestimento por meio de vibração e, em seguida, simultaneamente a introdução do material, é feita a retirada do tubo e o apiloamento do material por meio da queda de um pilão, Figura 2.43.

De acordo com Mitchell (1981) o diâmetro das estacas de compactação mais utilizados varia entre 0,6 e 1,0 m e o espaçamento entre as estacas varia de 1,5 a 3,5 m, podendo estar distribuídas de forma retangular ou triangular. Broms (1991) ressalta que as estacas podem ser utilizadas para compactar solos granulares até a profundidade de $25 \mathrm{~m}$ e acrescenta que o seu diâmetro depende da resistência ao cisalhamento e da compressibilidade do solo. Já o 
espaçamento entre as estacas depende da densidade inicial do maciço e do grau de compactação final exigido no projeto.

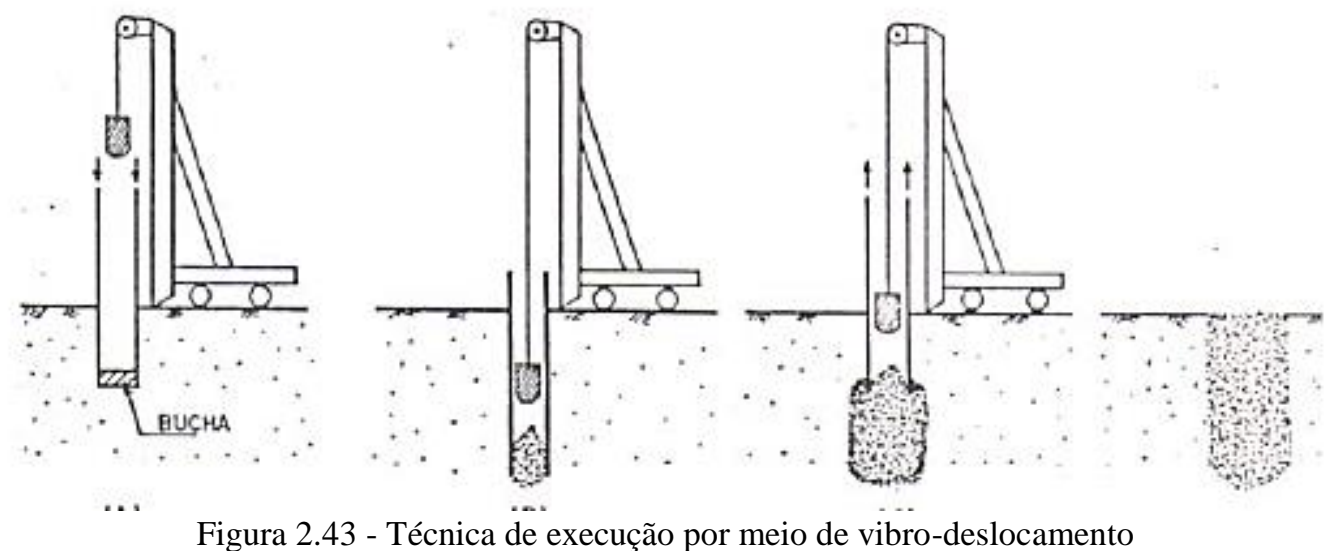

Fonte - Gusmão Filho (1998)

Mitchell (1970), em sua publicação sobre o estado da arte de melhoria de solos, apresenta uma equação para a determinação do espaçamento entre estacas granulares, a fim de se obter um determinado aumento da densidade relativa do solo. A equação proposta, que envolve uma malha de distribuição quadrada, é:

$$
L=\sqrt{\frac{\pi \cdot\left(1+e_{0}\right)}{e-e_{0}}} \cdot d
$$

Sendo:

$\mathrm{L}=$ espaçamento entre colunas;

$\mathrm{e}_{0}=$ índice de vazios inicial do terreno;

e = índice de vazios desejado após o melhoramento;

$\mathrm{d}=$ diâmetro das colunas.

Segundo Gusmão Filho (1998), quando maior for a compacidade inicial do solo melhorado com colunas granulares de compactação, menor será o efeito do reforço do solo. $\mathrm{O}$ autor constatou que para camadas com $\mathrm{N}_{\mathrm{SPT}}$ inicial superior a 20 golpes, verificou-se que o efeito do melhoramento é praticamente nulo para a energia normalmente adotada no Recife. 


\subsubsection{Colunas encapsuladas}

Outra técnica de reforço de solo são as colunas de areia, brita ou até mesmo de solocimento encapsuladas com material geossintético de alta resistência que geralmente é aplicada em solos moles e compressíveis,

Figura 2.44. A função do geotêxtil é garantir a permeabilidade da camada e possibilitar que as colunas funcionem não somente como estruturas resistentes, transmitindo as cargas de fundação aos estratos mais resistentes, mas também como drenos (NOGUEIRA, 2010).

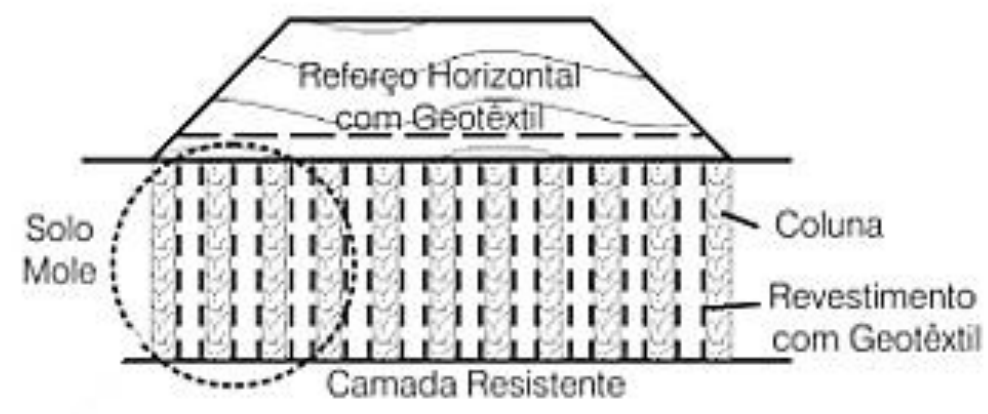

Figura 2.44 - Reforço de solo com colunas encapsuladas Fonte - Araújo (2009)

No trabalho desenvolvido por Ayadat e Hanna (2005), foi avaliado o desempenho de colunas granulares encapsuladas com diferentes tipos de geossintéticos. Neste estudo foi comprovada a eficiência do reforço quanto ao aumento da capacidade de carga e a redução do recalque de solos compressíveis com comportamento colapsível.

De acordo com os mesmos autores, o aumento da capacidade de carga pode ser explicado pelo acréscimo das tensões laterais fornecidas pelo reforço no entorno da coluna. Quanto aos diferentes tipos de geossintéticos avaliados, os autores concluíram que a resistência última das colunas aumentou com o aumento da rigidez do geossintético utilizado como ilustra a Figura 2.45. 


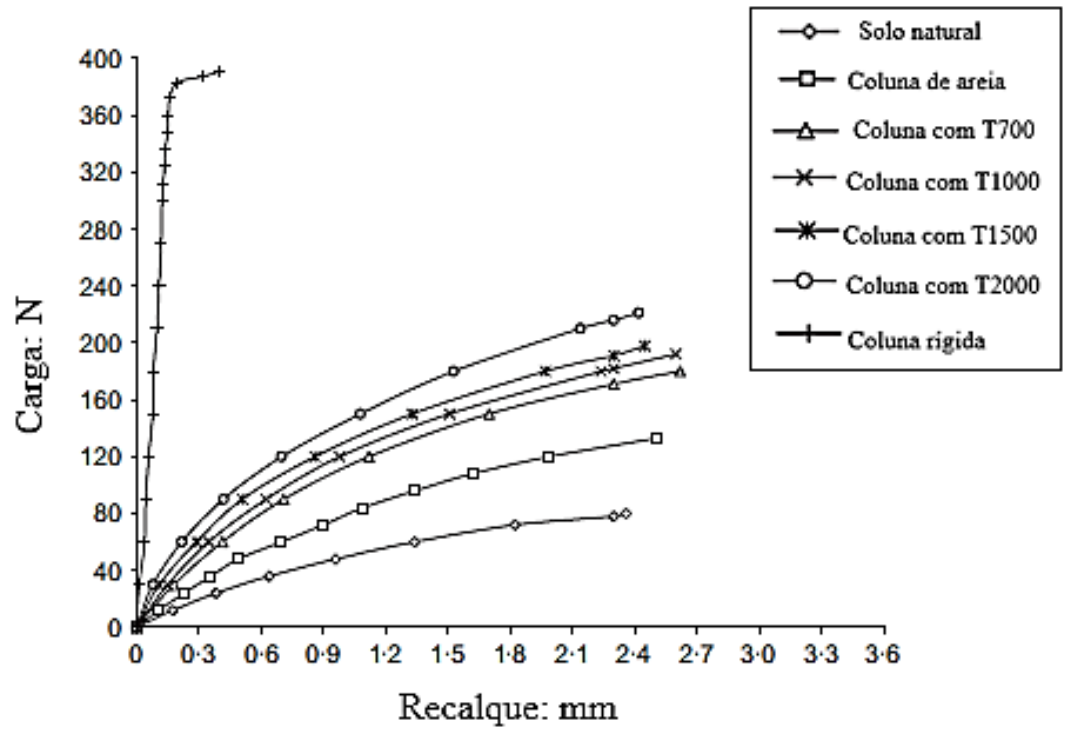

Figura 2.45 - Curva carga x recalque das colunas granulares encapsuladas com material geossintético. Fonte - Ayadat e Hanna (2005)

\subsubsection{Colunas de solo-cimento}

Para Segantini (1994), o solo cimento é um material que apresenta grande potencial de aplicação em fundações diretas para obras de pequeno porte. Contudo, alguns cuidados devem ser considerados em locais que apresentam solos superficiais colapsíveis.

A principal desvantagem da implantação do solo cimento como material de construção é devido à grande variedade dos solos existentes, o que implica na necessidade de ensaios como granulometria, índices físicos e compactação para caracterizar as jazidas que serão utilizadas (SEGANTINI et al. 1994).

Além das colunas de areia e brita, existem também as colunas de solo cimento. Segundo Conciani (2006), a mistura dos materiais solo e cimento já é utilizada no Brasil desde 1948 como técnica de reforço e estabilização do solo. Existem vários fatores que afetam a resistência de um solo misturado com cimento como, por exemplo, o tipo de solo, a dosagem do cimento e a relação água/cimento (FAROUK et al., 2013). Quanto maior o teor de cimento, maior é a resistência da mistura, no entanto, maior é o custo final do reforço. Segundo Farouk et al. (2013), as colunas de solo-cimento podem reduzir os recalques em até $80 \%$ porém, os resultados também dependem do número e da profundidade das colunas.

Conciani (2006) relata o emprego desta técnica como reforço de solo para apoiar um silo na cidade de Primavera do Leste no Mato Grosso. Um ano após a construção, os recalques apresentados corresponderam à metade do valor previsto em projeto. Estes resultados 
mostraram que a técnica de reforço com colunas de solo cimento pode ser implantada em projetos de fundações de obras de pequeno a médio porte.

Andrade Filho (1989) apresentou a utilização de tubulões de solo cimento como técnica de reforço de solo. Os tubulões nada mais são do que estacas como base alargada, que têm como função melhorar a resistência de ponta. Andrade Filho (1989) descreve em seu trabalho um caso real em que o reforço de solo com tubulões de solo cimento foi a solução mais econômica para o caso analisado.

\subsubsection{DSM}

As colunas de solo cimento também podem se apresentar na forma DSM (Deep Soil Mixing). Esta técnica consiste na melhoria do solo por meio de uma mistura "in - situ" do solo com diferentes aglutinantes estabilizadores que reagem com o solo e com a água existente no solo. Tanto a cal como a combinação de cal e cimento podem ser utilizadas no tratamento pela metodologia DSM (MORETTI, 2012). A seleção do agente estabilizador e a determinação da sua dosagem dependem das características do solo local e do aumento de resistência necessária (TAKI e YANG, 1991).

Os componentes estabilizadores são injetados no solo de forma seca ou úmida por meio de um equipamento de perfuração rotativo vazado com pás na sua extremidade. Esta ferramenta promove a perfuração do solo e em seguida o aglutinante é lançado e misturado com solo por meio da rotação das pás, formando as colunas de solo cimento (MORETTI, 2012). A Figura 2.46 ilustra o equipamento utilizado para corte e mistura do solo durante a execução das colunas DSM.

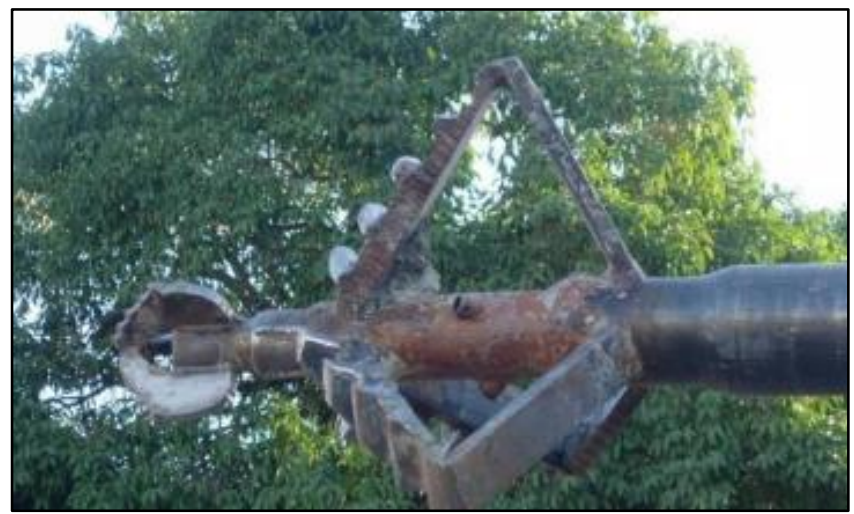

Figura 2.46 - Detalhe da ferramenta utilizada para corte e mistura do solo Fonte - Moretti (2012) 
Segundo Aluce et al. (2000), os diâmetros típicos dessas colunas variam de 0,6 a 1,5 $\mathrm{m}$ e podem atingir até $40 \mathrm{~m}$ de profundidade. Porbaha (1998) relata que os principais objetivos de adotar esta técnica de reforço seriam o aumento da resistência, redução da deformabilidade e permeabilidade, sendo esta última conveniente para os casos de solos contaminados.

As principais aplicações das colunas DSM em obras são: como paredes cut off, paredes de contenção, tratamento do solo, remediação de áreas contaminadas, redução da liquefação de solos arenosos, redução de recalques em aterros rodoviários e aterros de acesso de pontes, escavação de taludes, além de serem utilizadas como reforço de solos orgânicos e argilosos Rathmayer (1996 ${ }^{1}$ apud MORETTI, 2012).

\subsubsection{Jet Grouting}

O jet grouting consiste em uma técnica de tratamento do solo executada pela ação de jato de calda de cimento aplicada por bicos de pequeno diâmetro (2 a $4 \mathrm{~mm}$ ) dispostos lateralmente em uma haste metálica. A haste, cujo diâmetro varia entre 75 e 90 mm, perfura o solo com movimentos rotacionais e a calda de cimento é liberada à alta velocidade, podendo chegar a $400 \mathrm{~m} / \mathrm{s}$. Devido ao grande poder de impacto, o solo in situ é desagregado e misturado com a calda de cimento injetada formando uma massa de solo cimento resistente após a cura da mistura. Quando atingida a profundidade desejada, as hastes são extraídas lentamente, em direção à superfície do terreno, dando origem a colunas de solo cimento, aproximadamente cilíndricas, denominadas de "colunas de jet grouting”, como ilustra a Figura 2.47. O raio da coluna depende da distância até a qual ocorre o esgotamento da pressão de jateamento (CARLETTO, 2009).

Esta técnica de tratamento se aplica a qualquer tipo de solo, não havendo restrições granulométricas, geológicos ou da presença de água. Além disso, as colunas podem ser executadas em várias direções: horizontal, vertical e inclinada (CARLETTO, 2009).

Segundo o mesmo autor, dentre as principais aplicações desta técnica de tratamento destacam-se:

- Estabilização temporária de emboques e desemboques de túneis;

- Formação de cortinas de vedação em barragens;

- Formação de paredes de contenção e lajes de fundo para escavações cilíndricas;

\footnotetext{
${ }^{1}$ RATHMAYER, H. Deep mixing methods for soft subsoil improvement in the Nordic Countries. Proceedings $2^{\text {nd }}$ International Conference on Ground Improvement Geosystems. IS -Tokyo 96, Balkema, Rotterdam, Netherlands, 1996, p. $869-878$. 
- Reforço de fundações;

- Estabilização de taludes contra escorregamentos;

- Execução de colunas em solos moles com a finalidade de receber o carregamento e de transmiti-lo à camada portante subjacente.

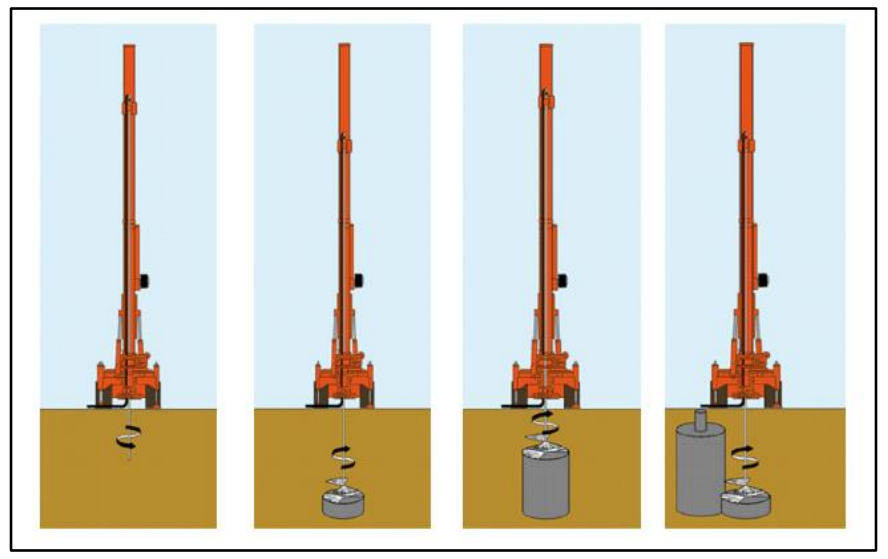

Figura 2.47 - Execução das colunas de jet grouting Fonte - Carletto (2009)

Os sistemas de jet grouting podem ser classificados em monofluido, bifluido ou trifluido conforme o número e o tipo de fluído jateado simultaneamente no interior do solo. No sistema monofluído ocorre o bombeamento apenas da calda de cimento. No bifluido, ocorre o bombeamento da calda de cimento juntamente com ar comprimido, que tem como função aumentar a eficiência do sistema, possibilitando executar colunas com diâmetros maiores. No terceiro e último sistema, o trifluido, ocorre o jateamento de água e ar comprimido que tem como função a abertura do furo e em seguida o jateamento da calda de cimento, Figura 2.48 (ABRAMENTO et al., 1998).
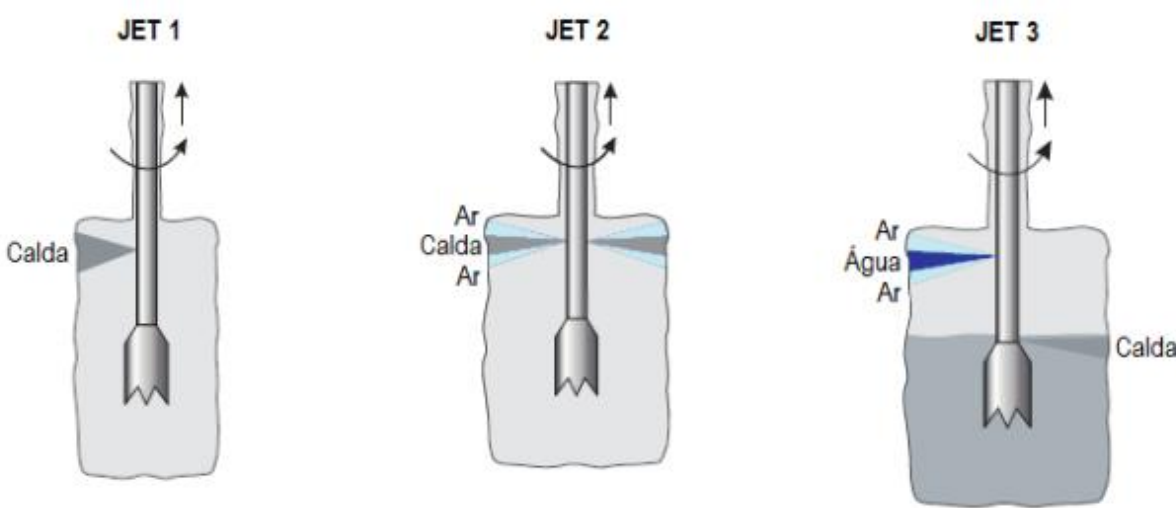

Figura 2.48- Sistemas tradicionais de Jet grouting - monofluido, bifluido e trifluido Fonte - Careltto (2009) 
Os três sistemas também se diferenciam pela capacidade de cada um deles de desagregar o terreno acompanhando a seguinte ordem: trifuido, bifluido e monofluido. A Tabela 2.5 apresenta as variações dos diâmetros das colunas que podem ser executadas com os três diferentes sistemas de execução.

Tabela 2.5- Faixas dos diâmetros das colunas que podem ser obtidos com os diferentes sistemas de execução

\begin{tabular}{|l|ccc|}
\hline \multirow{2}{*}{$\begin{array}{l}\text { Sistemas de } \\
\text { Jet grouting }\end{array}$} & Monofluido & Bifluido & Trifluido \\
\cline { 2 - 4 } & 0,4 a $0,8 \mathrm{~m}$ & 0,9 a $1,8 \mathrm{~m}$ & 1,9 a $3,0 \mathrm{~m}$ \\
\hline
\end{tabular}

\subsection{AVALIAÇÃO DO SOLO REFORÇADO COM COLUNAS}

A eficiência do melhoramento do solo geralmente é avaliada por meio de ensaios in situ. Porém, também pode ser avaliada através de amostras indeformadas ensaiadas em laboratório. Os principais ensaios realizados para este fim são: sondagem SPT, cone, provas de carga em placa e pressiômetro.

\subsubsection{Sondagem SPT}

O ensaio SPT é o mais utilizado para avaliar o ganho de resistência devido ao melhoramento do solo. Através de métodos semi-empíricos de cálculo, é possível determinar a capacidade de carga relativa ao solo antes e após o melhoramento.

A Figura 2.49 ilustra os resultados do ensaio SPT realizado antes e após o melhoramento do solo com estacas de compactação de areia, executadas no nordeste do Brasil, com a finalidade de avaliar o ganho de resistência e a influência radial do efeito da compactação. 


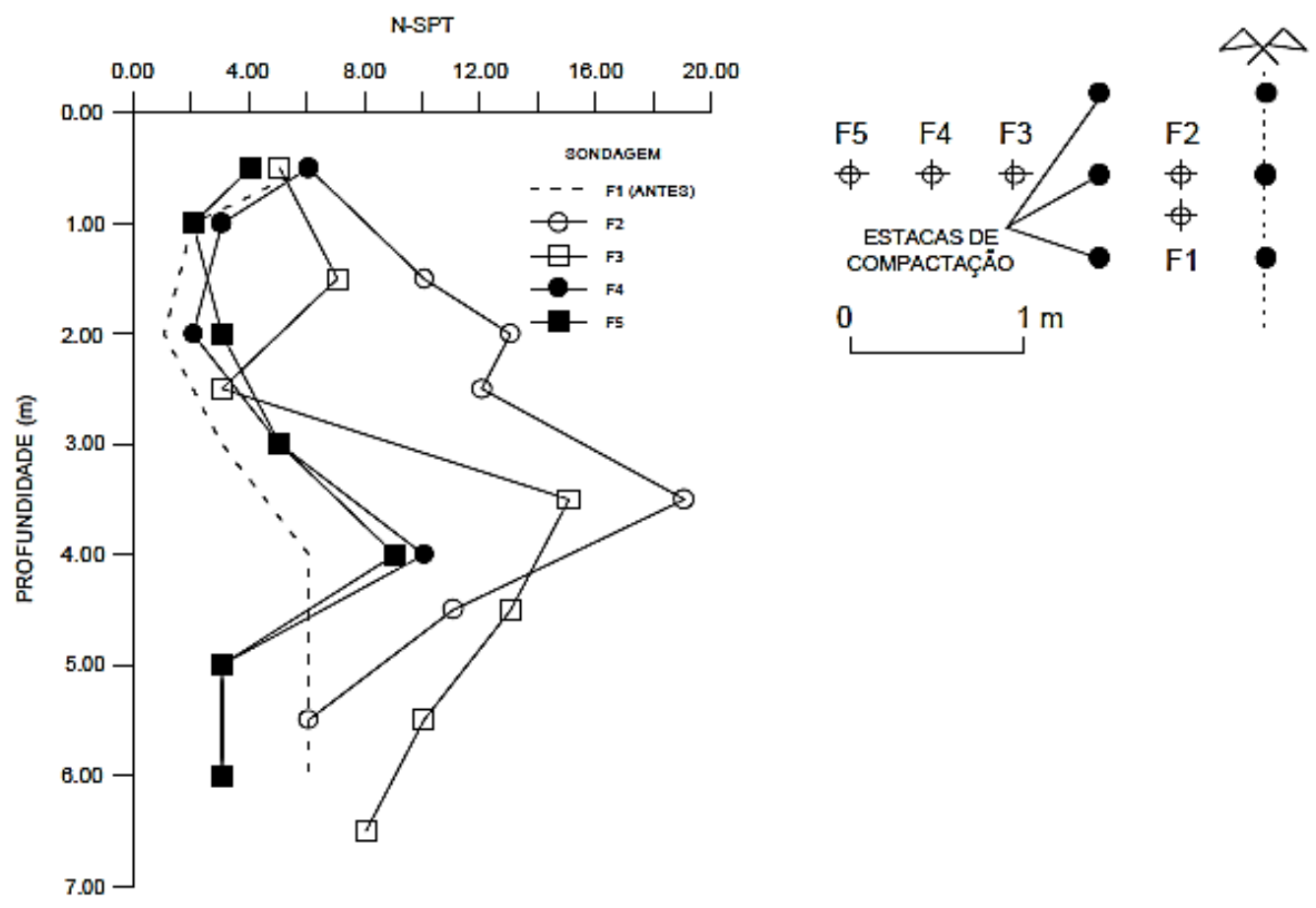

Figura 2.49 - Influência radial do efeito da compactação Fonte - Gusmão (2005)

\subsubsection{Prova de carga em placa}

Os ensaios de prova de carga sobre placa também servem para avaliar o desempenho do solo reforçado. Este ensaio funciona como uma espécie de "modelo reduzido" do elemento de fundação, como por exemplo, uma sapata.

Apesar do seu custo e da dificuldade de execução, devido à necessidade de sistemas de reação, as provas de carga apresentam algumas vantagens por permitir avaliar de três formas o solo reforçado: avaliação do solo entre as colunas de compactação, do elemento de reforço, e do grupo de colunas, como ilustra a Figura 2.50.

a)

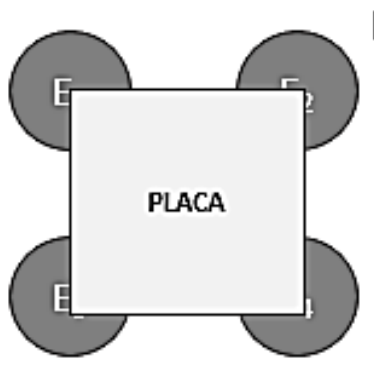

b)

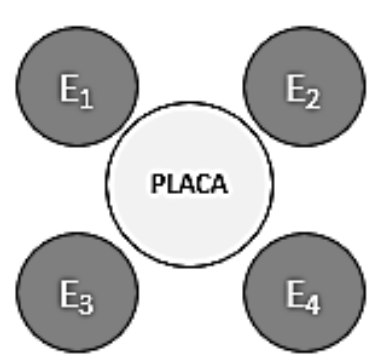

c)
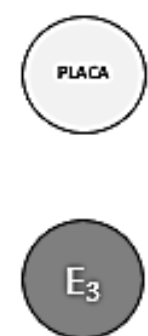

$\mathrm{E}_{2}$

$\mathrm{E}_{4}$

Figura 2.50- Formas de avaliar um solo reforçado com colunas utilizando o ensaio de prova de carga em placa. a) ensaio em um grupo de coluna, b) ensaio no solo entre colunas, c) ensaio no elemento de reforço 


\subsubsection{Ensaio de cone (CPT)}

O ensaio CPT oferece algumas vantagens com relação ao SPT. Neste ensaio o registro de dados é feito de forma contínua ao longo da profundidade, o que permite uma descrição mais detalhada do subsolo. Porém, dependendo da resistência do solo alcançada pelo reforço, pode haver limitação do CPT à penetração devido à carga limite de trabalho do equipamento.

Soares (2002), realizou ensaios CPT para avaliar o efeito do melhoramento do solo com colunas de areia. $\mathrm{O}$ autor executou as colunas com três espaçamentos diferentes 80, 90 e $100 \mathrm{~cm}$ em malha quadrada, e os ensaios CPT foram feitos no centro da malha. Os resultados do ensaio CPT encontrados pelo autor para o solo com e sem reforço, estão apresentados nas Figura 2.51 e 2.52. É possível notar um aumento significativo da resistência de ponta nos primeiros $5 \mathrm{~m}$ de profundidade.
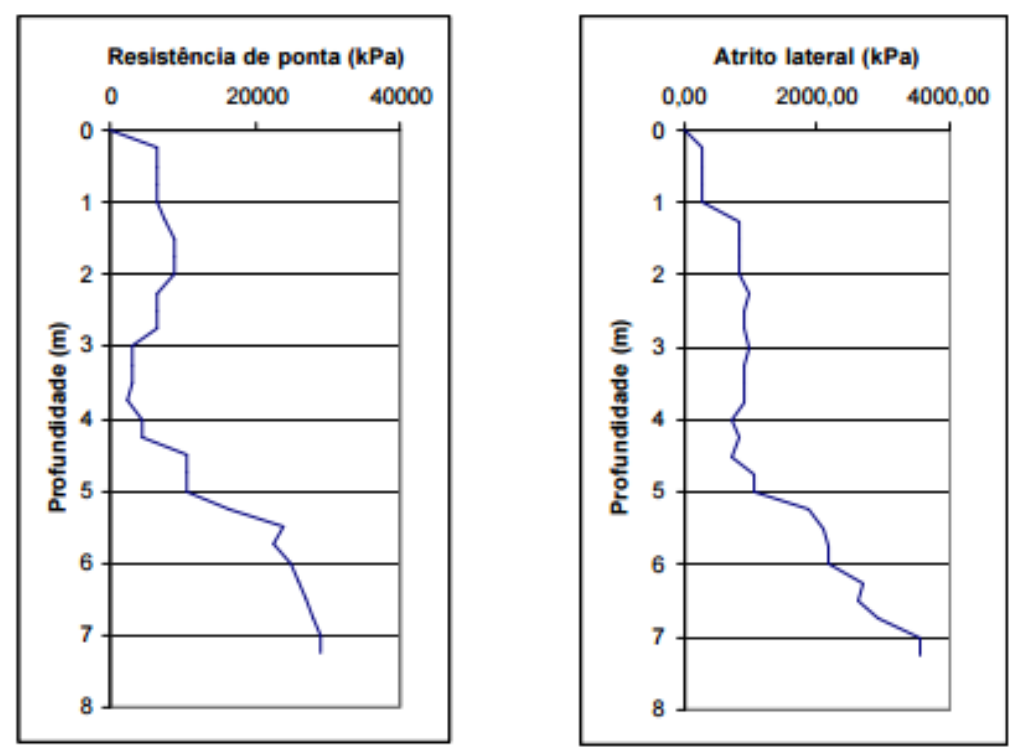

Figura 2.51 - Ensaio de cone em solo natural Fonte - Soares (2002) 

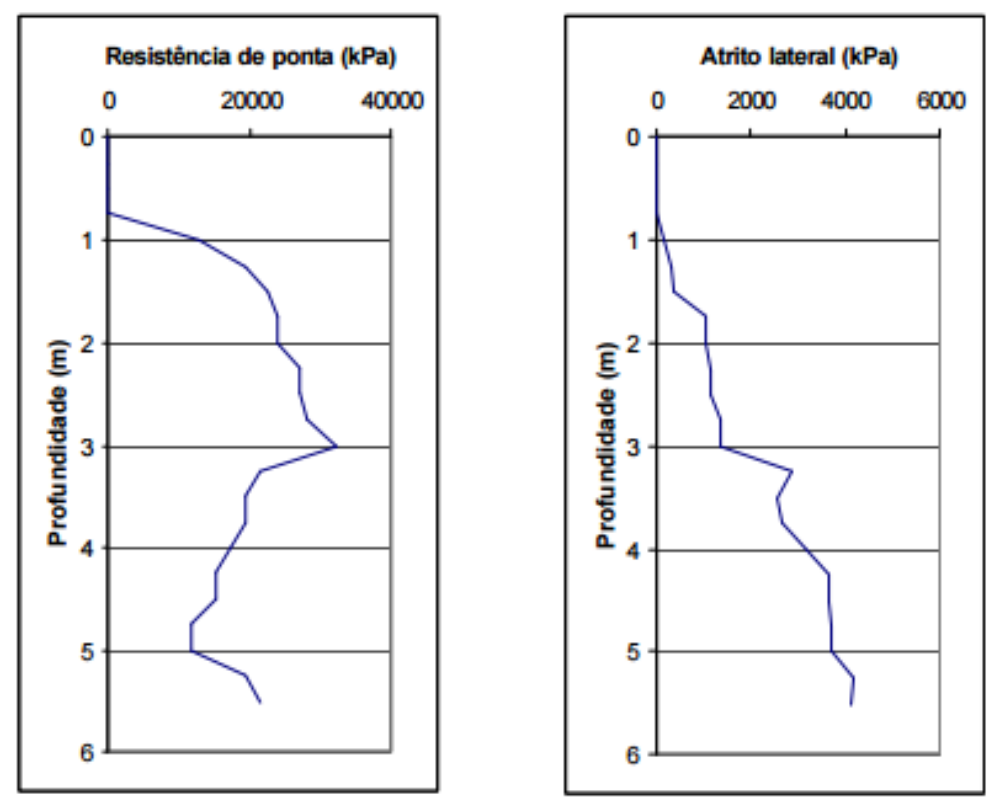

Figura 2.52 - Ensaio de cone em solo com colunas espaçadas de $90 \mathrm{~cm}$ Fonte - Soares (2002)

\subsubsection{Pressiômetro}

O ensaio pressiométrico permite determinar o módulo de deformabilidade do solo, que possui relação direta com a compressibilidade do solo. Este parâmetro é de grande interesse geotécnico, uma vez que é difícil de ser determinado por meio de outros ensaios de campo e laboratório. Este ensaio não é muito usual para analisar o efeito da melhoria do solo.

\subsubsection{Ensaios em laboratório com amostras indeformadas}

Com a retirada de amostras indeformadas do terreno, é possível determinar os índices físicos do solo como peso específico, teor de umidade. Como o volume da amostra é conhecido, pode-se determinar a melhoria do solo por meio da compacidade do solo e da variação do índice de vazios.

\subsubsection{Módulo de deformabilidade a partir de ensaios de campo e laboratório}

O comportamento tensão $x$ deformação típico do solo é não elástico e não linear. A complexidade deste comportamento exige a adoção de simplificações para a determinação de parâmetros, como por exemplo, o módulo de deformabilidade. 
Por meio dos ensaios utilizados para analisar a eficiência do solo reforçado, é possível estimar parâmetros de deformabilidade do solo.

\section{a) SPT e CPT}

Os ensaios SPT e CPT, executados no solo reforçado, podem ser correlacionados pelas equações empíricas existentes para a determinação do módulo de deformabilidade dos solos. Porém, estas correlações não consideram os níveis de tensão aplicados na obra. Alves (1998) em seu trabalho, adota uma correlação empírica para estimar o módulo baseada em um fator $\alpha$, que depende do tipo de solo, e do valor de $\mathrm{N}_{\text {spt }}$ obtido no ensaio.

\section{b) Prova de carga em placa}

Nos ensaios de prova de carga em placa é possível determinar o módulo de deformabiliadade baseado na curva tensão $x$ recalque obtida no ensaio. Para a sua determinação, é feita a simplificação do comportamento do solo para elástico e linear, considerando apensas o trecho retilíneo no início da curva. Segundo Vargas (1977) o trecho de proporcionalidade entre as tensões aplicada e as deformações muitas vezes é limitado aos baixos valores de tensão.

Existem alguns métodos baseados na Teoria da Elasticidade para determinar o módulo de deformabilidade do solo a partir dos resultados de prova de carga em placa. O primeiro método consiste na retroanálise da solução de Boussinesq, válida para placa circular rígida em meio homogêneo. O cálculo do módulo é feito com base na Equação 2.7.

$$
E=\frac{\sigma \cdot D}{\rho} \cdot\left(1-v^{2}\right) \cdot \frac{\pi}{4}
$$

\section{Em que:}

E - módulo de deformabilidade;

$\sigma-$ tensão média aplicada na placa;

D - diâmetro da placa;

$\rho$ - recalque provocado pela tensão $\sigma$;

$v$ - coeficiente de Poisson; 
Para utilizar a equação (2.7), conhecendo-se os valores de tensão e recalque, é necessário adotar um coeficiente de Poisson para o cálculo do módulo de deformabilidade do solo. Os valores típicos de coeficiente de Poisson da maioria dos solos residuais variam de 0,2 a 0,4 (MENEGOTTO, 2004).

Outro modo de determinar o módulo de deformabilidade com base nos ensaios de prova de carga é através da retroanálise dos resultados pelo método de (SCHMERTMANN, 1978). Neste método, dada uma tensão vertical atuando na superfície, considera-se que o meio é elástico, isotópico e homogêneo. Esta teoria, desenvolvida para solos arenosos, se justifica por ser razoável adotar o comportamento tensão $x$ deformação como linear para tensões admissíveis que se afastam dos níveis de ruptura.

Schmertmann (1978) considera que a deformação máxima não ocorre no contato entre a sapata e o solo, mas à uma profundidade, em torno de B/2, sendo B a largura da sapata. A partir desta profundidade, as deformações diminuem gradualmente e são desprezadas em profundidades superiores a $2 \mathrm{~B}$. Consequentemente, o autor propõe um fator de influência $\left(I_{z}\right)$ para o cálculo do recalque cujo diagrama apresenta forma triangular ao longo da profundidade, como ilustra a Figura 2.53. O autor considera dois diagramas diferentes para separar os casos de sapata quadrada e sapata corrida.

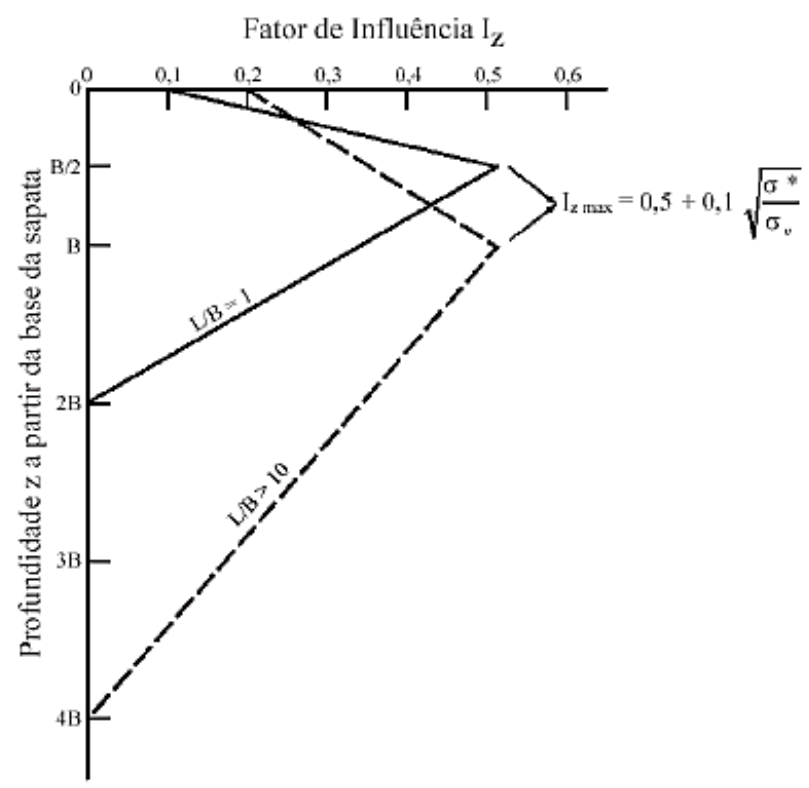

Figura 2.53 - Fator de influência na deformação vertical Fonte - Schmertmann (1978)

A formulação proposta por Schmertmann (1978) baseia-se na equação (2.8) em que considera-se dois parâmetros $\mathrm{C}_{1}$ e $\mathrm{C}_{2}$ no cálculo do recalque. $\mathrm{C}_{1}$ é um fator de correção para 
reduzir o recalque devido ao embutimento da sapata no solo e $\mathrm{C}_{2}$ é outro fator de correção baseado na parcela de recalque que se desenvolve com o tempo devido ao efeito de creep.

Para o cálculo do módulo é feita a subdivisão em camadas, sendo o recalque final correspondente ao somatório do recalque de cada i-ésima camada.

$$
\rho_{d}=C_{1} \cdot C_{2} \cdot \sigma^{*} \cdot \sum_{i=1}^{n}\left(\frac{I_{z}}{E_{s}} \cdot \Delta_{z}\right)_{i}
$$

$\mathrm{I}_{\mathrm{z}}=$ fator de influência

$\mathrm{C}_{1}=$ fator de correção devido ao embutimento da sapata

$\mathrm{C}_{2}=$ fator de correção devido ao efeito do tempo

$\mathrm{E}_{\mathrm{s}}=$ módulo de deformabilidade da camada

$\sigma^{*}=$ tensão líquida aplicada pela sapata

$\Delta_{\mathrm{z}}=$ espessura da i-ésima camada

Como resultados das provas de carga tem-se as tensões aplicadas e os recalques correspondentes a cada nível de tensão. Para o cálculo do módulo considera-se que o mesmo é constante em cada subcamada e que o somatório dos recalques para cada subcamada, à um determinado nível de tensão, é igual ao recalque final encontrado na prova de carga. Desta forma, é possível determinar um módulo de deformabilidade do solo a partir da retroanálise pelo método de Schmertmann (1978).

\section{c) Pressiômetro}

No ensaio pressiométrico uma sonda é colocada em um pré-furo, com diâmetro menor ou igual a 1,15 vezes o diâmetro da sonda. A sonda é colocada dentro do furo, até atingir a profundidade desejada e em seguida é feita a expansão da sonda devido à aplicação de incrementos de pressão.

Como resultado dos ensaios pressiométricos em campo tem-se uma curva que relaciona a pressão e o volume de fluído pressurizado introduzido no sistema para a expansão da sonda em intervalos de tempo considerados (SALLES, 2013).

O módulo de deformabilidade do solo pode ser determinado EPMT é calculado pela declividade da curva pseudoelástica corrigida. A equação utilizada para o cálculo do módulo é: 


$$
E_{P M T}=2 \cdot(1+v)\left[V_{i}+\left(\frac{V_{f}-V_{0}}{2}\right)\right] \frac{d P}{d V}
$$

Onde $\mathrm{V}_{\mathrm{i}}$ é o volume inicial da célula de medição, $v$ é o coeficiente de poisson do solo, $\mathrm{V}_{\mathrm{f}}$ é o volume da cavidade no fim do trecho elástico e $\mathrm{V}_{0}$ é o volume da cavidade no início do trecho elástico.

\section{d) Amostras indeformadas}

O módulo de deformabilidade E do solo também pode ser determinado por ensaios triaxiais realizados em laboratório com as amostras de solo retiradas do campo. Neste ensaio é possível obter a curva tensão $x$ deformação, Figura 2.54. Nota-se que o comportamento da curva obtida neste ensaio é não linear. Como não se trata de uma reta, a relação entre a tensão e a deformação do solo não pode ser expressa por um único valor, portanto é necessário definir métodos para se calcular o módulo de deformabilidade (MENEGOTTO, 2004).

De acordo com Pinto (1996), dois procedimentos para a determinação do módulo de deformabilidade são geralmente empregados: módulo de deformabilidade tangencial $\left(\mathrm{E}_{\mathrm{tg}}\right)$ e módulo de deformabilidade secante $\left(\mathrm{E}_{\mathrm{sec}}\right)$. $\mathrm{O} \mathrm{E}_{\mathrm{tg}}$ relaciona a tensão e a deformação do solo em um ponto considerado e o $E_{\text {sec }}$ relaciona a tensão e a deformação entre dois pontos. Este módulo varia de acordo com o estágio de carregamento, por isso é usual referencia-lo para um determinado nível de tensão ou deformação. Normalmente, o módulo secante mais utilizado é aquele a partir da origem, indicado pelo símbolo $\mathrm{E}_{\mathrm{s} 0}$. $\mathrm{Na}$ origem, os dois módulos são equivalentes, caracterizando o módulo tangencial inicial $\left(\mathrm{E}_{0}\right)$. $\mathrm{O}$ símbolo $\mathrm{E}_{50}$ corresponde ao módulo sob um determinado nível de tensão igual a 50\% daquele que provocaria a ruptura do solo, indicando portanto, a deformabilidade do solo quando solicitado por uma tensão com fator de segurança igual a dois. 


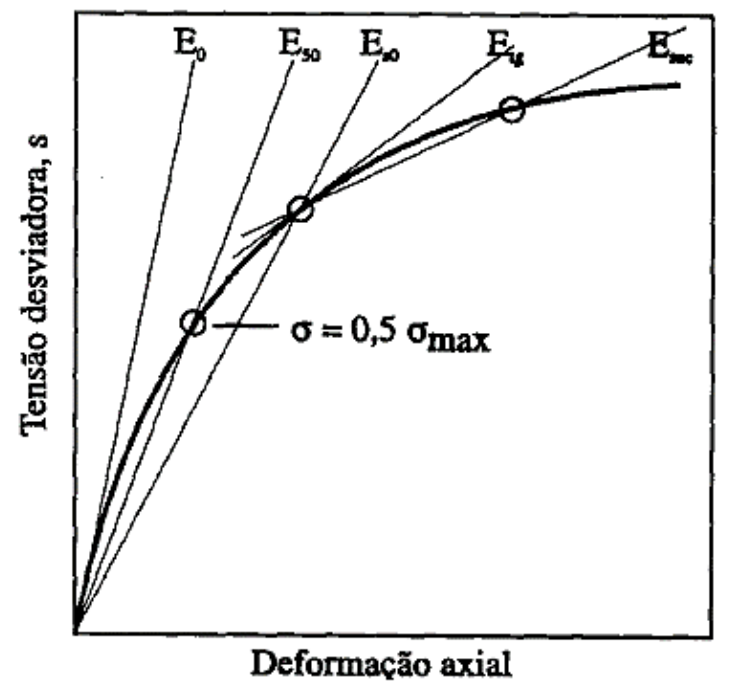

Figura 2.54 - Curva típica do ensaio triaxial e definição dos módulos

\subsection{SAPATAS APOIADAS EM SOLO REFORÇADO COM COLUNAS}

Dentre as várias técnicas de reforço de solo, a inclusão de colunas tem sido considerada uma das mais versáteis e com melhores resultados com relação ao custo de implantação (ALAMGIR et al., 1996). Diferentes técnicas de instalação foram desenvolvidas para os vários tipos de colunas executadas como reforço em solos arenosos soltos e solos compressíveis. Para compreender o comportamento das colunas utilizadas como reforço de fundações é necessário analisar o desempenho isolado dos elementos e do conjunto constituinte no sistema. Existem uma série de abordagens teóricas e empíricas na literatura para avaliar o comportamento do solo reforçado com colunas, com diferentes modos de analisar a ruptura e a distribuição de tensões no solo.

\subsubsection{Sapata estaqueada}

Para compreender melhor o comportamento do solo reforçado com colunas, uma forma de analisar é considera-lo como a associação de dois elementos de fundações, sapatas e estacas, sendo as colunas associadas às estacas. Segundo Vesic (1974² apud PASSOS, 2005), a capacidade de carga de um grupo de estacas em solos granulares é superior à soma das capacidades das cargas individuais das estacas. Porém, devido à complexidade em determinar

\footnotetext{
${ }^{2}$ VESIC, A. S. Bearing capacity of shallow foundations. Handbook of Foundations Engineering, Winterkorn, H. and Fang, H. Y., Chapter 3, New York, 1974, p. $121-147$. 
este acréscimo de resistência, a prática define que, nestes casos, a capacidade de carga seja dada pela soma das capacidades de carga das estacas isoladas.

O mecanismo de ruptura de um grupo de estacas é diferente do mecanismo de ruptura de uma estaca isolada. Isto ocorre pois, para o grupo de estacas há a superposição dos efeitos dos bulbos de pressão. De acordo com Silva (1996), quando há a aproximação dos elementos de fundação, ocorre a interação entre os elementos adjacentes, modificando as tensões normais atuantes na face dos elementos.

Nas sapatas estaqueadas, o contato da sapata com o solo aumenta as tensões verticais e horizontais na interface estaca/solo, a tensão normal e consequentemente a resistência por cisalhamento na interface. Além disso, parte do esforço aplicado pela sapata é absorvido pelo solo subjacente, sendo as estacas responsáveis por absorver o restante da carga. Fisicamente um bloco de estacas poderia ser considerado como uma "sapata estaqueada" quando o bloco de coroamento estiver em contato com o solo, pois este funciona como um elemento de fundação superficial (SALES, 2000).

Kishida e Meyerhof (1965) realizaram estudos teóricos quanto à contribuição do bloco de fundação apoiado no solo e sobre um grupo de estacas em termos de capacidade de carga. Destes estudos surgiram duas possíveis formas de se considerar a ruptura do sistema:

a) Para estacas pouco espaçadas, há uma tendência de ruptura de um conjunto, como se fosse uma única estaca, ou um “tubulão equivalente". Neste caso, a capacidade de carga do sistema deve ser considerada como a capacidade de carga do "tubulão equivalente", somada à capacidade de carga do bloco superficial, considerando apenas a área do bloco externa àquela ocupada pelo tubulão, com ilustra a Figura 2.55.a.

b) Para estacas com grandes espaçamentos, a capacidade de carga do sistema seria a soma da capacidade de carga do grupo de estacas com a capacidade de carga do bloco, como ilustra a Figura 2.55.b. 


\section{SAPATA ESTAQUEADA}

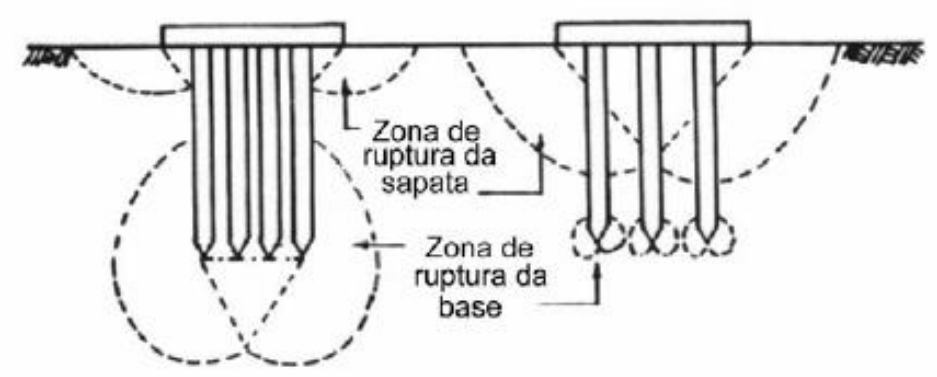

(a)

(b)

Figura 2.55- Formas de ruptura de uma sapata estaqueada Fonte - Sales (2000)

Akinmusuru (1980) estudou a influência da sapata na capacidade de carga do grupo de estacas. $\mathrm{O}$ autor realizou uma série de testes em laboratório de sapatas estaqueadas em areia, utilizando modelos reduzidos e concluiu que a capacidade de carga de uma sapata estaqueada é superior à soma da capacidade de carga da sapata com a capacidade do grupo de estacas. Os resultados foram expressos na seguinte equação:

$Q_{t}=\alpha \cdot Q_{s}+\beta \cdot Q_{c}$

Sendo:

$\mathrm{Q}_{\mathrm{t}}$ - capacidade de carga da sapata estaqueada;

$\mathrm{Q}_{\mathrm{s}}$ - Capacidade de carga do grupo de estacas;

$\mathrm{Q}_{\mathrm{c}}$ - Capacidade de carga da sapata;

$\alpha$ - Fator de incremento de capacidade de carga do grupo de estacas devido à interação, sendo geralmente maior do que 1 e função do comprimento das estacas e tamanho das sapatas;

$\beta$ - Fator de incremento de capacidade de carga de sapata devido à presença do grupo de estacas.

Liu et al. (1985) realizaram uma série de 51 provas de carga em estacas isoladas e em grupo de estacas, variando características como: diâmetro, comprimento, espaçamento e números de estaca no grupo. Os ensaios foram executados na condição natural e inundada do solo, considerando o efeito do bloco apoiado no solo.

Os autores observaram que no teste com grupo de nove estacas, espaçadas com distância de três vezes o diâmetro e bloco apoiado sobre o solo, que a estaca central absorveu a menor carga dentre as estacas até que a capacidade de carga máxima das estacas externas fosse 96 
atingida. Porém, logo após alcançar este máximo, a estaca central passou a absorver a maior carga. Os autores atribuíram este fato ao acréscimo das tensões horizontais de confinamento das estacas.

Os autores também notaram que a relação entre o comprimento (L) das estacas e o tamanho do bloco (B) influenciava na mobilização do atrito lateral e observaram que para valores de L/B maiores do que 1,5, o atrito lateral foi maior do que o encontrado considerando uma estaca isolada. No entanto, quando a relação L/B era menor do que 1 , o valor do atrito lateral considerando o grupo era menor do que para uma estaca isolada.

Com base nos resultados encontrados, os autores propuseram uma nova expressão para calcular a capacidade de carga de um bloco estaqueado:

$$
Q_{t}=N \cdot\left(\eta_{S} \cdot Q_{s u}+\eta_{p} \cdot Q_{p u}\right)+Q_{c}
$$

Em que:

$Q_{t}$ - Capacidade de carga última do bloco estaqueado;

$Q_{c}$ - Capacidade de carga do bloco isolado;

$Q_{s u}$ - Atrito lateral último de uma estaca isolada;

$Q_{p u}$ - Carga última de ponta de uma estaca isolada;

$N$ - Número de estacas;

$\eta_{s^{-}}$Fator de influência do atrito lateral devido à interação entre bloco/solo/estaca;

$\eta_{p}$ - Fator de influência na carga da ponta devido à interação entre bloco/solo/estaca.

Os fatores $\eta_{\mathrm{s}}$ e $\eta_{\mathrm{b}}$ são definidos como:

$$
\begin{aligned}
& \eta_{s}=G_{s} \cdot C_{s} \\
& \eta_{p}=G_{p} \cdot C_{p}
\end{aligned}
$$

Sendo que $G_{s}$ e $G_{p}$ são os coeficientes que consideram, respectivamente, o efeito da interação estaca-solo na resistência lateral e na resistência de ponta; e $C_{s}$ e $C_{p}$ são os coeficientes que consideram o efeito da interação bloco/estaca/solo na resistência lateral e na resistência de ponta.

Liu et al. (1985) apresentou as equações auxiliares para o cálculo da capacidade de carga do sistema de fundação, lembrando que os coeficientes são válidos para solos arenosos. 


$$
\begin{aligned}
G_{s} & =\frac{\alpha}{\ln \{e+1-[(m+n) / 2 n]\}} \\
G_{p} & =\frac{8}{\left\{[(s / d)-3]^{2}+9\right\}} \\
C_{s} & =1+0,1 \cdot(s / d)-0,9 \cdot B_{c} / H \\
C_{p} & =1+0,2 \cdot(s / d) \cdot\left(B_{c} / H\right)
\end{aligned}
$$

Onde:

$s$ - Espaçamento entre estacas;

$d$ - Diâmetro da estaca;

$m$ - Maior dimensão do bloco;

$n$ - Menor dimensão do bloco;

$B_{c}$ - Média geométrica entre o comprimento e a largura do bloco;

$H$ - Comprimento da estaca.

\subsubsection{Módulo de Elasticidade equivalente para o solo reforçado}

De acordo com Burland et al. (1977 ${ }^{3}$ apud SALES, 2000) a grande maioria dos projetos de fundações consideram apenas o critério da capacidade de carga (estado limite último) no dimensionamento das estacas. Estes autores sugerem que seria mais econômico buscar um projeto com o número mínimo de estacas que conduzisse a valores de recalque aceitáveis à fundação. Foram eles que introduziram o termo "elementos redutores de recalque" considerando o grupo de estacas em que o critério principal para o dimensionamento seria o recalque admissível.

Alves et al. (2000) estudaram um outro método de cálculo que considerou o efeito do recalque do grupo de estacas. Os autores propuseram a aproximação da camada de solo melhorado com estacas de compactação a uma camada homogênea equivalente mais resistente. A técnica consistiu em determinar, por tentativa e erro, o módulo de elasticidade equivalente, considerando o meio homogêneo, que apresentasse o mesmo recalque do meio elástico heterogêneo (solo melhorado com colunas). Para a realização desta análise, os autores utilizaram o programa PROGEO considerando o modelo de deformação plana para estimar o módulo equivalente da camada melhorada. Os parâmetros considerados para os cálculos foram:

\footnotetext{
${ }^{3}$ BURLAND, J.; BROMSS, B.; MELLO, V. Behavior of foundations and Structures. State-of-art volume. [Proceedings...] $9^{\text {th }}$ International Society of Soils Mechanics and Geotechnical Engineering, 1977, p. $495-546$. 98
} 
- Variação da relação espaçamento/diâmetro das colunas. Foram geradas três malhas com as seguintes relações: 2, 4 e 8;

- Módulo de elasticidade das estacas. Foram considerados dois módulos para as estacas granulares: $500 \mathrm{MPa}$ para estacas granulares com cimento e $100 \mathrm{MPa}$ para estacas granulares sem cimento;

- Módulo de elasticidade do terreno melhorado. Quatro valores de módulos de elasticidade foram considerados: 12,5;25; 50; $100 \mathrm{MPa}$.

Os resultados obtidos, em função do espaçamento relativo entre as colunas $(s)$ e do diâmetro das colunas $(d)$, estão apresentados em dois ábacos, ilustrados nas Figura 2.56 e 2.57, sendo que o primeiro considera o módulo de elasticidade da coluna de $100 \mathrm{MPa}$ e o segundo o módulo de 500 MPa. Segundo Alves (1998), o módulo de elasticidade (E) do solo melhorado pode ser estimado pela equação:

$$
E=\alpha \cdot N_{S P T}
$$

Sendo $\alpha$ igual a 1,5 para solos arenosos, 3,0 para solos finos, e 2,5 para areias finas (siltosas ou argilosas) e N $\mathrm{N}_{\text {SPT }}$ o valor previsto pelo modelo proposto pelo autor obtido na Figura 2.58.

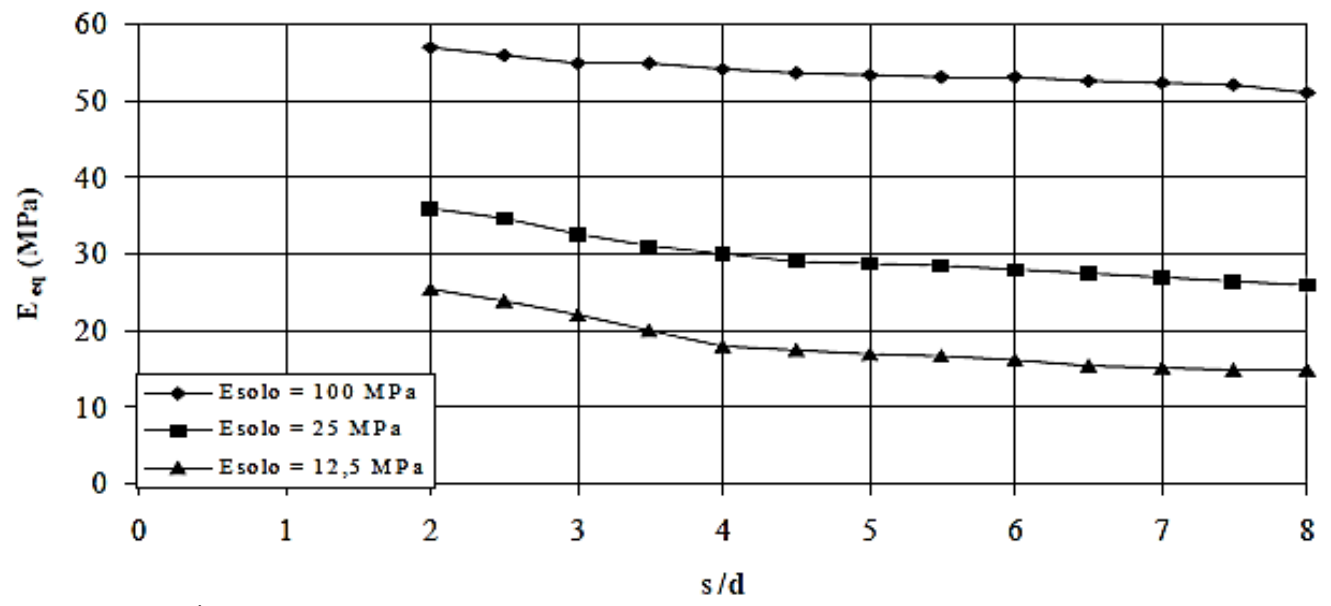

Figura 2.56- Ábaco para estimativa do módulo de elasticidade equivalente Ecoluna $=100 \mathrm{MPa}$ Fonte - Alves et al. (2000) 


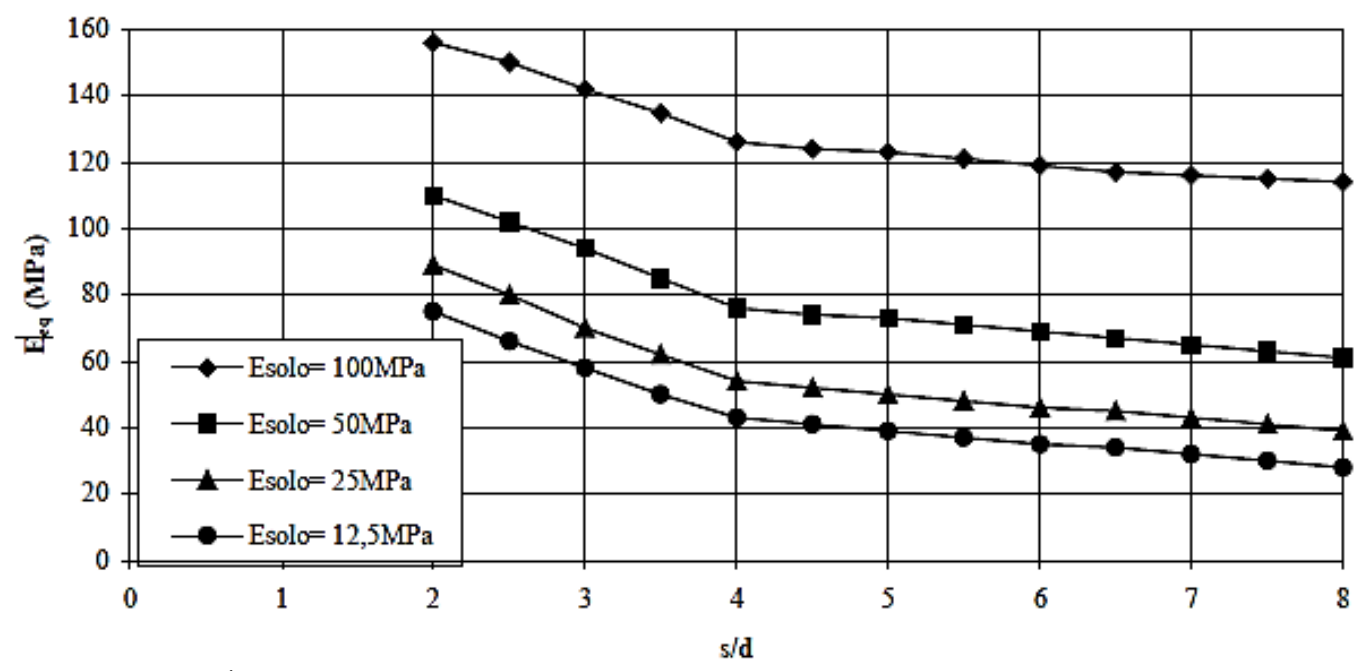

Figura 2.57- Ábaco para estimativa do módulo de elasticidade equivalente Ecoluna $=500 \mathrm{Mpa}$ Fonte - Alves et al. (2000)

Alves (1998) estudou diversos métodos de previsão do acréscimo no valor do $\mathrm{N}_{\mathrm{SPT}}$ do solo reforçado com colunas de areia e brita e propôs uma equação que prevê o efeito da redução dos vazios devido à compactação. Segundo o mesmo autor, o aumento da compacidade no entorno da coluna possui a forma aproximada de um sino. Na equação proposta, é possível calcular a redução dos vazios devido a cravação da coluna em um ponto situado a uma distância $r$ da coluna.

$$
\Delta_{n}=\frac{1}{8} \cdot n_{0}^{2} \cdot e^{\frac{1 \cdot r^{2} \cdot n_{0}{ }^{2}}{2 . d^{2}}}
$$

Para o cálculo da redução do índice de vazios é necessário conhecer três parâmetros influentes na compactação: o diâmetro $d$ da coluna, a compacidade inicial do terreno $n_{0}$ e a distância $r$ entre o ponto analisado e a coluna. Para o caso de uma malha de colunas, ocorre a superposição do efeito entre as colunas.

Alves et al. (2000) apresentam um ábaco, ilustrado na Figura 2.58, para o projeto de uma malha quadrada de colunas de areia e brita. Os autores consideram como $s$ o espaçamento de eixo a eixo entre as colunas e $d$ o diâmetro das colunas. Pelo ábaco é possível determinar o valor do $\mathrm{N}_{\mathrm{SPT}}$ final do solo reforçado, considerando os valores do $\mathrm{N}_{\mathrm{SPT}}$ original e de $\sigma^{\prime}{ }_{v}$, que varia entre 30 e $70 \mathrm{kN} / \mathrm{m}^{2}$.

A eficiência do melhoramento do solo por meio de estacas de compactação é influenciada pela compacidade inicial do solo, granulometria e energia de compactação adotada. De acordo com Gusmão Filho \& Gusmão (1994), o aumento da energia de 100 
compactação implica em uma maior eficiência do melhoramento. Porém, há um limite de compactação em que, o aumento da energia não mais influencia no melhoramento.

Segundo Sousa (2003), outro fato observado nas obras é que o melhoramento possui baixa eficiência até $1 \mathrm{~m}$ de profundidade da superfície reforçada. Por isso, as sapatas devem ser executadas com embutimento mínimo de $1 \mathrm{~m}$ em relação à superfície melhorada.

O mesmo autor acrescenta que a presença de estacas granulares no terreno provoca o aumento da rigidez horizontal e vertical, resultando em uma menor compressibilidade. $\mathrm{O}$ parâmetro geotécnico diretamente relacionado a compressibilidade do solo é o seu índice de vazios $(e)$. Quando $e_{\text {natural }}$ se encontra próximo ao $e_{\text {máximo }}$ o solo está no seu estado mais fofo, o que torna possível uma melhoria significativa. Quando o $e_{\text {natural }}$ se encontra próximo ao $e_{\text {mínimo, }}$ dificilmente será obtida melhoria com a compactação do solo.

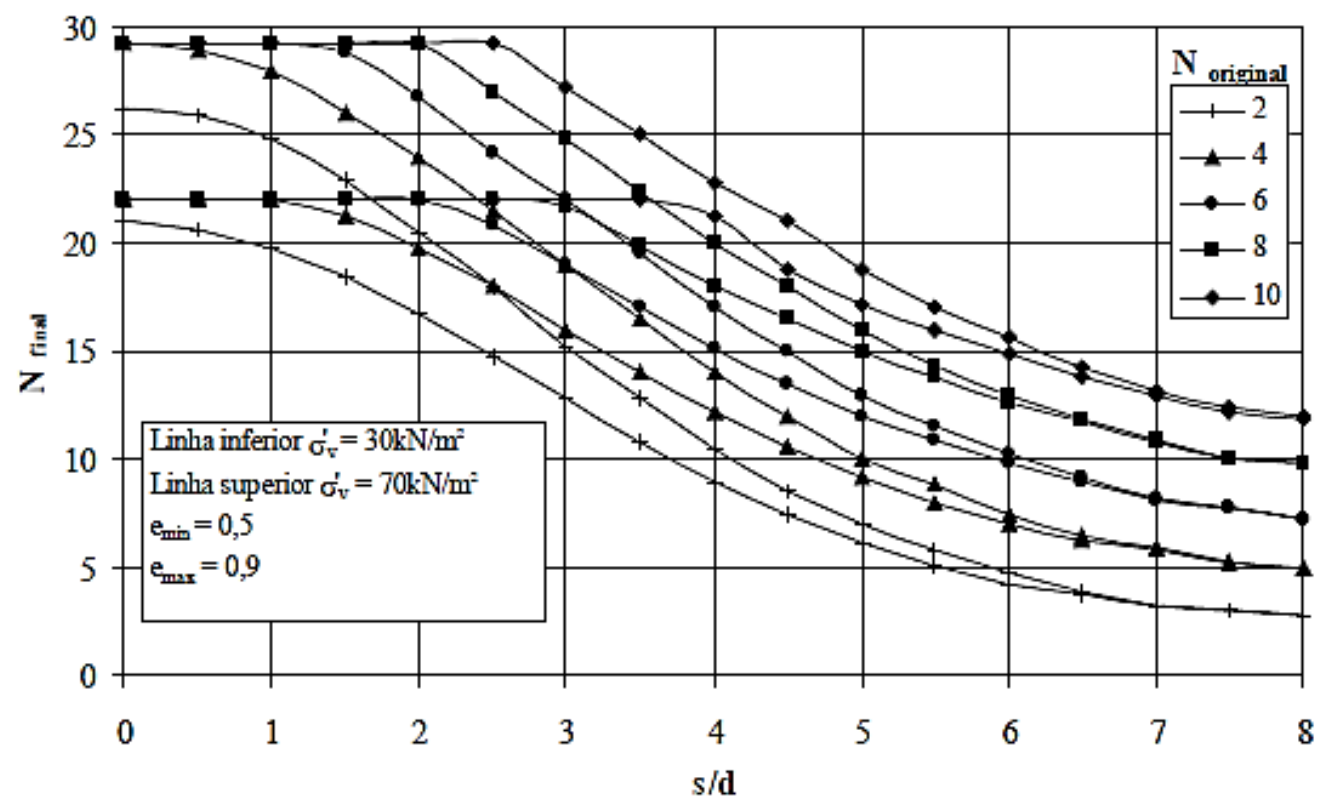

Figura 2.58 - Ábaco para o projeto de malha de colunas de areia e brita Fonte - Alves et al. (2000)

\subsubsection{Análise da rigidez e da transferência de carga do solo reforçado}

Sabe-se que quando uma carga é aplicada pela sapata em um solo reforçado com colunas, parte desta carga é absorvida pelo solo entre colunas e parte é absorvida pelas colunas. Estas parcelas dependem do tipo de estaca (areia, brita, argamassa) e das condições de contorno da ponta da estaca. A pressão de contato solo-sapata não é uniforme devido a diferença de rigidez entre a coluna e o solo entre as colunas (GUSMÃO, 2005). 
Segundo Décourt (1998), a rigidez (R) é definida como a relação entre a carga (Q) aplicada à uma fundação e o recalque (s) que ela acarreta. $\mathrm{O}$ autor defini que a carga de ruptura física $\left(\mathrm{Q}_{\mathrm{uu}}\right)$ corresponde à carga aplicada, quando o recalque tende a infinito, levando a rigidez a zero. A aplicação prática deste conceito normalmente é feita através de um gráfico conhecido como "gráfico de rigidez" em que os valores de R correspondem as ordenadas e o valor de Q as abcissas.

Passos et al. (2014) analisaram o comportamento da rigidez do solo reforçado com colunas de solo e brita $(\mathrm{R})$ e da carga aplicada $(\mathrm{Q})$ dos ensaios de prova de carga realizados no centro do solo reforçado e solo natural e no conjunto solo com colunas. A Figura 2.59 ilustra a disposição da placa nos ensaios e a Figura 2.60 apresenta as curvas da variação da rigidez com a carga aplica.

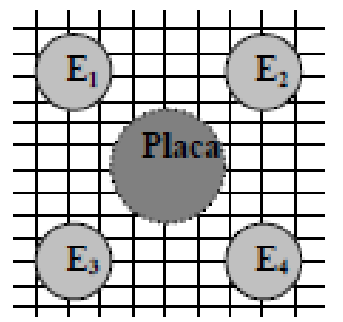

a)

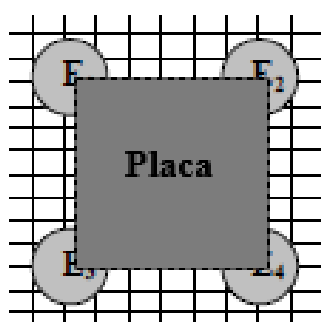

b)

Figura 2.59 - a) Ensaio de prova de carga no solo b) Ensaio de prova de carga no conjunto coluna solo Fonte - Passos et al. (2014)

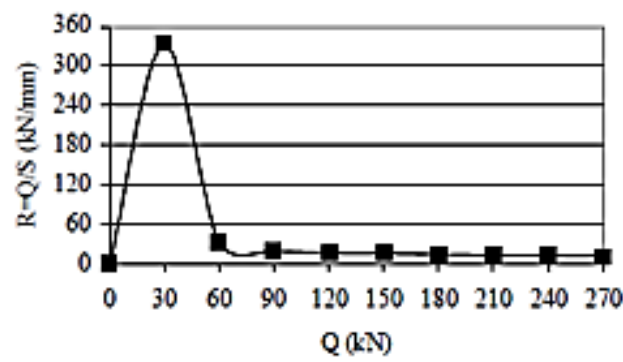

(a)

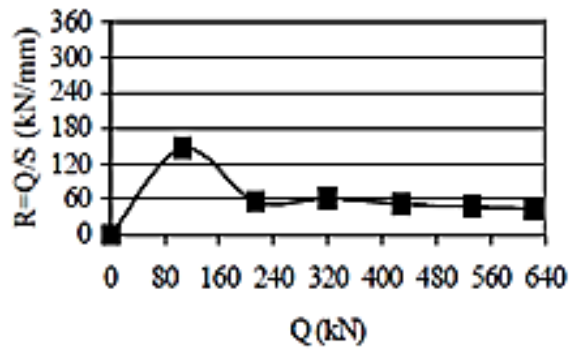

(b)

Figura 2.60 - Gráfico de rigidez: a) apenas do solo e b) solo com colunas de solo e brita Fonte - Passos et al. (2014)

Além disso, os mesmos autores avaliaram a variação da rigidez (R) com a carga aplicada (Q) para os ensaios de prova de carga em placa realizados sobre a coluna compactada para dois diferentes níveis de carregamento, acima de $160 \mathrm{kN}$ e abaixo de $160 \mathrm{kN}$. Os resultados encontrados estão apresentados na Figura 2.61. 
a)

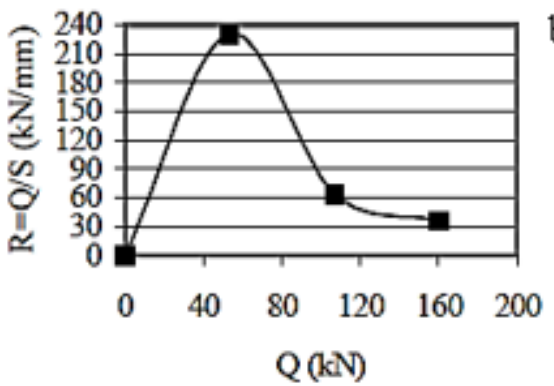

b)

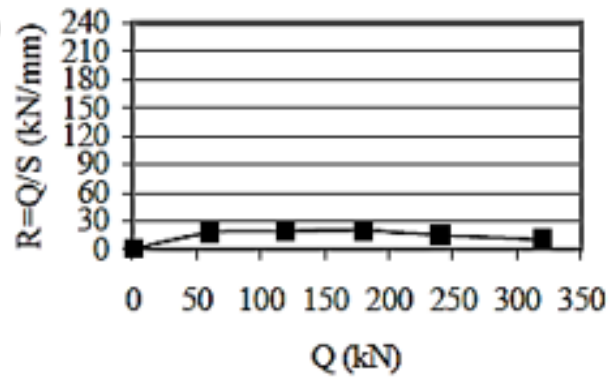

Figura 2.61- Gráfico de rigidez da coluna: a) para nível de carregamento superior a $160 \mathrm{kN}$ e b) para nível de carregamento superior a $160 \mathrm{kN}$

Fonte - Passos et al. (2014)

Os autores observaram que a coluna ensaiada de forma isolada apresentou maior rigidez do que o conjunto solo/colunas para um nível de carregamento inferior a $80 \mathrm{kPa}$, sendo que para $80 \mathrm{kPa}$ não houve grandes diferenças nos valores de rigidez entre o solo melhorado e do elemento de reforço. Segundo Passos et al., (2014), a partir deste ponto, a estaca começa a perder rigidez de forma acentuada verificando-se uma maior rigidez do conjunto solo/colunas. Para um nível de carregamento de aproximadamente $150 \mathrm{kN}$, a rigidez do solo reforçado e do elemento de reforço se equivalem, à aproximadamente $30 \mathrm{kN} / \mathrm{mm}$, o que confirma ser o conjunto solo/coluna o maior responsável pela absorção de cargas. Para Passos et al., (2014), quando o carregamento é superior a $160 \mathrm{kN}$, ocorre o esmagamento da cabeça da coluna pois, como ilustra a Figura 2.61 b, a rigidez praticamente se anula, alcançando a ruptura do elemento.

Segundo Gusmão (2005), para resolver o problema de transferência de carga de uma sapata apoiada em solo melhorado, admite-se que uma sapata rígida, em que o recalque do solo e da sapata são iguais. Tem-se a carga total da sapata calculada pela equação 2.20. A Figura 2.62 ilustra as considerações para a formulação desta equação.

$$
V_{\text {sapata }}=\left(q_{\text {coluna }} \cdot A_{\text {coluna }}\right)+\left(q_{\text {solo }} \cdot A_{\text {solo }}\right)
$$




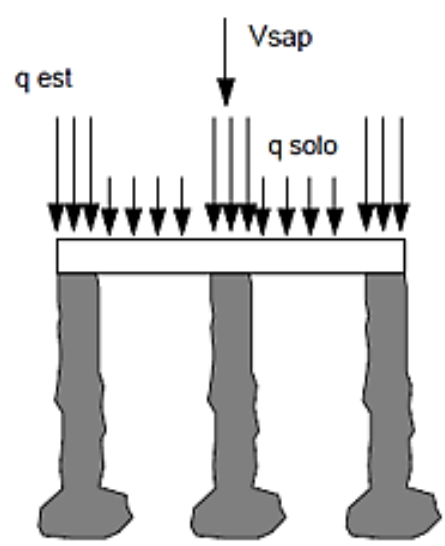

Figura 2.62 - Distribuição do carregamento no contato sapata solo reforçado Fonte - Gusmão (2005)

Pacheco (2002) estudou o comportamento de estacas de argamassa e de areia e brita como reforço de solo. $\mathrm{O}$ autor analisou, por meio de prova de carga em placa, a porcentagem da carga absorvida pelo solo e a porcentagem absorvida pela coluna como mostra a Figura 2.63 e 2.65. Este autor verificou que para terrenos melhorados com estacas de areia e brita, as cargas absorvidas pelo solo e pela estaca variam de 40 a $60 \%$. Os resultados encontrados são equivalentes ao de Passos et al., (2014) pois a parcela de carga absorvida pela estaca e a parcela de carga absorvida pelo solo se equivalem com o aumento do recalque, o que evidencia uma proximidade dos valores de rigidez do solo melhorado e da estaca executada.

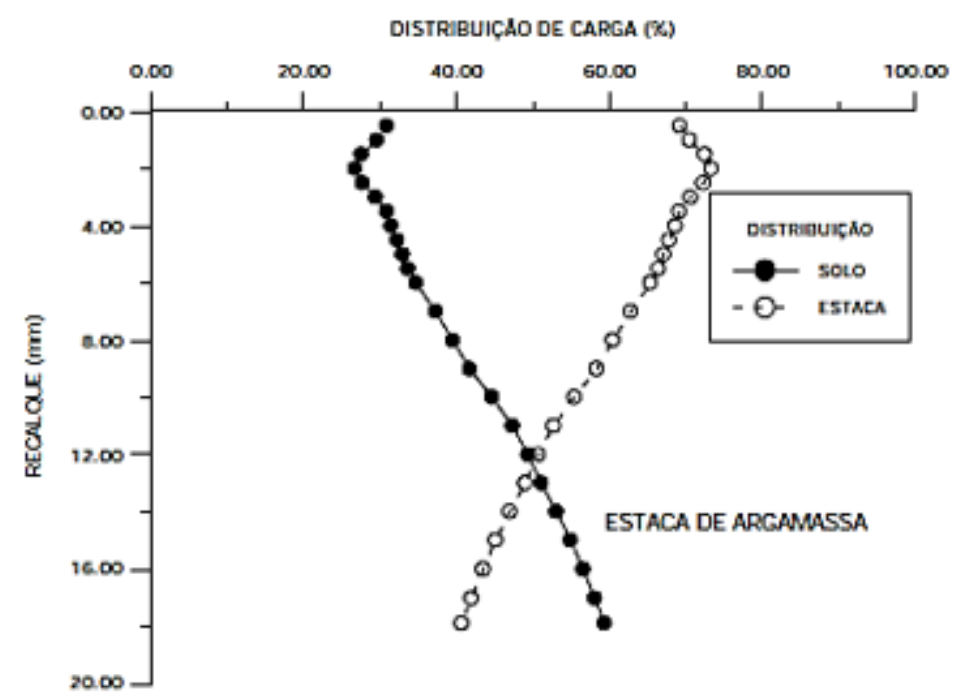

Figura 2.63 - Distribuição da carga no ensaio de placa para as estacas de argamassa Fonte - Gusmão (2005) 


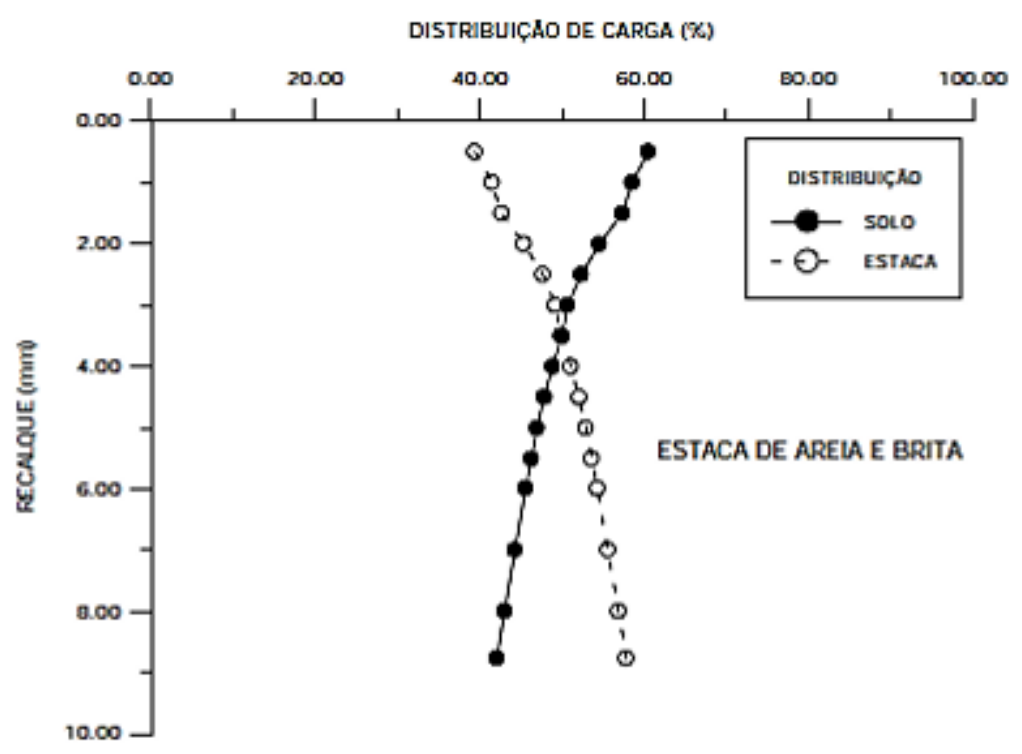

Figura 2.64 - Distribuição da carga no ensaio de placa para as estacas de solo e brita Fonte - Gusmão (2005)

Para o terreno melhorado com estacas de argamassa, verifica-se que ao se aplicar a carga, a parcela de absorção pela estaca é bem superior à parcela absorvida pelo solo. Com a evolução do recalque, observa-se que a participação do solo na absorção de carga cresce gradualmente Pacheco (2002). Este fato está diretamente associado à rigidez da estaca de argamassa, quando comparada à rigidez do solo melhorado.

\subsubsection{Célula unitária}

Compreender o mecanismo de transferência de carga entre o elemento de fundação e o solo reforçado com colunas de compactação não é uma tarefa simples, pois depende de vários parâmetros como a rigidez das colunas, características do solo local, espaçamento e diâmetro das colunas.

Com a finalidade de facilitar a interpretação do comportamento das colunas sob o efeito do carregamento, um dos métodos existentes de simplificação do caso é, por exemplo, o conceito de "célula unitária". Para reforçar um solo é necessário um número significativo de colunas e geralmente elas estão organizadas de maneira que, quando carregadas, ocorre a interferência do efeito das colunas vizinhas, conhecido como "efeito de grupo".

De acordo com Kirsch et al. (2010), para situações em que há um grande número de colunas igualmente espaçadas, com o mesmo diâmetro e mesma profundidade, pode-se considerar como uma "malha infinita". Neste caso, o comportamento das colunas sob o efeito do carregamento pode ser descrito pelo conceito de "célula unitária" em que, 
independentemente da posição em que a coluna se encontre na malha, todas as colunas se comportam de maneira semelhante. Esta técnica de análise é bastante utilizada no dimensionamento de colunas de brita e colunas DSM.

As colunas de compactação geralmente são distribuídas em malhas triangulares, retangulares ou hexagonais. A Figura 2.65 ilustra a disposições das células unitárias em malha triangulares e quadradas, que são as distribuições comumente encontradas.

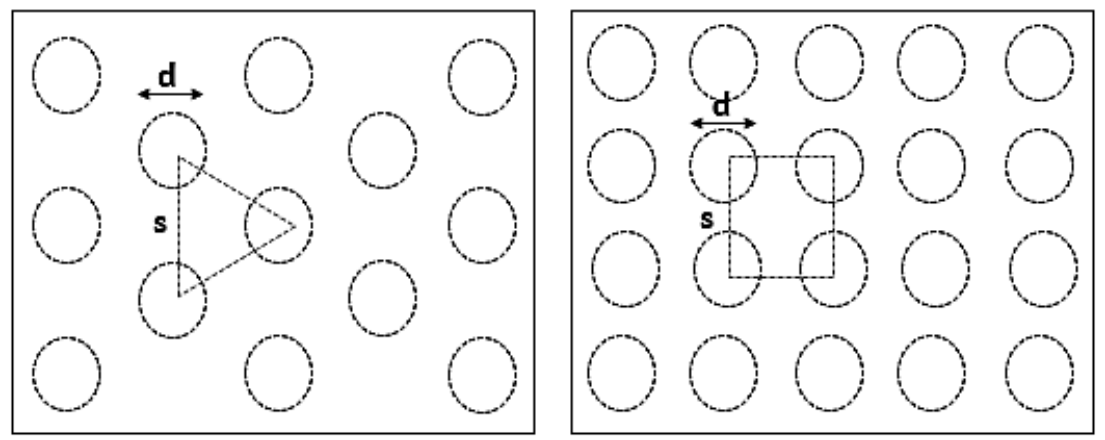

Figura 2.65 - Conceito de célula unitária e padrões de malha Fonte - Kirsch et al. (2010)

O efeito da vibrocompactação nas colunas de brita gera uma densificação do solo no entorno das colunas, criando uma zona rígida com diâmetro equivalente $d_{e}$. Robinsky e Morrison (1964) analisaram o efeito da compactação ao redor de estacas modelo em uma caixa contendo areia. Segundo os autores, o raio de influência ao redor das estacas encontrado foi de 3,5 a 4,5 diâmetros em solo fofo e de 5 a 6 diâmetros em solos medianamente compacto. Abaixo da zona compactada, a influência encontrada foi de 2,5 a 4,5 diâmetros em solo fofo e de 3 a 4,5 diâmetros em solo medianamente compacto.

Gusmão (2005) descreve sobre o melhoramento de solos arenosos com colunas de areia compactadas. O autor realizou ensaios SPT em diferentes distâncias das colunas para analisar o efeito da compactação no seu entorno. Os ensaios permitiram observar que uma única coluna, com $300 \mathrm{~mm}$ de diâmetro, promoveu a compactação do solo circundante à um raio da ordem de 2 a 2,5 vezes o diâmetro da coluna. Tem-se, portanto, que o espaçamento da malha de melhoramento deve ser de 4 a 5 vezes o diâmetro da coluna.

Segundo Gusmão (2005), na prática de projetos de reforço de solo tem sido utilizada a malha quadrada, com lado igual a 3 ou 4 vezes o diâmetro da coluna. Além disso, a coluna deve cobrir toda a projeção da sapata estendendo-se uma ou duas fileiras além da projeção.

O solo no entorno da coluna, para o modelo de "célula unitária", é aproximado a uma área circular equivalente considerando que os elementos possam estar distribuídos em malha 
quadrada, triangular e hexagonal (BERGADO et al., 1994; ALAMGIR et al., 1996). O diâmetro equivalente pode ser calculado pelas equações a seguir.

$$
D_{e}=C \cdot s
$$

Para a malha quadrada $(\mathrm{C}=1,13)$ :
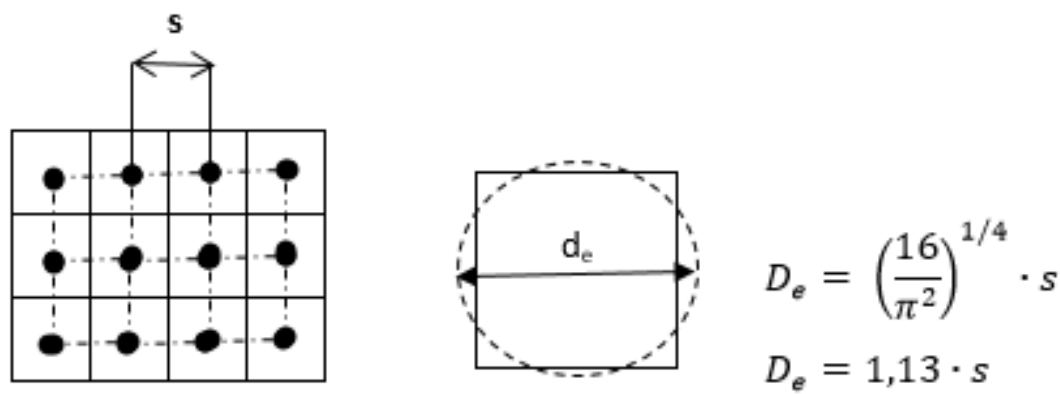

Para a malha triangular $(\mathrm{C}=1,05)$ :
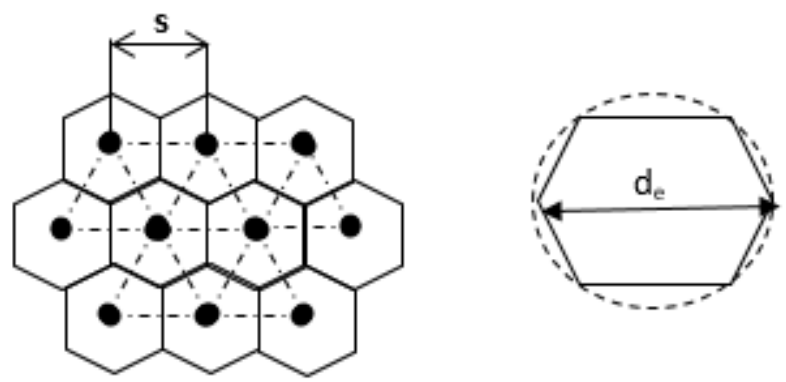

$$
\begin{aligned}
& D_{e}=\left(\frac{12}{\pi^{2}}\right)^{1 / 4} \cdot s \\
& D_{e}=1.05 \cdot s
\end{aligned}
$$

Para malha hexagonal $(\mathrm{C}=1,29)$ :
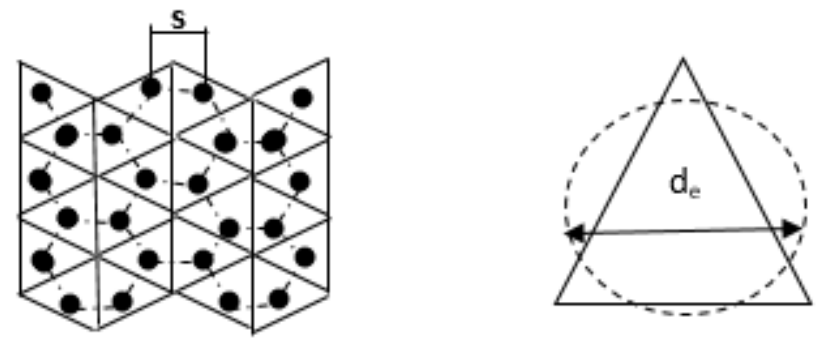

$$
\begin{aligned}
& D_{e}=\left(\frac{27}{\pi^{2}}\right)^{1 / 4} \cdot s \\
& D_{e}=1,29 \cdot s
\end{aligned}
$$

Sendo $s$ o espaçamento entre as colunas de compactação.

De acordo com Bergado et al. (1994), a distribuição das colunas formando uma malha de triângulos equiláteros fornece uma maior densificação, proporcionando um melhor reforço da área. 
Outro parâmetro importante do conceito de malha infinita é a razão de área de substituição $\left(a_{c}\right)$, calculada pelo quociente entre a área da coluna $\left(A_{c}\right)$ e a área da célula unitária (A), ilustradas na Figura 2.66. As colunas de solo cimento tipo DSM, possuem usualmente razões de substituição $\left(\mathrm{a}_{\mathrm{c}}\right.$ ) da ordem de 0,20 a 0,33 (MORETTI, 2012).

$$
a_{c}=\frac{A_{c}}{A}=\frac{1}{C^{2}} \cdot\left(\frac{d}{d_{e}}\right)^{2}
$$

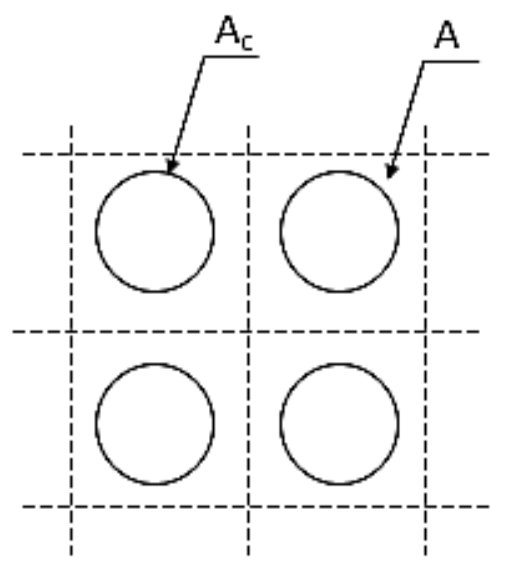

Figura 2.66- Representação da área da coluna e da célula unitária

Fonte - Bergado (1994)

Como a célula unitária é simétrica, a carga é uniformemente distribuida sobre a malha infinita e aplicada em um radier rígido. Consequentemente, nenhuma tensão cisalhante ou deformação horizontal é gerada no entorno das colunas. A carga uniformemente distribuída irá se concentrar nas colunas, uma vez que estas são mais rígidas do que o solo no entorno, e uma pequena parcela será absorvida pela solo. A distribuição de tensão entre a coluna e o solo da célula unitária é chamada de concentração de tensão $(n)$ e é representada pela razão entre a tensão vertical na coluna $\left(\sigma_{c}\right)$ e a tensão vertical no solo $\left(\sigma_{S}\right)$ (KIRSCH et al., 2010).

$$
n=\frac{\sigma_{c}}{\sigma_{s}}
$$

Equilibrando as forças verticais, obtém-se a seguinte relação:

$$
\sigma=\sigma_{c} \cdot \frac{A_{c}}{A}+\sigma_{s} \cdot\left(1-\frac{A_{c}}{A}\right)=a_{c} \cdot \sigma_{c}+\left(1-a_{c}\right) \cdot \sigma_{s}
$$

Reordenando a equação anterior para determinar a tensão na coluna e tensão no solo é possível obter: 


$$
\begin{aligned}
& \sigma_{c}=\sigma \cdot \frac{n}{\left(1+(n-1) \cdot a_{c}\right)}=n_{c} \cdot \sigma \\
& \sigma_{s}=\sigma \cdot \frac{n}{\left(1+(n-1) \cdot a_{c}\right)}=n_{s} \cdot \sigma
\end{aligned}
$$

Sendo $n_{s}$ e $n_{c}$ a razão de tensão aplicada na coluna e no solo da célula unitária.

O conceito de célula unitária estipula a mesma deformação para a coluna de compactação e o solo no entorno (KISCH et al., 2010).

$$
S_{S}=S_{c}
$$

Priebe (1976 ${ }^{4}$ apud KIRSCH et al., 2010) foi o primeiro a definir o parâmetro $\beta$ referente à melhoria obtida com o reforço. Este parâmetro é calculado pela razão entre o recalque do solo sem tratamento $(s)$ e o recalque do solo melhorado $\left(s_{i}\right)$.

$$
\beta=\frac{s}{s_{i}}=\frac{\sigma}{\sigma_{s}}=1+(n-1) \cdot a_{c}
$$

\subsubsection{Capacidade de carga do solo reforçado com colunas}

As tensões aplicadas na fundação tendem a se concentrar no material mais rígido, ou seja, nas colunas, havendo um alívio de tensão no solo circundante. Assumindo que as deformações da coluna de compactação e do solo são iguais no plano horizontal, a redução das tensões aplicadas no solo local resulta em uma redução dos recalques (KIRSCH et al., 2010).

Kirsch et al. (2010) estudaram colunas de brita inseridas em solo mole. Segundo os autores, em contraste com o mecanismo de transferência de carga dos elementos de fundação como as estacas, em que a carga é transferida pelo atrito lateral e pelo contato da ponta, as colunas de compactação transmitem a carga ao solo estimulando as tensões de empuxo horizontais, sem que haja deslocamentos relativos entre a coluna e o solo.

Devido ao confinamento, as colunas de compactação, que são caracterizadas pela alta densidade e rigidez, podem se romper por abaulamento ("bulging”), como ilustra a Figura 2.67, devido à alta concentração de carga nas colunas e a baixa capacidade de carga do solo no seu entorno.

\footnotetext{
${ }^{4}$ PRIEBE, H. Abschätzung des Setzungsverhaltens eines durch Stopverdichtung verbesserten Baugrundes. Die Bautechnik, 1976, v. 53, n. 5, p. $160-162$.
} 


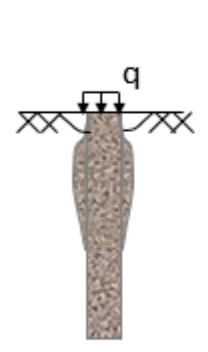

coluna única

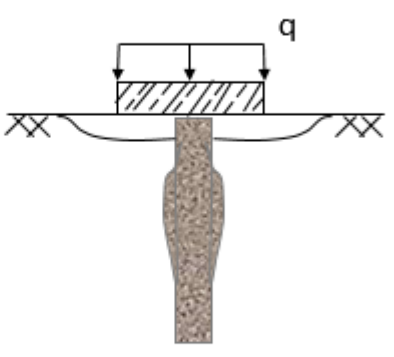

coluna única sob sapata

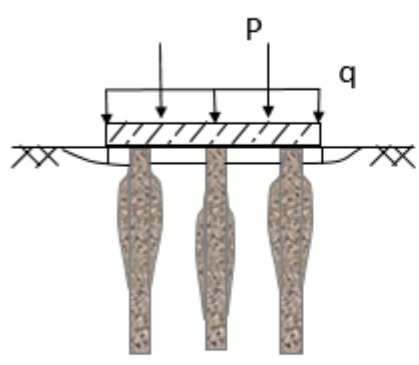

grupo de colunas sob sapata

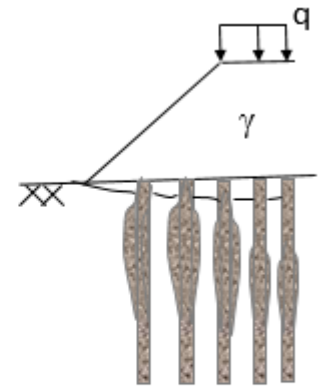

malha de colunas sob aterro

Figura 2.67 - Diferentes cenários de carregamento das colunas de brita Fonte - Kirsch et al. (2010)

A ruptura por abaulamento da coluna é a mais comum de acontecer, uma vez que o solo não é capaz de suportar o esforço horizontal causado pela coluna. De acordo com Kirsch et al. (2010), as colunas de compactação pequenas, com profundidade inferior a quatro vezes o seu diâmetro, podem romper por afundamento no solo, Figura 2.68.

Segundo os mesmos autores, os grupos de coluna apresentam mecanismos similares de ruptura e não é tarefa simples determina-lo. A complexidade do problema envolve a interação entre a carga aplicada, o solo e a coluna, e a determinação dos seus parâmetros geométricos.

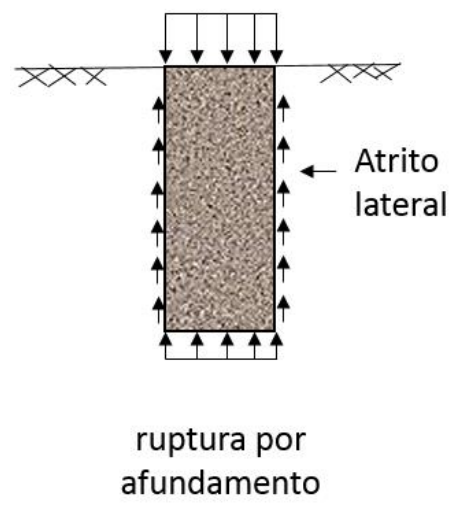

Figura 2.68- Ruptura por afundamento de uma coluna isolada Fonte - Bergado et al. (1994)

A maneira mais simples de determinar a tensão horizontal em solos coesivos, que governa a capacidade de carga da coluna, é através da carga vertical $(q)$ aplicada e da resistência não drenada do solo $\left(C_{u}\right)$ (KIRSCH et al., 2010). A equação estima a tensão horizontal no solo ao lado da coluna. 


$$
\sigma_{s, h}^{\prime}=q+2 C_{u}
$$

A tensão vertical máxima na coluna pode ser calculada por meio do coeficiente de empuxo passivo para o equilíbrio horizontal.

$$
\sigma_{c, v, m a ́ x}^{\prime}=\sigma_{s, h}^{\prime} \cdot \tan ^{2}\left(\frac{\pi}{4}+\frac{\varphi_{c}}{2}\right)=\left(q+2 C_{u}\right) \cdot \tan ^{2}\left(\frac{\pi}{4}+\frac{\varphi_{c}}{2}\right)
$$

Sendo $\varphi_{c}$ o ângulo de atrito do material da coluna de compactação.

Baseado na hipótese de Greenwood (1970 5 apud KIRSCH et al., 2010), a coluna carregada está sujeita a uma pressão triaxial devido ao confinamento. Calcular a capacidade de carga última do grupo é uma tarefa bastante complexa e exige algumas simplificações. De acordo com Bergado et al. (1994), o método mais comum de calcular a capacidade de carga de um grupo assume que a ruptura do sistema se dará de forma planar ao longo do grupo de colunas, Figura 2.69. Considera-se que a tensão de ruptura última $q_{u l t}$, e a tensão horizontal $\sigma_{3}$ são as tensões principais e são calculadas pelas equações:

$$
q_{u l t}=\sigma_{3} \cdot \tan ^{2} \beta+2 C_{m e ́ d} \cdot \tan \beta
$$

A tensão horizontal principal $\sigma_{3}$ é calculada pelo empuxo para uma sapata longa e utilizando a teoria de expansão de cavidade.

$$
\sigma_{3}=\frac{\gamma_{s} \cdot B \cdot \tan \delta}{2}+2 \cdot C_{u}
$$

Sendo $\sigma_{3}$ a tensão horizontal média em $\mathrm{kPa}, \delta$ a inclinação do plano de ruptura, $\gamma_{\mathrm{s}}$ peso específico do solo úmido ou saturado, $c_{u}$ resistência não drenada do solo coesivo reforçado, $\mathrm{c}_{\text {méd }}$ coesão média em $\mathrm{kPa}, \varphi_{\text {méd }}$ ângulo de atrito médio, B a largura da sapata e $c$ a coesão do solo reforçado.

$$
\delta=45^{\circ}+\frac{\varphi_{m e ́ d}}{2}
$$

\footnotetext{
${ }^{5}$ GREENWOOD, D. A. Mechanical improvement of soils below ground surface. Conference on Ground Improvement Engineering. [Proceedings...] Institute of Civil Engineers, London, 1970. P. 11 - 22.
} 


$$
\begin{aligned}
& \tan \varphi_{\text {méd }}=\frac{n \cdot \tan \varphi_{c}}{\frac{A}{A_{c}}+n-1}=n_{c} \cdot a_{c} \cdot \tan \varphi_{c} \\
& C_{\text {méd }}=\left(1-a_{c}\right) \cdot c
\end{aligned}
$$
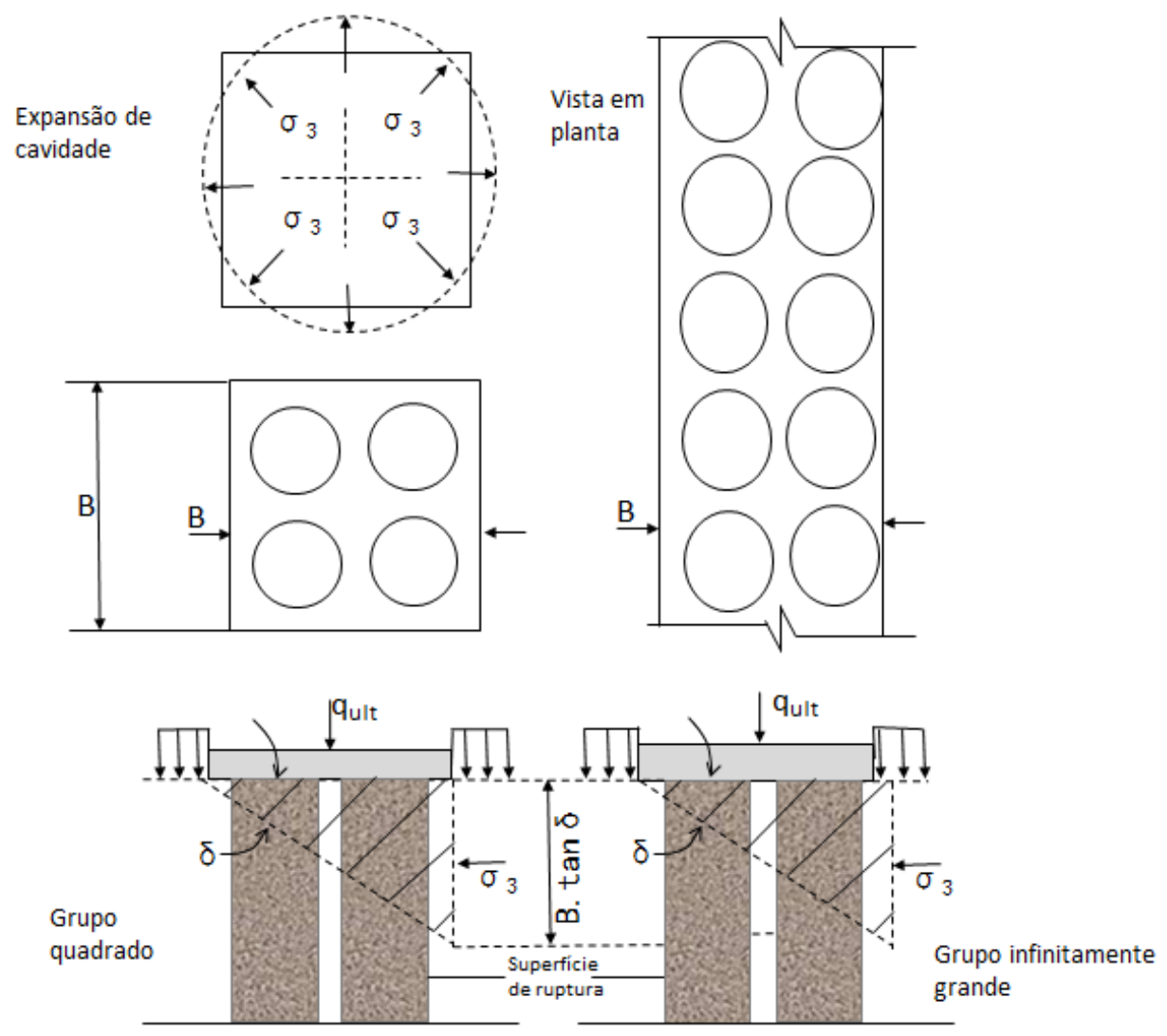

Figura 2.69 - Análise do comportamento de grupo de colunas granulares Fonte - BERGADO et al. (1994)

\subsection{ESTACAS APILOADAS}

De acordo com a norma brasileira ABNT NBR 6122/96 a definição de estaca apiloada é "um tipo de fundação profunda executada por perfuração com emprego de soquete". A Norma acrescenta, em uma observação, que as estacas apiloadas são um tipo especial de estacas que não são classificadas nem como estacas escavadas e nem como cravadas.

Seu método executivo consiste na abertura de um fuste, com diâmetro geralmente da ordem de 0,30 m, com apiloamento do solo por meio da queda de um soquete de massa variando entre 300 e $600 \mathrm{~kg}$, suspenso por um cabo de aço a certa altura, Figura 2.70. A queda do pilão provoca o deslocamento do solo lateralmente e para baixo formando, no entorno do fuste, um anel de solo compactado (GONÇALVES, 2006). 


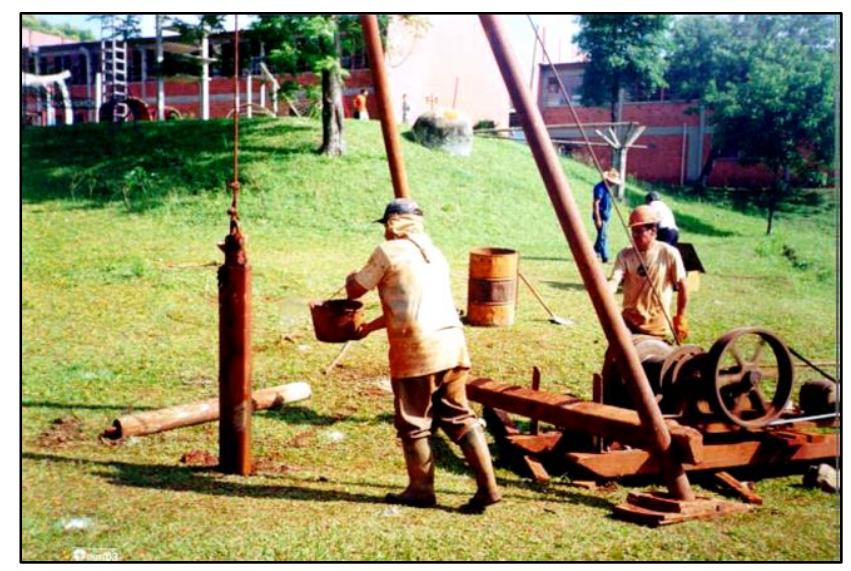

Figura 2.70 - Abertura do fuste da estaca apiloada com o auxílio do pilão Fonte - Gonçalves (2006)

As estacas apiloadas, também conhecidas como estaca pilão, são consideradas como estacas de deslocamento, pois no processo executivo de abertura do furo não ocorre a retirada do solo, mas sim o seu deslocamento para as laterais e para baixo e posteriormente a concretagem (GONÇALVES, 2006).

\subsubsection{Estacas apiloadas em solos colapsíveis}

Alguns trabalhos foram realizados com o objetivo de analisar o comportamento das estacas apiloadas em solos colapsíveis como Gonçalves (2006) e Moraes (2005).

Segundo Gonçalves (2006), na condição de colapso do solo, a parcela de resistência de ponta se torna insignificante e a capacidade de carga das estacas depende praticamente da resistência gerada pelo atrito lateral.

Moraes e Segantini (2002) apresentaram os resultados obtidos em seis provas de carga estáticas à compressão realizadas em três estacas apiloadas executadas em solo colapsível na cidade de Ilha Solteira /SP. Em cada estaca foi colocado um elemento de EPS (isopor) com espessura de $50 \mathrm{~mm}$ para que fosse medida somente a resistência lateral no início do ensaio. Foram realizadas duas provas de carga para cada estaca sendo a primeira na condição não saturada e a segunda na condição inundada. Os autores observaram que as três curvas carga $x$ recalque obtidas nos ensaios com solo não saturado apresentaram um ponto de inflexão quando atingiram um recalque de $50 \mathrm{~mm}$. Isso significa que somente após este recalque é que a ponta começou a contribuir para a capacidade de carga. 


\subsection{INFLUÊNCIA DA GEOMETRIA DO PILÃO NA EXECUÇÃO DAS COLUNAS}

A geometria da ponta do pilão pode influenciar o efeito da compactação no entorno das colunas. Na Romênia o solo tipo loess, que apresenta colapso, cobre 19\% do território do país. Burlacu et al. (2013) estudaram um reforço de solo para reduzir o efeito do colapso com colunas de compactação dinâmica utilizando três geometrias diferentes de ponta do pilão. A primeira ponta com ângulo de $30^{\circ}$, a segunda com ângulo de $60^{\circ}$ e a terceira com ponta hemisférica (arredondada), como ilustra a Figura 2.71.
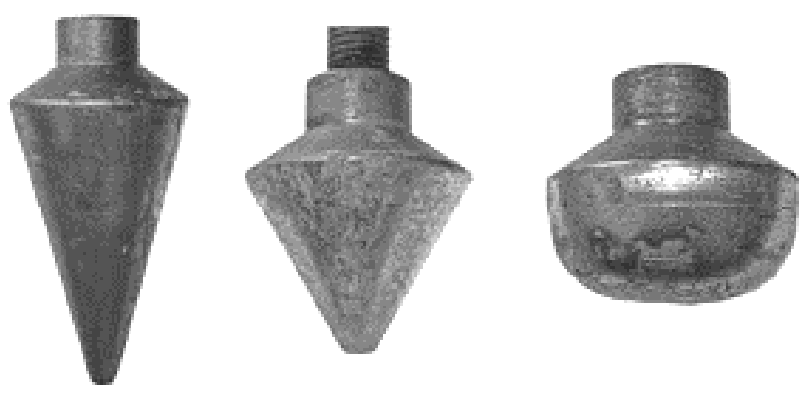

Figura 2.71 - Geometrias testadas: 1) $30^{\circ}$, 2) $60^{\circ}$, 3) hemisférico

Fonte - Burlacu et al. (2013)

As colunas foram construídas in situ, em escala reduzida 1:5 e o efeito de compactação no entorno da coluna foi avaliado com penetrômetro dinâmico DPM com avanço de $10 \mathrm{~cm}$. Como resultado desta análise, observou-se que para os ensaios realizados no centro da coluna, não houve grandes diferenças nos resultados. Para determinar o efeito radial da compactação, foram realizados ensaios DPM á uma distância igual a duas vezes o diâmetro da coluna (2Dc). Os ensaios indicaram que o cone com ângulo de $30^{\circ}$ ofereceu uma maior compactação no ponto analisado. Os autores concluíram que o formato da ponta com ângulo de $30^{\circ}$ é o formato ideal para execução das colunas. 


\section{CARACTERÍSTICAS DO SOLO ESTUDADO}

\subsection{ASPECTOS GEOLÓGICOS}

A cidade de São Carlos está localizada na zona de transição entre duas unidades geomorfológicas, Cuestas Basálticas e Planalto Ocidental, assentadas em rochas do grupo São Bento. Estas rochas são compostas por arenitos da formação Pirambóia e Botucatu e por migmatitos formados por derrames basálticos da Formação Serra Geral. Sobre estas rochas encontram-se conglomerados e arenitos do grupo Bauru, representado na região por arenitos de granulação média, com 45\% de areia e 35\% de argila (BORTOLUCCI, 1983).

Devido à ação do intemperismo e a erosão dos materiais do grupo Bauru e da Formação Serra Geral e Botucatu, originaram-se depósitos superficiais aluviais e coluviais, geologicamente denominado de Sedimento Cenozóico, que cobrem quase a totalidade da região centro-oeste do Estado de São Paulo (COSTA, 1999). Estes sedimentos foram expostos às condições climáticas características da região tropical, o que originou materiais porosos, pouco compactos e com comportamento colapsível.

A espessura da camada superficial do Sedimento Cenozóico em São Carlos varia entre 5 e $7 \mathrm{~m}$ e o seu contato com a camada inferior de solo residual do Grupo Bauru é feito por meio de uma camada fina de seixos de quartzo e limonita, Figura 3.1. O nível do lençol freático varia de 7,0 a 10,0 m de profundidade de acordo com a época do ano. (VIANNA, 2005).

\subsection{ASPECTOS GEOTÉCNICOS}

\subsubsection{Ensaios in situ}

O Campo Experimental de Fundações já foi muito estudado em pesquisas anteriores, o que favorece a obtenção de parâmetros do solo na sua condição natural. Dentre os ensaios em campo realizados estão cinco sondagens de simples reconhecimento (SPT) e cinco ensaios de penetração estática (CPTu) até a profundidade de $20 \mathrm{~m}$. Os resultados obtidos nos ensaios estão apresentados na Figura 3.1. 


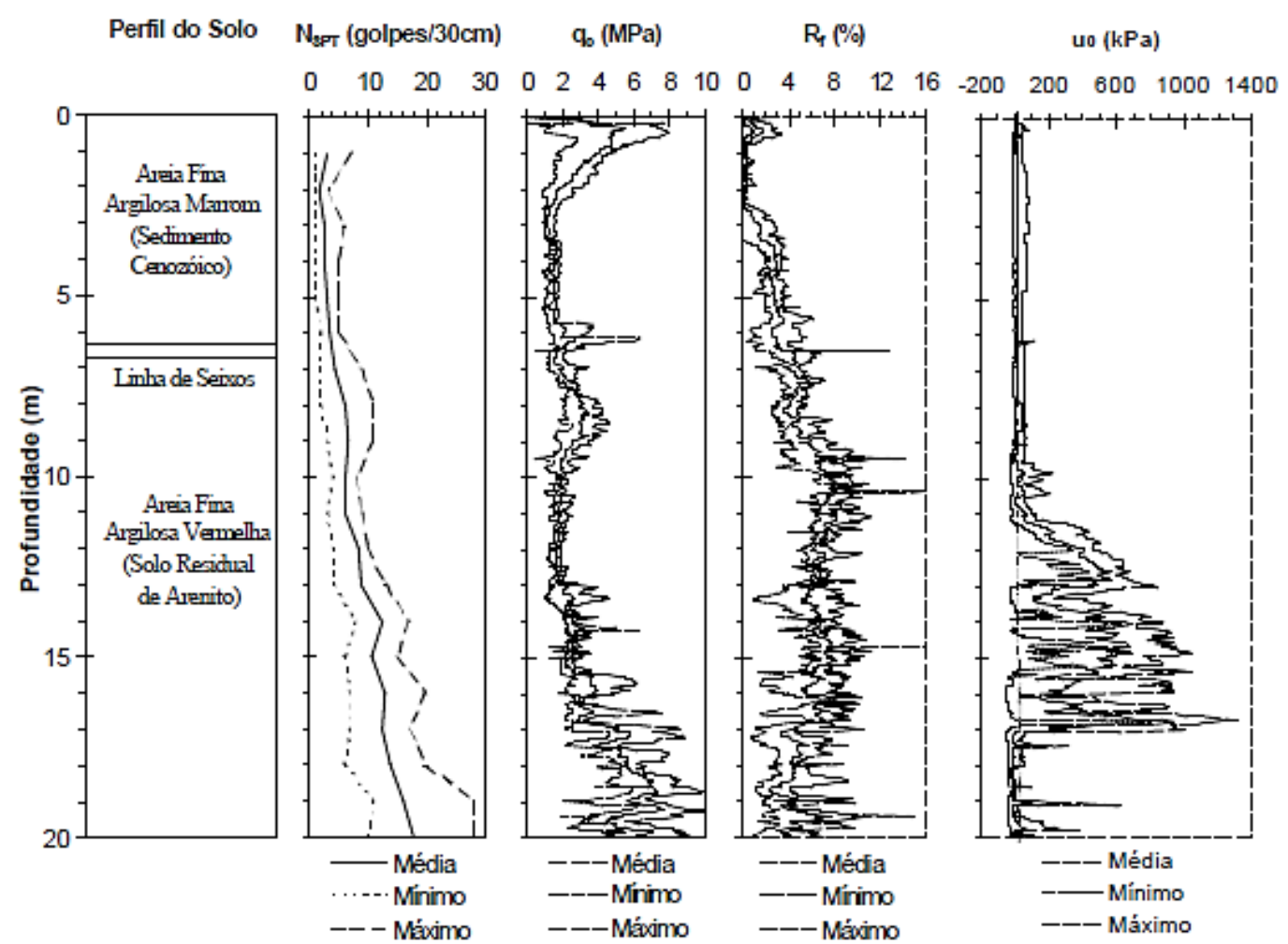

Figura 3.1 - Resultados dos ensaios penetrométricos de SPT e CPTu realizados no Campo Experimental de Fundações da Cidade de São Carlos Fonte - Menegotto (2004)

\subsubsection{Ensaios em laboratório}

Machado (1998) realizou ensaios em laboratório com amostras indeformadas retiradas do campo experimental da Escola de Engenharia da cidade de São Carlos, de um poço com 1,2 $\mathrm{m}$ de diâmetro e aproximadamente $10 \mathrm{~m}$ de profundidade. Os índices físicos determinados pelo autor, para cada metro de profundidade, foram w (teor de umidade), $\gamma_{\mathrm{d}}$ (peso específico aparente seco), $\gamma$ (peso específico natural) e $e$ (índice de vazios.). Os resultados obtidos estão apresentados na Tabela 3.1.

Tabela 3.1 - Resultados obtidos ao longo do perfil de coleta de blocos indeformados (Machado, 1998)

\begin{tabular}{|cccccccccc|}
\hline Profundidade & $\mathbf{1 , 0} \boldsymbol{m}$ & $\mathbf{2 , 0} \mathbf{m}$ & $\mathbf{3 , 0} \mathbf{m}$ & $\mathbf{4 , 0} \mathbf{m}$ & $\mathbf{5 , 0} \mathbf{m}$ & $\mathbf{6 , 0} \mathbf{m}$ & $\mathbf{7 , 0} \mathbf{m}$ & $\mathbf{8 , 0} \mathbf{m}$ & $\mathbf{9 , 0} \mathbf{m}$ \\
\hline $\boldsymbol{w}(\mathbf{\%})$ & 13,7 & 14,6 & 15,8 & 16,8 & 16,4 & 17,2 & 19,1 & 16,7 & 18,3 \\
$\boldsymbol{\gamma} \boldsymbol{d}\left(\mathbf{k N} / \mathbf{m}^{\mathbf{3}}\right)$ & 12,5 & 13,6 & 13,8 & 14,3 & 14,4 & 14,7 & 15,2 & 16,1 & 16,6 \\
$\boldsymbol{\gamma}\left(\mathbf{k N} / \mathbf{m}^{\mathbf{3}}\right)$ & 14,2 & 15,6 & 16,0 & 16,7 & 14,8 & 17,1 & 18,1 & 18,8 & 19,6 \\
$\boldsymbol{e}$ & 1,17 & 0,99 & 0,96 & 0,90 & 0,88 & 0,84 & 0,78 & 0,68 & 0,63 \\
\hline
\end{tabular}

Fonte - Machado (1998) 
A Tabela 3.2 apresenta os resultados dos ensaios de caracterização e compactação realizados com a energia Proctor Normal para as profundidades de 3, 5 e $8 \mathrm{~m}$ (MACHADO, 1998).

Tabela 3.2 - Resultados dos ensaios de caracterização e compactação

\begin{tabular}{|cccccc|}
\hline Prof. $(\boldsymbol{m})$ & $\gamma d$ máx $\left(\mathbf{k N} / \mathbf{m}^{\mathbf{3}}\right)$ & $\boldsymbol{w}_{\text {ot }}(\%)$ & $\boldsymbol{L}_{L}(\%)$ & $\boldsymbol{L}_{P}(\%)$ & $\gamma \mathbf{s}\left(\mathbf{k N} / \mathbf{m}^{\mathbf{3}}\right)$ \\
\hline $\mathbf{3 , 0}$ & 18,7 & 14,0 & 27,9 & 16,0 & 27,1 \\
$\mathbf{5 , 0}$ & 18,4 & 14,8 & 30,9 & 19,8 & 27,5 \\
$\mathbf{8 , 0}$ & 18,9 & 11,2 & 28,4 & 17,2 & 27,1 \\
\hline
\end{tabular}

Fonte - Machado (1998)

Para as mesmas profundidades, Machado (1998) também determinou as frações granulométricas constituintes de cada profundidade. Observa-se que para as profundidades $3 \mathrm{e}$ $5 \mathrm{~m}$ os resultados são muito próximos, com um aumento da proporção de areia com a profundidade e redução da porcentagem de silte. Já para a profundidade $8 \mathrm{~m}$, nota-se que houve uma redução do percentual de argila no solo.

Tabela 3.3 - Frações granulométricas do solo

\begin{tabular}{|cccc|}
\hline Prof. (m) & Areia (\%) & Silte (\%) & Argila (\%) \\
\hline $\mathbf{3 , 0}$ & 60,8 & 11,9 & 27,3 \\
$\mathbf{5 , 0}$ & 66,7 & 5,90 & 27,4 \\
$\mathbf{8 , 0}$ & 68,9 & 13,7 & 17,4 \\
\hline
\end{tabular}

Machado (1998) também determinou a curva de retenção de água no solo do campo experimental de fundações para a profundidade de 2,0 m (Figura 3.2). Para a sua determinação, o autor utilizou dois métodos distintos: para baixos valores de sucção foi adotada a técnica do funil de placa porosa, pois este método permite definir os valores de sucção com maior precisão para intervalos da ordem de $0,1 \mathrm{kPa}$. Para maiores valores de sucção (até $350 \mathrm{kPa}$ ), foi utilizado um equipamento denominado câmera de Richards.

Para ajustar os dados experimentais de sucção e umidade volumétrica Machado (1998) adotou a equação proposta por Fredlund e Xing (1994) empregando-se o método dos mínimos quadrados, Figura 3.2. 


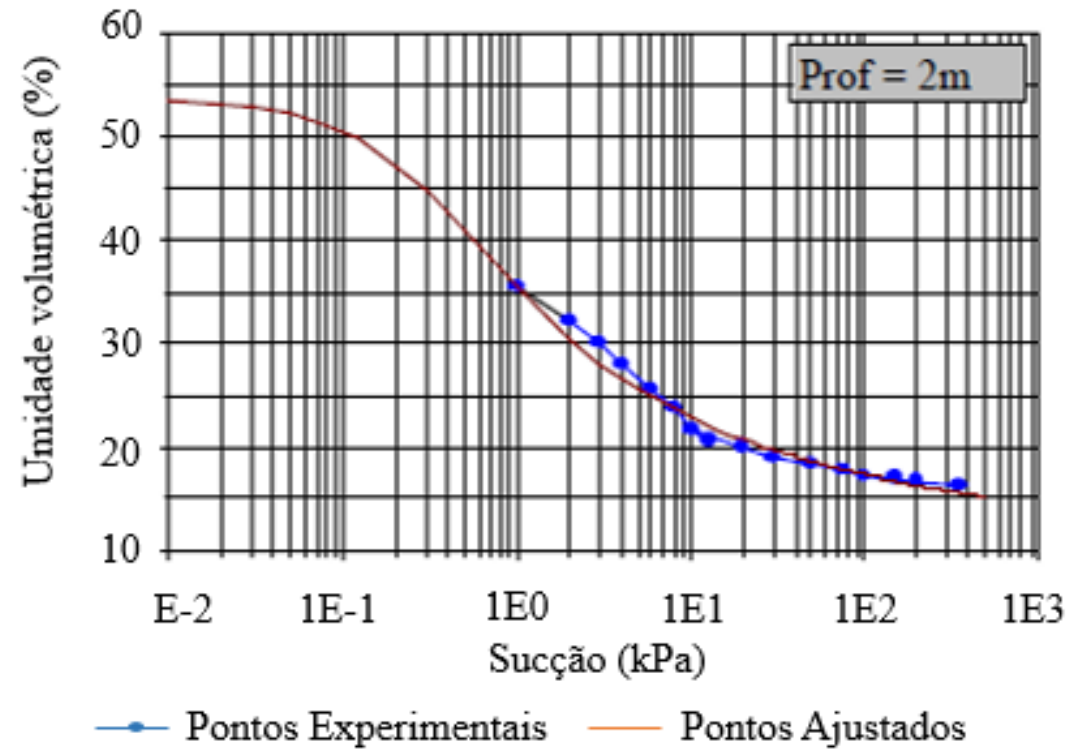

Figura 3.2 - Curva de retenção de água no solo para a profundidade de 2,0 m - Campo Experimental de Fundações

Fonte - Machado (1998)

\subsubsection{Resultados preliminares de prova de carga em placa}

Costa (1999) executou quatorze provas de carga no campo experimental de fundações da Escola de Engenharia da cidade de São Carlos, sendo quatro na condição natural e oito na condição inundada. O objetivo dos ensaios realizados pelo autor foi analisar a influência da sucção matricial no ganho de resistência, em termos de capacidade de carga, e no recalque de solos colapsíveis típicos da cidade. Para isso, o autor utilizou uma placa de aço com $25 \mathrm{~mm}$ de espessura, $80 \mathrm{~cm}$ de diâmetro, com área de $0,5 \mathrm{~m}^{2}$. A disposição dos ensaios no campo experimental de fundações está apresentada na Figura 3.3.

Destes quatorze ensaios quatro foram realizados de forma rápida (QML), sendo dois inundados e os outros dois com sucções de 15 e $22 \mathrm{kPa}$. No ensaio rápido, os estágios de carga foram mantidos por 15 minutos, de acordo com a proposição de Fellenius (1975), e as leituras dos recalques foram feitas nos tempos 1, 2, 3, 6, 9, 12 e 15 min. Os resultados obtidos para o solo inundado nestes ensaios estão apresentados na Figura 3.4 b.

Cinco ensaios foram realizados de forma lenta (SML), sendo três destes ensaios realizados no solo inundado e dois em solo com sucção de 10 e $30 \mathrm{kPa}$. A execução da prova de carga seguiu as orientações da norma ABNT NBR 6489/1984, com exceção do descarregamento que foi efetuado em dois estágios. De acordo com Costa (1999), isso se justifica pelo fato do solo possuir como característica praticamente nenhuma recuperação elástica. Os resultados obtidos para o solo inundado estão apresentados na Figura 3.4. a. 
Os outros três ensaios foram realizados de forma mista (MML) no solo inundado. A execução iniciou-se com aplicação de carregamentos do tipo lento (SML) até um estágio prédeterminado, e em seguida, com aplicação do carregamento tipo rápido (QML) até o término da prova de carga. Os ensaios mistos foram realizados de acordo com as mesmas premissas dos ensaios lentos e rápidos. Como critério de mudança do tipo de ensaio, foi adotada a tensão admissível provável. Em cada estágio da fase rápida, o incremento de carga aplicado era igual à metade do incremento empregado nos estágios da fase lenta. Os resultados deste ensaio estão apresentados na Figura 3.4.c.

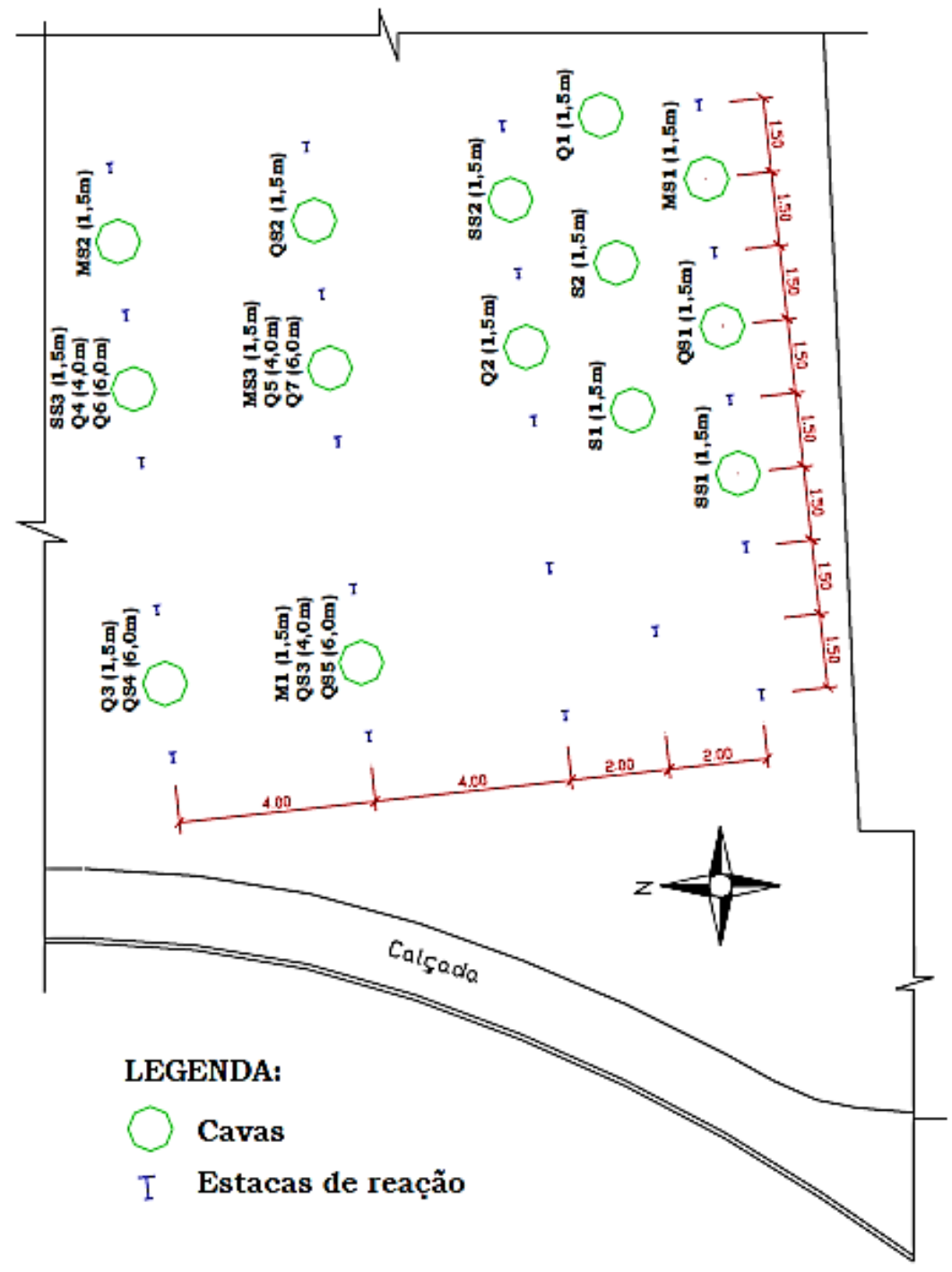

Figura 3.3 - Locação das provas de carga em placa realizadas no Campo Experimental de Fundações da EESC/ USP

Fonte - Menegotto (2004) 
Tabela 3.4 - Relação dos ensaios de prova de carga realizados

\begin{tabular}{|ccc|}
\hline \multicolumn{3}{|c|}{ Resultados prova de carga Costa (1999) } \\
\hline Designação & Tipo de carregamento & Sucção do solo (kPa) \\
\hline SS1 & Lento & 0 \\
QS1 & Rápido & 0 \\
MS1 & Misto & 0 \\
SS2 & Lento & 0 \\
QS2 & Rápido & 0 \\
MS2 & Misto & 0 \\
Q1 & Rápido & 15 \\
Q1-r* & Rápido & 0 \\
S1 & Lento & 10 \\
S1-r* & Lento & 0 \\
SS3 & Lento & 0 \\
S2 & Lento & 30 \\
MS3 & Misto & 0 \\
Q2 & Rápido & 22 \\
\hline
\end{tabular}

Fonte - Costa (1999)

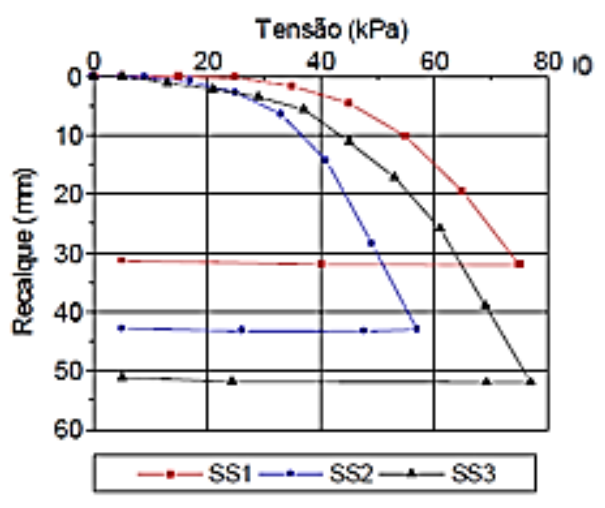

(a)

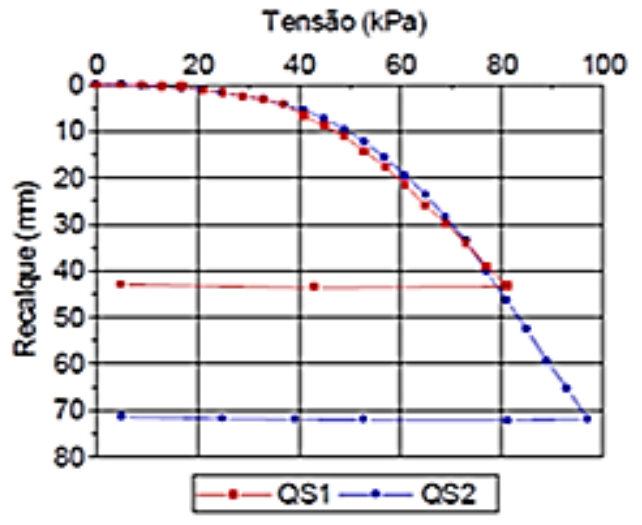

(b)

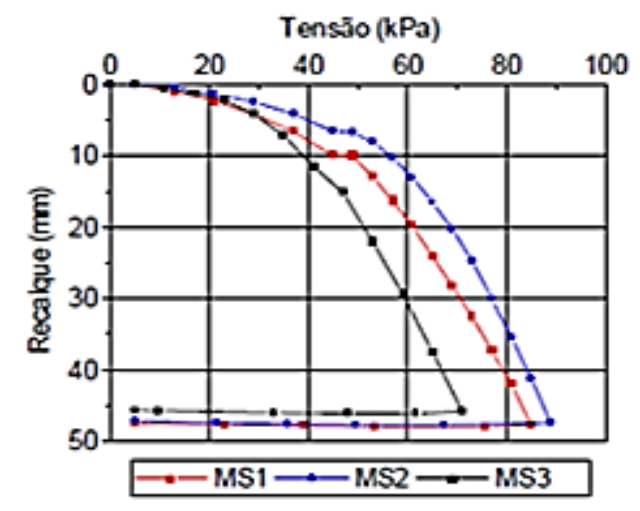

(c)

Figura 3.4 - Curvas tensão x recalque obtidas nos ensaios: (a) ensaio SML, (b) ensaio QML, (c) ensaio MML inundados

Fonte - Costa (1999) 
A Figura 3.5 ilustra os resultados das provas de carga rápidas (QML) com sucção de 15 e $22 \mathrm{kPa}, \mathrm{Q} 1$ e Q2 respectivamente, e lenta (SML) não inundadas, com sucção de 10 e 30 kPa, S1 e S2, obtidas por Costa (1999).
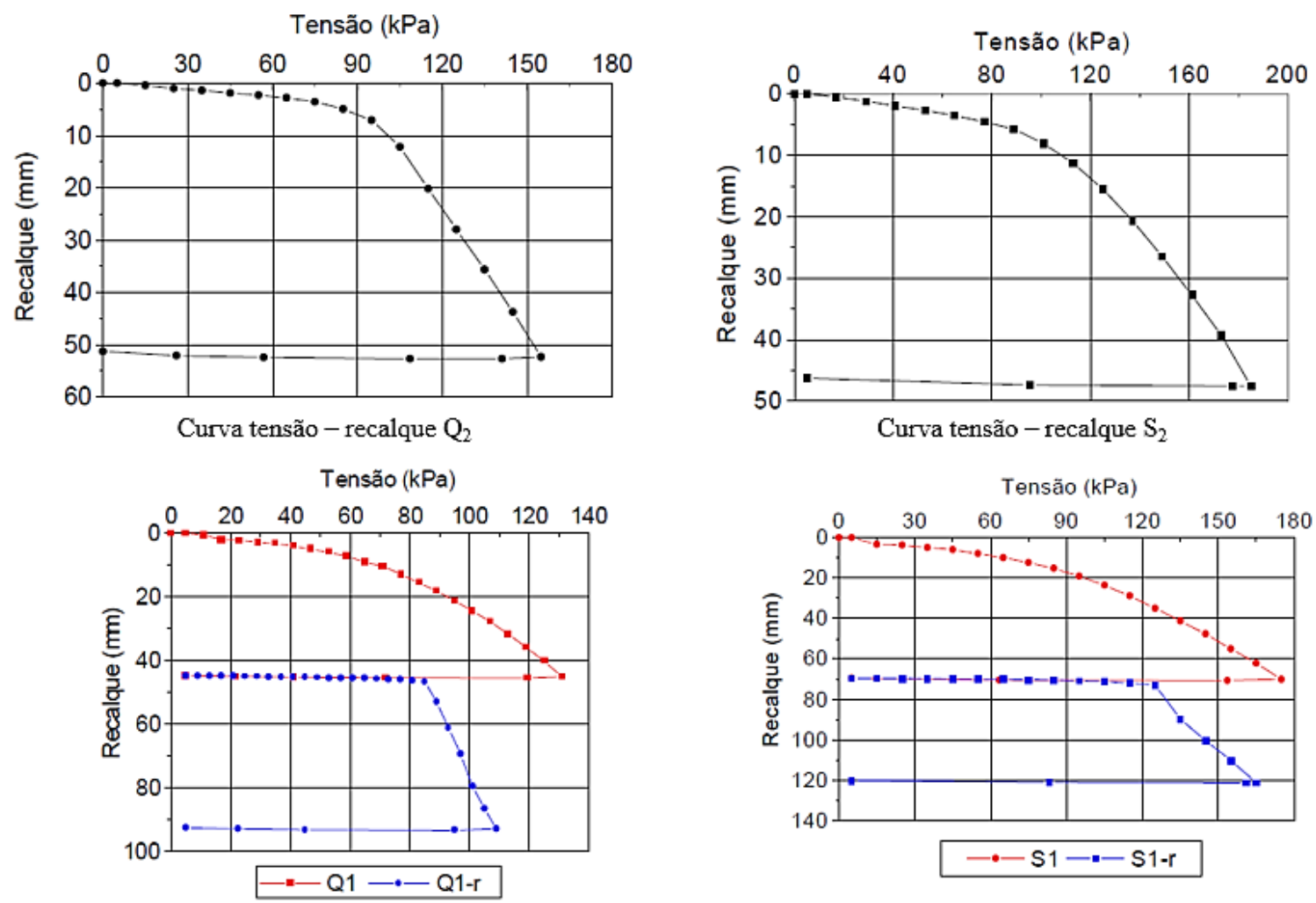

Figura 3.5 - Curvas tensão x recalque obtidas nos ensaios: (a) ensaio SML, (b) ensaio QML, (c) ensaio MML com sucção

Fonte: Costa (1999)

Costa (1999) notou a variação da capacidade de carga obtida no ensaio de prova de carga com relação ao teor de umidade do solo no momento do ensaio. Os resultados obtidos para as provas de carga lentas (SML) estão apresentados na Figura 3.5. 


\section{MATERIAIS E MÉTODOS}

Esta pesquisa foi dividida em duas etapas principais: $1^{\mathrm{a}}$ ) ensaios em laboratório e $2^{\mathrm{a}}$ ) ensaios em campo.

\subsection{ENSAIOS EM LABORATÓRIO}

\subsubsection{Caracterização do solo em laboratório}

Inicialmente foram feitos ensaios de caracterização e de compactação com o solo estudado em laboratório, seguindo as Normas Brasileiras. Para isto, foram retiradas amostras deformadas do campo experimental de fundações da Escola de Engenharia de São Carlos/ USP com o auxílio do trado tipo cavadeira, como ilustra a Figura 4.1. O material foi coletado a partir da profundidade de $1,5 \mathrm{~m}$, com relação ao nível do terreno, pois considera-se que a camada de solo acima desta cota é constituída por aterro. O local de coleta da amostra indeformada está apresentado na figura do Anexo A, e sua escolha foi devido à proximidade do local onde seriam executadas as provas de carga em placa.

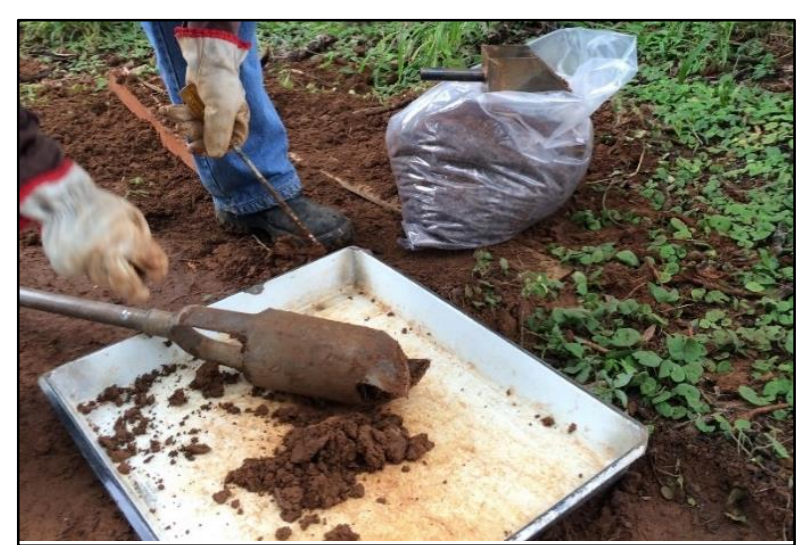

Figura 4.1 - Amostra deformada retiradas do Campo Experimental de Fundações com trado tipo cavadeira

Os ensaios de caracterização realizados consistiram em: análise granulométrica conjunta ABNT NBR 7181/1984, massa específica dos sólidos ABNT NBR 6508/1984, limites de liquidez ABNT NBR 6459/1984 e de plasticidade ABNT NBR 7180/1984. Para o ensaio de compactação, foi utilizada energia Proctor Normal ABNT NBR 7182/1986. Os ensaios foram realizados no laboratório de Mecânica dos Solos do departamento de Geotecnia da Escola de Engenharia de São Carlos. 
Além destes ensaios, também foi determinada a massa específica natural do solo. Para a sua determinação, foram retiradas amostras indeformadas, com o auxílio de anéis circulares de PVC.

\subsubsection{Classificação MCT}

A metodologia MCT (Miniatura Compactada Tropical) possibilita classificar se o solo possui comportamento laterítico ou não-laterítico. Por este motivo, foi realizada tal classificação para comprovar o comportamento laterítico do solo estudado.

Para a sua execução foram utilizadas as amostras deformadas retiradas do Campo Experimental de Fundações até uma profundidade de 3,5 m com relação ao nível do terreno. Para obter os coeficientes e o índice que permitem classificar o solo, foi realizado o ensaio Mini-MCV, de acordo com a norma rodoviária DNER-ME 258/94. Neste ensaio, os corpos de provas foram compactados com energias de compactação crescentes e, em seguida, efetuou-se o ensaio de "perda de massa por imersão". Desta forma, foi possível obter os coeficientes empíricos necessários para a classificação MCT. (PAULO: repetitivo, reescrever. Ver considerações do Glauco)

\subsubsection{Execução de colunas de solo compactado em escala reduzida}

Na literatura, poucos estudos são encontrados a respeito da influência da geometria da ponta do pilão nos efeitos de compactação das colunas utilizadas como reforço de solo. Devido à dificuldade de visualizar e mensurar esses efeitos em campo, as colunas de compactação foram executadas em laboratório, em escala reduzida. O objetivo deste ensaio foi avaliar, de forma qualitativa, os efeitos da compactação no entorno da coluna causados pelas diferentes geometrias dos pilões.

Para a execução do ensaio foram utilizadas três caixas de madeirite com dimensões 30 x 30 x $30 \mathrm{~cm}$, com todas as faces removíveis, apresentadas na Figura 4.2. O solo utilizado para preencher a caixa foi retirado do Campo Experimental de Fundações da Escola de Engenharia de São Carlos (EESC/USP), a uma profundidade de $0,5 \mathrm{~m}$, pois havia o interesse em compreender os efeitos da compactação das diferentes geometrias do pilão para este tipo de solo. 
Procurou-se compactar o solo no interior da caixa de modo que a massa específica e o grau de compactação fossem os mesmos do solo natural do campo experimental. Como cada caixa foi preenchida duas vezes, o controle da compactação do solo de preenchimento da caixa permitiu que os resultados encontrados pudessem ser comparados.

A compactação foi feita em 12 camadas. Para isto, foram desenhadas linhas espaçadas de 2,5 cm no interior da caixa, com o intuito de delimitar a altura final de cada camada compactada (Figura 4.2.b). Conhecendo-se a massa específica natural do campo, e a umidade do solo de preenchimento, foi calculada a massa de solo correspondente a cada camada para que o solo fosse compactado no interior da caixa com o mesmo grau de compactação do solo no campo, $68 \%$. Em seguida, após adicionar a massa calculada, foi feita a compactação manual, com o soquete ilustrado na Figura 4.2.a, de modo que a camada atingisse a linha de referência. Esse processo foi repetido até que a caixa fosse totalmente preenchida.
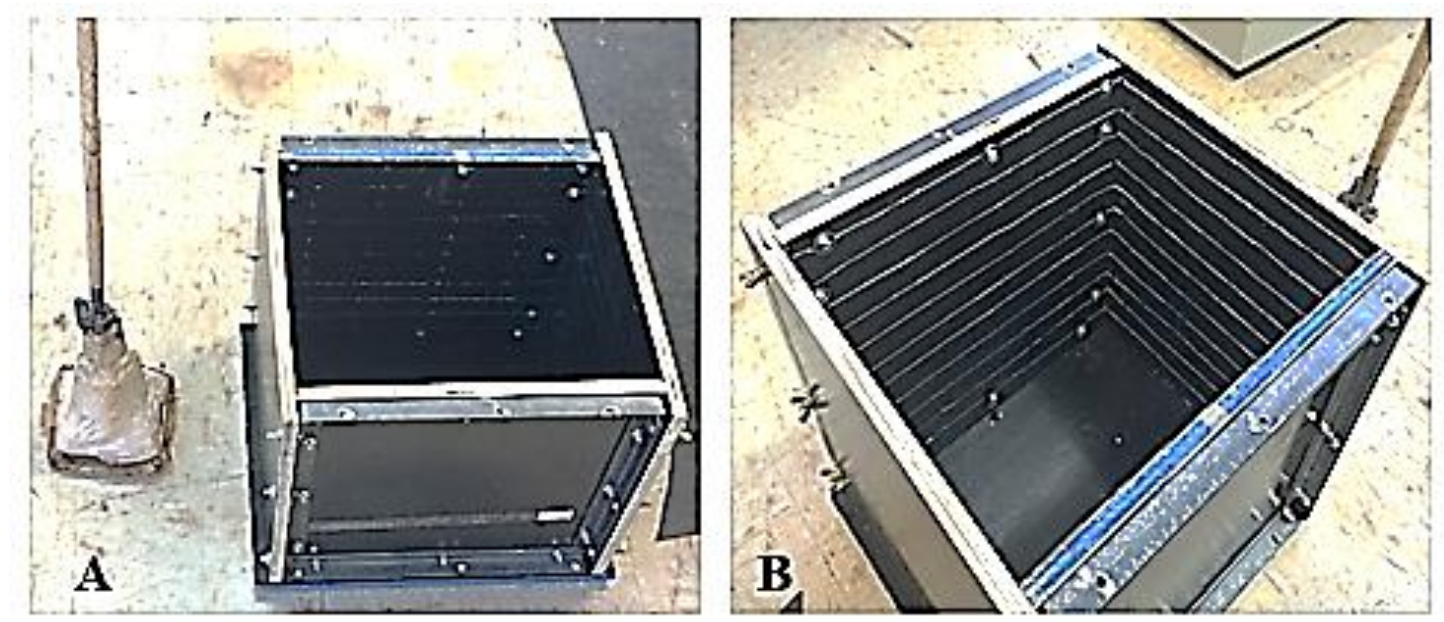

Figura 4.2 - A) Soquete utilizado para compactação das camadas; B) delimitação das camadas

Os pilões utilizados na execução das colunas foram confeccionados em aço, e suas dimensões foram definidas de acordo com as dimensões da caixa, de forma que o solo pudesse se deslocar lateralmente durante a compactação sem que ocorresse o efeito de borda da caixa nos resultados das colunas. Nesta análise foram utilizadas duas geometrias de ponta do pilão, cônica (A) e cilíndrica (B). Ambos os pilões utilizados possuíam diâmetro de 25,4 mm, como ilustra a Figura 4.3. A ponta do pilão cilíndrico foi torneada com ângulo de ápice de $30^{\circ}$, com base nos resultados de eficiência de compactação obtidos por Burlacu et al. (2013). Acreditavase que o pilão de forma cônica, tipo A, proporcionaria uma maior compactação lateral do solo, o que implicaria em um melhor reforço do solo. 


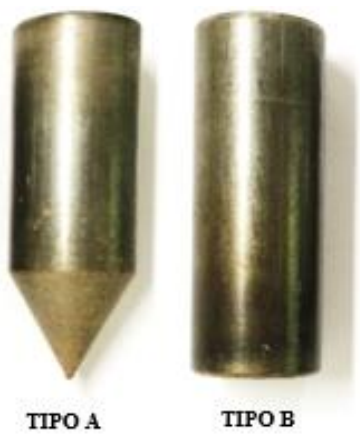

Figura 4.3 - Geometrias dos pilões: Tipo A (cônica) e Tipo B (cilíndrica)

Para a execução das colunas foi utilizada uma prensa de compressão estática EMIC, do laboratório de Geossintéticos da EESC, sendo feita uma adaptação para o encaixe do pilão na célula de carga, como ilustrada na Figura 4.4.

Com o auxílio da prensa, inicialmente foi feita a cravação estática do pilão, perfurando o solo, até alcançar a profundidade de $12,5 \mathrm{~cm}$. Em seguida, a coluna foi preenchida com um solo arenoso claro, com cor diferente do solo utilizado no preenchimento da caixa, de modo que houvesse um contraste entre os dois solos. O preenchimento da coluna foi feito em 5 camadas e a compactação de cada camada foi executada com o mesmo pilão utilizado na perfuração.

Na primeira camada de preenchimento da coluna foram adicionados $60 \mathrm{~g}$ de solo, com o auxílio de um funil, e a compactação da camada foi realizada pelo controle do deslocamento medido pela prensa, de forma que a altura final da camada fosse de $2,5 \mathrm{~cm}$.

Para as outras 4 camadas, foram adicionados $30 \mathrm{~g}$ de solo e a compactação foi feita da mesma forma que a primeira camada, controlando a altura final de forma que fosse igual a 2,5 $\mathrm{cm}$. $\mathrm{O}$ intuito de adicionar mais solo na camada inferior foi de criar uma base mais rígida na coluna de maneira que o solo adicionado nas demais camadas tendesse a se deslocar para as laterais, permitindo uma melhor análise do comportamento lateral da compactação causado pelas diferentes geometrias de pilão. 


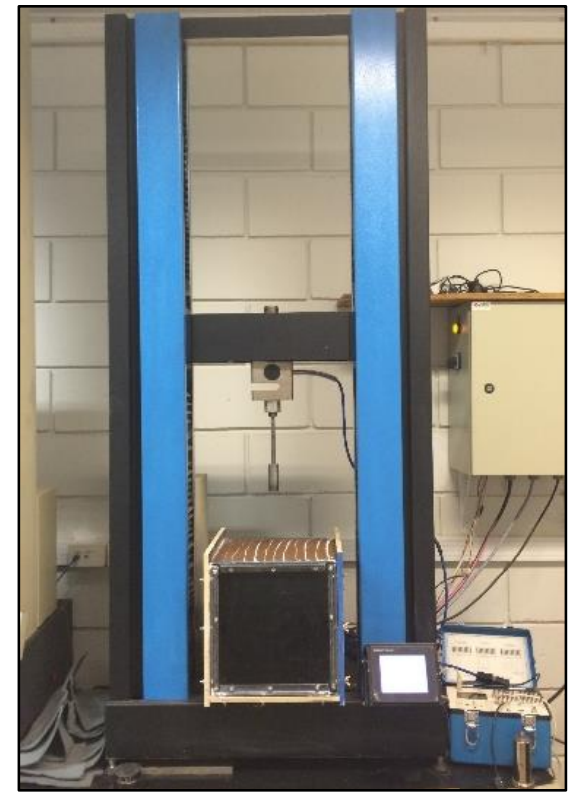

Figura 4.4 - Prensa do Laboratório de Geossintéticos da EESC/USP utilizada nos ensaios

Em cada uma das caixas, foram executadas duas colunas diferentes. No decorrer dos ensaios surgiu a ideia de avaliar o efeito da compactação do pilão mais usual, tipo B, em coluna encamisadas com material sintético. O objetivo principal desta análise foi verificar se haveria interferência do encamisamento na compactação da coluna.

O material utilizado como membrana de revestimento foi um preservativo, constituído por látex, com diâmetro de $5,2 \mathrm{~cm}$. Como a suas dimensões eram maiores do que as dimensões do pilão, o material permitiu a movimentação lateral do solo de preenchimento da coluna. A disposição dos ensaios em cada caixa ensaiada está esquematizada na Figura 4.5.

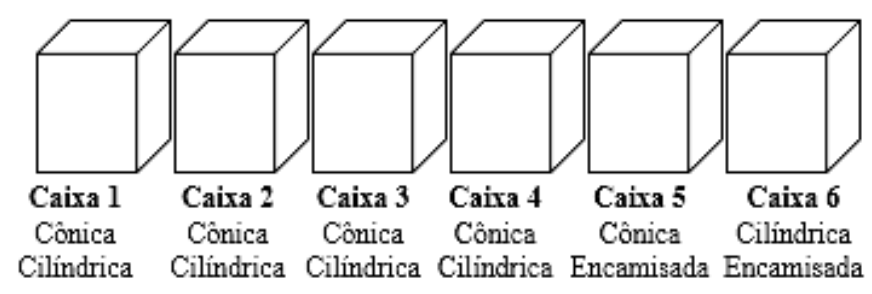

Figura 4.5 - Disposição dos ensaios (dois ensaios em cada caixa)

Após a execução das colunas, as caixas foram transportadas ao laboratório para que fosse feita a análise qualitativa de cada coluna. Nesta análise foram avaliados parâmetros como: profundidade final de cada coluna e variação do diâmetro ao longo da profundidade. Além disso, também foi avaliada a similaridade dos resultados encontrados nos ensaios.

Para que esta análise fosse possível, uma das faces da caixa foi removida para permitir a escavação do solo. Com o auxílio de uma espátula, o solo foi removido até que o 
centro das colunas fosse alcançado. Como o solo utilizado nas colunas era mais claro do que o solo no interior da caixa, foi possível analisar a geometria final das colunas e comparar os resultados encontrados por meio de fotografias. A Figura 4.6 ilustra a fotografia da escavação de uma das caixas ensaiadas.

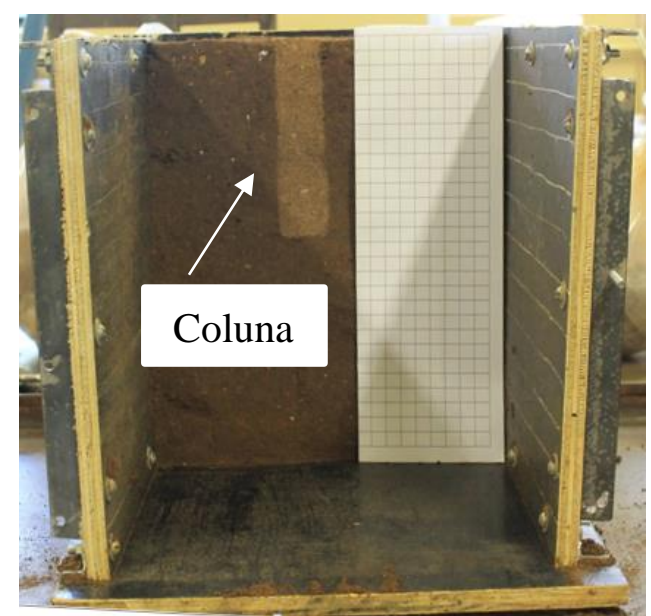

Figura 4.6 - Foto da escavação da caixa 4: coluna executada com pilão tipo B

\subsection{ENSAIOS EM CAMPO}

\subsubsection{Execução das colunas}

No Campo Experimental de Fundações foram executadas duas colunas de solo compactado e uma coluna de solo e brita compactada. Para a confecção das colunas, foi utilizado o equipamento da estaca Strauss constituído por um tripé metálico, roldana e pilão, ilustrado na Figura 4.7. O pilão acoplado ao equipamento é pendurado em um tripé metálico por meio de um cabo de aço e de uma roldana.

O método executivo das colunas foi similar ao da estaca apiloada, que consiste na perfuração do solo por meio da queda livre do pilão. Quando o pilão é liberado, ocorre o deslocamento do solo lateralmente e para baixo, melhorando as condições do solo no entorno do pilão. O furo é aprofundado com o aumento do número de golpes do pilão, permitindo assim a abertura de uma coluna no solo. O furo foi executado até que fosse atingida a profundidade de 3,5 m abaixo do nível do terreno, como mostra a Figura 4.12.

O pilão utilizado nos ensaios possuía diâmetro de $216 \mathrm{~mm}$ (8,5 polegadas), 1,70 $\mathrm{m}$ de altura, e o seu peso era de aproximadamente $700 \mathrm{~kg}$. A altura da torre do equipamento era da 
ordem de $5 \mathrm{~m}$. Porém, não se pode controlar a altura de queda livre do pilão, uma vez que em cada golpe a altura atingida dependia do operador.

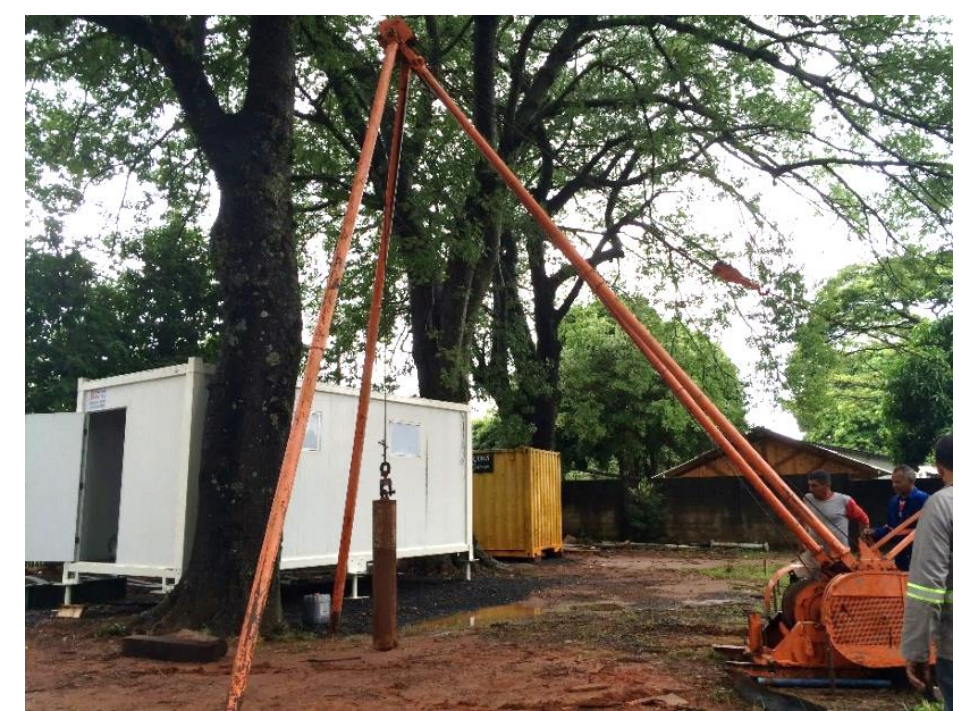

Figura 4.7 - Equipamento utilizado na execução das colunas

Para o preenchimento das colunas de solo compactado, foi retirado solo do próprio Campo Experimental de Fundações, com o auxílio de uma retroescavadeira. Devido à dificuldade de modificar as condições de umidade do solo retirado para as condições ótimas, o solo foi compactado no interior da coluna na própria umidade de campo, que na época da execução das colunas estava com umidade igual a $15 \%$. Portanto, a coluna foi compactada com umidade de $2 \%$ a mais do que a umidade ótima, ou seja, no ramo úmido da curva de compactação.

$\mathrm{Na}$ fase de perfuração do solo para a execução das colunas, o pilão sofria algumas variações do seu alinhamento durante a queda livre, fazendo com que houvesse o alargamento do furo com relação ao seu diâmetro. Observou-se na superfície, após a fase de perfuração do solo, que o diâmetro final da coluna era de aproximadamente $25 \mathrm{~cm}$.

O solo retirado foi disposto em camadas no interior da coluna e para a execução de cada camada foi colocado um balde cheio de solo com o auxílio de um funil, como ilustra a Figura 4.8. A massa de solo de cada balde, com umidade de $15 \%$, correspondia a aproximadamente $14 \mathrm{~kg}$. Adotando-se $25 \mathrm{~cm}$ como o diâmetro final do furo, e conhecendo-se a massa específica seca máxima do solo, do ensaio de compactação do solo em laboratório, foi possível determinar a altura final desejada para cada camada, neste caso o valor adotado foi de $12 \mathrm{~cm}$. 


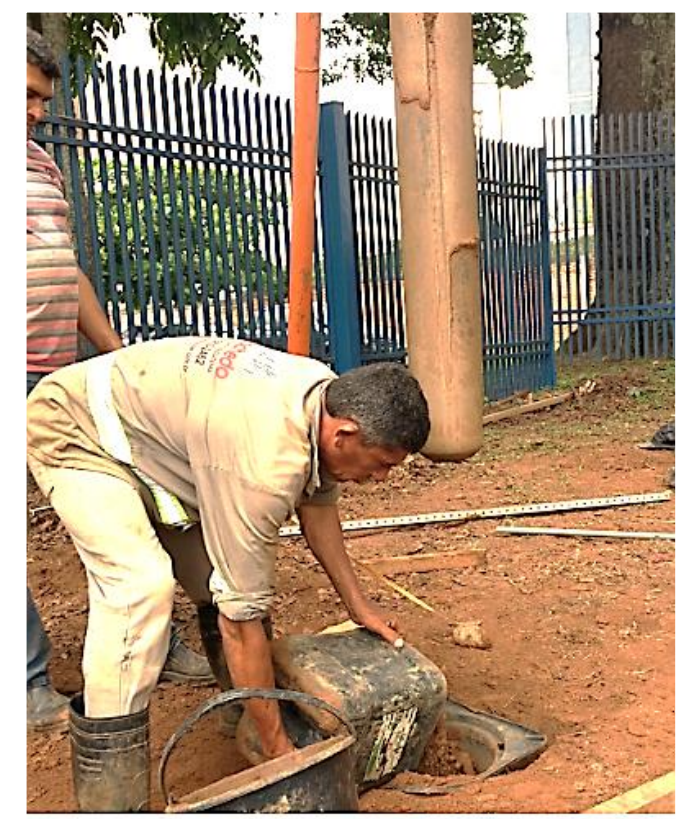

Figura 4.8 - Preenchimento da coluna durante a execução

Inicialmente, objetivava-se estimar o número de golpes necessários para que cada camada atingisse a altura final desejada. Para isto, foram aplicados 2 golpes do pilão e em seguida, pela diferença de cotas medida antes e após o preenchimento da coluna, era possível conhecer a altura da camada. O processo foi repetido até que a variação da altura da camada compactada desejada fosse alcançada, determinando assim o número de golpes ideal para a compactação de cada camada.

Porém, durante a execução de uma coluna teste feita para estimar o número de golpes ideal para cada camada, notou-se que para as camadas inferiores, quando eram aplicados golpes para atingir a altura desejada de camada compactada, ocorria o afundamento total da camada, de modo que a profundidade do topo do material compactado ficava igual à profundidade do fundo do furo anteriormente ao preenchimento com solo. Para as quatro primeiras camadas esse processo se repetiu. Portanto, para as demais camadas, a compactação foi controlada pela variação da altura da camada a cada golpe, até que fosse atingida uma altura aproximadamente igual a $12 \mathrm{~cm}$, com variação em torno de $\pm 2 \mathrm{~cm}$ para mais ou para menos, o que tornou a execução das colunas mais lenta. Adotou-se este último método para a execução das colunas que foram ensaiadas, medindo-se a variação da altura da camada a cada golpe. O número de golpes para compactar cada camada variou de 6 a 15, sendo que o número de golpes era maior para as camadas mais superficiais.

Além das colunas de solo compactado, também foi executada uma coluna de solo e brita sendo que $30 \%$ da mistura era constituída de solo, retirado do próprio Campo 
Experimental, e $70 \%$ de brita tipo 1 . O método executivo foi o mesmo da coluna de solo compactada, sendo lançado um balde da mistura, e aplicada a mesma quantidade de golpes para a altura final de cada camada fosse cerca de $12 \mathrm{~cm}$.

O intuito de executar esta coluna de solo e brita foi de comparar os resultados de eficiência encontrados para esta coluna, com os resultados encontrados para as colunas de solo compactado. Conhecendo o real desempenho de cada uma delas, foi possível analisar qual método melhor funcionaria como reforço de solo para a redução dos efeitos do colapso. A Figura 4.9 apresenta a relação das colunas executadas em campo.

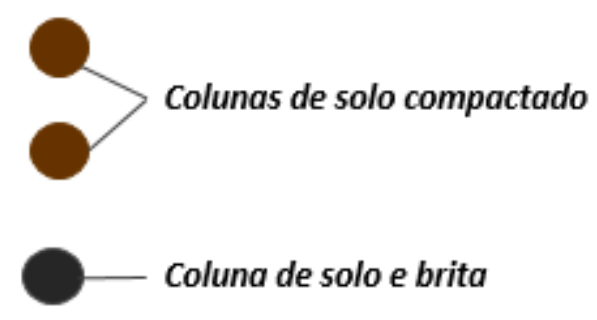

Figura 4.9 - Relação das três colunas executadas em campo

Durante a execução das colunas de reforço, foram retiradas três amostras em três pontos ao longo da sua profundidade para a determinação do teor de umidade do solo durante a execução das colunas. Os teores de umidade encontrados para cada coluna estão apresentados na Tabela 4.1 .

Tabela 4.1 - Teores de umidade do solo ao longo da profundidade durante a execução das colunas

\begin{tabular}{|cc|cc|cc|}
\hline \multicolumn{2}{|c|}{ Coluna de Solo Compactado 1} & \multicolumn{2}{c|}{ Coluna de Solo Compactado 2} & \multicolumn{2}{c|}{ Coluna de Solo e Brita } \\
\hline Prof. (m) & $\boldsymbol{w}(\%)$ & Prof. $(\boldsymbol{m})$ & $\boldsymbol{w}(\%)$ & Prof. (m) & w (\%) \\
\hline 1,30 & 13,4 & 1,25 & 14,4 & 1,16 & 5,4 \\
2,50 & 14,5 & 1,74 & 15,3 & 2,40 & 4,9 \\
3,35 & 13,8 & 3,03 & 14,2 & 3,52 & 7,4 \\
\hline
\end{tabular}

\subsubsection{Análise da eficiência do reforço}

A avaliação da eficiência da técnica de melhoria do solo foi feita por meio de provas de carga em placa em solo com e sem reforço com colunas. Além disso, também foi avaliado o efeito radial da compactação no entorno da coluna. O objetivo desta análise é identificar o efeito da compactação no solo circundante à coluna. 


\subsubsection{Prova de carga em placa}

Para análise do reforço, foram executadas cinco provas de carga estáticas tipo lenta, seguindo as recomendações da norma ABNT NBR 6489/1996, com carregamento de $20 \mathrm{kPa}$. Sobre as duas colunas de solo compactado, foram realizadas duas provas de carga em placa, sendo a primeira coluna ensaiada na condição inundada e a segunda coluna na condição de umidade natural do terreno. Como a resistência do solo não saturado varia com a umidade, é fundamental determinar o valor da sucção no momento da execução do ensaio de prova de carga não inundado. Para isto, foi instalado um tensiômetro próximo ao local do ensaio não inundado, para determinar a sucção do solo durante o ensaio.

O objetivo de realizar um ensaio inundado e outro em condição natural de umidade foi analisar se haveria variações nos resultados das curvas carga $x$ recalque dos ensaios em solo reforçado, uma vez que o efeito da sucção é menos influente em solos compactados. Além disso, como a condição inundada é flagrante para o efeito do colapso, foi possível analisar se as colunas compactadas reduziram ou não o colapso, refletido no ganho de capacidade de carga do solo.

A terceira prova de carga em placa executada foi sobre a coluna de solo e brita na condição inundada. Como só havia sido executada uma coluna de solo e brita, esta foi ensaiada para a condição inundada (mais desfavorável).

Para verificar o efeito do reforço, foram executadas duas provas de carga estáticas em placa no solo sem reforço, nas condições inundada e natural. A sucção do solo no ensaio realizado na condição natural, foi determinada por um tensiômetro instalado próximo ao local do ensaio. A relação das provas de carga realizadas neste trabalho está apresentada na Figura 4.10.

O ensaio de prova de carga em placa no terreno sem reforço foi inicialmente conduzido na condição de umidade natural do terreno. Em seguida, na mesma cava, foi realizado o ensaio na condição inundada explicitada no item a). 


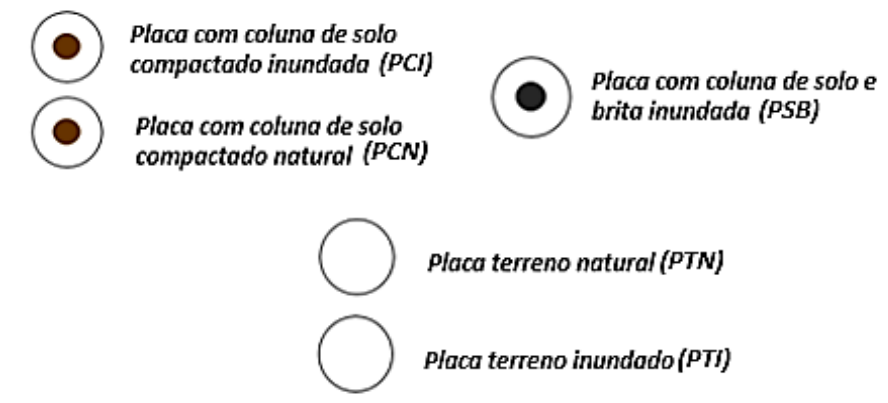

Figura 4.10 - Relação dos ensaios de prova de carga em placa no terreno com e sem reforço

Com a finalidade de simplificar a análise do reforço, foi considerado que cada sistema placa+coluna se comportaria como uma "célula unitária" sob o efeito do carregamento, uma vez que, para reforçar o solo de apoio da fundação direta geralmente é necessário um número significativo de colunas.

Cada prova de carga realizada em sistema placa+coluna foi interpretada como uma célula unitária constituinte de uma malha de distribuição quadrada. Isso se justifica pois o diâmetro da placa utilizada corresponde ao diâmetro equivalente $(D e)$, proposto por Bergado et al. (1994) e Alamgir et al. (1996), que inclui o efeito de densificação do solo provocado pela compactação das colunas.

O diâmetro final da coluna foi considerado como $25 \mathrm{~cm}$, e o diâmetro da placa utilizada no ensaio era de $80 \mathrm{~cm}$. De acordo com a bibliografia, o raio de influência do efeito de compactação no entorno da coluna é de aproximadamente 1,5 vezes o seu diâmetro. Portanto, como o diâmetro considerado foi de $25 \mathrm{~cm}$, o raio de influência seria em torno de $37,5 \mathrm{~cm}$.

Sabendo-se que, para uma malha quadrada o diâmetro equivalente $(D e)$ pode ser calculado pela Equação (4.1) e conhecendo-se o diâmetro da coluna e da placa, é possível concluir que o diâmetro equivalente $D e$ é de aproximadamente igual ao diâmetro da placa, justificando a análise do ensaio como uma "célula unitária" (pela Equação 4.1, $D e=1,13.75=84,7 \mathrm{~cm}$, e o diâmetro da placa usada nos ensaios foi de $80 \mathrm{~cm}$ ). A razão de substituição para este caso $\left(\mathrm{a}_{\mathrm{c}}\right)$, que é a razão entre a área da coluna e a área da célula, é de 0,09. A Figura 4.11 ilustra as considerações realizadas.

$$
\begin{aligned}
& D_{e}=\left(\frac{16}{\pi^{2}}\right)^{1 / 4} \cdot s \\
& D_{e}=1,13 \cdot s
\end{aligned}
$$




\section{Sapata reforçada com quatro colunas}
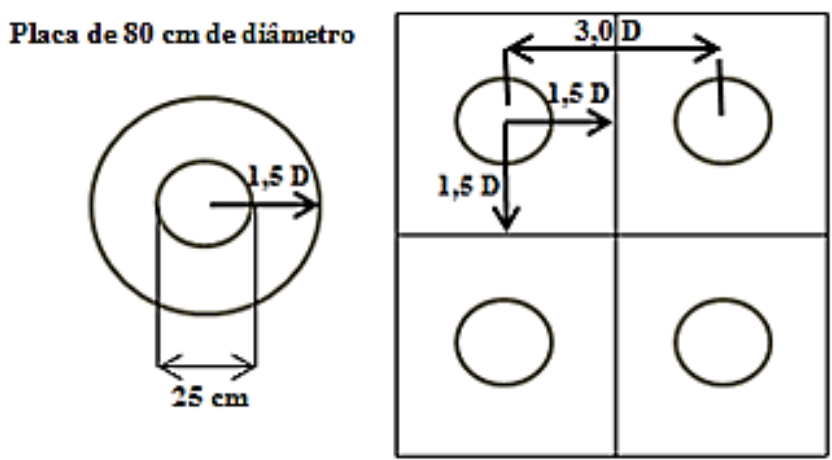

Figura 4.11 Relação entre o efeito do reforço de solo e a placa utilizada no ensaio de prova de carga

Antes da execução das provas de carga, foi aberto um poço com profundidade de 1,5 $\mathrm{m}$, com a finalidade de remover a camada de aterro do terreno. A placa foi apoiada na base desta cava, como ilustrado na Figura 4.12, e centralizada na coluna. Portanto, para baixo da placa restaram $2 \mathrm{~m}$ de coluna compactada. Como a placa utilizada nos ensaios possuía $80 \mathrm{~cm}$ de diâmetro, o bulbo de tensões atingiu à profundidade de $1,6 \mathrm{~m}$, sendo os $2 \mathrm{~m}$ restantes de coluna suficientes para o ensaio.

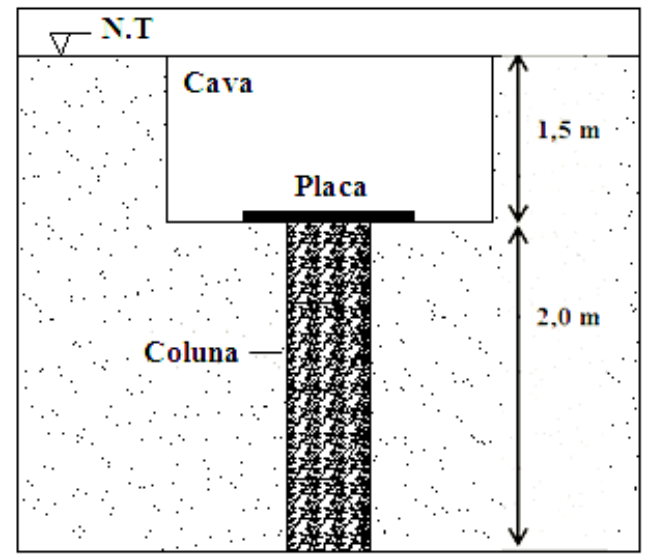

Figura 4.12 - Esquematização do ensaio nas colunas

\section{a) Processo de inundação}

Nas provas de carga em placa realizadas em outros trabalhos geralmente a inundação do solo é feita no estágio correspondente à tensão admissível provável ou em algum outro estágio de tensão (AGNELLI, 1992; TEIXEIRA, 1993; CARVALHO e SOUZA, 1990). A curva obtida neste ensaio para solos com comportamento colapsível possui uma descontinuidade, sofrendo um aumento do recalque acentuado. Porém, a grande dificuldade de 
conduzir ensaios desta forma é que não se conhece exatamente em qual carga o colapso ocorrerá.

Outro método de se conduzir a inundação do ensaio de prova de carga, utilizado por autores como Reznik (1993), Miguel (1996) e Costa (1999), consiste em realizar a inundação antes do início do ensaio de prova de carga. Desta forma, o colapsibilidade do solo não se manifestará por um recalque abrupto, mas sim pela redução da capacidade de carga e aumento dos recalques quando comparada com um ensaio realizado em terreno natural.

Neste trabalho foram utilizados os dois métodos de inundação supracitados. Para as provas de carga inundadas com colunas (de solo compactado e solo e brita), a inundação da cava foi feita antes do início do ensaio. Para isto, uma mangueira foi acoplada à uma torneira com água potável proveniente da rede pública e esta mangueira foi levada até o local do ensaio. Foi mantida uma lâmina de água constante durante um período não inferior a 24 horas, como ilustrado na Figura 4.13.

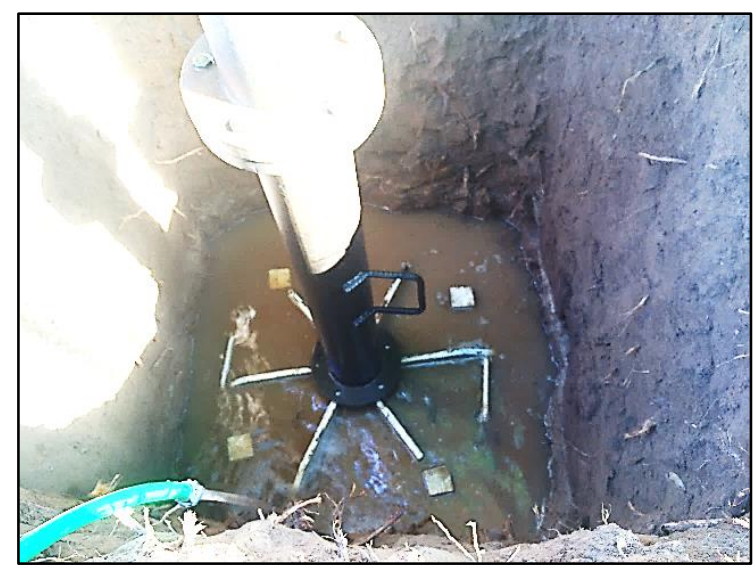

Figura 4.13 - Inundação do solo de apoio da placa para a prova de carga inundada

A sucção do solo na época dos ensaios estava muito baixa devido às constantes chuvas. Antes de começar a inundação da cava, o tensiômetro marcava uma sucção de $11 \mathrm{kPa}$. Ao iniciar a inundação, foram feitas leituras do tensiômetro de hora em hora, e a sucção chegou a quase zero após quatro horas. Portanto, conclui-se que o tempo de inundação mantido neste ensaio foi suficiente para zerar a sucção.

No ensaio realizado em solo sem reforço, desejava-se obter uma curva que ilustrasse o efeito do colapso do solo. Por isso, inicialmente, a prova de carga foi conduzida com uma sucção de $6 \mathrm{kPa}$. Com a curva carga-recalque obtida neste ensaio, foi possível determinar a tensão admissível para o solo ensaiado. 
Na mesma cava foi conduzido um reensaio com a mesma sucção mantida até que o estágio referente à tensão admissível fosse alcançado. Quando atingido, foi iniciada a inundação e os recalques foram medidos até a sua estabilização. Quando estabilizado, continuou-se o ensaio e os carregamentos com o solo na condição inundada.

\section{b) Materiais utilizados}

\section{Placa}

A placa utilizada nos ensaios de prova de carga possui formato circular, diâmetro de $0,80 \mathrm{~m}$, espessura de $1,5 \mathrm{~cm}$, resultando em uma área de $0,50 \mathrm{~m}^{2}$. As chapas soldadas na parte superior da placa, proporcionam uma maior rigidez ao conjunto, que pesa aproximadamente $150 \mathrm{~kg}$. Antes de apoiar a placa sobre o terreno, foi feito o nivelamento do solo de apoio com uma fina camada de areia. A Figura 4.14 mostra a placa utilizada nos ensaios.

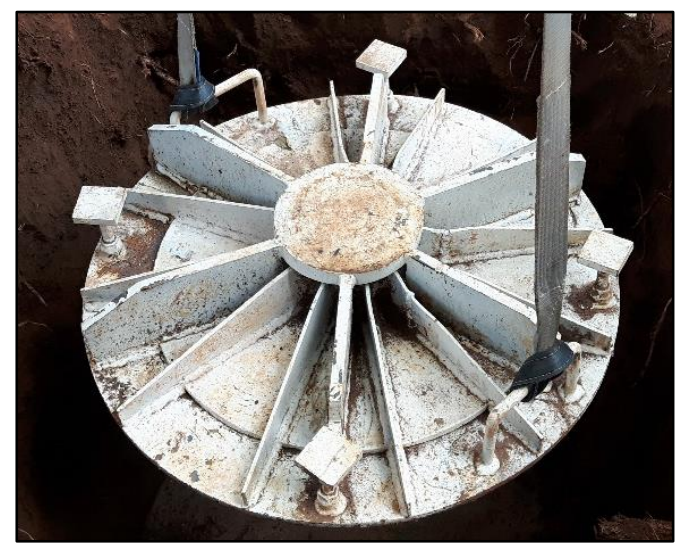

Figura 4.14 - Placa utilizada nos ensaios de prova de carga

\section{Macaco hidráulico e bomba}

Para a realização dos ensaios, foi utilizado um macaco hidráulico, cuja capacidade de aplicação de carga era de $500 \mathrm{kN}$. O acionamento do macaco foi efetuado por uma bomba manual. Os carregamentos eram aplicados através do macaco até que as cargas desejadas fossem atingidas, sendo mantidas até o término de cada estágio. O macaco hidráulico e a bomba utilizada estão apresentados na Figura 4.15. 

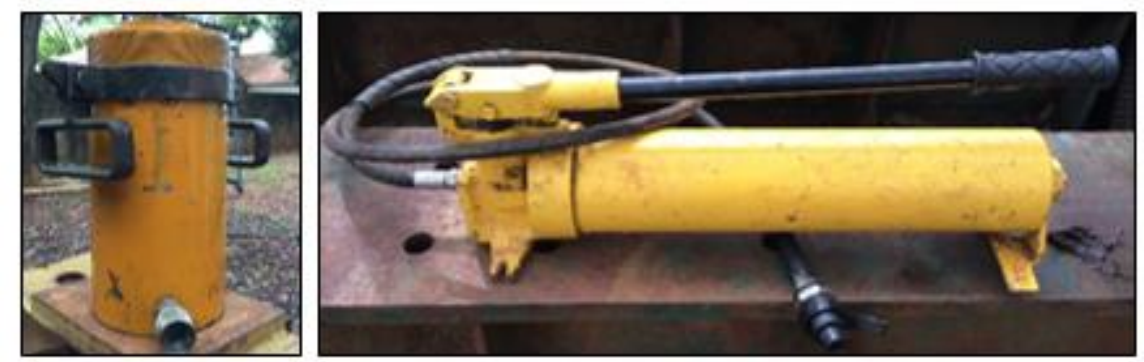

Figura 4.15 - Macaco hidráulico e bomba utilizados nos ensaios

\section{Célula de carga}

Nos ensaios foi utilizada uma célula de carga com capacidade de 100 tf. Esta célula foi acoplada a um painel de leitura digital, da marca Alfa, para a leitura e controle da aplicação de carga. A célula utilizada havia sido calibrada e aferida em laboratório antes da realização dos ensaios (Figura 4.16).

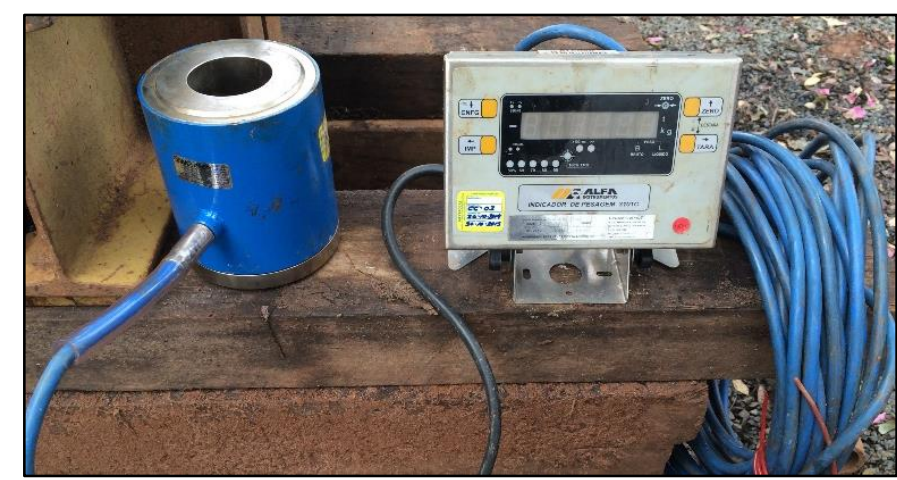

Figura 4.16 - Célula de carga utilizada nos ensaios

\section{Torre de transferência}

Como foram abertas as cavas para ultrapassar as camadas de aterro, com 1,5 m de profundidade, para que o ensaio fosse realizado sem que houvesse a interferência dos efeitos desta camada, foi necessário utilizar torres de transferência para permitir que a carga aplicada na superfície pelo conjunto macaco e bomba, fosse transferida ao centro da placa, apoiada na base da cava, e distribuída no solo.

Foram utilizadas duas torres, uma com 1,50 m de altura e a outra com 1,20 m, emendadas com 5 parafusos (Figura 4.17). As torres de transferência possuíam diâmetro externo de aproximadamente $170 \mathrm{~mm}$ e a espessura da parede de aço era de $10 \mathrm{~mm}$. Como observado na Figura 4.17, a torre possuía dois discos, com $25 \mathrm{~mm}$ de espessura 
e $30 \mathrm{~cm}$ de diâmetro, soldados nas extremidades do cilindro para permitir uma melhor distribuição da carga aplicada. Segundo Costa (1999), a tensão admissível das torres de transferência é de aproximadamente $100 \mathrm{MPa}$.

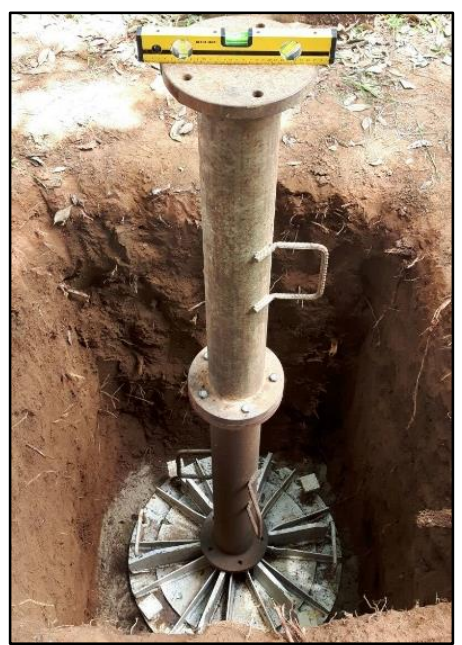

Figura 4.17 - Torre de transferência de carga utilizada nos ensaios

\section{Extensômetros mecânicos}

Para as leituras dos recalques foram utilizados quatro extensômetros mecânicos da marca Mitutoyo, com resolução de $0,01 \mathrm{~mm}$ e curso total de $50 \mathrm{~mm}$. As bases magnéticas dos extensômetros foram fixadas na torre de transferência de modo que ficassem diametralmente opostos, como ilustrado na Figura 4.18. Como as cargas aplicadas nos ensaios eram muito baixas, foi desconsiderada a deformação elástica das torres de transferência. Desta forma, a média aritmética das quatro leituras permitiria determinar o recalque médio de cada estágio.

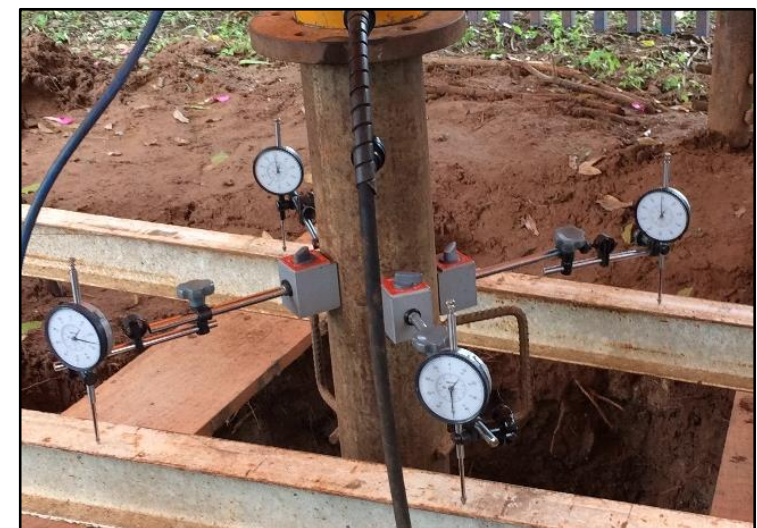

Figura 4.18 - Instalação dos extensômetros mecânicos para medir o deslocamento vertical da placa nas provas de carga 


\section{Vigas de referência}

As vigas de referência utilizadas nos ensaios foram dois perfis tipo I metálicos, com cerca 3,0 m de comprimento. As vigas foram apoiadas em cavaletes metálicos, distantes da região ensaiada (Figura 4.19).

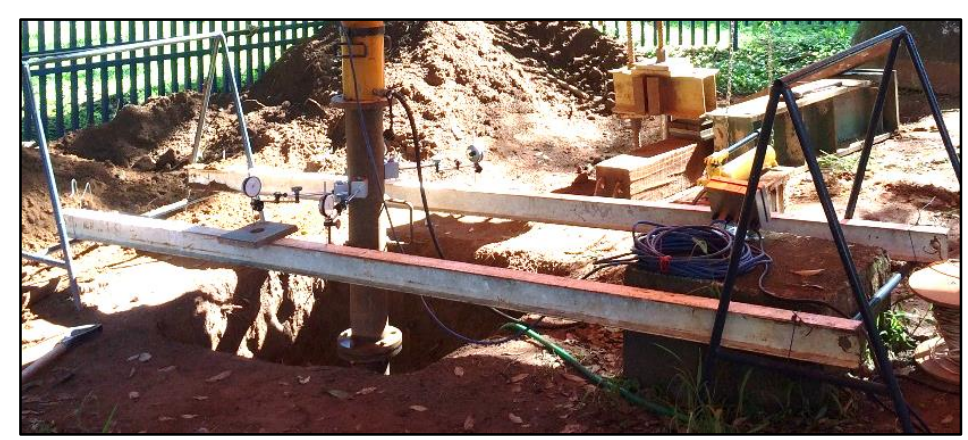

Figura 4.19 - Vigas de referência utilizadas nos ensaios

\section{c) Sistema de Reação}

O sistema de reação foi formado por uma viga metálica em I (bitola W 610 x 101,0), com $4 \mathrm{~m}$ de comprimento, ligada às estacas de reação por uma composição de tirantes (aço Dywidag normalizado ST 85/100) com diâmetro de $32 \mathrm{~mm}$. A carga foi aplicada pelo macaco hidráulico na viga, e a composição de barras transmitiram essas cargas às estacas de reação. A Figura 4.20 ilustra o esquema geral das provas de carga realizadas.

Como estaca de reação foram utilizadas estacas do tipo raíz, já instaladas no campo e utilizadas como reação de outras pesquisas. Estas estacas possuíam diâmetro de $25 \mathrm{~cm}$ e $16 \mathrm{~m}$ de profundidade. Para a prova de carga na coluna de solo e brita, foi utilizada uma estaca raiz e foi necessário instalar uma estaca helicoidal como reação pois no local disponível para os ensaios, não havia mais estaca de reação disponível. A estaca helicoidal utilizada como reação possui três hélices, $14 \mathrm{~m}$ de profundidade e capacidade de carga de 25 tf. 


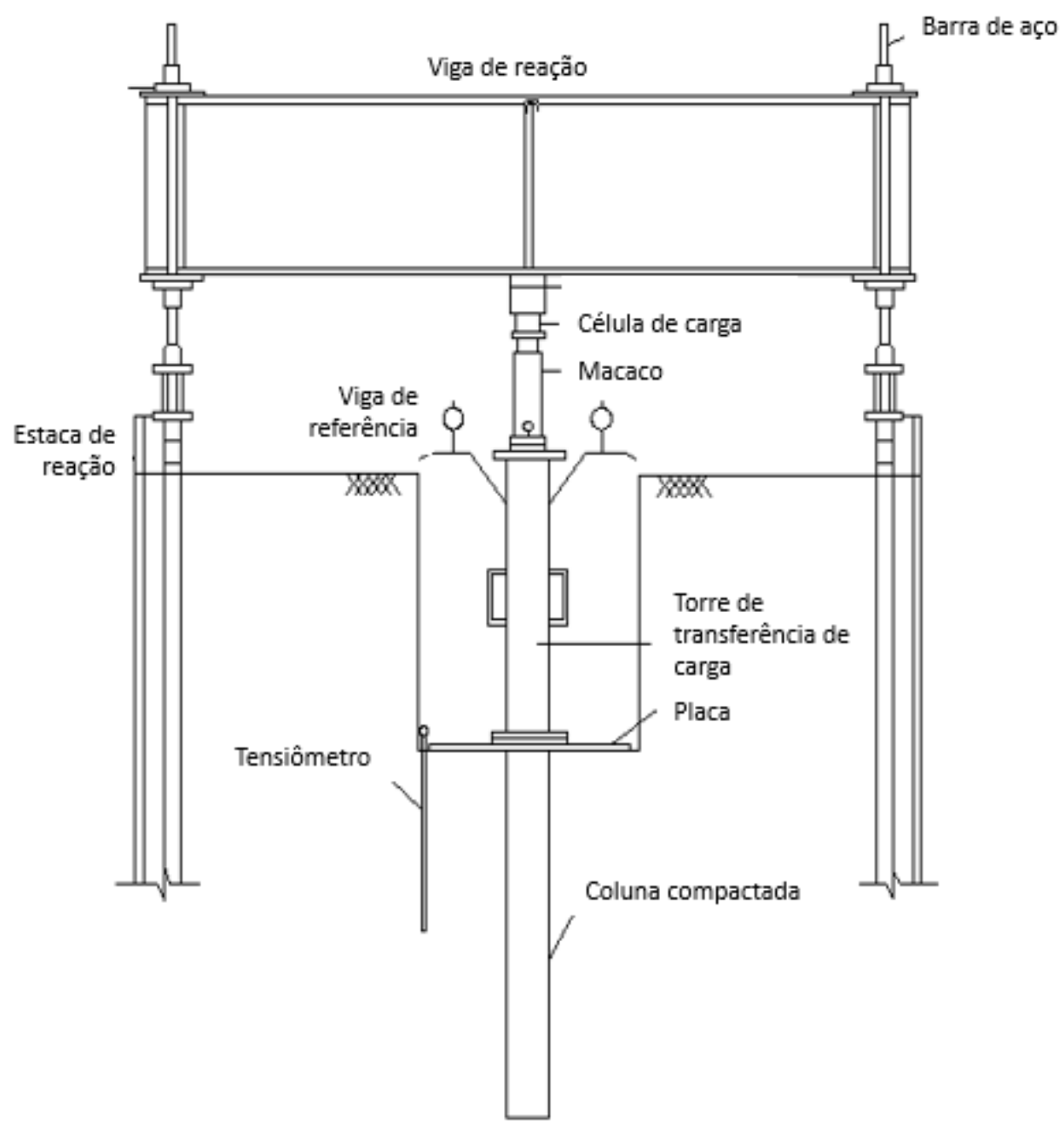

Figura 4.20- Esquema das provas de carga realizadas

\section{d) Medidas de sucção}

Para as provas de carga realizadas nas condições de umidade natural, foi necessário medir a sucção no momento do ensaio. Para isto, foram instalados tensiômetros no interior da cava, próximo ao local do ensaio.

Os tensiômetros foram instalados na base da cava, a uma profundidade de $0,5 \mathrm{~m}$ pois desejava-se conhecer a sucção próxima ao centro do bulbo de tensões gerado pela placa pois neste ponto estão concentradas as maiores tensões. A Figura 4.21 ilustra a instalação do tensiômetro no interior da cava.

A marca dos tensiômetros utilizados era Soil Moisture, com um reservatório na parte superior chamado de "jet fill" que facilitou a complementação do nível d'água do tubo, além de contribuir para retirada de bolhas. $\mathrm{O}$ tubo possui diâmetro de aproximadamente 20 milímetros, e a cápsula porosa localizada na extremidade inferior, possui permeabilidade de $10^{-5} \mathrm{~cm} / \mathrm{s}$. 
Antes da sua instalação, os equipamentos foram devidamente saturados em laboratório e verificados para que não houvesse fraturas no tubo e na cápsula porosa. Os tensiômetros foram instalados no campo pelo menos 48 horas antes do início do ensaio de prova de carga. Para a sua instalação foi utilizado um trado, com diâmetro um pouco menor do que o tubo do tensiômetro.

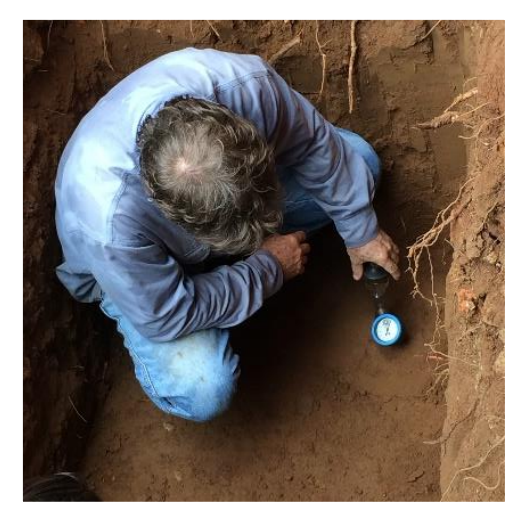

Figura 4.21 - Instalação do tensiômetro no interior da cava

\section{e) Determinação do módulo de deformabilidade equivalente}

Com base nos resultados de prova de carga obtidos em campo, foi estimado o módulo de deformabiliadade equivalente (para o sistema solo+coluna) para a tensão admissível ( $\left.E_{a d m}\right)$ e para os vários níveis de tensão ensaiados (inferiores à tensão admissível) por meio da retroanálise do método de Schmertmann (1978).

Para isto, a placa circular foi transformada em uma sapata quadrada, para determinar a largura da sapata B adota nas equações. Como a placa utilizada possui diâmetro de $80 \mathrm{~cm}$, o valor de B encontrado considerando uma sapata quadrada foi de $71 \mathrm{~cm}$. Além disso, também foi feita a simplificação de que o módulo de elasticidade seria constante até a profundidade $2 \mathrm{~B}$.

Para determinar o módulo, foi feita a divisão do solo em subcamadas até atingir a profundidade $2 \mathrm{~B}$, sendo que cada subcamada possuía a altura de 0,5B. Conhecendo-se os valores de tensão aplicada e o recalque final para cada estágio de carregamento do solo, foi considerado que a somatória dos recalques de cada subcamada deveria ser igual ao recalque encontrado no ensaio de prova de carga, para um determinado nível de tensão, considerando o mesmo módulo de deformabilidade para cada subcamada. Para o cálculo do módulo, foi utilizada a função atingir meta do Excel.

Como o ensaio de prova de carga em placa foi representativo de uma célula unitária do sistema reforçado, o módulo de deformabilidade encontrado foi considerado como um 
módulo de deformabilidade equivalente para o solo reforçado, como se o solo fosse um meio homogêneo. A Figura 4.22 ilustra a simplificação realizada para interpretação dos resultados.

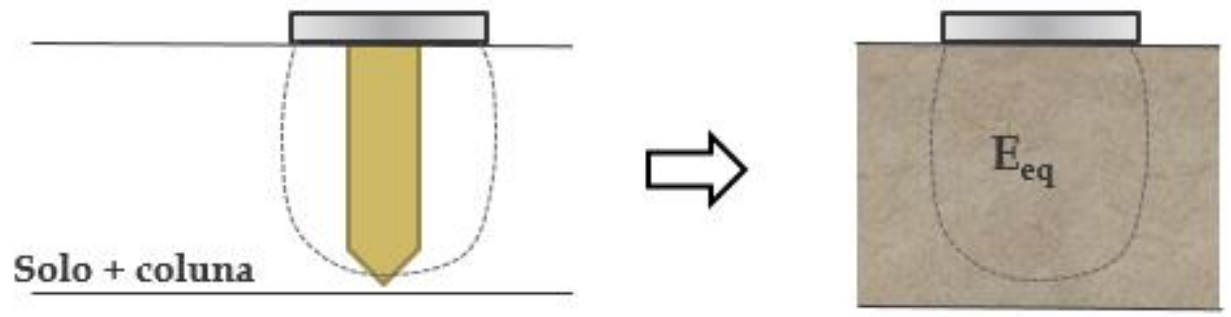

Figura 4.22 - Esquematização da simplificação para o módulo de deformabilidade equivalente

\subsubsection{Análise do efeito da compactação no entorno da coluna}

De acordo com Liu et al. (1985), o raio de influência do efeito da compactação no entorno da coluna é de aproximadamente três vezes o seu diâmetro. Para verificar se esta hipótese é ou não verdadeira, foi avaliada a variação diametral do índice de vazios em volta da coluna.

Para isto, durante a execução da cava para remover a camada de aterro, aproveitou-se a escavação para retirar, a aproximadamente 1,20 m de profundidade, amostras indeformadas com anéis de PVC. Inicialmente, foram retiradas amostras no centro da coluna, e às distâncias de 25, 35 e $45 \mathrm{~cm}$ do centro da coluna, Figura 4.23. As amostras foram levadas ao laboratório para a determinação do índice de vazios de cada anel.

Este procedimento foi executado para as duas cavas com coluna de solo compactado e para a cava com a coluna de solo e brita, porém para a coluna de solo e brita não foi possível tirar a amostra indeformada do seu centro devido à presença das britas. Com os resultados deste ensaio, foi possível analisar os efeitos radiais de compactação das diferentes colunas executadas. 

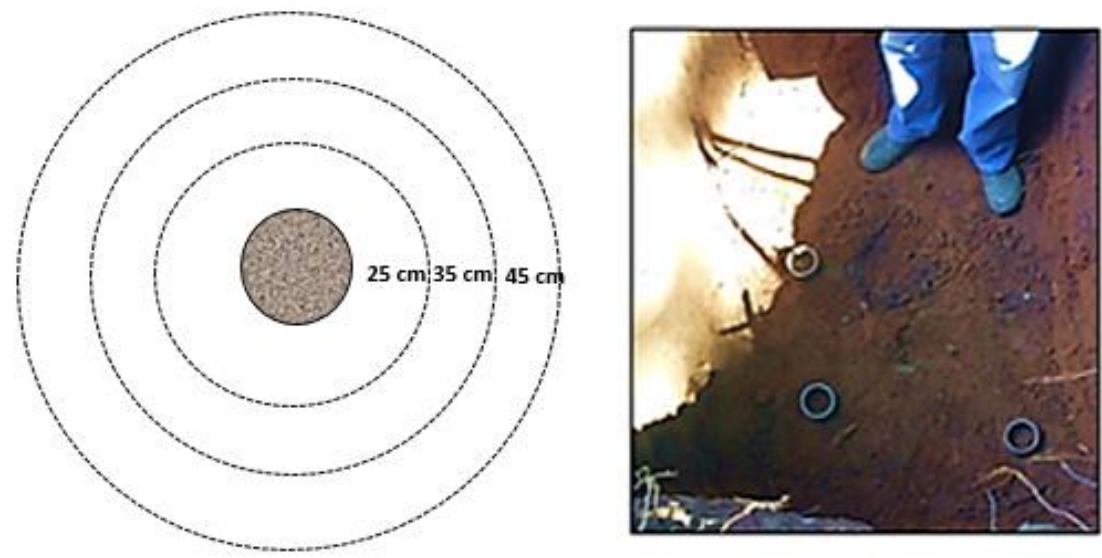

Figura 4.23- Ilustração da disposição das amostras indeformadas retiradas no entorno das colunas 


\section{ANÁLISE E RESULTADOS}

\subsection{ANÁLISE E RESULTADOS DOS ENSAIOS EM LABORATÓRIO}

\subsubsection{Ensaios de caracterização e compactação}

O solo estudado foi classificado como areia média a fina argilosa marrom, composta por $64 \%$ de areia, $28 \%$ de argila e $8 \%$ de silte, como mostra a

Figura 5.1. Para esta composição, o Sistema Unificado de Classificação dos Solos classifica-o como SC - areia argilosa.

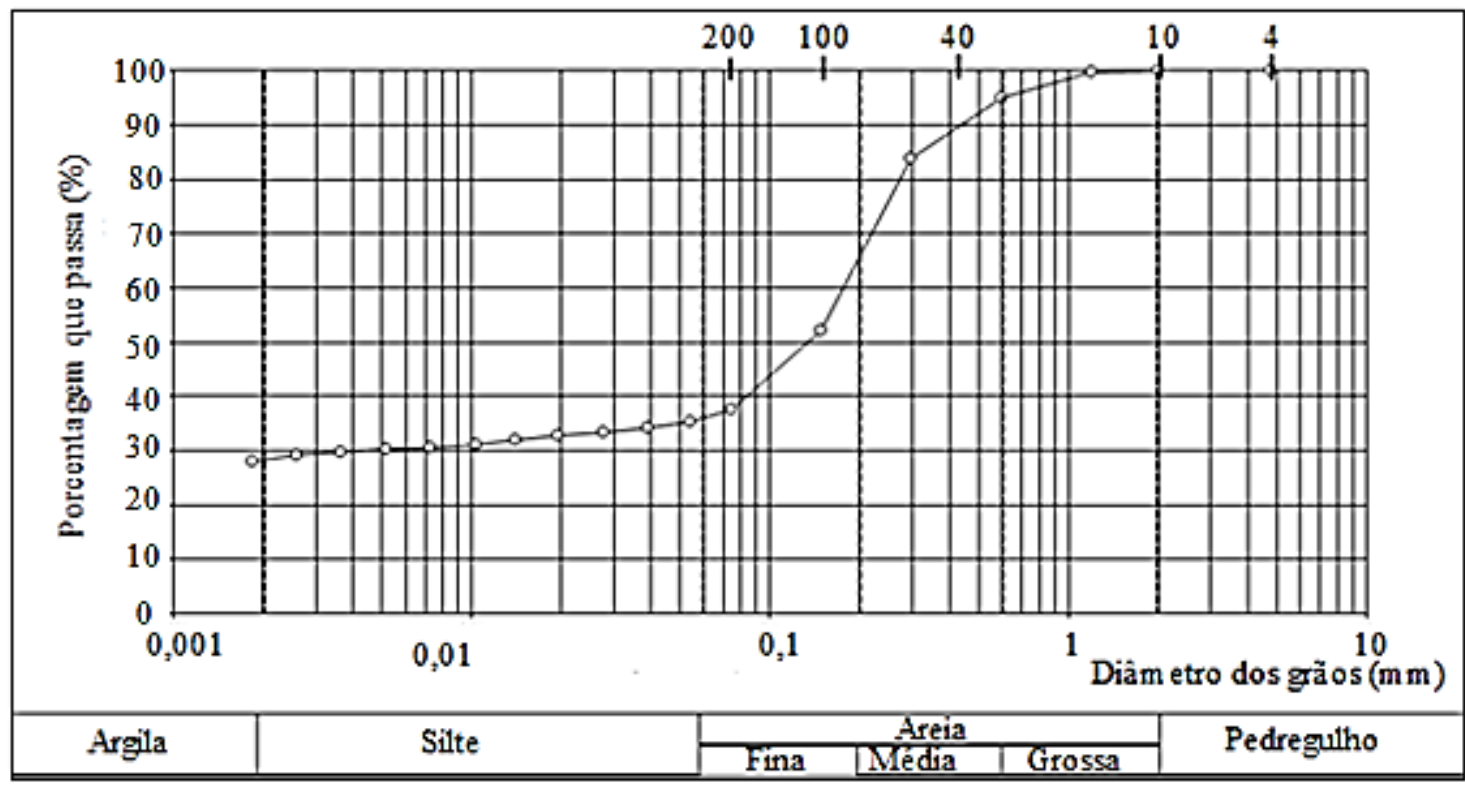

Figura 5.1 - Curva de Granulometria ABNT NBR 6502/95

Os resultados obtidos para a massa específica dos sólidos e os limites de consistência estão apresentados na Tabela 5.1.

Tabela 5.1 - Resultados de massa específica dos sólidos e limites de consistência do solo

\begin{tabular}{|cccc|}
\hline $\begin{array}{c}\text { Massa Especifica dos } \\
\text { sólidos }\left(\boldsymbol{\rho}_{s}\right)\end{array}$ & $\begin{array}{c}\text { Limite de Liquidez } \\
(\text { LL) }\end{array}$ & $\begin{array}{c}\text { Limite de plasticidade } \\
\text { (LP) }\end{array}$ & $\begin{array}{c}\text { Índice de plasticidade } \\
\text { (IP) }\end{array}$ \\
\hline $2,75 \mathrm{~g} / \mathrm{cm}^{3}$ & $29 \%$ & $17,7 \%$ & $11,3 \%$ \\
\hline
\end{tabular}

Para determinação da massa especifica do campo, foram extraídas três amostras indeformadas, a uma profundidade de 1,5 m do nível do terreno, utilizando anéis de PVC com diâmetro interno de $50 \mathrm{~mm}$. Durante a análise, o primeiro anel rompeu não sendo possível 
determinar a massa específica do solo por este método. Neste caso, foi necessário talhar o corpo de prova e determinar a sua massa específica com a utilização da balança hidrostática, seguindo as recomendações da ABNT NBR 10838/1988. Para os outros dois corpos de prova a determinação pôde ser feita utilizando os anéis. Os resultados obtidos nestes ensaios estão apresentados na Tabela 5.2. Conhecendo-se os parâmetros do solo, foi possível determinar também o grau de compactação de $68 \%$ e índice de vazios de 1,05 para o maciço à profundidade de $1,5 \mathrm{~m}$.

Tabela 5.2 - Massa específica do solo do Campo Experimental de Fundações à profundidade de 1,50 m

\begin{tabular}{|lcccc|}
\hline & Anel 1 & Anel 2 & Anel 3 & Valor médio \\
\hline Massa específica $\left(\boldsymbol{\rho} \mathbf{g} / \mathbf{c m}^{3}\right)$ & 1,55 & 1,42 & 1,51 & 1,49 \\
Massa específica aparente $\left(\rho_{\boldsymbol{d}} \mathbf{g} / \mathbf{c m}^{3}\right)$ & 1,39 & 1,27 & 1,35 & 1,34 \\
\hline
\end{tabular}

No ensaio de compactação foi empregada a energia de Proctor Normal em cinco amostras com teores de umidade diferentes. A massa específica aparente seca máxima $\left(\rho_{d \text { máx }}\right)$ encontrada foi de $1,98 \mathrm{~g} / \mathrm{cm}^{3}$ e o teor de umidade ótimo correspondente foi de 13,2\%. A curva de compactação obtida no ensaio está ilustrada na Figura 5.2.

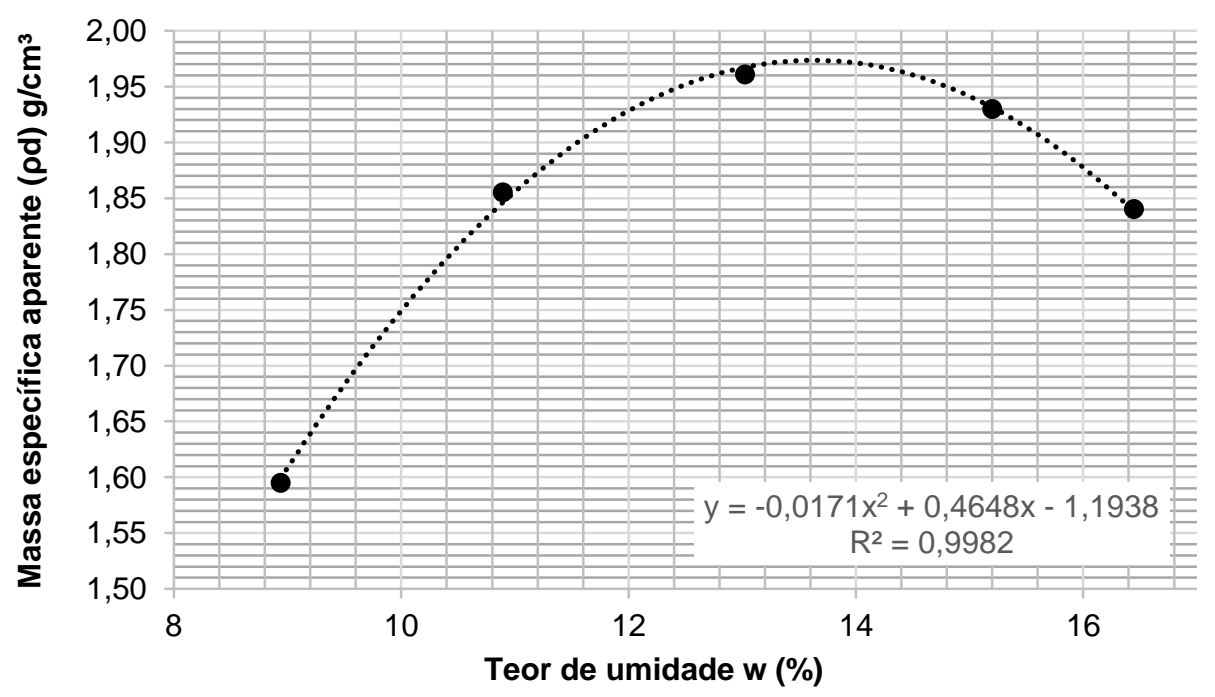

Figura 5.2 - Resultado da curva de compactação na energia Proctor Normal

\subsubsection{Classificação MCT}

Para a classificação do solo com comportamento laterítico estudado, foi utilizado o ensaio MCT. O solo ensaiado foi classificado como laterírico argiloso, como ilustra a Figura 5.3. De acordo com a classificação MCT (Nogami e Villibor, 1995), as propriedades do solo 146 
lateritítico argiloso quando compactado são: baixa expansão, média a elevada contração, baixo coeficiente de permeabilidade e baixo coeficiente de sorção.

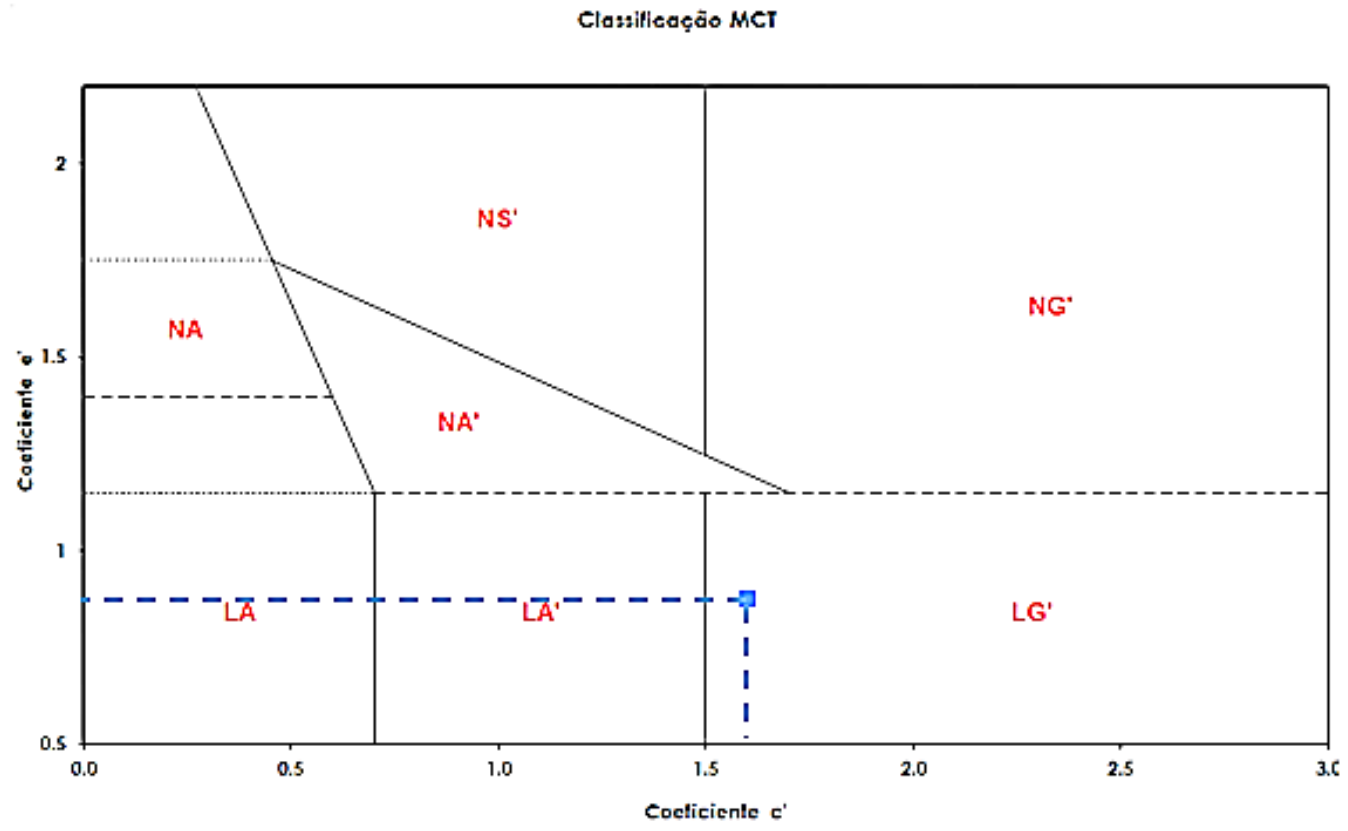

Figura 5.3 - Resultado da classificação MCT

\subsubsection{Execução das colunas de solo compactado em escala reduzida}

Por meio das fotografias tiradas para cada coluna, foi possível identificar algumas características peculiares das diferentes geometrias dos pilões devido à similaridade dos resultados encontrados.

A Figura 5.4 apresenta as geometrias típicas encontradas para os três tipos de colunas ensaiadas. A coluna $\mathrm{E}$ corresponde à coluna encamisada com membrana sintética, executada com o pilão cilíndrico, tipo B. A coluna B corresponde à coluna executada com pilão tipo B, sem encamisamento, e a coluna A representa os resultados encontrados para as colunas executadas com o pilão tipo A (cônico). 


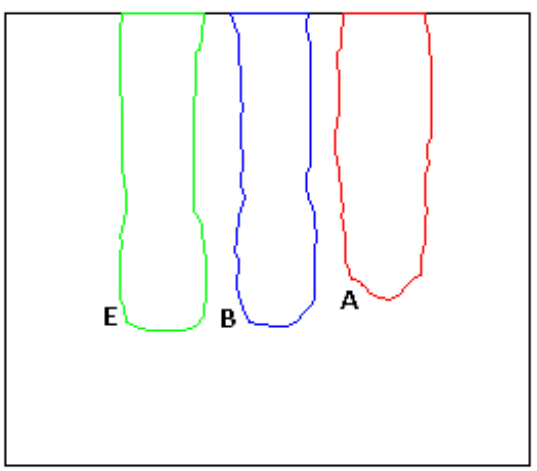

Figura 5.4 - Comparação da geometria final dos três tipos de coluna estudados (E- encamisada; Bpilão tipo B; A- pilão tipo A)

É possível observar que as colunas executadas com o pilão tipo B ficaram mais profundas do que àquelas executadas com o pilão tipo A. Além disso, nota-se também que a coluna A apresentara diâmetro maior ao longo da profundidade do que as colunas B.

Estas diferenças mostram que o pilão B provocou o deslocamento do solo para baixo, ao passo que o pilão A promoveu o deslocamento do solo para as laterais. Quanto ao encamisamento das colunas, nota-se que o material não impediu que ocorresse a movimentação do solo durante a compactação. Além disso, observa-se também uma similaridade entre a geometria das colunas executadas com o pilão tipo B com e sem encamisamento.

A Tabela 5.3 apresenta os valores médios dos resultados encontrados nas fotografias das colunas para as 6 caixas ensaiadas. Os parâmetros avaliados para cada coluna foram a profundidade e a variação do diâmetro ao longo da coluna. Conhecendo-se o diâmetro médio das colunas, a profundidade final de cada uma delas, e a massa de solo adicionada para preenche-las, foi possível determinar o volume final médio e a massa específica de cada coluna.

Tabela 5.3 - Valores médios dos resultados encontrados

\begin{tabular}{|cccc|}
\hline & Ponta Cilíndrica & Encamisada & Ponta Cônica \\
\hline Profundidade $(\mathrm{cm})$ & 13,2 & 13,1 & 12,1 \\
Diâmetro médio $(\mathrm{cm})$ & 3,13 & 3,15 & 3,29 \\
Acréscimo do diâmetro (\%) & $23 \%$ & $24 \%$ & $30 \%$ \\
Volume $\left(\mathrm{cm}^{3}\right)$ & 101,6 & 102,1 & 102,9 \\
$\boldsymbol{\rho}\left(\mathrm{g} / \mathrm{cm}^{3}\right)$ & 1,77 & 1,76 & 1,75 \\
\hline
\end{tabular}

Alguns resultados experimentais de cada caixa são apresentados a seguir com a finalidade de comprovar as diferenças encontradas para as colunas executadas com as diferentes geometrias de pilão. 
As Figuras 5.5 e 5.6 ilustram a comparação dos resultados encontrados nas caixas 3 e 4. Em ambas as caixas, foram executadas duas colunas, sendo uma com o pilão A e outra com o pilão B. Nota-se que as colunas A ficaram mais curtas do que as colunas B nas duas caixas. Além disso, verifica-se que as colunas A ficaram mais grossas do que as colunas B.

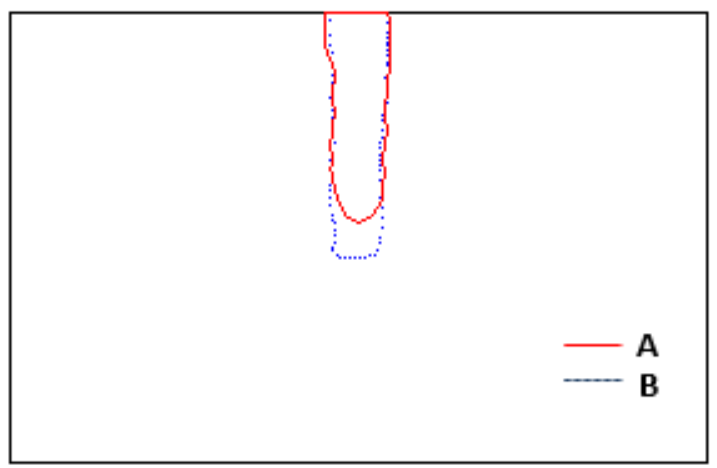

Figura 5.5 - Caixa 3: Comparação entre colunas executadas com pilão tipo A e pilão tipo B

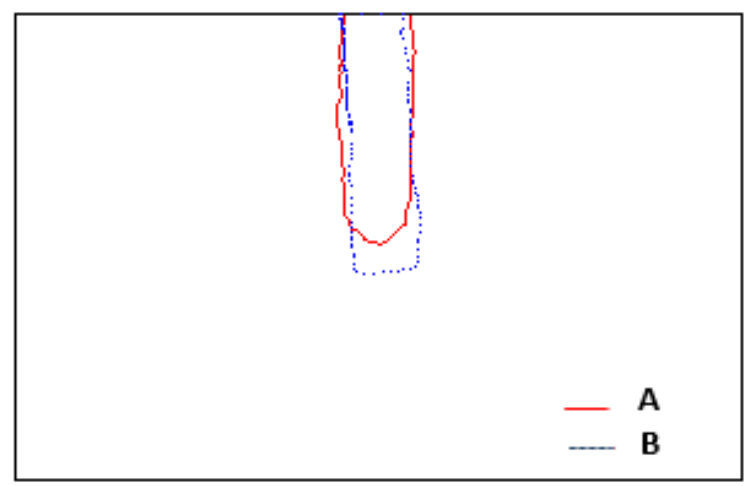

Figura 5.6 - Caixa 4: comparação das colunas executadas com pilão tipo A e pilão tipo B

Na caixa 5 foram executadas duas colunas, ambas com pilão tipo B. Porém, uma delas foi encamisada e a outra não. A Figura 5.7 mostra a comparação dos resultados obtidos para a caixa 4 e a Figura 5.8 apresenta a comparação dos resultados obtidos na caixa 5. Nota-se que para a caixa 5 ambas as colunas apresentam dimensões similares, com profundidades e diâmetros aproximados. Isto mostra que a utilização da camisa sintética não limitou aos efeitos da compactação. 


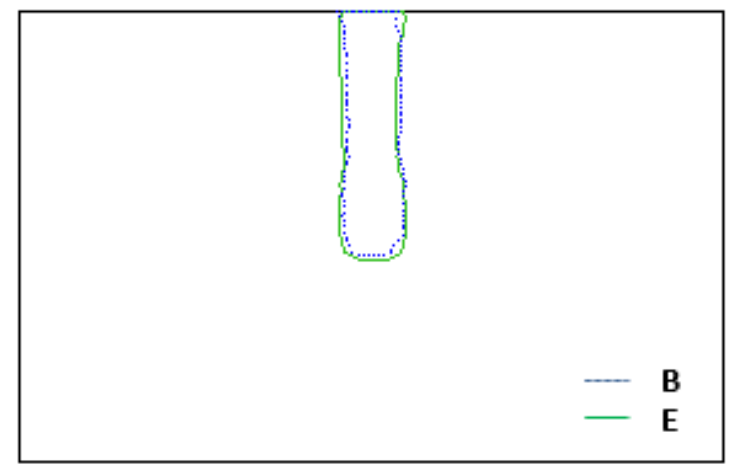

Figura 5.7 - Caixa 5: comparação das colunas executadas com pilão tipo B com e sem encamisamento

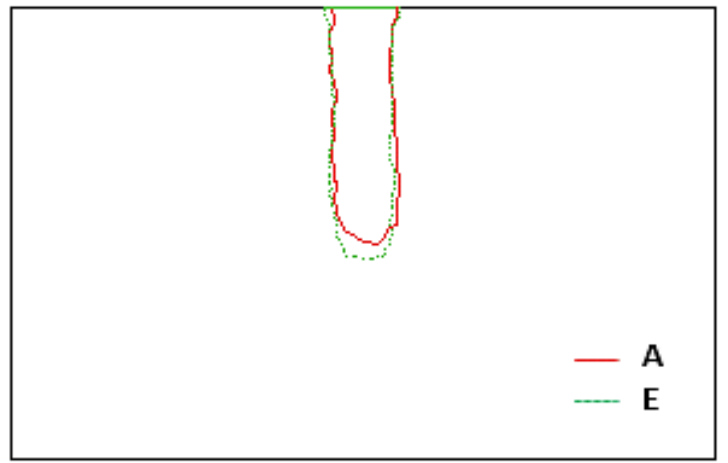

Figura 5.8- Caixa 6: comparação das colunas executadas com pilão tipo A e com pilão tipo B Encamisada

A Figura 5.9 ilustra as fotografias após a escavação das coluna da caixa 4, a Figura 5.10 após a escavação da caixa 5 e a Figura 5.11 mostra as fotos logo após a escavação da caixa 6. A caixa 6 possuía duas colunas sendo uma encamisada, realizada com pilão tipo $B$, e outra sem encamisamento, executada com pilão tipo A. Nas figuras 5.9, 5.10 e 5.11 é possível observar a diferença entre os comprimentos finais das colunas, sendo a coluna E mais longa e mais do que a coluna B, comprovando que o pilão tipo B descola o solo para baixo, ao contrário do pilão tipo A que empurra o solo para as laterais.

Estes resultados das colunas do tipo B, apesar de serem qualitativos, estão de acordo com o comportamento observado durante a execução das colunas em campo, em que foi utilizado um pilão cilíndrico. Como comentado anteriormente neste texto, durante a execução das colunas no campo experimental de Fundações da EESC/USP, observou-se que um grande volume de solo foi deslocado para baixo da cota da base do furo aberto para o preenchimento com solo laterítico compactado. 


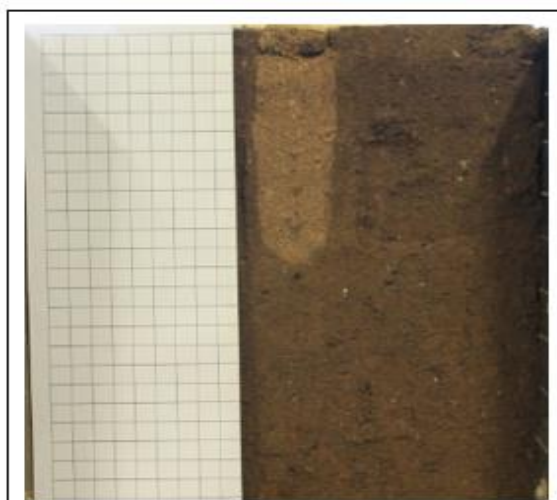

a) Coluna com pilão tipo $\mathrm{A}$

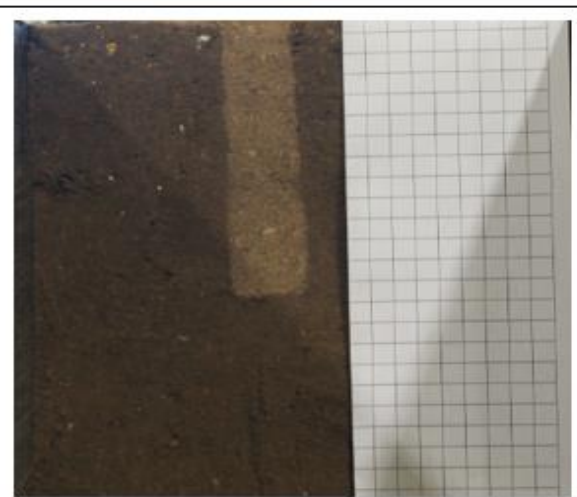

b) Coluna com pilão tipo $B$

Figura 5.9 - Caixa 4: Fotos após a escavação da caixa

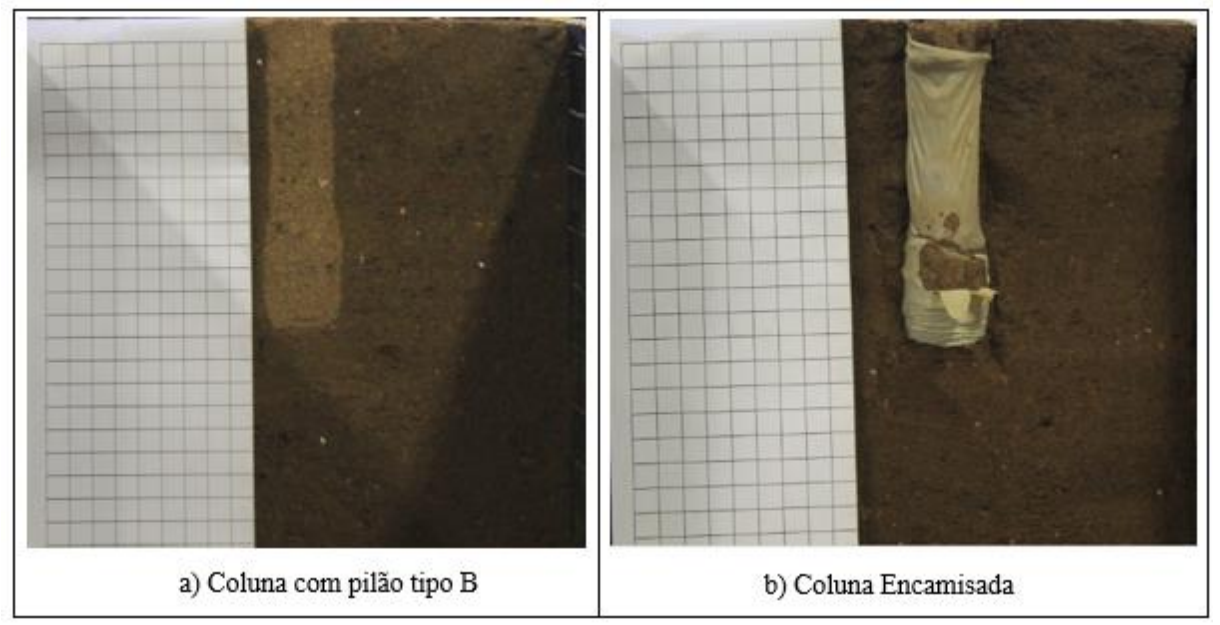

Figura 5.10 - Caixa 5: Fotos após a escavação da caixa

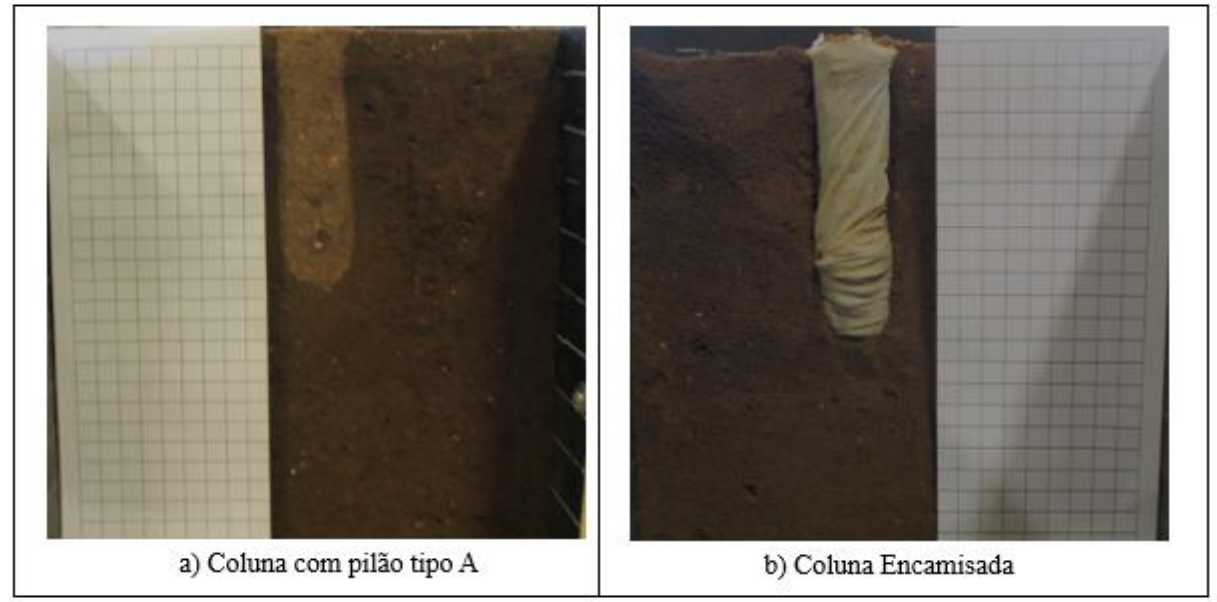

Figura 5.11 - Caixa 6: Fotos após a escavação da caixa 


\subsection{ANÁLISE E RESULTADOS DOS ENSAIOS EM CAMPO}

\subsubsection{Variação do índice de vazios no entorno das colunas}

As disposições dos anéis retirados para avaliar o efeito radial da compactação no entorno das colunas estão apresentadas nas figuras abaixo. Foi considerada como Coluna 1 a coluna de solo compactado ensaiada na condição inundada, e como Coluna 2, a coluna de solo compactada ensaiada na umidade natural do terreno.

Inicialmente, previa-se a retirada de amostras às distâncias de 25, 35 e $45 \mathrm{~cm}$ do centro da coluna, devido ao tamanho da cava executada. Porém, após a execução dos ensaios para a determinação dos valores de índice de vazio, notou-se que ainda havia influência do efeito da compactação em maiores distâncias. Por isto, foram retirados mais dois anéis, à $65 \mathrm{~cm}$ e à 90 cm do centro da coluna, para analisar até qual distância não haveria mais influência do efeito da compactação das colunas.

A Figura 5.12 ilustra a posição dos anéis retirados no entorno da coluna de solo compactado 1 .

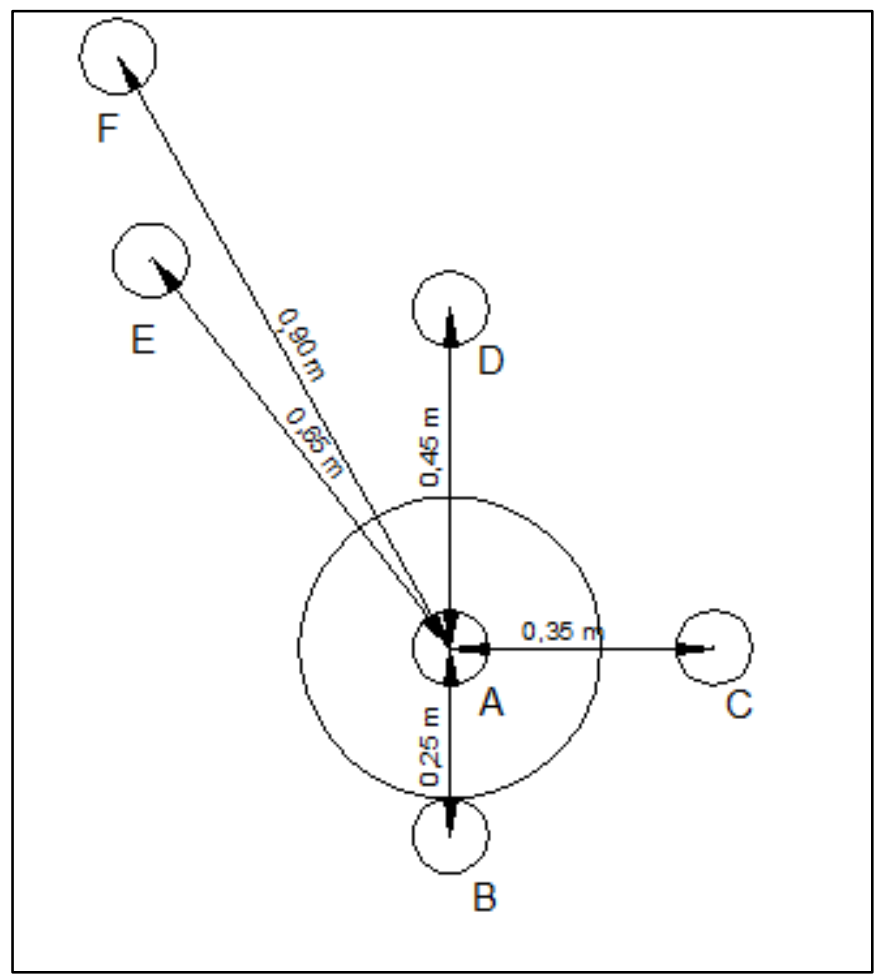

Figura 5.12 - Posição dos anéis retirado no entorno da coluna de Solo Compactado 1

Os anéis foram levados ao laboratório para a determinação dos parâmetros $\rho_{\mathrm{d}}, e, \mathrm{e} w$ para cada anel retirado. Os resultados encontrados estão apresentados na Tabela 5.4. 
Tabela 5.4 - Resultados da variação do índice de vazios no entorno da coluna de solo compactada 1

\begin{tabular}{|ccccc|}
\hline Distância $(\mathbf{c m})$ & $\boldsymbol{e}$ & $\boldsymbol{\rho d}\left(\mathbf{g} / \mathbf{c m}^{\mathbf{3}}\right)$ & $\boldsymbol{w}(\mathbf{\%})$ & GC (\%) \\
\hline $\mathbf{0}$ & 0,53 & 1,80 & 14,7 & 95,2 \\
$\mathbf{2 5}$ & 0,48 & 1,86 & 13,7 & 98,4 \\
$\mathbf{3 5}$ & 0,58 & 1,74 & 15,8 & 87,9 \\
$\mathbf{4 5}$ & 0,73 & 1,59 & 19,6 & 80,3 \\
$\mathbf{6 5}$ & 0,95 & 1,41 & 20,3 & 71,2 \\
$\mathbf{9 0}$ & 1,14 & 1,28 & 19,5 & 64,6 \\
\hline
\end{tabular}

A Figura 5.13 mostra a posição dos anéis retirados no entorno da coluna de solo compactado 2, cujo ensaio de prova de carga foi realizado na condição de umidade natural do terreno.

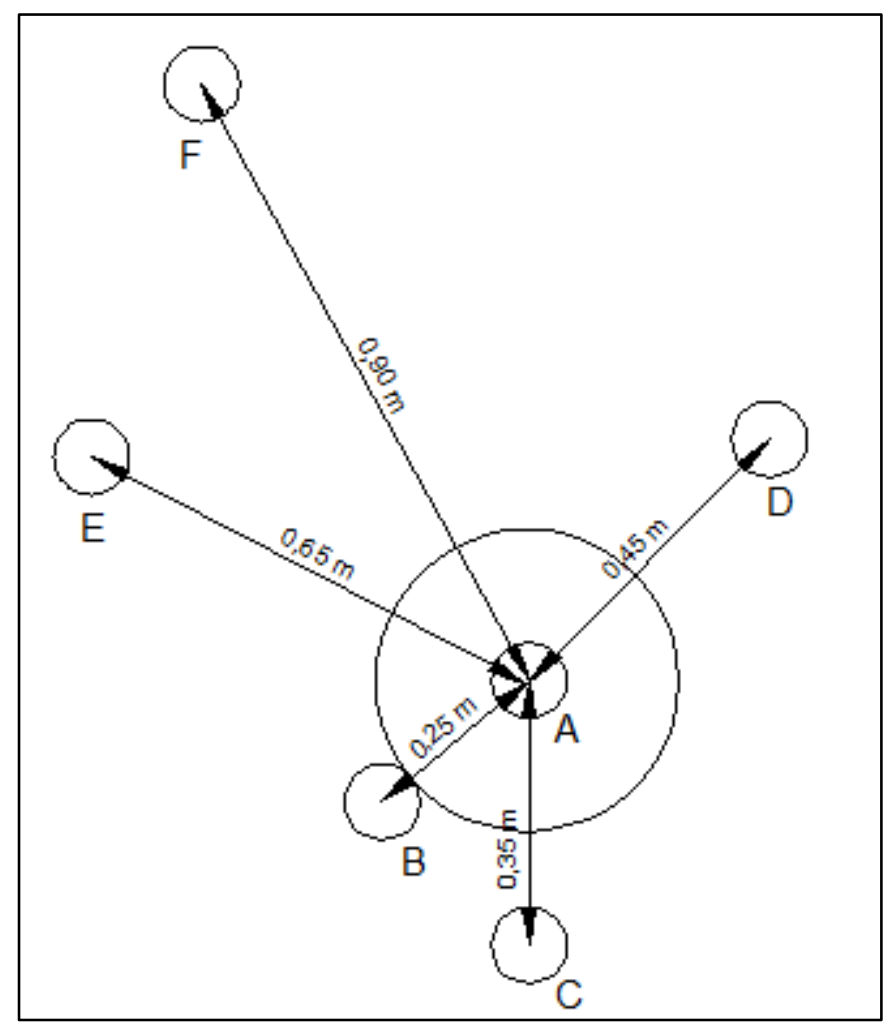

Figura 5.13 - Posição dos anéis retirado no entorno da coluna de Solo Compactado 2

Os resultados de $\rho_{\mathrm{d}}, e$, e $w$ encontrados para cada anel estão apresentados na Tabela 5.5. Os valores de $e$ e $\rho_{\mathrm{d}}$ encontrados para o anel retirado à $35 \mathrm{~cm}$ do centro da coluna foram desprezados pois, pelos resultados encontrados nota-se que houve algum erro durante os ensaios. 
Tabela 5.5 - Resultados da variação do índice de vazios no entorno da coluna de solo compactada 2

\begin{tabular}{|ccccc|}
\hline Distância $(\mathbf{c m})$ & $\boldsymbol{e}$ & $\boldsymbol{\rho d}\left(\mathbf{g} / \mathbf{c m}^{\mathbf{3}}\right)$ & $\boldsymbol{w}(\%)$ & $\boldsymbol{G C} \mathbf{( \% )}$ \\
\hline $\mathbf{0}$ & 0,49 & 1,85 & 14,6 & 93,4 \\
$\mathbf{2 5}$ & 0,38 & 1,99 & 14,9 & 100,0 \\
$\mathbf{3 5}$ & 0,93 & 1,42 & 16,3 & 71,7 \\
$\mathbf{4 5}$ & 0,65 & 1,67 & 17,4 & 84,3 \\
$\mathbf{6 5}$ & 0,98 & 1,39 & 16,8 & 70,2 \\
$\mathbf{9 0}$ & 0,98 & 1,39 & 16,4 & 70,2 \\
\hline
\end{tabular}

As localizações dos anéis retirados no entorno da coluna de solo e brita estão apresentas na Figura 5.14. Para esta coluna foram retirados anéis apenas para as distâncias de 25, 35 e $45 \mathrm{~cm}$ do centro da coluna, pois observou-se que à $45 \mathrm{~cm}$ já não houve mais a redução do índice de vazios devido à compactação da coluna. Além disso, não foi possível retirar o anel no centro da coluna devido à presença das britas.

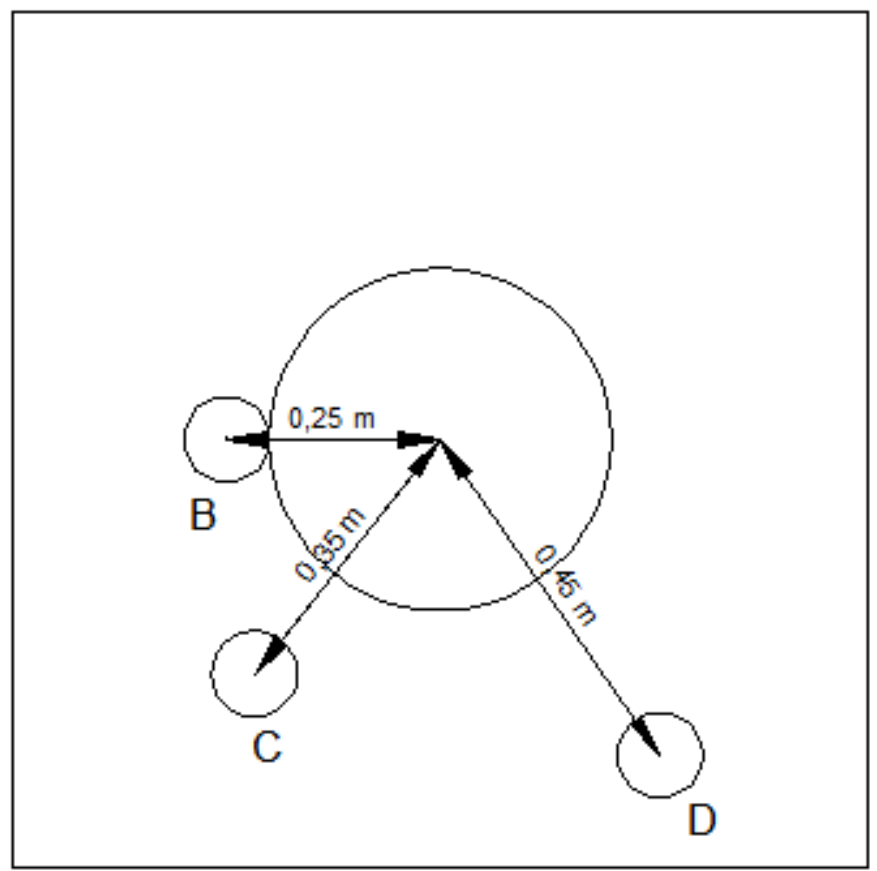

Figura 5.14 - Posição dos anéis retirados no entorno da coluna de solo e brita

5.6 .

Os resultados de $\rho_{\mathrm{d}}, e$, e $w$ encontrados para cada anel estão apresentados na Tabela

Tabela 5.6 - Resultados da variação do índice de vazios no entorno da coluna de solo e brita

\begin{tabular}{|ccccc|}
\hline Distância $(\mathbf{c m})$ & $\boldsymbol{e}$ & $\boldsymbol{\rho d}\left(\mathbf{g} / \mathbf{c m}^{\mathbf{3}}\right)$ & $\boldsymbol{w}(\%)$ & $\boldsymbol{G C}(\%)$ \\
\hline $\mathbf{2 5}$ & 0,78 & 1,55 & 18,6 & 78,3 \\
$\mathbf{3 5}$ & 0,91 & 1,44 & 17,7 & 72,7 \\
$\mathbf{4 5}$ & 1,08 & 1,32 & 17,2 & 66,7 \\
\hline
\end{tabular}


Para compreender melhor o efeito da compactação no entorno das três colunas analisadas, foram feitos alguns gráficos com os dados encontrados. A Figura 5.15 apresenta as curvas que relacionam a variação índice de vazios com a distância do centro das colunas.

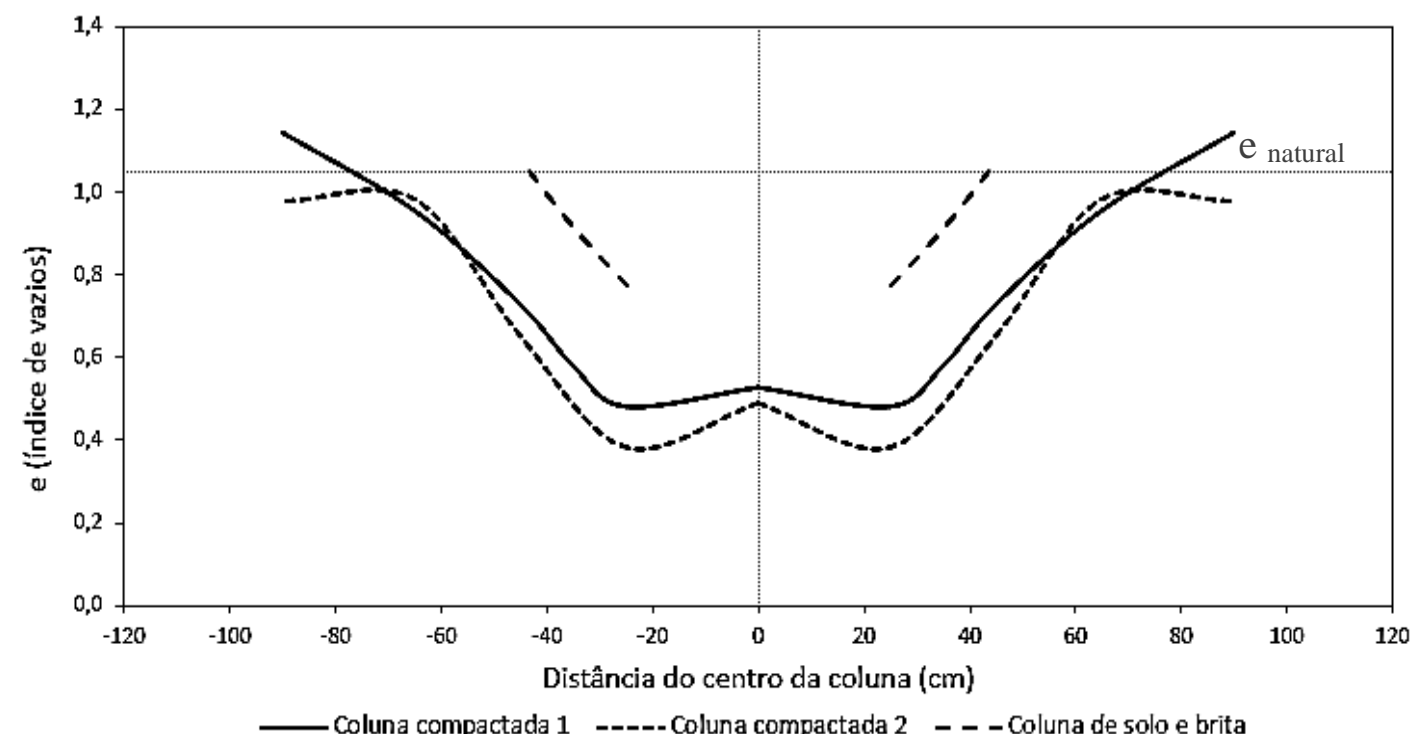

Figura 5.15 - Resultados da variação do índice de vazios no entorno das três colunas ensaiadas

Pelas curvas, verifica-se uma similaridade da variação do índice de vazios encontrados para as duas colunas de solo compactado. Observa-se que a compactação no entorno da coluna de solo compactado foi maior do que a compactação em volta da coluna de solo e brita.

Considerando que o índice de vazios natural do terreno à profundidade ensaiada é de 1,05 , nota-se que o feito do melhoramento do solo na direção radial para a coluna de solo e brita atingiu um raio de $45 \mathrm{~cm}$, enquanto que para a coluna de solo compactado 1 o melhoramento atingiu um raio de $80 \mathrm{~cm}$, e para a coluna de solo compactado 2, o raio atingido foi de $90 \mathrm{~cm}$.

Considerando estes valores supracitados, para a coluna de solo e brita, o melhoramento atingiu um raio de 1,8 D, ao passo que para as colunas de solo compactado, o melhoramento atingiu um raio de aproximadamente 3,2 D. Os resultados encontrados para as colunas de solo compactado validam as considerações realizadas de que o ensaio de placa representaria uma célula unitária do sistema reforçado.

Para as duas colunas de solo compactado ensaiadas, os índices de vazios à distância de $25 \mathrm{~cm}$ do centro das colunas foram menores do que os índices de vazios no centro das próprias colunas. Este efeito provavelmente ocorreu pois, durante o apiloamento para a abertura das colunas, houve o deslocamento das partículas de solo para as laterais, provocando assim a compactação do solo no entorno, reduzindo o seu índice de vazios. 
Também foram plotados em um gráfico os valores de massa específica aparente seca $\left(\rho_{d}\right)$ obtidos para as três colunas analisadas. As curvas relacionam $\rho_{d}$ com a distância do centro da coluna, como mostra a Figura 5.16.

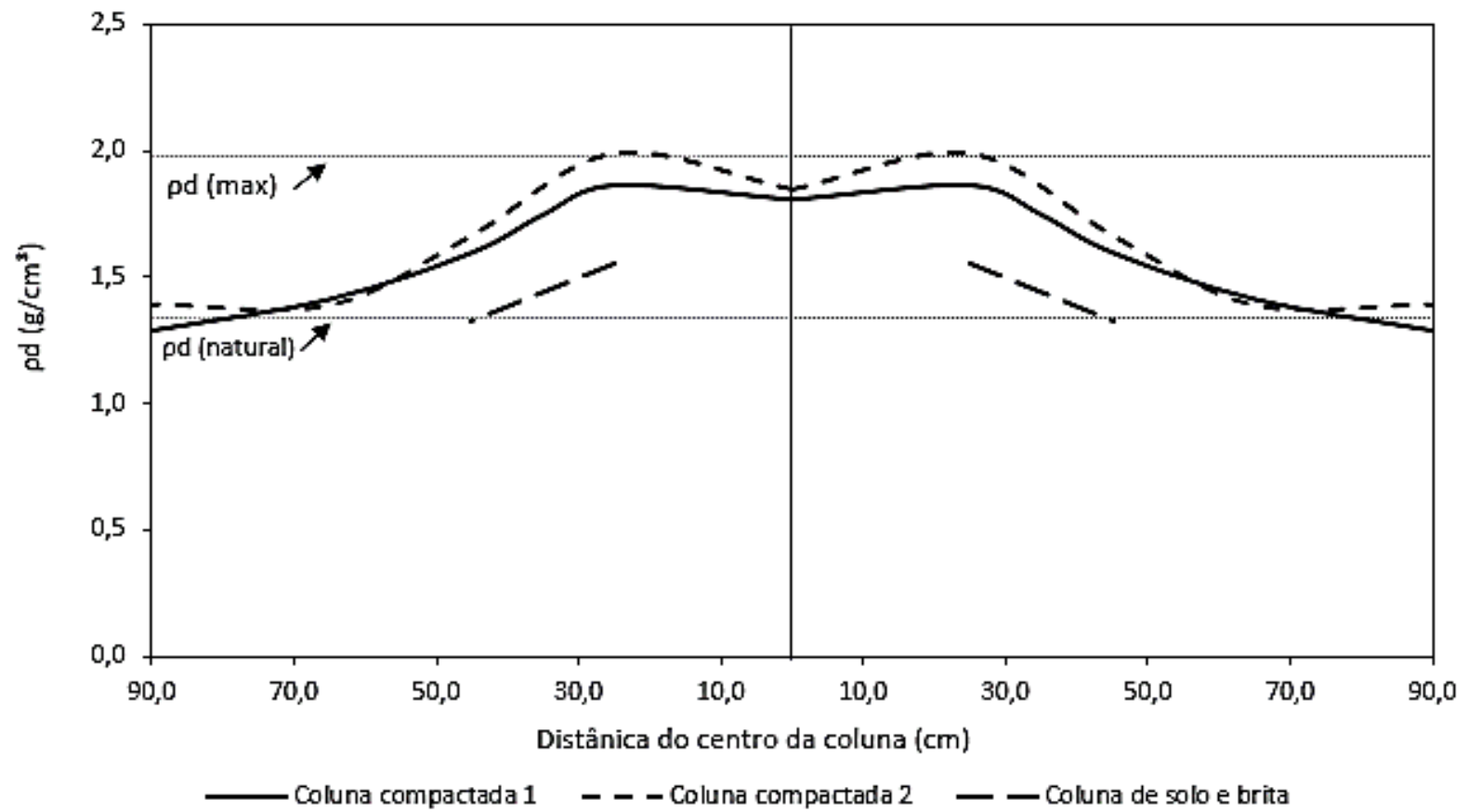

Figura 5.16 - Resultados da variação da massa específica aparente seca no entorno das três colunas ensaiadas

Pelas curvas obtidas nos ensaios observa-se que a maior massa específica aparente seca $\left(\rho_{d}\right)$ encontrada está situada à $25 \mathrm{~cm}$ do centro da coluna, sendo que para a coluna de solo compactado $2, \mathrm{o} \rho_{\mathrm{d}}$ atingiu o valor do $\rho_{d \text { máx }}$ do ensaio de compactação realizado em laboratório para a energia Proctor normal. Os demais pontos ensaiados não atingiram o valor do $\rho_{d}$ máx.

Para a coluna de solo e brita, à um raio de $45 \mathrm{~cm}$ do centro da coluna, o valor do $\rho_{\mathrm{d}}$ alcançou o mesmo valor encontrado para o terreno natural, sem reforço. Já para as colunas de solo compactado, o $\rho_{\mathrm{d}}$ atingiu o valor de campo à uma distância de aproximadamente $80 \mathrm{~cm}$ do centro da coluna.

Além dos anéis retirados no entorno das colunas, também foi analisado o teor de umidade do solo antes e após a execução das provas de carga, sendo que antes da prova de carga a cava estava na sua umidade natural. As amostras antes e após o ensaio foram retiradas no centro das colunas de solo compactado e à 25,35 e $45 \mathrm{~cm}$ do centro. Na coluna 1 , a prova de carga foi realizada na condição inundada, e a coluna 2 foi ensaiada na umidade natural. Porém, esta última cava foi inundada após o ensaio devido às constantes chuvas da época.

Com as diferenças dos teores de umidade no entorno da coluna, às distâncias de 25, 35 e $45 \mathrm{~cm}$ do seu centro, após a inundação da cava, é possível analisar o efeito da compactação 
devido à consequente redução da permeabilidade do solo. Os valores de umidade encontrados antes e após os ensaios estão apresentados na Tabela 5.7.

Tabela 5.7 - Variação do teor de umidade no entorno da coluna antes e após o ensaio de prova de carga

\begin{tabular}{|llcc|llcc|}
\hline & & Coluna 1 & Coluna 2 & & & Coluna 1 & Coluna 2 \\
\hline & Centro & 14,7 & 14,6 & & Centro & 14,9 & 15,4 \\
w antes & $\mathbf{2 5} \mathbf{~ c m}$ & 13,7 & 14,9 & w após & $\mathbf{2 5} \mathbf{~ c m}$ & 14,1 & 15,2 \\
PCE (\%) & $\mathbf{3 5} \mathbf{~ c m}$ & 15,8 & 16,3 & PCE (\%) & $\mathbf{3 5} \mathbf{~ c m}$ & 19,8 & 19,2 \\
& $\mathbf{4 5} \mathbf{~ c m}$ & 19,6 & 17,4 & & $\mathbf{4 5} \mathbf{~ c m}$ & 20,9 & 19,9 \\
\hline
\end{tabular}

Observa-se que no centro da coluna e à $25 \mathrm{~cm}$ do seu centro, as variações das umidades foram menores, o que indica uma menor permeabilidade do solo nestes pontos. Porém, para as demais distâncias, a permeabilidade aumentou o que reflete o aumento dos teores de umidade após os ensaios com relação aos valores medidos antes. Após a realização das provas de carga em placa houve constante chuva, o que pode ter influenciado os valores do teor de umidade amostrado, uma vez que para maiores distâncias do centro das colunas o solo se encontrava menos compactado, ou seja, mais permeável.

\subsubsection{Provas de carga em placa}

As curvas tensão aplicada $x$ recalque obtidas nas provas de carga realizadas estão apresentadas nas Figuras 5.17, 5.19, 5.20 e 5.21. A Figura 5.17 apresenta os resultados do ensaio de placa sobre a coluna de solo compactado na condição inundada (Coluna 1). Os resultados de capacidade de carga encontrados em campo superaram o previsto para a coluna de solo compactado ensaiada da condição inundada. Devido ao extenso tempo gasto no ensaio, e às condições climáticas desfavoráveis, o recalque médio máximo atingido no ensaio foi de $21,31 \mathrm{~mm}$.

O critério de ruptura utilizado na interpretação das curvas foi uma analogia ao critério proposto pela ABNT NBR 6122/2010 para prova de carga em estaca, que adota como a tensão de ruptura àquela correspondente ao recalque máximo de $\mathrm{D} / 30$. Para placa circular convencional, com diâmetro de $0,80 \mathrm{~m}$, o recalque máximo corresponde a $25 \mathrm{~mm}$.

Como este ensaio foi finalizado prematuramente, a curva tensão $x$ recalque obtida não atingiu o critério de ruptura pré-estabelecido, sendo necessária a extrapolação da curva. $\mathrm{O}$ método de extrapolação que melhor se ajustou à curva foi o de Van der Veen (1953). A Figura 5.18 mostra os resultados obtidos para a curva extrapolada. 


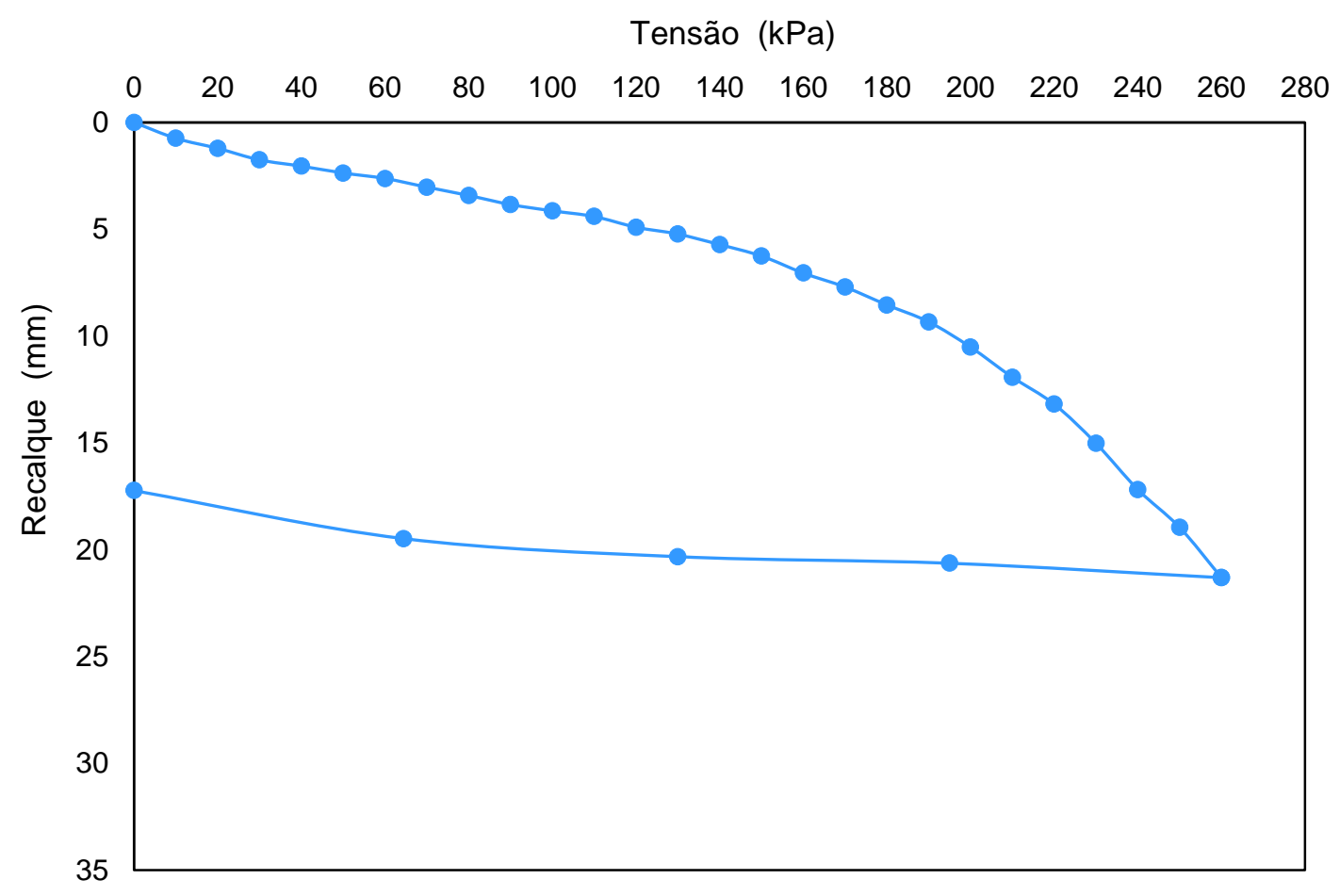

Figura 5.17 - Curva tensão $x$ recalque para a coluna de solo compactado na condição inundada (PCI)

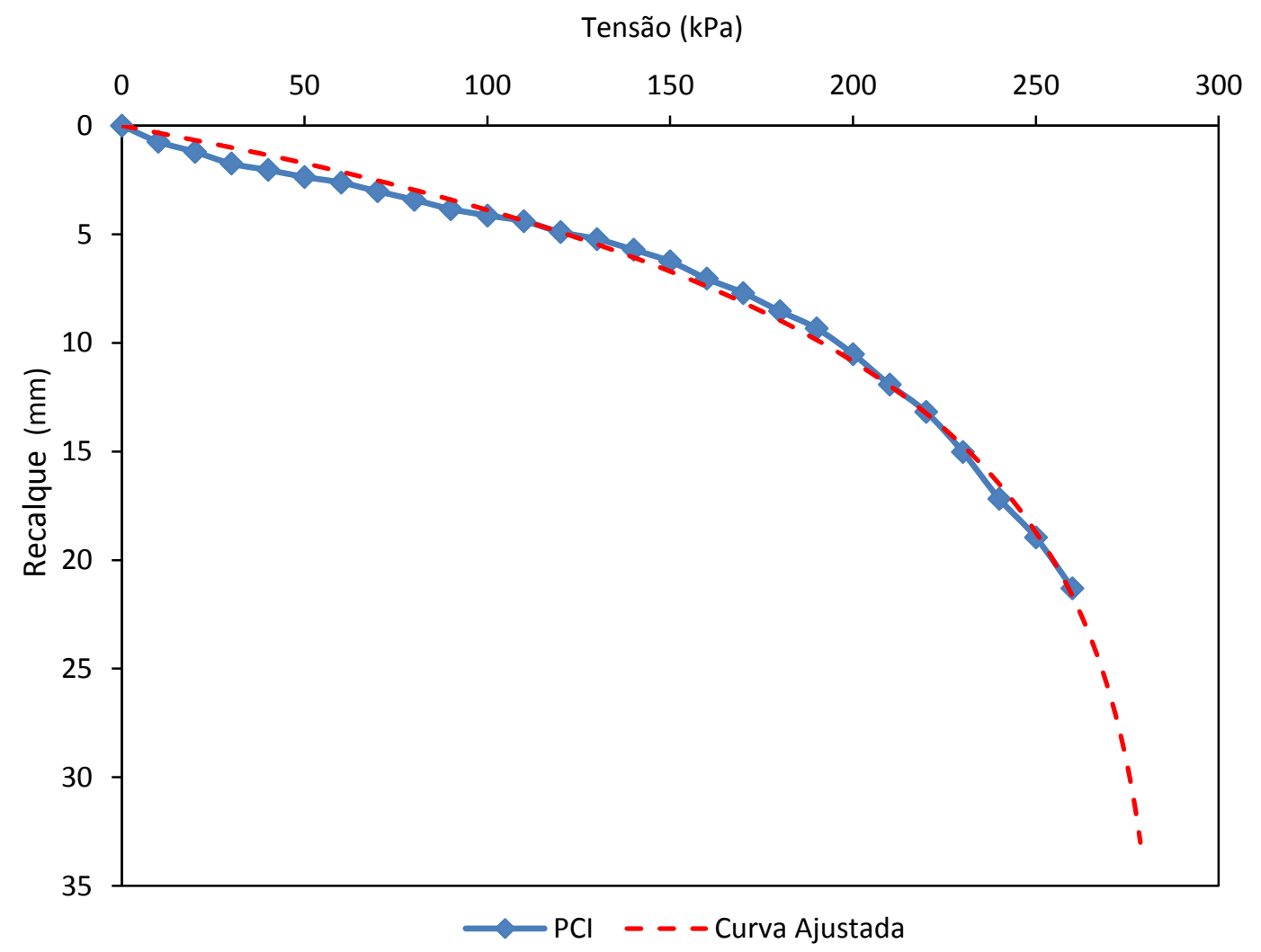

Figura 5.18 - Extrapolação da curva tensão x recalque para a coluna de solo compactado inundada (PCI) pelo método proposto

Fonte - Van der Veen (1953) 
Com base na curva extrapolada, foi possível obter uma tensão de ruptura igual a 268 kPa pelo critério estabelecido pela ABNT NBR 6122/2010.

A Figura 5.19 apresenta os resultados obtidos no ensaio de prova de carga para a coluna de solo compactado natural, cuja sucção medida pelo tensiômetro instalado à $0,5 \mathrm{~m}$ de profundidade era de $13 \mathrm{kPa}$

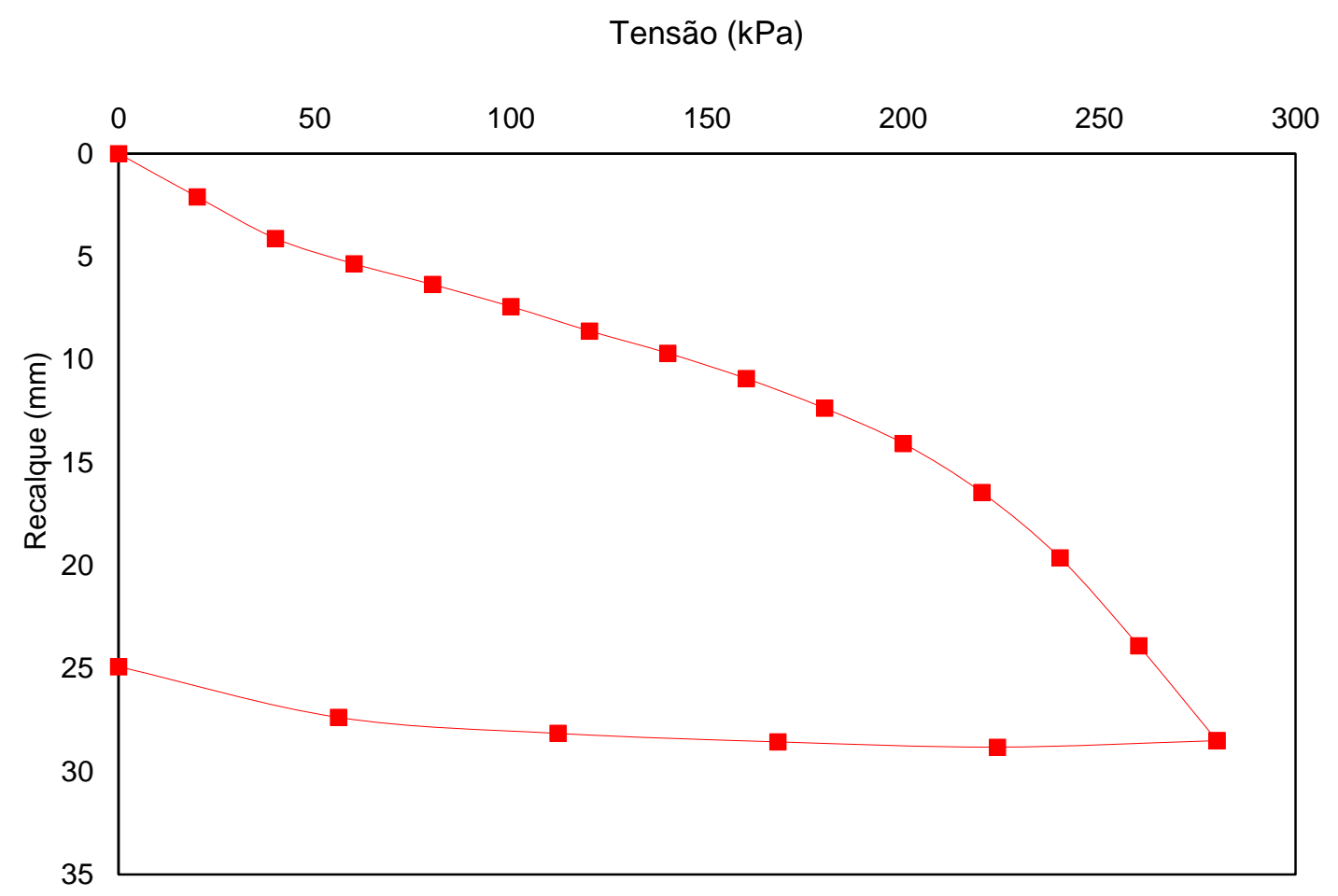

Figura 5.20 - Curva tensão x recalque para a coluna de solo compactado com sucção de $13 \mathrm{kPa}(\mathrm{PCN})$

Com base nos resultados, obteve-se uma tensão de ruptura de $265 \mathrm{kPa}$ aplicando-se o critério estabelecido pela ABNT NBR 6122/2010. Os valores das tensões de ruptura encontradas nos ensaios para as duas colunas de solo compactado foram muito próximos, sendo a tensão de ruptura do ensaio na condição natural, com sucção de $13 \mathrm{kPa}$, um pouco inferior ao resultado obtido no ensaio inundado. Esta pequena variação pode estar associada a dois fatores.

O primeiro fator considera que a princípio não houve inferência do efeito da sucção nos resultados. Isso se justifica pois este efeito é menos significativo em solos compactados. Pela variação dos índices de vazios no entorno da coluna, é possível observar que os efeitos da compactação atingiram um raio de aproximadamente $80 \mathrm{~cm}$ do centro das colunas. Portanto, a placa utilizada nos ensaios, cujo diâmetro é de $0,80 \mathrm{~m}$, estava apoiada em solo compactado devido ao melhoramento causado pelas colunas. O segundo fator está relacionado à variabilidade da execução das colunas e também à variabilidade do terreno no local ensaiado que podem ter comprometido nos resultados encontrados. 
A Figura 5.21 apresenta os resultados do ensaio para a coluna de solo e brita compactada, ensaiada na condição inundada.

Com base nos resultados, obteve-se uma tensão de ruptura de $180 \mathrm{kPa}$ aplicando-se o critério estabelecido pela ABNT NBR 6122/2010. Observa-se que a tensão de ruptura encontrada para a coluna de solo e brita foi aproximadamente $30 \%$ menor do que as tensões de ruptura obtidas para as colunas de solo compactado.

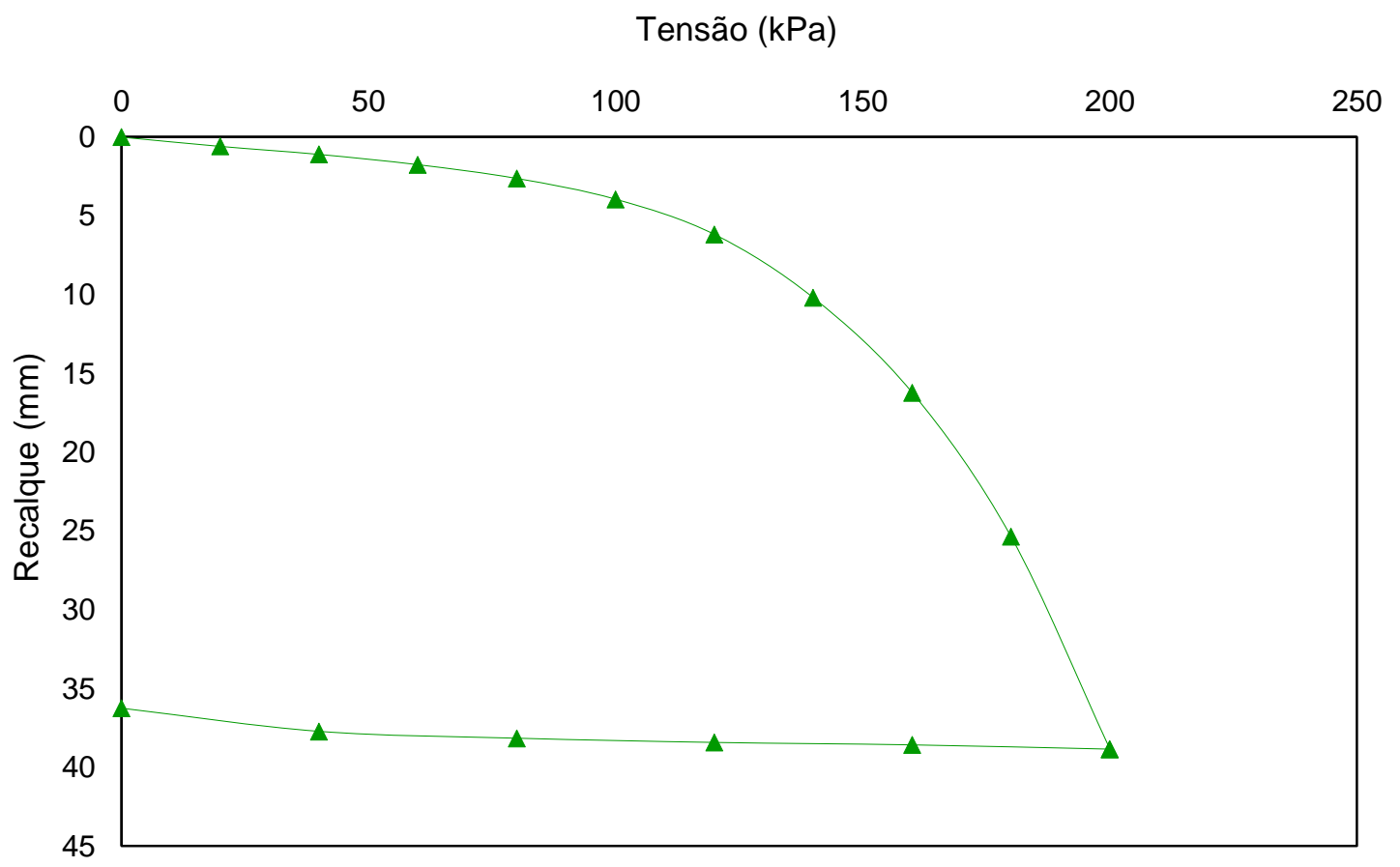

Figura 5.21 - Curva tensão x recalque para a coluna de solo e brita na condição inundada (PSB)

No início do ensaio esta coluna apresentou uma maior rigidez do que as colunas de solo compactado, mas no decorrer do ensaio os recalques começaram a se intensificar mais rapidamente do que nas colunas de solo. Provavelmente, os vazios relacionados à diferença de geometria e tamanho dos grãos foram maiores do que os vazios da coluna de solo. Além disso, as amostras de solo obtidas no entorno da coluna com brita mostram que a compactação do solo envolvente foi bem inferior comparada ao caso da coluna de solo. Consequentemente, estes fatos fizeram com que ocorressem recalques maiores do que os recalques das colunas de solo durante a prova de carga.

A Figura 5.22 apresenta os resultados do ensaio em placa sem reforço com coluna. A primeira curva foi obtida na condição natural do terreno. Em seguida, foi feito um reensaio com inundação da cava no estágio referente à tensão admissível, determinada com base nos 
resultados do primeiro ensaio. A sucção medida pelo tensiômetro, instalado à uma profundidade de $0,5 \mathrm{~m}$ abaixo da cota de apoio da placa, era de $6 \mathrm{kPa}$ no momento do ensaio.

Tensão (kPa)

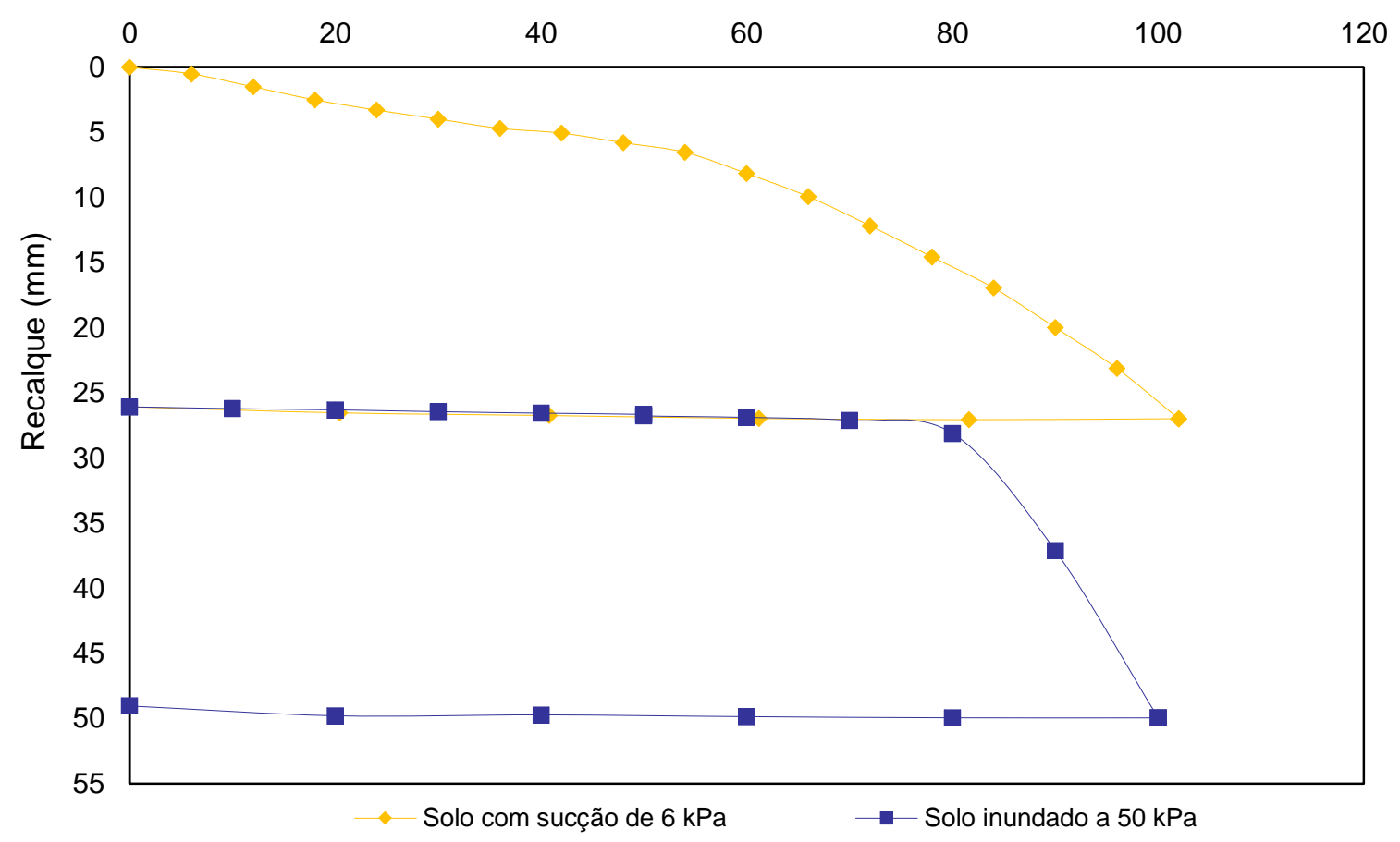

Figura 5.22 - Curva tensão x recalque o para o solo com sucção de $6 \mathrm{kPa}$ e para a condição inundada na tensão admissível de $50 \mathrm{kPa}$

Aplicando-se o critério estabelecido pela ABNT NBR 6122/2010, a tensão de ruptura encontrada foi de $100 \mathrm{kPa}$ para o solo sem reforço, no ensaio com sucção de $6 \mathrm{kPa}$. Aplicandose o fator de segurança igual a 2, adotou-se a tensão admissível como $50 \mathrm{kPa}$.

O segundo foi conduzido nas mesmas condições de umidade e sucção até atingir a tensão admissível de $50 \mathrm{kPa}$. Neste estágio foi feita a inundação, obtendo-se a segunda curva do ensaio. Porém, como a sucção estava muito baixa, não foi possível enxergar a ocorrência do colapso pela descontinuidade da curva. No entanto, verifica-se que a segunda curva tensão $x$ recalque obtida no ensaio é mais íngreme, o que indica a ruptura do solo para níveis de tensão inferiores. Portanto, é possível observar que houve a redução da capacidade de carga do solo devido à inundação do terreno mesmo que para baixos valores de sucção.

Na Figura 5.23 são apresentadas as curvas tensão $x$ recalque obtidas para os três ensaios realizados no solo reforçado por colunas de solo compactado e de solo e brita, sendo dois deles realizados na condição inundada e um na condição de umidade natural. 
Para as três curvas obtidas para o solo reforçado, observa-se que no trecho final do descarregamento do ensaio houve uma parcela elástica recuperável nas três curvas, para tensões entre 50 e $65 \mathrm{kPa}$, identificada pelo trecho pontilhado na Figura 5.23. Observa-se que o trecho referente à recuperação elástica é paralelo ao trecho linear no início da curva tensão recalque.

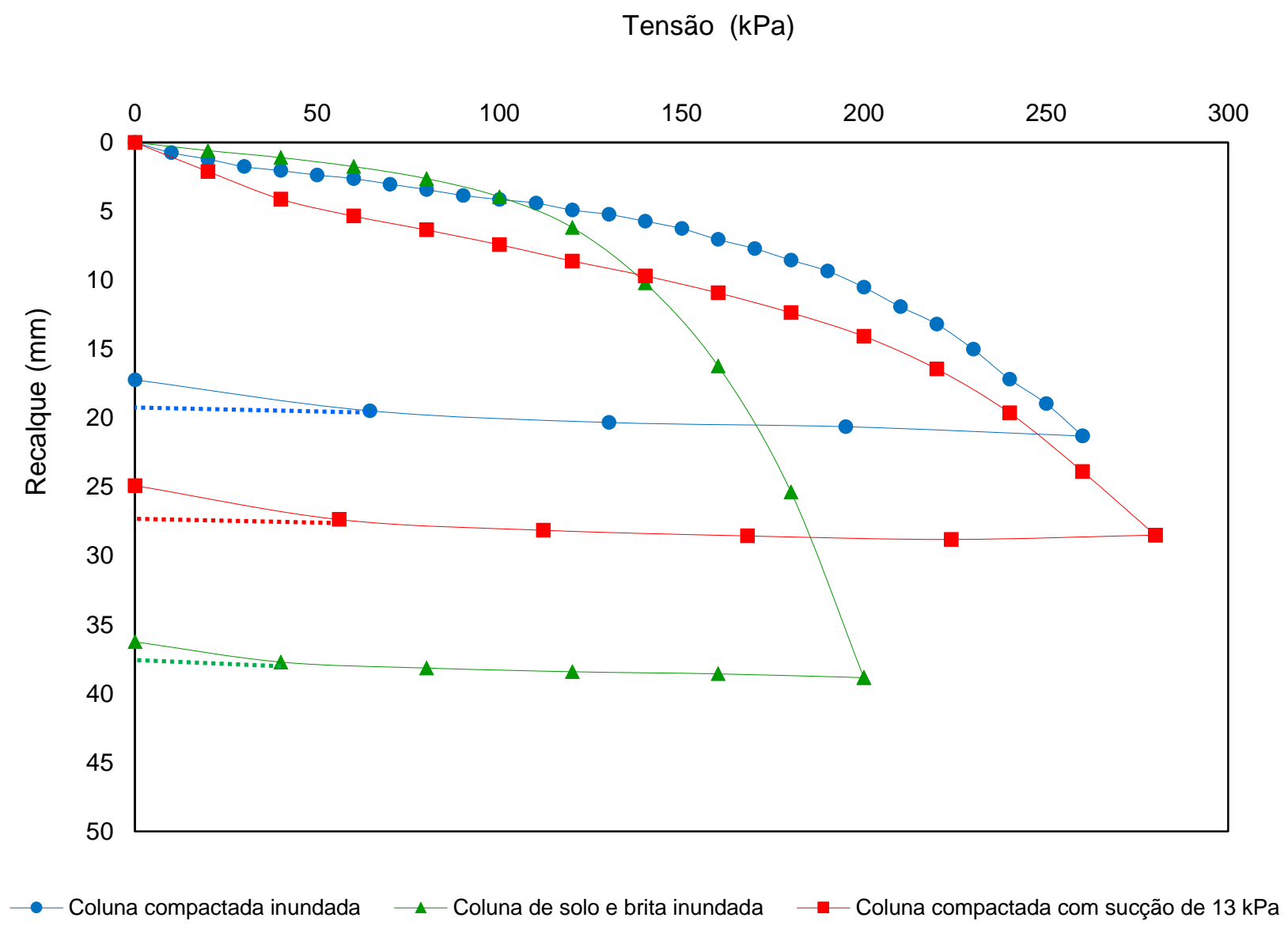

Figura 5.23 - Comparação das curvas carga x recalque obtidas para o terreno reforçado com colunas

Nota-se que existe uma diferença no trecho de descarregamento das provas de carga em placa realizadas nos solos com e sem reforço. As curvas ilustradas na Figura 5.24 apresentam os resultados dos ensaios de placa inundados de Costa (1999), executados para a mesma profundidade dos ensaios com reforço, à 1,5 m. Pelas curvas de descarregamento do Costa (1999), é possível observar uma deformação completamente plástica (sem recuperação elástica do recalque). Além disso, o resultado apresentado na Figura 5.22 (ensaio em placa sem coluna) apresenta as mesmas características de deformação completamente plástica, sendo este ensaio realizado com placa apoiada a 1,5 m porém com sucção de $6 \mathrm{kPa}$.

As curvas obtidas nos ensaios de placa realizados por Costa (1999) mostram que mesmo para sucções mais altas, de 10 e de $30 \mathrm{kPa}$, houve deformação totalmente plástica que 
pode ser observada na curva de descarregamento ilustrada na Figura 5.26. Portanto, é possível inferir que o material compactado conferiu ao solo esta parcela de deformação elástica devido ao aumento da rigidez proporcionado pela compactação do solo na coluna e no seu entorno.

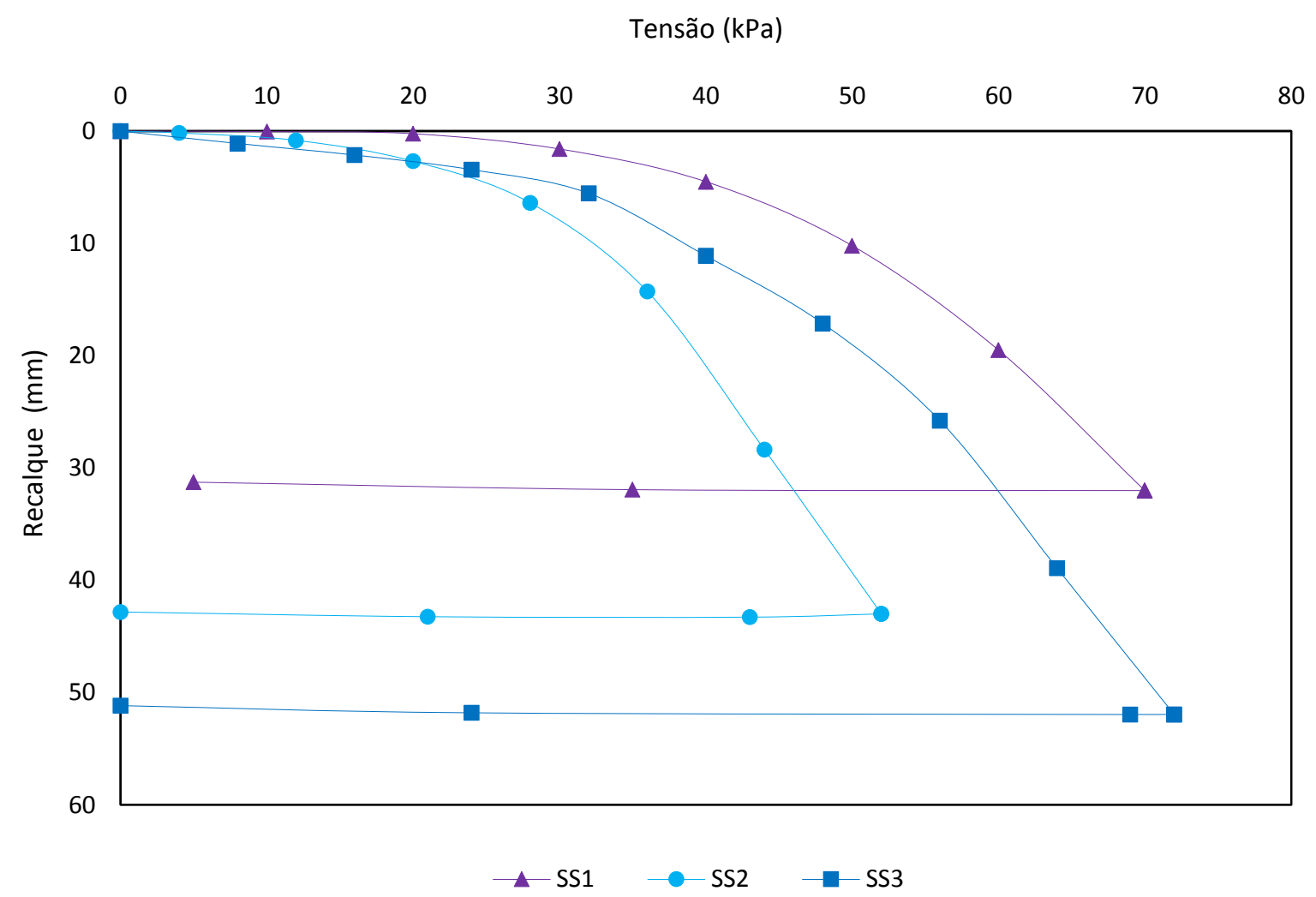

Figura 5.24 - Curvas carga x recalque para placas inundadas obtidas por Costa (1999) à profundidade de 1,50 m

A Figura 5.25 ilustra a comparação das curvas tensão $x$ recalque obtidas para o solo com e sem reforço. Pelas curvas é possível visualizar o efeito do melhoramento do solo devido à inclusão das colunas. Na mesma figura está presente também a curva SS1 obtida por Costa (1999) que corresponde à melhor curva referente aos ensaios de placa na condição inundada, sem reforço.

A tensão de ruptura referente à curva SS1, aplicando-se o critério estabelecido pela ABNT NBR 6122/2010, é de 64,5 kPa. Comparando-se o resultado da tensão de ruptura na condição inundada de um solo sem reforço com o valor encontrado para a tensão de ruptura do solo reforçado com colunas de solo compactado inundado, $268 \mathrm{kPa}$, tem-se um aumento da capacidade de carga de 4 vezes devido ao reforço. Para as colunas de solo e brita, cuja tensão de ruptura obtida nos ensaios foi de $180 \mathrm{kPa}$, tem-se um aumento da capacidade de carga de 2,8 vezes, comparando com o solo inundado sem reforço. 


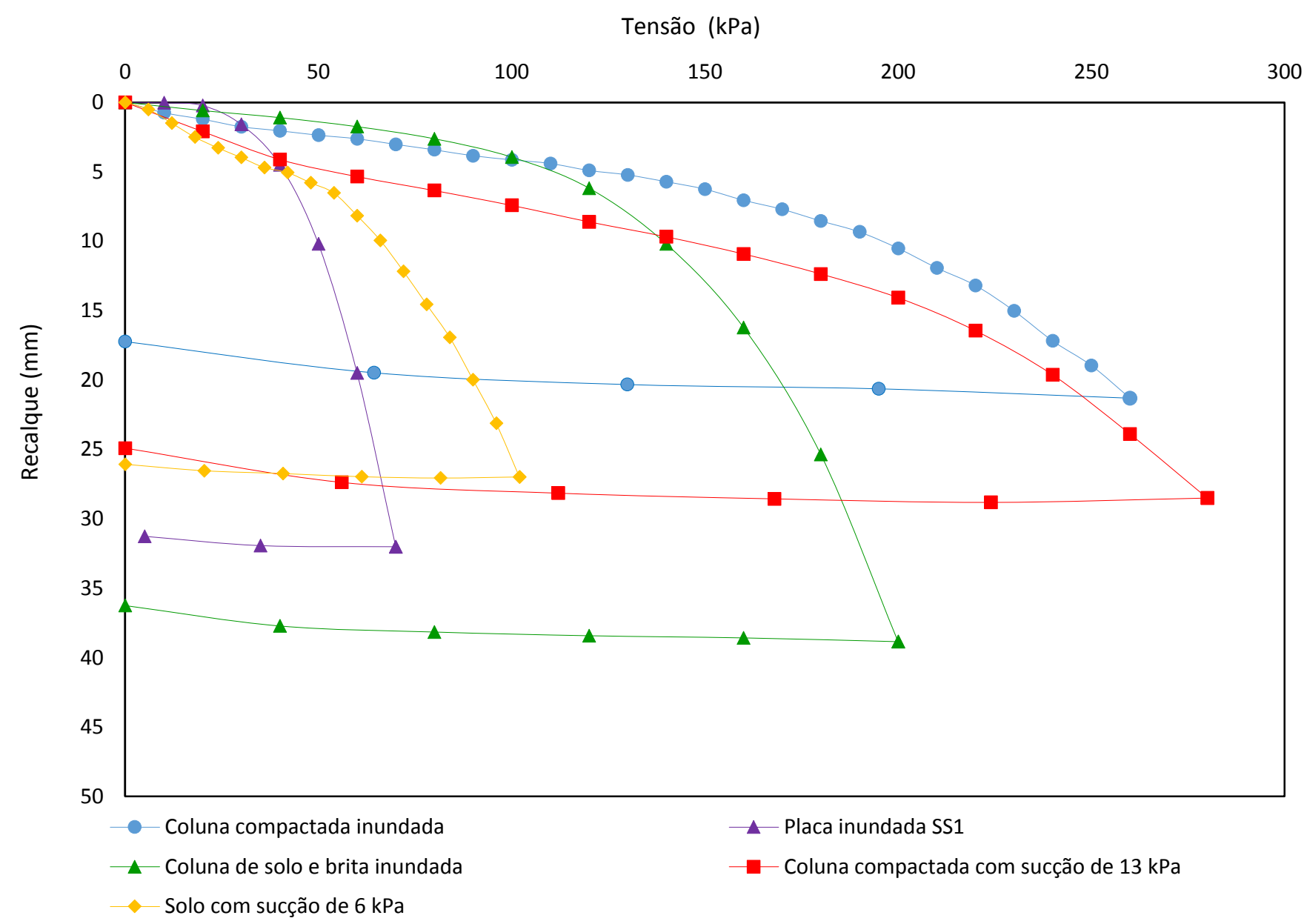

Figura 5.25 - Comparação das curvas tensão x recalque para o solo reforçado e sem reforço

A Figura 5.26 apresenta os resultados dos ensaios realizados com sucção para o solo com e sem o reforço com coluna. Também estão incluídas nesta figura as curvas dos ensaios em placa realizados por Costa (1999) com sucção. Nesta figura é possível observar que o reforço com as colunas de solo compactado conferiu ao solo uma capacidade de carga maior do que os resultados encontrados pelo autor para os ensaios em placa sem reforço, com sucção de 10 e $30 \mathrm{kPa}$. Além disso, observa-se também que o resultado do ensaio de placa encontrado para a sucção de $6 \mathrm{kPa}$ é muito próximo do resultado encontrado por Costa (1999) para a sucção de $10 \mathrm{kPa}$. 


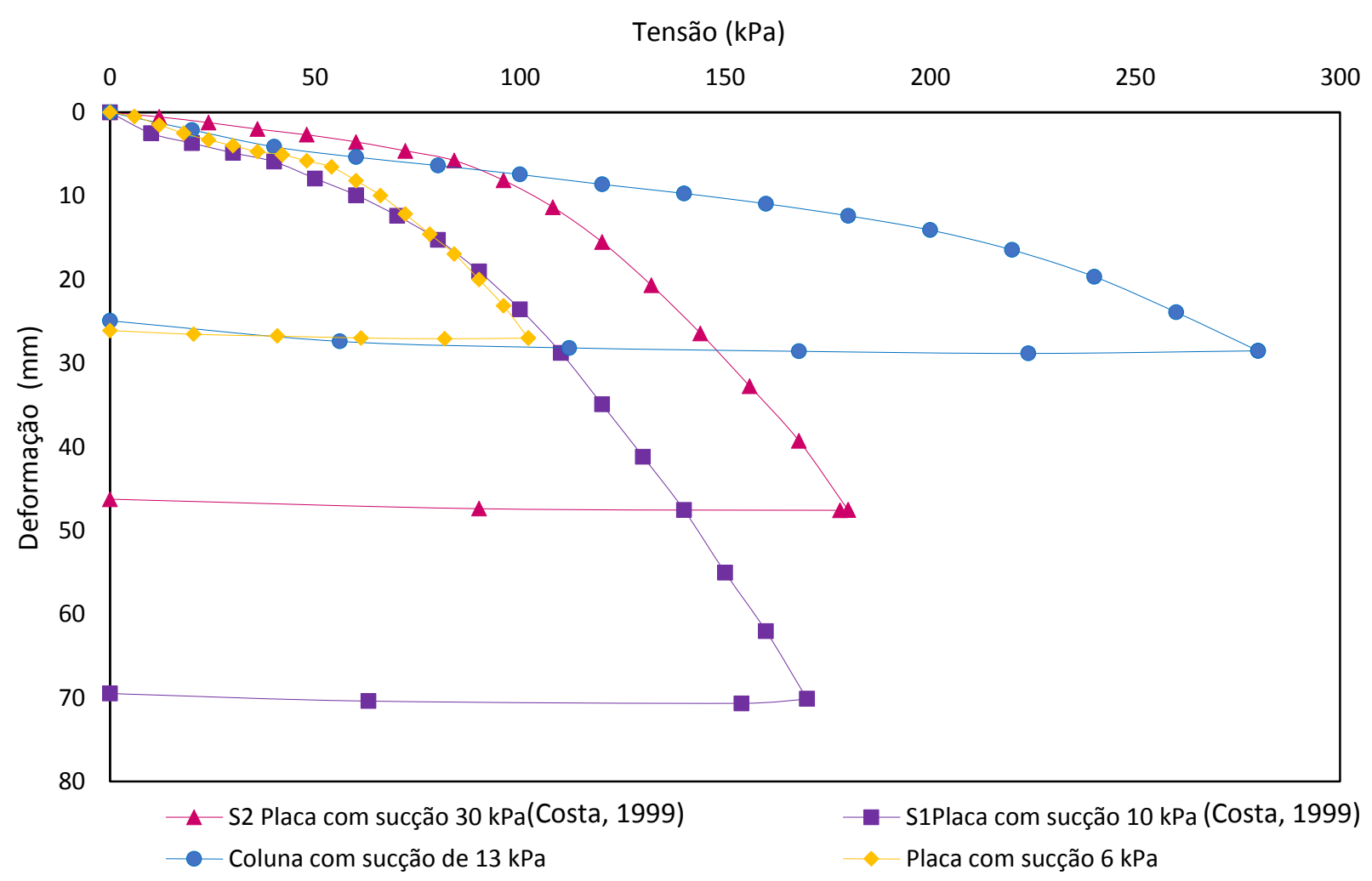

Figura 5.26 - Curvas tensão x recalque para ensaios de placa no solo com reforço e sem reforço na condição de umidade natural do terreno (com sucção)

\subsubsection{Análise da deformabilidade do solo reforçado}

Para a estimativa do módulo de deformabilidade do solo com e sem reforço, foi feita a retroanálise pelo método de Schmertmann (1978) utilizando-se os dados obtidos nos ensaios de prova de carga em placa. Considerou-se nos cálculos que o módulo seria constante até a profundidade de $2 \mathrm{~B}$, sendo $\mathrm{B}$ a largura de uma sapata quadrada com área equivalente à placa utilizada nos ensaios.

Os resultados encontrados estão apresentados na Figura 5.27. Observa-se que o módulo de deformabilidade do solo varia de acordo com a tensão aplicada no ensaio. Nota-se que as quatro curvas apresentam inicialmente valores crescentes do módulo, até um determinado nível de tensão, e em seguida uma redução acentuada do seu valor. Isto acontece pois, durante o início do ensaio de prova de carga em placa, para baixos níveis de tensão e recalque, ocorre a compactação do solo abaixo da placa. Porém, com o aumento das tensões aplicadas, os recalques se intensificam provocando a redução da rigidez do solo e consequentemente, do seu módulo de deformabilidade.

Observa-se nas curvas apresentadas na Figura 5.27 que a relação entre tensão e deformação não é retilínea, portanto não pode ser representada por um único módulo. Foi 
necessário definir como seria calculado o módulo de deformabilidade e qual nível de tensão seria considerado.

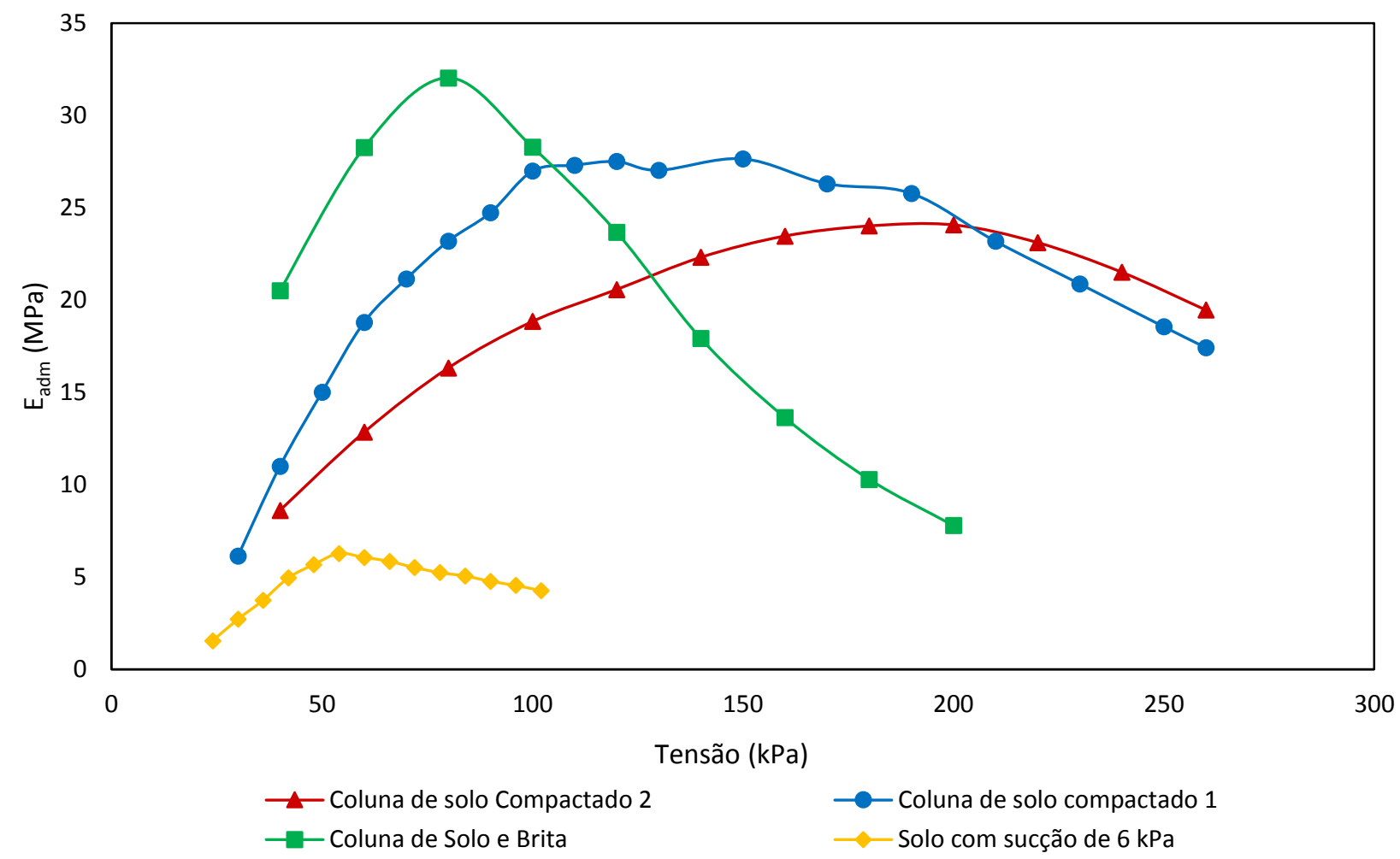

Figura 5.27 - Resultados da variação do módulo de deformabilidade do solo, com e sem reforço, com o aumento da tensão aplicada.

Para o trecho inicial das curvas tensão $x$ recalque obtidas nos ensaios de prova de carga, foi considerado que este trecho seria elástico linear até os níveis de tensão admissível. Como as tensões aplicadas na obra correspondem à tensão admissível, esta foi então a tensão utilizada para a determinação dos módulos de cada coluna e do solo sem reforço. O símbolo correspondente ao módulo de deformabilidade para as tensões admissíveis adotado foi $\mathrm{E}_{\mathrm{adm}}$, Os módulos encontrados para o solo com e sem reforço estão apresentados na Tabela 5.8.

Observa-se que para os níveis de tensões admissíveis, a coluna de solo e brita apresentou um módulo de deformabilidade $\left(\mathrm{E}_{\mathrm{adm}}\right)$ maior do que as colunas de solo compactado. Comparando-se os valores dos módulos admissíveis dos solos reforçados com o solo sem reforço verifica-se um aumento de 3,7 vezes devido a execução da coluna de solo e brita, de 3,2 vezes devido à coluna de solo compactado 1 e de 2,57 por causa da coluna de solo compactado 2 . 
Tabela 5.8 - Módulo de deformabilidade para os valores de tensões admissíveis

\begin{tabular}{|cccc|}
\hline Ensaio & $\boldsymbol{\sigma}_{\text {rup }}(\mathbf{k P a})$ & $\boldsymbol{\sigma}_{\text {adm }}(\mathbf{k P a})$ & $\boldsymbol{E}_{\text {adm }}(\mathbf{M P a})$ \\
\hline Coluna de solo e brita & 180 & 90 & 31,74 \\
Coluna de solo compactado 1 & 268 & 134 & 27,33 \\
Coluna de solo compactado 2 & 265 & 132,5 & 21,93 \\
Solo sem reforço com sucção de 6 $\mathrm{kPa}$ & 100 & 50 & 8,54 \\
\hline
\end{tabular}

Nas tabelas abaixo são apresentados os dados necessários para a determinação do $\mathrm{E}_{\mathrm{adm}}$ aplicando-se a retroanálise do método de Schmertmann (1978), uma vez que eram conhecidas as tensões admissíveis para cada caso ensaiado, bem como, os recalques correspondentes a estes níveis de tensão. Na Tabela 5.9 estão apresentados os dados referentes à coluna de solo compactado 1, sendo a tensão admissível igual a $134 \mathrm{kPa}$ e o recalque, para este nível de tensão igual a $5,40 \mathrm{~mm}$.

Tabela 5.9 - Aplicação da retroanálise pelo método de Schmertmann (1978) para determinar o $\mathrm{E}_{\mathrm{adm}}$ para a coluna de solo compactado 1

\begin{tabular}{|c|c|c|c|c|c|c|c|c|c|}
\hline Subcamada & $\Delta z(m)$ & $\sigma(k P a)$ & $\sigma v(k P a)$ & $\sigma^{*}(k P a)$ & Iz & $C 1$ & $C 2$ & $E_{a d m}(M P a)$ & $\rho i(\mathrm{~mm})$ \\
\hline 1 & 0,35 & 134 & 5,28 & 128,72 & 0,45 & 0,98 & 1 & \multirow{4}{*}{27,33} & 0,73 \\
\hline 2 & 0,71 & 134 & 10,56 & 123,44 & 0,83 & 0,96 & 1 & & 2,54 \\
\hline 3 & 1,06 & 134 & 15,85 & 118,15 & 0,50 & 0,93 & 1 & & 2,13 \\
\hline \multirow[t]{2}{*}{4} & 1,42 & 134 & 21,13 & 112,87 & 0,17 & 0,91 & 1 & & 0,88 \\
\hline & & & & & & & & $\Sigma \rho=$ & 5,40 \\
\hline
\end{tabular}

Tabela 5.10 - Aplicação da retroanálise pelo método de Schmertmann (1978) para determinar o $\mathrm{E}_{\mathrm{adm}}$ para a coluna de solo compactado 2

\begin{tabular}{|c|c|c|c|c|c|c|c|c|c|}
\hline Subcamada & $\Delta z(m)$ & $\sigma(k P a)$ & $\sigma v(k P a)$ & $\sigma^{*}(k P a)$ & Iz & C1 & $C 2$ & $E_{\text {adm }}(\mathrm{MPa})$ & pi (mm) \\
\hline 1 & 0,35 & 132,5 & 5,28 & 127,22 & 0,45 & 0,98 & 1 & \multirow{4}{*}{21,93} & 0,90 \\
\hline 2 & 0,71 & 132,5 & 10,56 & 121,94 & 0,83 & 0,96 & 1 & & 3,11 \\
\hline 3 & 1,06 & 132,5 & 15,85 & 116,65 & 0,50 & 0,93 & 1 & & 2,61 \\
\hline \multirow[t]{2}{*}{4} & 1,42 & 132,5 & 21,13 & 111,37 & 0,17 & 0,91 & 1 & & 1,08 \\
\hline & & & & & & & & $\Sigma p=$ & 7,70 \\
\hline
\end{tabular}

Na Tabela 5.10 estão apresentados os dados para o solo reforçado com a coluna 2, cuja tensão admissível é 132,5 kPa e o recalque correspondente à está tensão é de 7,70 mm. Já na Tabela 5.11 estão apresentados os dados para o solo reforçado com coluna de solo e brita, sendo a tensão admissível de $90 \mathrm{kPa}$ e o recalque correspondente à está tensão é de $3 \mathrm{~mm}$. 
Na Tabela 5.12 estão apresentados os dados do solo sem reforço, sendo que a tensão admissível corresponde à $50 \mathrm{kPa}$ e o recalque do solo quando aplicada esta tensão é de 5,90 $\mathrm{mm}$.

Tabela 5.11 - Aplicação da retroanálise pelo método de Schmertmann (1978) para determinar o Eadm para a coluna de solo e brita

\begin{tabular}{|cccccccccc|}
\hline Subcamada & $\boldsymbol{\Delta z}(\boldsymbol{m})$ & $\boldsymbol{\sigma}(\mathbf{k P a})$ & $\boldsymbol{\sigma} \boldsymbol{v}(\mathbf{k P a})$ & $\boldsymbol{\sigma}^{*}(\mathbf{k P a})$ & $\boldsymbol{I z}$ & $\boldsymbol{C 1}$ & $\mathbf{C 2}$ & $\boldsymbol{E}_{\boldsymbol{a d m}}(\mathbf{M P a})$ & $\boldsymbol{\rho} \boldsymbol{i}(\mathbf{m m})$ \\
\hline 1 & 0,35 & 90 & 5,28 & 84,72 & 0,40 & 0,97 & 1 & & 0,37 \\
2 & 0,71 & 90 & 10,56 & 79,44 & 0,75 & 0,93 & 1 & 31,74 & 1,24 \\
3 & 1,06 & 90 & 15,85 & 74,15 & 0,45 & 0,89 & 1 & & 1,00 \\
4 & 1,42 & 90 & 21,13 & 68,87 & 0,15 & 0,85 & 1 & & 0,39 \\
& & & & & & & & $\boldsymbol{\Sigma} \boldsymbol{p}=$ & $\mathbf{3 , 0 0}$ \\
\hline
\end{tabular}

Tabela 5.12 - Aplicação da retroanálise pelo método de Schmertmann (1978) para determinar o E adm $_{\text {para o solo }}$ sem reforço

\begin{tabular}{|cccccccccc|}
\hline Subcamada & $\boldsymbol{\Delta z}(\boldsymbol{m})$ & $\boldsymbol{\sigma}(\mathbf{k P a})$ & $\boldsymbol{\sigma} \boldsymbol{v}(\mathbf{k P a})$ & $\boldsymbol{\sigma}^{*}(\mathbf{k P a})$ & $\mathbf{I z}$ & $\mathbf{C 1}$ & $\mathbf{C 2}$ & $\boldsymbol{E}_{\text {adm }}(\mathbf{M p a})$ & $\boldsymbol{\rho} \boldsymbol{i}(\mathbf{m m})$ \\
\hline 1 & 0,35 & 50 & 5,28 & 44,72 & 0,35 & 0,94 & 1 & & 0,85 \\
2 & 0,71 & 50 & 10,56 & 39,44 & 0,66 & 0,87 & 1 & 6,03 & 2,65 \\
3 & 1,06 & 50 & 15,85 & 34,15 & 0,40 & 0,77 & 1 & & 1,83 \\
4 & 1,42 & 50 & 21,13 & 28,87 & 0,13 & 0,63 & 1 & & 0,57 \\
& & & & & & & & $\boldsymbol{\Sigma} \boldsymbol{p}=$ & $\mathbf{5 , 9 0}$ \\
\hline
\end{tabular}

Além dos módulos de deformabilidade $\mathrm{E}_{\mathrm{adm}}$, também foram determinados os módulos referentes à recuperação elástica das colunas de compactação, evidenciadas no último estágio do trecho de descarregamento do ensaio de prova de carga em placa. A estimativa do módulo também foi feita pela retroanálise do método de Schmertmann (1978). Para isto, foi considerado que o recalque corresponderia a variação entre os pontos do prolongamento da curva carga $x$ recalque no último estágio, como se não houvesse recuperação elástica, e o recalque obtido no alívio total do carregamento. O símbolo correspondente ao módulo de deformabilidade adotado para o trecho de recuperação elástica foi $\mathrm{E}_{\mathrm{el}}$. Os resultados obtidos para cada elemento de reforço ensaiado estão apresentados na Tabela 5.13.

Nas tabelas abaixo são apresentados os dados necessários para a determinação do $E_{\mathrm{el}}$ aplicando-se a retroanálise do método de Schmertmann (1978). Na Tabela 5.14 estão 
apresentados os dados referentes à coluna de solo compactado 1 , sendo a tensão no último estágio de descarregamento igual a $64 \mathrm{kPa}$ e a variação do recalque de $2,25 \mathrm{~mm}$.

Na Tabela 5.15 estão apresentados os dados referentes à coluna de solo compactado 2, sendo a tensão aplicada de $56 \mathrm{kPa}$ e a variação do recalque de $2,46 \mathrm{~mm}$.

Tabela 5.13 - Módulo de deformabilidade elástico obtido no descarregamento ( $\left.\mathrm{E}_{\mathrm{el}}\right)$

\begin{tabular}{|cc|}
\hline Ensaio & Eel (MPa) \\
\hline Coluna de Solo e Brita & 15,34 \\
Coluna de Solo Compactado 1 & 17,80 \\
Coluna de Solo Compactado 2 & 21,70 \\
\hline
\end{tabular}

Tabela 5.14 - Aplicação da retroanálise pelo método de Schmertmann (1978) para determinar o E $\mathrm{el}_{\mathrm{el}}$ da coluna de solo compactado 1

\begin{tabular}{|cccccccccc|}
\hline Subcamada & $\boldsymbol{\Delta z}(\boldsymbol{m})$ & $\boldsymbol{\sigma}(\mathbf{k P a})$ & $\boldsymbol{\sigma} \boldsymbol{v}(\mathbf{k P a})$ & $\boldsymbol{\sigma}^{*}(\mathbf{k P a})$ & $\mathbf{I z}$ & $\boldsymbol{c 1}$ & $\boldsymbol{c 2}$ & $\boldsymbol{E s}(\mathbf{M P a})$ & $\boldsymbol{\rho} \boldsymbol{i}(\mathbf{m m})$ \\
\hline 1 & 0,35 & 64 & 5,28 & 58,72 & 0,37 & 0,96 & 1 & & 0,34 \\
2 & 0,71 & 64 & 10,56 & 53,44 & 0,69 & 0,90 & 1 & 21,70 & 1,09 \\
3 & 1,06 & 64 & 15,85 & 48,15 & 0,42 & 0,84 & 1 & & 0,82 \\
4 & 1,42 & 64 & 21,13 & 42,87 & 0,14 & 0,75 & 1 & & 0,29 \\
& & & & & & & & $\boldsymbol{\Sigma} \boldsymbol{\rho}=$ & $\mathbf{2 , 2 5}$ \\
\hline
\end{tabular}

Tabela 5.15 - Aplicação da retroanálise pelo método de Schmertmann (1978) para determinar o Eel da coluna de solo compactado 2

\begin{tabular}{|cccccccccc|}
\hline Subcamada & $\boldsymbol{\Delta z}(\boldsymbol{m})$ & $\boldsymbol{\sigma}(\mathbf{k P a})$ & $\boldsymbol{\sigma} \boldsymbol{v}(\mathbf{k P a})$ & $\boldsymbol{\sigma}^{*}(\mathbf{k P a})$ & $\boldsymbol{I} \boldsymbol{z}$ & $\boldsymbol{C 1}$ & $\boldsymbol{C 2}$ & $\boldsymbol{E s}(\mathbf{M P a})$ & $\boldsymbol{\rho} \boldsymbol{i}(\boldsymbol{m m})$ \\
\hline 1 & 0,35 & 56 & 5,28 & 50,72 & 0,35 & 0,94 & 1 & & 0,34 \\
2 & 0,71 & 56 & 10,56 & 45,44 & 0,67 & 0,88 & 1 & & 1,08 \\
3 & 1,06 & 56 & 15,85 & 40,15 & 0,40 & 0,80 & 1 & 17,80 & 0,78 \\
4 & 1,42 & 56 & 21,13 & 34,87 & 0,13 & 0,69 & 1 & & 0,26 \\
& & & & & & & & $\boldsymbol{\Sigma} \boldsymbol{p}=$ & $\mathbf{2 , 4 6}$ \\
\hline
\end{tabular}

Na Tabela 5.16 estão apresentados os dados referentes à coluna de solo e brita, sendo a tensão do último estágio de descarregamento igual a $40 \mathrm{kPa}$ e a variação do recalque de 1,47mm. Os módulos de deformabilidade $\left(\mathrm{E}_{\mathrm{el}}\right)$ calculados indicam que as colunas de solo compactado 1 e 2 apresentaram uma maior recuperação elástica do que a coluna de solo e brita.

Tabela 5.16 - Aplicação da retroanálise pelo método de Schmertmann (1978) para determinar o E $\mathrm{el}_{\mathrm{el}}$ da coluna de

\begin{tabular}{|c|c|c|c|c|c|c|c|c|c|}
\hline Subcamada & $\Delta z(m)$ & $\sigma(k P a)$ & $\sigma v(k P a)$ & $\sigma^{*}(k P a)$ & $I z$ & C1 & $C 2$ & $E s(M P a)$ & pi (mm) \\
\hline 1 & 0,35 & 40 & 5,28 & 34,72 & 0,33 & 0,92 & 1 & \multirow{4}{*}{15,34} & 0,24 \\
\hline 2 & 0,71 & 40 & 10,56 & 29,44 & 0,63 & 0,82 & 1 & & 0,70 \\
\hline 3 & 1,06 & 40 & 15,85 & 24,15 & 0,38 & 0,67 & 1 & & 0,43 \\
\hline \multirow[t]{2}{*}{4} & 1,42 & 40 & 21,13 & 18,87 & 0,13 & 0,44 & 1 & & 0,10 \\
\hline & & & & & & & & $\Sigma p=$ & 1,47 \\
\hline
\end{tabular}




\subsubsection{Análise da rigidez do solo reforçado}

Com base nos resultados das provas de carga em placa realizadas foi possível analisar a variação da rigidez das colunas e do solo com o acréscimo de tensão. Para isto, foi feito um gráfico conhecido como "Gráfico de Rigidez" em que os valores de rigidez correspondem as ordenadas e os valores das tensões aplicadas, as abcissas.

A Figura 5.28 apresenta o gráfico obtido para o comportamento da rigidez do solo com o aumento da tensão para os ensaios realizados na coluna de solo e brita (ensaio inundado), coluna de solo compactado 1 (ensaio inundado), coluna de solo compactado 2 (ensaio com sucção de $13 \mathrm{kPa}$ ), e no solo sem reforço (com sucção de $6 \mathrm{kPa}$ ).

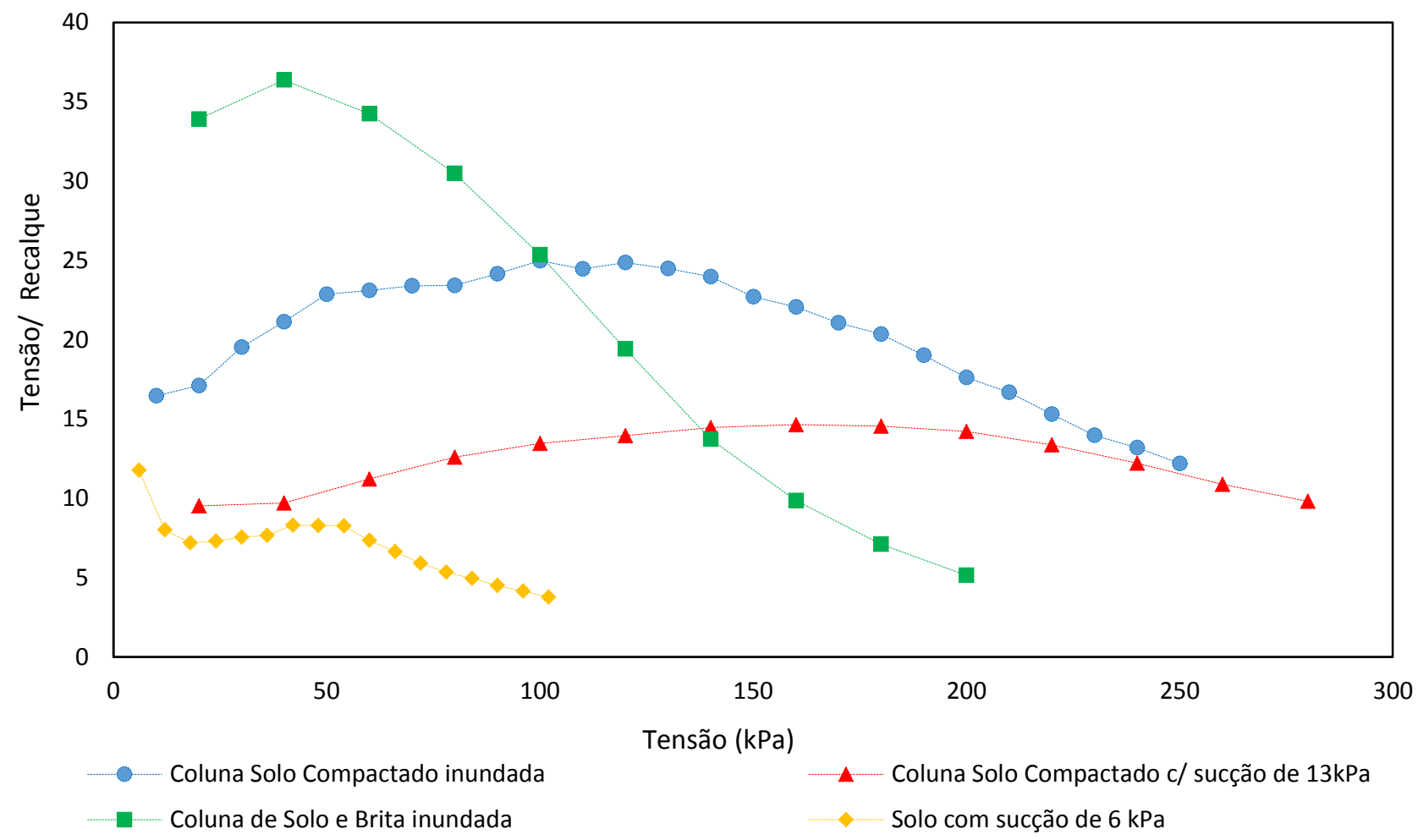

Figura 5.28 - Curvas Tensão x Rigidez para os estágios de carregamento dos ensaios de prova de carga sobre placa realizados

Pelas curvas obtidas verifica-se que todas elas sofrem um aumento da rigidez durante o ensaio e logo em seguida a sua redução. Isto ocorre devido a compactação do solo abaixo da placa, que provoca o aumento da rigidez do solo.

Observa-se pelas curvas de rigidez $x$ tensão que nenhum ensaio atingiu a ruptura de acordo com Décourt (1998), pois nenhuma das curvas obtidas interceptou o eixo das abcissas, com valor de rigidez igual a zero. 
Pelo gráfico nota-se que a rigidez da coluna de solo e brita é maior do que a rigidez da coluna de solo compactado a um nível de tensão inferior a $100 \mathrm{kPa}$, sendo que, para este carregamento as rigidezes das colunas de solo e brita e de solo compactado (1) são iguais e equivalentes a $25 \mathrm{kPa} / \mathrm{mm}$. Por outro lado, a perda de rigidez ao longo do carregamento também é maior e mais rápida comparada com os ensaios nas colunas de solo.

Já para a coluna de solo compactado (2), a sua rigidez se iguala à rigidez da coluna de solo e brita para a tensão de $139 \mathrm{kPa}$, atingindo o valor de $14,2 \mathrm{kPa} / \mathrm{mm}$. A partir deste ponto, ocorre a perda acentuada de rigidez da coluna de solo e brita, atingindo valores inferiores as rigidezes das colunas de solo compactado, com o acréscimo da tensão aplicada.

Observa-se que para os níveis de tensões admissíveis, a coluna de solo e brita apresentou rigidez maior do que as colunas de solo compactado. Porém, para as tensões de ruptura, as colunas de solo compactado apresentaram rigidezes maiores do que a coluna de solo e brita. Isto ocorre porque com o aumento gradativo da carga aplicada no ensaio, as tensões mobilizadas no solo vão atingindo maior raio de alcance em torno da coluna, e o solo circundante às colunas de solo (sem brita) foi mais compactado do que no caso da coluna de brita.

Para o solo sem reforço, com sucção de $6 \mathrm{kPa}$, nota-se que no início do ensaio, para baixos níveis de tensão, há uma acentuada perda de rigidez do solo até alcançar a tensão de 17,5 $\mathrm{kPa}$. Atribui-se os altos valores de rigidez encontrados para o solo sem reforço no início do ensaio de prova de carga, aos efeitos combinados de cimentação, típica dos solos lateríticos, e aos efeitos de sucção. Para tensões superiores à 17,5 kPa, observa-se um ligeiro aumento da rigidez, até atingir aproximadamente a tensão admissível de $50 \mathrm{kPa}$ (Tabela 5.17) e em seguida há a nítida redução da rigidez com o acréscimo de tensão.

Tabela 5.17 - Tensão admissível e tensão de ruptura encontradas nas provas de carga em placa

\begin{tabular}{|ccc|}
\hline Ensaio & $\boldsymbol{\sigma}_{\text {rup }}(\mathbf{k P a})$ & $\boldsymbol{\sigma}_{\text {adm }}(\mathbf{k P a})$ \\
\hline Coluna de solo e brita & 180 & 90 \\
Coluna de solo compactado 1 & 268 & 134 \\
Coluna de solo compactado 2 & 265 & 132 \\
Solo sem reforço com sucção de 6 $\mathrm{kPa}$ & 100 & 50 \\
\hline
\end{tabular}




\section{CONCLUSÃO}

Este trabalho foi dividido em duas etapas principais. A primeira etapa envolveu os ensaios em escala reduzida para avaliar qualitativamente os efeitos da compactação no entorno das colunas devido às diferentes geometrias de pilão utilizadas na execução dos elementos de reforço. Na segunda etapa foram executadas colunas de solo compactado e de solos+brita em escala real, e a eficiência do reforço foi avaliada por meio da comparação entre provas de carga em placa executadas sobre a área reforçada e sobre o solo natural. Deste modo, as conclusões desta pesquisa são divididas em duas partes:

\section{i. Ensaios em modelos reduzidos de colunas}

Os modelos reduzidos de colunas de solo compactado confirmam a hipótese inicial do trabalho de que haveria diferença na compactação do solo no entorno da coluna quando compactado com diferentes geometrias de ponta do pilão.

Devido à similaridade dos resultados encontrados e à padronização da sua execução foi possível comparará-los, e concluiu-se que as colunas executadas com pilão tipo A (cônico) ficaram mais curtas e mais grossas do que as colunas executadas com o pilão tipo B (cilíndrico). Sabendo-se que houve o devido controle na perfuração do furo a ser preenchido, e que a mesma massa de solo foi adicionada para a execução das colunas, é possível inferir que o pilão cônico, tipo A, tende a empurrar o solo radialmente e que o pilão cilíndrico, tipo $\mathrm{B}$, tende a empurrar o solo para baixo durante a compactação.

Também foi analisada a interferência do encamisamento das colunas no efeito de compactação. Com base nos resultados encontrados foi possível concluir que não houve intervenção da membrana de revestimento nos efeitos de compactação pois, a coluna encamisada apresentou geometria similar à obtida nas colunas compactadas com o mesmo pilão, porém sem encamisamento.

Sabendo-se que as colunas utilizadas como reforço de solo têm como finalidade a densificação do solo no seu entorno, devido ao deslocamento das partículas para as laterais, conclui-se que, mesmo em pequena escala, o pilão com geometria cônica (A) ofereceu uma maior compactação radial do solo, o que pode implicar em melhores condições de reforço. No entanto, os resultados dos ensaios de campo mostraram que a coluna cilíndrica foi eficiente na compactação no solo em seu entorno, apesar de grande volume de solo ter sido deslocado para baixo no início da compactação do solo dentro do furo aberto para a execução da coluna. 


\section{ii. Ensaios do solo reforçado em campo}

Na segunda etapa deste trabalho, antes da execução das provas de carga, verificou-se o efeito radial da compactação no entorno das colunas de compactação com a finalidade de analisar o espaçamento ideal para a execução de uma malha de colunas. Para as colunas de solo compactado, o efeito da compactação atingiu um raio de $80 \mathrm{~cm}$ a partir do centro da coluna de diâmetro de $25 \mathrm{~cm}$ (3,2 vezes o seu diâmetro). Para a coluna de solo e brita, o efeito da compactação foi verificado até um raio de $45 \mathrm{~cm}$ do centro da coluna, ou de 1,8 vezes o seu diâmetro. Tem-se então que o espaçamento das colunas deverá ser no máximo igual a 6,4 vezes o diâmetro, para as colunas de solo compactado, e de 3,6 vezes o diâmetro, para as colunas de solos e brita. Portanto, é necessária uma maior quantidade de colunas de solo e brita por $\mathrm{m}^{2}$ para densificação do terreno.

Com base nestes resultados preliminares de prova de carga em placa realizados no terreno com e sem reforço, conclui-se que a técnica de melhoramento do solo avaliada nesta pesquisa é eficiente para a redução de recalque em solo colapsível. Uma única coluna de solo compactado conferiu ao solo um acréscimo de capacidade de carga de 4 vezes e uma coluna de solo e brita conferiu ao solo um aumento da capacidade de carga de 2,8 vezes, sendo ambos na condição inundada.

Comparando-se as curvas tensão $x$ recalque obtidas para as colunas de solo compactado na condição inundada e com sucção de $13 \mathrm{kPa}$, nota-se que não houve acréscimo de capacidade de carga devido ao efeito da sucção. Os resultados mostram que os efeitos da sucção são menos pronunciados em solos compactados.

Nas provas de carga realizadas, obteve-se uma tensão de ruptura maior para as colunas de solo compactado do que para as colunas de solo e brita, o que confirma a maior eficiência deste método de reforço. Estes resultados são explicados pelos valores da variação do índice de vazios do solo no entorno da coluna, que foram menores para o caso das colunas de solo, indicando que ocorreu maior compactação do solo em volta da coluna.

Pelas curvas tensão $x$ recalque dos ensaios de prova de carga no solo reforçado com coluna, no trecho de descarregamento, observou-se que no último estágio houve uma parcela de recuperação elástica do solo reforçado. Pode-se concluir que o material compactado foi que conferiu ao solo esta parcela de deformação elástica uma vez que, as curvas obtidas nos ensaios de prova de carga no solo sem reforço apresentaram deformação completamente plástica. 
Quanto aos valores de módulo de deformabilidade e rigidez, para as tensões admissíveis, a coluna de solo e brita apresentou maior módulo e maior rigidez do que as colunas de solo compactado. Porém, para as tensões de ruptura, houve a inversão dos valores de módulo e rigidez, sendo estes maiores para as colunas de solo compactado do que para as colunas de solo e brita. Estes resultados mostram que as colunas de solo e brita se comportam melhor no estado limite de serviço (ELS) enquanto que as colunas de solo compactado apresentam melhor desempenho do estado limite último (ELU).

\section{SUGESTÕES PARA TRABALHOS FUTUROS}

Os resultados preliminares apresentados nesta pesquisa confirmam a eficácia deste método de reforço de solo proposto para solos colapsíveis. Como sugestão para continuidade da pesquisa, tem-se:

- Com os parâmetros de deformabilidade e resistência das colunas de solo laterítico compactado e de solo e brita ensaiadas, pode-se analisar o comportamento de uma fundação direta apoiada em solo reforçado com colunas por meio de simulação numérica.

- Além disso, numericamente, também poderão ser avaliados diferentes espaçamentos entre colunas, profundidade, e diferentes geometrias de distribuição para analisar a melhor malha de distribuição dos elementos de reforço.

- Devido à dificuldade de ensaiar uma malha de colunas em escala real, sugerese a análise do comportamento do efeito de grupo das colunas em centrífuga, pois permite o ensaio em escala reduzida, testando diâmetros, espaçamentos, profundidades, e geometrias de distribuição variadas. Neste ensaio é possível obter parâmetros de resistência e deformabilidade para um conjunto de colunas, além de possibilitar a analisar os mecanismos de ruptura do conjunto de colunas. 


\section{REFERÊNCIAS}

ASSOCIAÇÃO BRASILEIRA DE NORMAS. NBR 6122: projeto e execução de fundações. Rio de Janeiro, 2010. 91 p.

NBR 6122: projeto e execução de fundações. Rio de Janeiro, 1996. 33 p.

NBR 6489: prova de carga direta sobre terreno de fundação, procedimento. Rio de Janeiro, 1984. 2 p.

NBR 6508: grãos de solos que passam na peneira $4,8 \mathrm{~mm}$ : Determinação da massa específica. Rio de Janeiro, 1984. 8 p.

NBR 7180: solo: determinação do limite de plasticidade. Rio de Janeiro,1984. 3 p.

NBR 7181: solo: análise granulométrica. Rio de Janeiro, 1984. 13 p.

NBR 7182: solo: ensaio de compactação. Rio de Janeiro, 1986. 10 p.

NBR 6459: solo: determinação do limite de Liquidez. Rio de Janeiro, 1984. 6 p.

. NBR 12069: MB 3406: solo: ensaio de penetração de cone in situ (CPT) - método de ensaio. Rio de Janeiro, 1991.

NBR 10838: MB 2887: solo: determinação da massa específica aparente de amostras indeformadas, com o emprego da balança hidrostática. Rio de Janeiro, 1988. 4 p.

ABRAMENTO, M.; KOSHIMA, A.; ZIRLIS, A. C. Reforço do terreno. In: HACHICH, W. et al. Fundações: teoria e prática. 2. ed. São Paulo: Pini, 1988. cap. 18, p. 641-690.

AFLITOS, A. O. et al. Projeto formoso A: implantação de obras localizadas com fundações em solos colapsíveis. In: CONGRESSO BRASILEIRO DE MECÂNICA DOS SOLOS E ENGENHARIA DE FUNDAÇÕES, 9., 1990, Salvador. Anais... Salvador, 1990. v 2, p. 101 108.

AGNELLI, N. Estudo da colapsividade do solo de Bauru através de provas de carga diretas. Dissertação (Mestrado em Geotecnia) - Escola de Engenharia de São Carlos, Universidade de São Paulo, São Carlos, 1992. 172 p. 
AITCHISON, G. D. Engineering concepts of moisture changes in soils: statement of the review pane. In: MOISTURE EQUILIBRIA AND MOISTURE CHANGES IN THE SOILS BENEATH COVERED AREAS, 1965, Sydney. Proceedings... Sydney, Butterworths, 1965. p. 7-21.

Problems of soil mechanics and construction on soft clays and structurally unstable soils (collapsible, expansive and others). In: VIII INTERNATIONAL CONFERENCE ON SOIL MECHANICS AND FOUNDATION ENGINEERING, 8, 1973, Moscow. Proceedings... Moscow, 1973. v. 3, p. $161-190$.

AKINMUSURU, J. O. Interactions of piles and cap in piled footing. Journal of Geotechnical and Geoenvironmental Engineering. v. 106, n. 11, p. 1263-1268, 1980.

ALAMGIR, M.; MIURA, N.; POOROOSHASB, H. B.; MADHAV, M. R. Deformation analysis of soft ground reinforced by columnar inclusions. Computers and Geotechnics. v. 18, n.4, p. $267-290,1996$.

ALI, F. H.; RAHARDJO, H. Tropical residual soils engineering. Cap. 4. Londres: Taylor \& Francis Group, 2009.

ALI, N. A. Performance of partially replaced collapsible soil: field study. Alexandria Engineering Journal, v. 54. n. 3, p. 527-532, 2015.

ALONSO, E. E.; GENS, A.; JOSA, A. Constitutive model for partially saturated soils. Geotechnique, v. 40, n. 3, p. 405-430, 1990.

AL RAWAS, A. State of the art: review of collapsible soils. Science and Technology, Special Review, Sultan Qaboos University, 2000, p. 115 - 135.

ALUCE, G. et al. An introduction to the deep soil mixing methods as used in geotechnical applications. Virgina: Department of Commerce National Technical Information Service Springfield, 2000.

ALVES, A. M. L. Contribuição ao estudo de estacas de compactação em solos granulares. Dissertação (Mestrado em Geotecnia) - COPPE (Instituto Alberto Luiz Coimbra de PósGraduação e Pesquisa de Engenharia), Universidade Federal do Rio de Janeiro, Rio de Janeiro, 1998. $190 \mathrm{p}$. 
ALVES, A.M.L.; LOPES, F.R.; ARAGÃO, C.J.G. Proposta de método de projeto de fundações superficiais em solos melhorados por estacas de compactação. In: SEMINÁRIO DE ENGENHARIA DE FUNDAÇÕES ESPECIAIS E GEOTECNIA, 4., 2000,. Anais... São Paulo 2000, v. 2, p. 102-112.

ANDRADE, J.F. Reforço de solos com a utilização de tubulões em solo-cimento. Dissertação (Mestrado em Geotecnia) - Escola de Engenharia de São Carlos, Universidade de São Paulo, São Carlos, 1989, 190 p.

ARAÚJO, G.L.S. Estudo em laboratório e em campo de colunas granulares encamisadas com geossintéticos. Tese (Doutorado em Geotecnia). Universidade de Brasília, Brasília, 2009. $166 \mathrm{p}$.

AYADAT, T.; HANNA, M. Encapsulated stone columns as a soil improvemnet technique for collapsible soil. Ground Improvement. v.9, nº 4. p. 137-147, 2005.

BARDEN, L; SIDES, G. R. Engineering behavior and structure of compacted clay. Journal of the Soil Mechanics and Foundation Division, American Society of Civil Engineers. v. 96, SM 4, p. 1171-1200, 1970.

BELES, A. A.; STÂNCULESCU, I. I. Thermal treatment as a means of improving the stability of earth masses. Geotechinique, v. 8, n. 4, p. 158-165, 1958.

BENATTI, J. C. B. et al. Collapsibility study for tropical soil profile using oedometric tests with controlled suction. In: INTERNATIONAL CONFERENCE ON UNSATURATED SOILS, 5., 2011, Barcelona. Proceedings ... Barcelona, 2011. v. 1, p. 193 - 198.

BERGADO, D. T.; CHAI, J. C.; BALASUBRAMANIAM, A. S. Improvement techniques of soft ground in subsiding and lowland environment. Rotterdam: A. A. Balkema, 1994.

BORTOLUCCI, A. A. Caracterização geológico-geotécnica da região urbana de São Carlos - SP, a partir de sondagens de simples reconhecimento.. Dissertação (Mestrado em Geotecnia) - Escola de Engenharia de São Carlos, Universidade de São Paulo, São Carlos, 1983. $67 \mathrm{p}$.

BROMS, B. B. Deep compaction of granular soils. In: FANG, H.Y. Foundation engineering handbook. 2. ed. New York: Van Nostrand Reinhold, 1991. p. 814-832.

BURLACU, C.; OLINIC, E.; MANEA, S. Compacted soil columns for foundations on collapsible soils: laboratory and in-situ experimental study. In: INTERNATIONAL 
CONFERENCE ON SOIL MECHANICS AND GEOTECHNICAL ENGINEERING, 2013, Paris. Proceedings... Paris, 2013. p. 2433-2436.

CARLETTO, M.F.W. Jet grouting (sistema monofluido): um método teórico simplificado para a previsão do diâmetro das colunas. Tese (Doutorado em Geotecnia). Escola Politécnica, Universidade de São Paulo, São Paulo, 2009. 131 p.

CARVALHO, D.; SOUZA, A. Análise do efeito do umedecimento do solo em fundações rasas e profundas em solos porosos. In: CONGRESSO BRASILEIRO DE MECÂNICA DOS SOLOS E ENGENHARIA DE FUNDAÇÕES, 9., 1990, Salvador. Anais... Salvador: ABGE; ABMS, 1990. v. 2, p. 109-114.

CINTRA, J. C. A.; ALBIEIRO, J. H.; VILAR, O. M. Pile load on colapsible soil: conclusuin and recommendation. In: INTERNATIONAL CONFERENCE ON SOIL MECHANICS AND FOUNDATION ENGINEERING, 14., 1997, Hamburgo. Proceedings... Hamburgo, 1997. p. 781-782.

CINTRA, J. C. A.; AOKI, N. Projeto de fundações em solos colapsíveis. São Carlos: EESC/USP, 2009.

CINTRA, J. C. A. Fundações em solos colapsíveis. 2005. 124 f. Tese (Livre-Docência) Escola de Engenharia de São Carlos, Universidade de São Paulo, São Carlos, 2005.

COLEMAN, J. D. Stress strain relations for partly saturated soil. Geotechnique, v.12, n 4. p. 348-350, 1962.

CONCIANI, W. Fundações para construção de habitação de interesse social no Estado do Mato Grosso. Cuiabá: CEFET MT, 2006.

COSTA, Y. D. J. Estudo do comportamento de solo não saturado através de prova de carga em placa. Dissertação (Mestrado em Geotecnia) - Escola de Engenharia de São Carlos, Universidade de São Paulo, São Carlos, 1999. 160 p.

CRAIG, R. F. Mecânica dos solos. Rio de Janeiro: LTC, 2007.

DÉCOURT, L. Capacidade de carga em estacas executas no campo experimental de engenharia geotécnica da Universidade Estadual de Londrina. In: CONGRESSO BRASILEIRO DE MECÂNICA DOS SOLOS E ENGENHARIA GEOTÉCNICA, 12., 2002, São Paulo. Anais... São Paulo: ABMS, 2002. v. 3, p. 1545-1555. 
DÉCOURT, L. Ruptura de fundações e coeficientes de segurança à luz do conceito de rigidez. In: CONGRESSO BRASILEIRO DE MECÂNICA DOS SOLOS E ENGENHARIA GEOTÉCNICA, 11., 1998, Brasília. Anais... Brasília: ABMS, 1998. p. 1599- 1606.

DEPARTAMENTO NACIONAL DE ESTRADAS DE RODAGEM. DNER-ME 258: solos compactados em equipamento miniatura: mini: MCV. Rio de Janeiro, 1994.

DIAS, I. M. Estudo de solos tropicais para uso em pavimentação a partir de ensaios triaxiais estáticos. Dissertação (Mestrado em Geotecnia) - Escola de Engenharia de São Carlos, Universidade de São Paulo, São Carlos, 2007. 139 p.

FARIAS, W. M. et al. Influência da compactação nos micros e mesoporos nanoestruturados e na área superficial específica de um solo laterítico. In: SIMPÓSIO BRASILEIRO DE SOLOS NÃO SATURADOS, 7., 2011, Pirinópolis. Anais ...Pirinópolis, 2011. v. 1, p. 169-175.

FAROUK, A.; SHAHIEN, M. Ground improvement using soil-cement columns: experimental investigation. Alexandria Engineering Journal. v. 52, n. 4, p. 733-740, 2013.

FELLENIUS, B. H. The load of piles and new proof testing procedure. In: Journal of the Geotechnical Engineering Division, v. 101, n. 9, GT9, p. 855- 869, 1975.

FERNANDES, M. M. Sebenta de mecânica dos solos. Porto: FEUP, 1994. v. I.

FERREIRA, S. R. M. Microestrutura de solos colapsíveis e técnica de melhoramento. In: CONGRESSO BRASILEIRO DE MECÂNICA DOS SOLOS E ENGENHARIA GEOTÉCNICA, 15, 2000, Gramado. Anais... [S.1]: ABMS, 2010.

FERREIRA, R. C.; PERES, J. E. E.; BENVENUTO, C. Uma análise de modelos geotécnicos para a previsão de recalques em solos colapsíveis. In: CONGRESSO BRASILEIRO DE GEOLOGIA DE ENGENHARIA, $6^{\circ}$ CONGRESSO BRASILEIRO DE MECÂNICA DOS SOLOS E ENGENHARIA DE FUNDAÇÕES, 9, 1990, Salvador. Anais...São Paulo: ABGE/ABMS. V.2, p. 73-79.

FOOKES, P. G. Tropical residual soils. London: The Geological Society, 1993.

FREDLUND, D. G.; MORGERSTERN, N.; WIDGER, R. A. The Shear strength of unsaturadted soils. Canadian Geotechnical Journal. v. 15, n. 3, p. 313-321, 1978. 
FREDLUND, D. G.; RAHARDJO, H. Soil mechanics for unsaturated soils. New York: John Wiley\& Sons, 1993. p. 517

FREDLUND, D. G.; XING, A. Equations for the soil-water characteristics curve. Canadian Geotechical Journal, v. 31, n. 4, p. 521-532, 1994.

GEORGETTI, G.B. Resistência de um solo não saturado a partir de ensaios com teor de umidade constante (CW). Dissertação (Mestrado em Geotecnia) - Escola de Engenharia de São Carlos, Universidade de São Paulo, São Carlos, 2010. 108 p.

GERSCOVICHI, D. M. S. Estabilidade de taludes. São Paulo: Oficina de Textos, 2013.

GONÇALVES, R. L. Estudo do comportamento de estacas apiloadas em solo colapsível da região de Londrina/PR. Dissertação (Mestrado) - Faculdade de Engenharia Civil, Universidade Estadual de Londrina, Paraná, 2006. 170 p.

GONTIJO, H. (2015). Apostila: Águas Subterrâneas. Universidade de Itauna, 24 p.

GUSMÃO, A. D. Melhoramento de terrenos arenosos. Capítulo 6. Pernambuco: Universidade Federal de Pernambuco, 2005., v. 1. p.331-363.

GUSMÃO FILHO, J. A. Fundações em solos não saturados. In: SIMPÓSIO SOBRE SOLOS NÃO SATURADOS, 2., 1994, Recife. Anais... Recife: UFPE, 1994. p. 217-230.

1998.

Fundações do conhecimento geológico à prática da engenharia. Recife: UFPE,

HILF, J. W. An Investigation of pore water pressure in compacted cohesive soils. Denver: [s.n.], 1956. 109 p. (Techinical Memorandum 624).

HILLEL, D. Soil and water: physical principles and processes. New York: Academic Press, 1971. p. 5 - 127.

HO, D. Y. F.; FREDLUND, D. G. A. A Multistage triaxial test for unsaturated soil. Geotechnical Testing Journal. v. 5, n. 1/2, p. $18-25,1982$.

HOGENTOGLER, C. A. Engineering properties of soil. New York: McGraw-Hill, 1937. 
HOLTZ, R. D.; KOVACS, W. D.; SHEAHAN, T. An Introduction to geothecnical engineering. New Jersey: Pearson Education, 1981.

HOUSTON, S. L. et al. Geotechnical engineering practice for collapsible soils. Geotechnical and Geological Engineering, v. 19, n. 3 , p. 333-355, 2001.

JENNING, J. E.; KNIGHT, K. The Additional settlement of foundations due to a colapse of structure of sandy subsoils on wetting. In: International Congress of Soil Mechanics and Foundation Enginnering, 4., 1957. [Proceedings...] London, 1957. v.1, p. 316 - 319.

JENNING, J. E.; KNIGHT, K. A Guide to construction on or with materials exhibiting additional settlement due to collapse of grain structure. In: $6^{\text {th }}$ REGIONAL CONFERENCE FOR AFRICA ON SOIL MECHANICS \& FOUNDATION ENGINEERING, 1975,. [Proceedings...], Durban, 1975, v. 1, p. $99-105$.

KIRSCH, K.; KIRSCH F. Ground improvement by deep vibratory methods. New York: Spon Press, 2010.

KISHIDA, H.; MEYERHOF, G. G. Bearing capacity of pile groups under eccentric loads in sand. In: INTERNATIONAL CONFERENCE ON SOIL MECHANICS AND FOUNDATION ENGINEERING, 6., 1965, Toronto. Proceedings... Toronto, 1965. v.2, p. 270 - 274.

KURNAKOV, E. G. Construction of a continuous base of an installation under construction by thermal stabilization of soils. Soil Mechanics and Foundation Engineering, v. 9, n. 3, p. 184$186,1972$.

LAMBE, T. W. The Structure of compacted clay. Journal of Soil Mechanics and Foundation Division, American Society of Civil Engineers, v. 84, n. SM-2, p. 1-37, 1958.

LEONARDS, G. A. Foundations engineering. New York: Mc Graw-Hill, 1962.

LITVINOV, I. M. Stabilization of settling and weak clayey soils by thermal treatment. Washington: Highway Research Board, 1960. p. 94-112. (Highway Research Board Special Report, n. 60).

LIU, J. L.; YUAN, Z. L.; ZHANG, K. P. Cap - pile - soil interaction of bored pile groups. In: $11^{\text {th }}$ INTERNATIONAL CONFERENCE ON SOIL MECHANICS AND FOUNDATION ENGINEERING, 1985, [Proceedings...] San Francisco, 1985, v. 4, p. 1433- 436. 
LOBO, A. S.; FERREIRA, C. V.; ALBIEIRO, J. H. Problemas de fundações em solo colapsível: estudo de casos. In: III SIMPÓSIO BRASILEIRO DE SOLOS NÃO SATURADOS,. Anais... Rio de Janeiro, 1977. p. 77-89.

LUTENEGGER, A. J.; SABER, R. T. Determination of collapse potential of soils. Geotechnical Testing Journal, v. 11, n. 3, p. 173-178, 1988.

MACHADO, S.L. Aplicação de conceitos de elastoplasticidade a solos não saturados.. Tese (Doutorado em Geotecnia) - Escola de Engenharia de São Carlos, Universidade de São Paulo, São Carlos, 1998. 361 p.

MASSAD, F. Escavações a céu aberto em solos tropicais: região Centro Sul do Brasil. São Paulo: Oficina de Textos, 2005.

MASSAD, F. Obras de terra: curso básico de geotecnia. São Paulo: Oficina de Textos, 2010.

MATYAS, E. L.; RADHAKRISHNA, H. S. Volume change characteristics of partially saturated soils. Geotechnique, v. 18, n . 4, p. 432-448, 1968.

MELFI, A. J. Laterita e processos de laterização: aula inaugural da pós-graduação em Geotecnia da USP. São Carlos: CETEPE, 1994.

MELLO, V. F. B. Thoughts on soil engineering applicable to residual soils. In: SOUTHEAST ASIAN CONFERENCE ON SOIL ENGINEERING, 3., 1972, Hong Kong. Proceedings... Hong Kong: Southeast Asian Society of Soil Engineering, 1972.

MENEGOTTO, M. L. Previsão da curva tensão x recalque de ensaios de placa em solo não saturado. 2004. 224 f. Tese (Doutorado em Geotecnia) - Escola de Engenharia de São Carlos, Universidade de São Paulo, São Carlos, 2004.

MIGUEL, M. G. Execução e análise de prova de carga horizontal em estacas em solo colapsível. 1996. 168 f. Dissertação (Mestrado em Geotecnia) - Escola de Engenharia de São Carlos, Universidade de São Paulo, São Carlos, 1996.

MITCHELL, J. K. Soil improvement: state-of-art report. In: $10^{\text {th }}$ INTERNATIONAL CONFERENCE ON SOIL MECHANICS AND FOUNDATION ENGINEERING, Proceedings... Stockholm, 1981, p. 509-565. 
MORAES, A. S.; SEGANTINI, A. A. S.; CARVALHO, D. Resistência à compressão do solo: cimento plástico. In: CONGRESSO BRASILEIRO DE ENGENHARIA AGRÍCOLA, 31., 2002, Salvador. Anais... Salvador: CONBEA, 2002.

MORAES, L. S. Prova de carga dinâmica em placa. Dissertação (Mestrado em Geotecnia) Escola de Engenharia de São Carlos, Universidade de São Paulo, São Carlos, 2005. 143 p. MORETTI, G. V. Comportamento à compressão de solo estabilizado com cimento utilizado em colunas de deep soil mixing.. Dissertação (Mestrado em Geotecnia) - Faculdade de Engenharia Agrícola, Universidade Estadual de Campinas, 2012. 153 p.

NOGAMI, J. S.; VILLIBOR, D. F. Uma Nova classificação de solos para finalidades rodoviárias. In: SIMPÓSIO BRASILEIRO DE SOLOS TROPICAIS EM ENGENHARIA, 1981, Rio de Janeiro. Anais... Rio de Janeiro: UFRJ, 1981. p. 30 - 41.

NOGAMI, J. S.; VILLIBOR, D. F. Pavimentação de baixo custo com solos lateríticos. São Paulo: Vilibor, 1995.

NOGUEIRA, E. G. Estudo de algumas soluções de tratamento de solos moles para construção de aterros no Trecho Sul do Rodoanel - SP. Dissertação (Mestrado em Geotecnia) - Escola Politécnica de São Paulo, Universidade de São Paulo, 2010. 166 p.

NOGUEIRA, J. B. Apostila de mecânica dos solos: caracterização. São Carlos: EESC, 1971.

OLSON, R. E. Effective stress theory of soil compaction. Journal of the Soil Mechanics and Foundation Division, American Society of Civil Engineers, v. 89, n. 2, p. 27 - 45, 1963.

ORTIGÃO, J. A. R. Introdução à mecânica dos solos dos estados críticos. Rio de Janeiro: Livros Técnicos e Científicos, 1993.

PACHECO, J. L. Estudo de Técnicas de Melhoramento de Terrenos Superficiais Arenosos no Recife. 2002, 122 f. Dissertação (Mestrado em Geotecnia). Universidade Federal de Pernambuco, Recife, 2002.

PASSOS, P. G. O. Melhoramento de solos arenosos com estacas de areia e brita. Tese (Doutorado em Geotecnia) - Faculdade de Tecnologia, Universidade de Brasília, Brasília, 2005. $159 \mathrm{p}$.

PASSOS, P. G.; BEZERRA, R. L.; GUSMÃO, A. D.; CAVALCANTE, E. H. Avaliação da resistência e deformabilidade de solos melhorados com estacas de areia e brita. In: CONGRESSO BRASILEIRO DE MECÂNICA DOS SOLOS E ENGENHARIA GEOTÉCNICA, 17., 2014, Goiânia. Anais... Goiânia: ABMS, 2014. 
PINTO, C. S. Curso básico de mecânica dos solos. São Paulo: Oficina de Textos, 2006.

PINTO, C. S. Propriedades dos solos. In: HACHICH, W. C. et al. (Eds.). Fundações teoria e prática. São Paulo: Pini, 1996. Cap. 2, p. 51-118.

PORBAHA, A. State of the art in deep mixng technology. Part 1: Basic concepts and overview of technology. Ground Improvement, v. 2, n. 2, p. 81 - 92, 1998.

PROCTOR, R. R. Fundamental principles of soil compaction. Engineering News Record, New York, v. 111, n. 9, p. 20-28, 1933.

REGINATO, A. R. Standard penetration test in collapsible soils. In: IV CONGRESO PANAMERICANO DE MECANICA DE SUELOS E INGENIERIA DE FUNDACIONES. [Proceedings of...] Porto Rico, 1971. v. 2, p. 77 - 84.

RESENDE, L. R. M. Capacidade de suporte de praias de rejeitos granulares de mineração e construção de aterros compactados. Dissertação (Mestrado em Geotecnia), Universidade Federal de Ouro Preto, Ouro Preto, 2012. 204 p.

REZNIK, Y. M. Plate load tests of collapsible soils. Journal of the Geotechnical Engineering Division, v. 119, n. 3, p. 608-615, 1993.

RIBEIRO JR, I.; FUTAI, M. M. Estudo de caso de um melhoramento de solos colapsíveis com compactação. In: XV CONGRESSO BRASILEIRO DE MECÂNICA DOS SOLOS E ENGENHARIA GEOTÉCNICA, [Anais...] Gramado, 2010.

RICHARDS, L. A. The usefulness of capillary potential to soil- moisture and plant investigators. Journal of the Agricultural Research. Washington, v. 37, n. 12, p. 719 - 742, 1928.

ROBINSKY, E. I.; MORRISON, C. F. Sand displacement and compactions arround model friction piles in sand. Canadian Geotechnical Journal, v. 1, n. 2, p. 81 - 93, 1964.

RODRIGUES, R. A. Modelação das deformações por colapso devidas à ascensão do lençol freático. Tese (Doutorado em Geotecnia) - Escola de Engenharia de São Carlos, Universidade de São Paulo, São Carlos, 2007, 298 p.

RODRIGUES, R. A.; VILAR, O. M. Colapso de solo desencadeado pela elevação do nível d’água. Revista Nacional de Gerenciamento de Cidades, v. 1, n. 6, p. 13-27, 2013. 
ROLLINGS, K. M.; KIM, J. H. U. S. Experience with dynamic compaction of collapsible soils. ASCE Special Geotechnical Publication, New York, n. 45, p. 26-43, 1994.

ROLLINGS, K. M.; ROGERS G. W. Mitigation measures for small structures on collapsible alluvial soils. Journal of Geotechnical Engineering, v. 120, n. 9, p. 1533 - 1553, 1994.

SALES, M. M. Análise do comportamento de sapatas estaqueadas. Tese (Doutorado em Geotecnia), Universidade de Brasília, Brasília, 2000, 257 p.

SALLES, J. C. Determinação de módulos de deformabilidade através de provas de carga no cone elétrico. Dissertação (Mestrado em Geotecnia), Escola de Engenharia de São Carlos, Universidade de São Paulo, São Carlos, 2013, 117 p.

SCHMETMANN, J. H. Static cone to compute static settlement over sand. Journal of the Soil Mechanics and Foundation Division, v. 96, n. 3, p. 1011 - 1043, 1970.

SCHMERTMANN, J. H. Guidelines for cone penetration test performance and design. Washington D. C.: US. Department of Transportation, 1978. 145 p. (Report FHWA - TS- 78209).

SCHNAID, F.; ODECRECHT, E. Ensaios de campo e suas aplicações à engenharia de fundações. São Paulo: Oficina de Textos, 2012. p. 223.

SEGANTINI, A. A. S. Utilização de solo-cimento em estacas apiloadas para obras de pequeno porte. Dissertação (Mestrado em Engenharia Agrícola) - Universidade Estadual de Campinas, 1994. 114 p.

SEGANTINI, A. A. S.; CARVALHO, D. Comportamento de estacas de pequeno diâmetro de solo-cimento. In: X CONGRESSO BRASILEIRO DE MECÂNICA DOS SOLOS E ENGENHARIA DE FUNDAÇÕES. [Anais...], Foz do Iguaçu, 1994. v. 1. p. 103 - 110.

SILVA, P. A. B. A. Capacidade de carga de grupos de estacas. Dissertação (Mestrado em Geotecnia) - Escola de Engenharia de São Carlos, Universidade de São Paulo, São Carlos, 1996. $123 \mathrm{p}$.

SOARES, W. C. Estacas de compactação para melhoria de solos. Dissertação. (Mestre em Geotecnia)- Escola de Engenharia de São Carlos, Universidade de São Paulo, São Carlos, 2002. $151 \mathrm{p}$. 
SOUTO SILVEIRA, E. B.; SILVEIRA, A. Low cost shallow foundation. In: II CONGRESSO PANAMERICANO DE MECANICA DOS SOLOS E ENGENHARIA DE FUNDAÇÕES. [Anais...] São Paulo, 1963, v. 1, p. 327 - 335.

SOUSA, L. C. M. Estudo experimental do comportamento de sapatas assentes em solo poroso reforçado. Dissertação (Mestrado em Geotecnia) -Universidade de Brasília, Brasília, 2003. $158 \mathrm{p}$.

SOUZA, A. Utilização de fundações rasas no solo colapsível de Ilha Solteira (SP). Dissertação (Mestrado em Geotecnia) - Escola de Engenharia de São Carlos, Universidade de São Paulo, São Carlos, 1993,126 p.

NETO, J. B. S. Comportamento de um solo colapsível avaliado a partir de ensaios de laboratório e campo, e previsão de recalques devido à inundação (Colapso). Tese (Doutorado em Geotecnia) - COPPE (Instituto Alberto Luiz Coimbra de Pós-Graduação e Pesquisa de Engenharia), Universidade Federal do Rio de Janeiro, 2004, 468 p.

TAKI, O.; YANG, D. S. Soil-cement mixed wall technique. Geotechnical Engineering Congress, ASCE. Proceedings... Denver, 1991. p 298 - 309.

TEIXEIRA, C. Z. Comportamento de estacas em solos colapsíveis. Dissertação (Mestrado em Geotecnia) - Escola de Engenharia de São Carlos, Universidade de São Paulo, São Carlos, 1993, $157 \mathrm{p}$.

TEIXEIRA, A. T.; GODOY, N. S. Análise, projeto e execução de fundações rasas. In: Hachich et al. Fundações: teoria e prática. São Paulo: Pini, 1996. Cap. 7, p. 227-264.

TERZAGHI, K. Theorical soil mechanics. New York: Wiley, 1943.

TSCHEBOTARIOFF, G. P. Fundações, estruturas de arrimo e obras de terra. São Paulo: McGraw-Hill, 1978. p. 513.

VAN DER VEEN, C. The bearing capacity of a pile. $3^{\text {rd }}$ International Conference on Soil Mechanics and Foundation Engineering. Proceedings...Zurich, 1953. P. 84-90.

VARGAS, M. Fundação sobre aterro compactado. Boletim, Conferência DNER, Rio de Janeiro, 1951, p. $51-60$.

VARGAS, M. Introdução à mecânica dos solos. São Paulo: McGraw Hill, 1977. 
VARGAS, M. Structurally unstable soils in southern Brazil. In: $8^{\text {th }}$ INTERNATIONAL CONFERENCE ON SOIL MECHANICS AND FOUNDATION ENGINEERING. Proceedings... Moscou, 1973. p. 239 - 246.

VIANNA, A. P. F. Influência da dimensão matricial no comportamento de fundações superficiais assentes em solo arenoso não saturado. Tese (Doutorado em Geotecnia) - Escola de Engenharia de São Carlos, Universidade de São Paulo, São Carlos, 2005, 308 p.

VILLAR, L. F. S.; GUIMARÃES, R. C.; RODRIGUES, J. K. G.; AZEVEDO, R. F.; CARVAlHO, J. C. Solos colapsíveis e expansivos In: CARVALHO et al. Solos Não Saturados no Contexto Geotécnico. 1 ed. ABMS, 2015. São Paulo - SP. Cap. 11, p. 257-296.

VILAR, O. M.; FERREIRA, S. R. M. Solos colapsíveis e expansivos In: CARVALHO et al. Solos não saturados no contexto geotécnico. São Paulo: ABMS, 2015. cap. 15, p. 415-427.

VILAR, O. M.; GAIOTO, N. Comportamento colapsível de um solo laterítico compactado. In: II SIMPÓSIO SOBRE SOLOS NÃO SATURADOS. Anais... Recife, 1994. v. 1, p. 185 - 190, 1994.

VILAR, O. M.; RODRIGUES, J. E; NOGUEIRA, J. B. (1981) Solos colapsíveis: um problema para a engenharia de solos tropicais. In: I SIMPÓSIO BRASILEIRO DE SOLOS TROPICAIS. Anais..., Rio de Janeiro, 1981. v. 1, p. 209 - 224.

VILAR, O. M.; RODRIGUES, R. A. Métodos expeditos para previsão da resistência de solos não saturados e identificação de solos colapsíveis. In: VI SIMPÓSIO BRASILEIRO DE SOLOS NÃO SATURADOS. [Anais...] Salvador, 2008. v.2, p. 575 - 592. 


\section{ANEXOS}

ANEXO A - LOCAÇÃO DOS FUROS DE SONDAGEM E DOS ENSAIOS DE PROVA DE CARGA REALIZADOS EM CAMPO

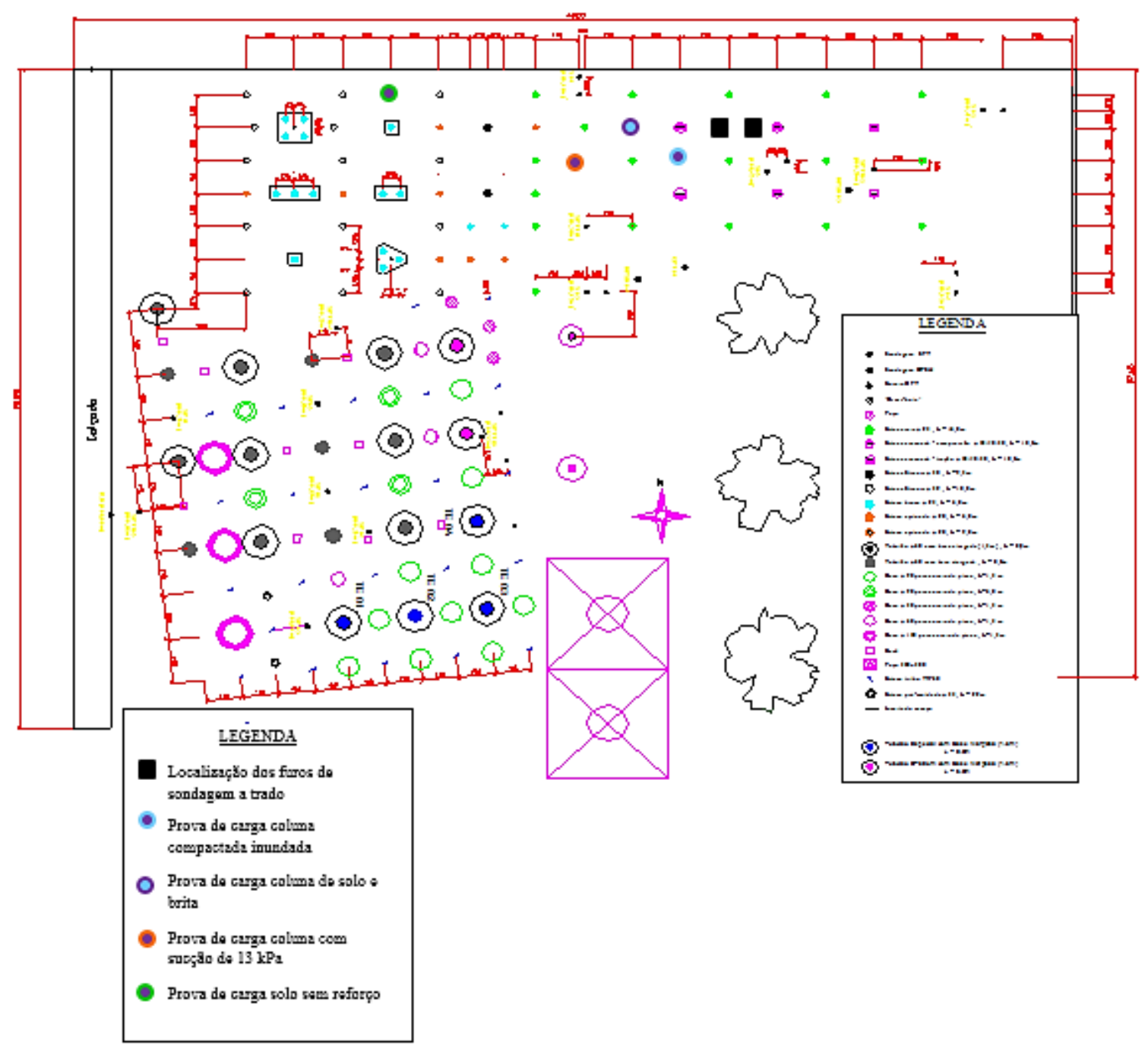


ANEXO B - RESULTADOS DOS ENSAIOS DE PROVA DE CARGA REALIZADOS

Prova de carga - coluna de solo compactado inundada

\begin{tabular}{|c|c|c|}
\hline \multicolumn{3}{|c|}{ CARREGAMENTO } \\
\hline Tensão (kPa) & Força (kN) & Recalque (mm) \\
\hline 0 & 0 & 0 \\
\hline 20 & 10 & 1,22 \\
\hline 40 & 20 & 2,05 \\
\hline 60 & 30 & 2,63 \\
\hline 80 & 40 & 3,42 \\
\hline 100 & 50 & 4,14 \\
\hline 120 & 60 & 4,91 \\
\hline 140 & 70 & 5,72 \\
\hline 160 & 80 & 7,05 \\
\hline 180 & 90 & 8,54 \\
\hline 200 & 100 & 10,52 \\
\hline 220 & 110 & 13,19 \\
\hline 240 & 120 & 17,19 \\
\hline 260 & 130 & 21,31 \\
\hline \multicolumn{3}{|c|}{ DESCARREGAMENTO } \\
\hline Tensão (kPa) & Força (kN) & Recalque (mm) \\
\hline 260,0 & 130 & 21,31 \\
\hline 195,0 & 97,50 & 20,64 \\
\hline 130,0 & 65,00 & 20,33 \\
\hline 64,4 & 32,20 & 19,48 \\
\hline 0,0 & 0,00 & 17,24 \\
\hline
\end{tabular}


Prova de carga - solo compactado natural com sucção de 13 kPa

\begin{tabular}{|ccc|}
\hline \multicolumn{3}{|c|}{ CARREGAMENTO } \\
\hline Tensão (kPa) & Força (kN) & Recalque (mm) \\
\hline 0 & 0 & 0,00 \\
20 & 10 & 2,10 \\
40 & 20 & 4,12 \\
60 & 30 & 5,35 \\
80 & 40 & 6,36 \\
100 & 50 & 7,43 \\
120 & 60 & 8,61 \\
140 & 70 & 9,69 \\
160 & 80 & 10,92 \\
180 & 90 & 12,37 \\
200 & 100 & 14,07 \\
220 & 110 & 16,45 \\
240 & 120 & 19,63 \\
260 & 130 & 23,89 \\
280 & 140 & 28,51 \\
\hline \multicolumn{3}{|c|}{ DESCARREGAMENTO } \\
\hline Tensão (kPa) & Força(kN) & Recalque (mm) \\
\hline 224 & 112 & 28,82 \\
168 & 84 & 28,56 \\
112 & 56 & 28,15 \\
56 & 28 & 27,38 \\
0 & 0 & 24,91 \\
\hline \multicolumn{2}{c}{} \\
\hline
\end{tabular}


Prova de carga - coluna de solo e brita inundada

\begin{tabular}{|ccc|}
\hline \multicolumn{3}{|c|}{ CARREGAMENTO } \\
\hline Tensão (kPa) & Força (kN) & Recalque (mm) \\
\hline 0 & 0 & 0 \\
20 & 10 & 0,59 \\
40 & 20 & 1,10 \\
60 & 30 & 1,75 \\
80 & 40 & 2,63 \\
100 & 50 & 3,95 \\
120 & 60 & 6,18 \\
140 & 70 & 10,20 \\
160 & 80 & 16,22 \\
180 & 90 & 25,37 \\
200 & 100 & 38,85 \\
\hline \multicolumn{3}{|c|}{ DESCARREGAMENTO } \\
\hline Tensão (kPa) & Força (kN) & Recalque (mm) \\
\hline 200 & 100 & 38,85 \\
160 & 80 & 38,58 \\
120 & 60 & 38,42 \\
80 & 40 & 38,16 \\
40 & 20 & 37,72 \\
0 & 0 & 36,25 \\
\hline
\end{tabular}


Prova de carga em placa - solo natural com sucção de 6 kPa

\begin{tabular}{|c|c|c|}
\hline \multicolumn{3}{|c|}{ CARREGAMENTO } \\
\hline Tensão kPa & Força (kN) & Recalque (mm) \\
\hline 0 & 0 & 0,00 \\
\hline 6 & 3 & 0,51 \\
\hline 12 & 6 & 1,50 \\
\hline 18 & 9 & 2,50 \\
\hline 24 & 12 & 3,29 \\
\hline 30 & 15 & 3,98 \\
\hline 36 & 18 & 4,70 \\
\hline 42 & 21 & 5,06 \\
\hline 48 & 24 & 5,80 \\
\hline 54 & 27 & 6,54 \\
\hline 60 & 30 & 8,16 \\
\hline 66 & 33 & 9,94 \\
\hline 72 & 36 & 12,17 \\
\hline 78 & 39 & 14,56 \\
\hline 84 & 42 & 16,94 \\
\hline 90 & 45 & 19,99 \\
\hline 96 & 48 & 23,13 \\
\hline 102 & 51 & 26,99 \\
\hline \multicolumn{3}{|c|}{ DESCARREGAMENTO } \\
\hline Tensão kPa & Força (kN) & Recalque (mm) \\
\hline 102 & 51 & 26,99 \\
\hline 81,6 & 40,8 & 27,06 \\
\hline 61,2 & 30,6 & 26,97 \\
\hline 40,8 & 20,4 & 26,74 \\
\hline 20,4 & 10,2 & 26,54 \\
\hline 0 & 0 & 26,07 \\
\hline
\end{tabular}


Prova de carga em placa - solo inundado

\begin{tabular}{|ccc|}
\hline \multicolumn{3}{|c|}{ CARREGAMENTO } \\
\hline Tensão $\mathbf{k P a}$ & Força (kN) & Recalque (mm) \\
\hline $\mathbf{0}$ & $\mathbf{0}$ & 26,07 \\
10 & 5 & 26,21 \\
20 & 10 & 26,31 \\
30 & 15 & 26,45 \\
40 & 20 & 26,56 \\
$\mathbf{5 0}$ & $\mathbf{2 5}$ & $\mathbf{2 6 , 7 7}$ \\
60 & 30 & 26,88 \\
70 & 35 & 27,12 \\
80 & 40 & 28,11 \\
90 & 45 & 37,12 \\
100 & 50 & 49,96 \\
\hline \multicolumn{3}{|c|}{ DESCARREGAMENTO } \\
\hline Tensão $\mathbf{k P a}$ & Força (kN) & Recalque (mm) \\
\hline 100 & 50 & 49,96 \\
80 & 40 & 49,96 \\
60 & 30 & 49,87 \\
40 & 20 & 49,73 \\
20 & 10 & 49,80 \\
0 & 0 & 49,05 \\
\hline
\end{tabular}


ANEXO B - RESULTADOS DOS ENSAIOS DE PROVA DE CARGA COSTA (1999)

Prova de carga em placa - terreno inundado

\begin{tabular}{|ccc|}
\hline \multicolumn{3}{|c|}{ PCE INUNDADA - SS1 } \\
\hline \multicolumn{3}{|c|}{ CARREGAMENTO } \\
\hline Tensão (kPa) & Força(kN) & Recalque (mm) \\
\hline 0 & 0,0 & 0,00 \\
10 & 5 & 0,04 \\
20 & 10 & 0,23 \\
30 & 15 & 1,59 \\
40 & 20 & 4,50 \\
50 & 25 & 10,20 \\
60 & 30 & 19,50 \\
70 & 35 & 32,01 \\
\hline \multicolumn{3}{|c|}{ DESCARREGAMENTO } \\
\hline Tensão (kPa) & Força(kN) & Recalque (mm) \\
\hline 70 & 35,0 & 32,0 \\
35 & 17,5 & 31,9 \\
5 & 2,5 & 31,3 \\
\hline
\end{tabular}




\begin{tabular}{|ccc|}
\hline \multicolumn{3}{|c|}{ PCE INUNDADA - SS2 } \\
\hline \multicolumn{3}{|c|}{ CARREGAMENTO } \\
\hline Tensão (kPa) & Força(kN) & Recalque (mm) \\
\hline 0 & 0,0 & 0,00 \\
4 & 2 & 0,16 \\
12 & 6 & 0,82 \\
20 & 10 & 2,68 \\
28 & 14 & 6,39 \\
36 & 18 & 14,28 \\
44 & 22 & 28,36 \\
52 & 26 & 42,99 \\
\hline \multicolumn{4}{|c|}{ DESCARREGAMENTO } \\
\hline Tensão (kPa) & Força(kN) & Recalque (mm) \\
\hline 52 & 26,0 & 43,0 \\
43 & 21,5 & 43,3 \\
21 & 10,5 & 43,2 \\
0 & 0 & 42,8 \\
\hline
\end{tabular}

\begin{tabular}{|ccc|}
\hline \multicolumn{3}{|c|}{ PCE INUNDADA - SS3 } \\
\hline \multicolumn{3}{|c|}{ CARREGAMENTO } \\
\hline Tensão (kPa) & Força (kN) & Recalque (mm) \\
\hline 0 & 0,0 & 0,00 \\
8 & 4 & 1,10 \\
16 & 8 & 2,13 \\
24 & 12 & 3,43 \\
32 & 16 & 5,54 \\
40 & 20 & 11,10 \\
48 & 24 & 17,14 \\
56 & 28 & 25,79 \\
64 & 32 & 38,92 \\
72 & 36 & 51,94 \\
\hline \multicolumn{3}{|c|}{ DESCARREGAMENTO } \\
\hline Tensão (kPa) & Força (kN) & Recalque (mm) \\
\hline 72 & 36,0 & 51,94 \\
69 & 34,5 & 51,95 \\
24 & 12 & 51,80 \\
0 & 0 & 51,16 \\
\hline
\end{tabular}


Prova de carga em placa - terreno com sucção

\begin{tabular}{|c|c|c|}
\hline \multicolumn{3}{|c|}{ PCE - com sucção de $10 \mathrm{kPa}(\mathrm{S} 1)$} \\
\hline \multicolumn{3}{|c|}{ CARREGAMENTO } \\
\hline Tensão (kPa) & Força(kN) & Recalque (mm) \\
\hline 0 & 0 & 0,00 \\
\hline 10 & 5 & 2,50 \\
\hline 20 & 10 & 3,68 \\
\hline 30 & 15 & 4,84 \\
\hline 40 & 20 & 5,90 \\
\hline 50 & 25 & 7,90 \\
\hline 60 & 30 & 9,89 \\
\hline 70 & 35 & 12,35 \\
\hline 80 & 40 & 15,23 \\
\hline 90 & 45 & 19,03 \\
\hline 100 & 50 & 23,53 \\
\hline 110 & 55 & 28,74 \\
\hline 120 & 60 & 34,92 \\
\hline 130 & 65 & 41,16 \\
\hline 140 & 70 & 47,55 \\
\hline 150 & 75 & 55,01 \\
\hline 160 & 80 & 62,02 \\
\hline 170 & 85 & 70,13 \\
\hline \multicolumn{3}{|c|}{ DESCARREGAMENTO } \\
\hline Tensão (kPa) & Força(kN) & Recalque $(\mathrm{mm})$ \\
\hline 170 & 85 & 70,13 \\
\hline 154 & 77 & 70,65 \\
\hline 63 & 31,5 & 70,38 \\
\hline 0 & 0 & 69,48 \\
\hline
\end{tabular}




\begin{tabular}{|ccc|}
\hline \multicolumn{3}{|c|}{ PCE - com sucção de 30 kPa (S2) } \\
\hline \multicolumn{3}{|c|}{ CARREGAMENTO } \\
\hline Tensão (kPa) & Força(kN) & Deslocamento (mm) \\
\hline 0 & 0 & 0,00 \\
12 & 6 & 0,54 \\
24 & 12 & 1,22 \\
36 & 18 & 2,00 \\
48 & 24 & 2,68 \\
60 & 30 & 3,53 \\
72 & 36 & 4,59 \\
84 & 42 & 5,76 \\
96 & 48 & 8,13 \\
108 & 54 & 11,33 \\
120 & 60 & 15,50 \\
132 & 66 & 20,66 \\
144 & 72 & 26,42 \\
156 & 78 & 32,73 \\
168 & 84 & 39,26 \\
180 & 90 & 47,55 \\
\hline \multicolumn{4}{|c|}{ DESCARREGAMENTO } \\
\hline Tensão (kPa) & Força(kN) & Deslocamento (mm) \\
\hline 180 & 90 & 47,55 \\
178 & 89 & 47,57 \\
90 & 45 & 47,38 \\
0 & 0 & 46,24 \\
\hline
\end{tabular}




\section{ANEXO C - CURVA DE CALIBRAÇÃO DA CÉLULA DE CARGA}

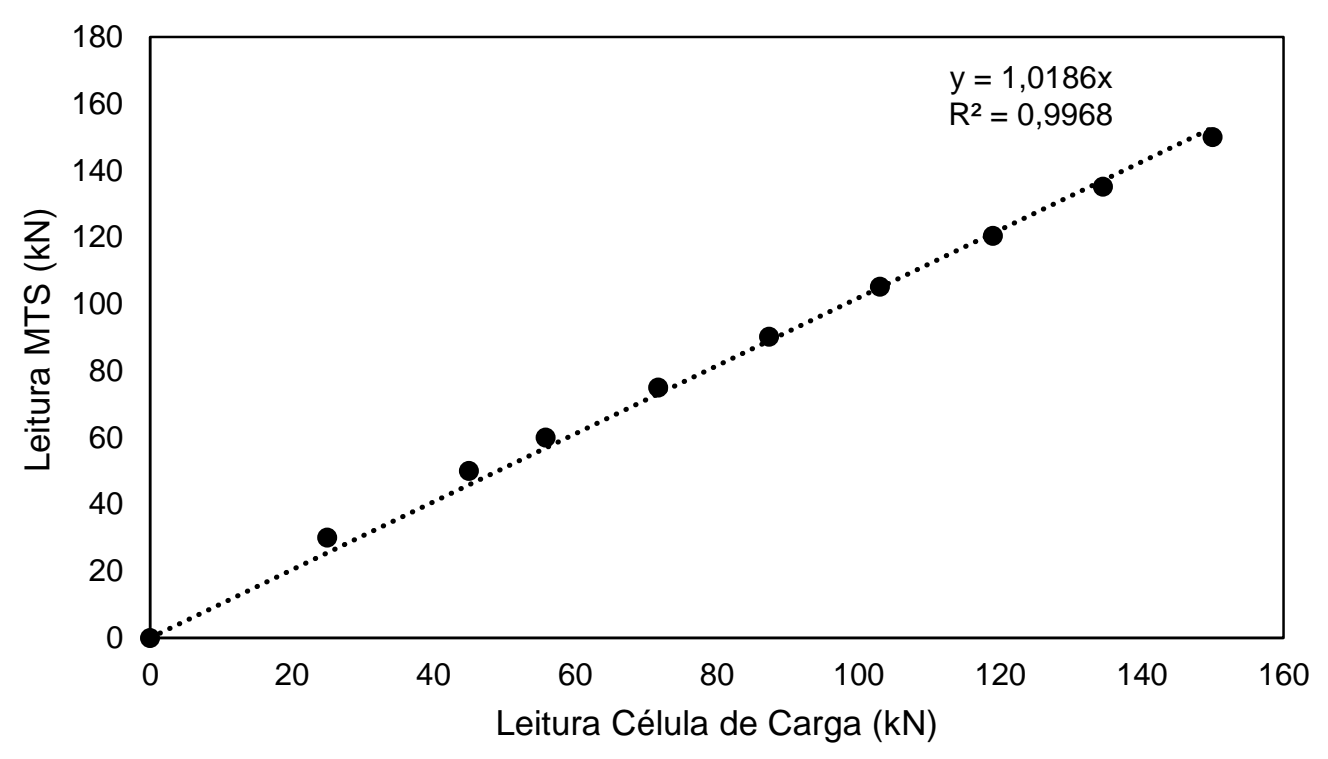

